\title{
Hanford Science and Technology Needs Statements, 1998
}

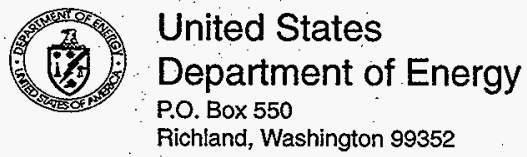

Approved for Public Release 


\section{LEGAL DISCLAIMER}

This report was prepared as an account of work sponsored by an agency of the United States Government. Neither the United States Government nor any agency thereof, nor any of their employees, nor any of their contractors, subcontractors or their employees, makes any warranty, express or implied, or assumes any legal liability or responsibility for the accuracy, completeness, or any third party's use or the results of such use of any information, apparatus, product, or process disclosed, or represents that its use would not infringe privately owned rights. Reference herein to any specific commercial product, process or service by trade name, trademark, manufacturer, or otherwise, does not necessarily constitute or imply its endorsement, recommendation, or favoring by the United States Government or any agency thereof or its contractors or subcontractors. The views and opinions of authors expressed herein do not necessarily state or reflect those of the United States Government or any agency thereof.

This report has been reproduced from the best available copy. Available in paper copy and microfiche.

Available to the U.S. Department of Energy and its contractors from

Office of Scientific and Technical Information

P.O. Box 62

Oak Ridge, TN 37831

(615) $576-8401$

Available to the public from the U.S. Department of Commerce National Technical Information Service

5285 Port Royal Road

Springlield, VA 22161

(703) $487-4650$

Printed in the United States of America

DISCLM-1.CHP (1-91) 


\section{Hanford Science and Technology Needs Statements, 1998}

Rev. 0 


\section{Department of Energy \\ Richland Operations Office \\ P.O. Box 550 \\ Richland, Washington 99352}

\section{DEC 171997}

98-STP-132

Distribution (Those on Attached List)

Addressees:

U.S. DEPARTMENT OF ENERGY, RICHLAND OPERATIONS OFFICE INTEGRATED FISCAL YEAR 1998 SITE SCIENCE AND TECHNOLOGY NEEDS STATEMENTS

Enclosed for your information and use is the integrated Hanford Site Science and Technology Needs Statements Document. The needs were developed by the Hanford Site Technology Coordination Group Management Council with full participation and endorsement of site user organizations. stakeholders, and regulators. This document has been prepared to focus the Hanford science and technology investments on site problems where no acceptable science or technology solutions currently exist.

If you have any questions, please contact David Biancosino. Science and Technology Programs Division. on (509) 372-4084.

STP:DLB

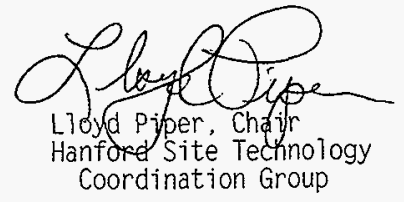

Enclosure 


\section{INTRODUCTION}

This document is a compilation of the Hanford science and technology needs statements for FY 1998. The needs were developed by the Hanford Site Technology Coordination Group (STCG) with full participation and endorsement of site user organizations, stakeholders, and regulators. The purpose of this document is to: (a) provide a comprehensive listing of Hanford science and technology needs, and (b) identify partnering and commercialization opportunities with industry, other federal and state agencies, and the academic community.

The Hanford STCG reviews and updates the needs annually. Once completed, the needs are communicated to DOE for use in the development and prioritization of their science and technology programs, including the Focus Areas, Cross-Cutting Programs, and the Environmental Management Science Program. The needs are also transmitted to DOE through the Accelerating Cleanup: $2006 \mathrm{Plan}$. The public may access the need statements on the internet on:

- the Hanford Home Page (www.hanford.gov),

- the Pacific Rim Enterprise Center's web site (www2.pacific-rim.org/pacific_rim), or

- the STCG web site at DOE headquarters (em-52.em.doe.gov/ifd/stcg/stcg.htm). This page includes links to science and technology needs for many DOE sites.

Private industry is encouraged to review the need statements and contact the Hanford STCG if they can provide technologies that meet these needs. On-site points of contact are included at the ends of each need statement. The Pacific Rim Enterprise Center (206-224-9934) can also provide assistance to businesses interested in marketing technologies to the DOE.

\section{DOCUMENT ORGANIZATION}

The Science and Technology Needs Document organizes the need statements by STCG subgroup: Decontamination \& Decommissioning, Mixed Waste, Subsurface Contaminant, and Tanks. (These subgroups correspond to four of the DOE Office of Science and Technology's Focus Areas.) Each section begins with a technology needs table that lists the needs in numerical order with a High, Medium, or Low designator. This table is followed by detailed descriptions of each technology need, including a problem statement and current baseline information. The . format of the technology need descriptions was developed by STCGs throughout the DOE complex for consistency from site to site. Following the technology need descriptions for each subgroup is a table listing the subgroup's science need, followed by their detailed descriptions. Science need statements include descriptions of the functional need and the problem to be solved as currently understood. At the end of each section, a crosswalk table is provided between last year's needs and this year's needs. This table lists any needs eliminated (and why), matches old need numbers to new numbers, describes how old needs have been broken out into several new needs or combined, and shows which needs are new for FY 1998. 


\section{DECONTAMINATION \& DECOMMISSIONING TECHNOLOGY NEEDS}

\begin{tabular}{|l|l|}
\hline ID \# & \multicolumn{1}{|c|}{ NEEDS TITLE } \\
\hline RL-DD01 & Capsule Leak Detection System for WESF \\
\hline RL-DD02 & Glove Box Volume Size Reduction System \\
\hline RL-DD03 & TRU Waste Decontamination of PFP \\
\hline RL-DD04 & TRU Waste Fixatives for PFP \\
\hline RL-DD05 & Characterization of Building 324 \\
\hline RL-DD06 & Decontamination of Building 324 \\
\hline RL-DD07 & Fixatives for Building 324 \\
\hline RL-DD08 & Remote Cutting Technologies \\
\hline RL-DD09 & Tank Remediation for Building 324 \\
\hline RL-DD010 & Radiation Hardened Robotics \\
\hline RL-DD011 & Structural Integrity Inspection Technologies \\
\hline RL-DD012 & Contaminant Mapping of K-Basin \\
\hline RL-DD013 & Decontamination of K-Basin Pool \\
\hline RL-DD014 & Fixatives for K-Basin \\
\hline RL-DD015 & Concrete Fuel Basin Decontamination \\
\hline RL-DD016 & Characterization Technologies \\
\hline RL-DD017 & Segregation Characterization \\
\hline RL-DD018 & Reactor Core Stabilization \\
\hline RL-DD019 & Physical Stress Monitors \\
\hline RL-DD020 & Bio-Control Technologies \\
\hline RL-DD021 & Metal Decontamination and Recycling \\
\hline
\end{tabular}




\section{TECHNOLOGY NEEDS/OPPORTUNITIES \\ STATEMENT OUTLINE \\ CAPSULE LEAK DETECTION SYSTEM FOR WESF}

Identification No.: RL-DD01

Date: August 11, 1997

Program: Decontamination and Decommissioning

OPS Office/Site: Richland Operations Office/Hanford Site

Operable Unit (if applicable): N/A

Waste Stream: Approximately 1900 stainless-steel capsules that contain 75 million Curies of cesium and strontium byproduct materials in the WESF pool cells.

Waste Management Unit (if applicable): N/A

Facility: Waste Encapsulation Storage Facility (WESF)

Site Priority Ranking: Medium

Need Title: Capsule Leak Detection System for WESF

Need Description: WESF is operated as a safe storage facility for a number of double-wall corrosion-resistant metal capsules that contain either cesium chioride or strontium fluoride from fuel processing waste. The capsules were distributed to five pool cells and stored underwater since about 1967. Current plans are to continue underwater storage until about 2011 at which time the capsules will be turned over to the High Level Waste disposal Program. Although no significant problems have been experienced, there is the continuing possibility of one or more of these capsules developing a leak and contaminating a pool cell. There is need for an effective monitoring system to quickly identify a leaking capsule such that it can be removed.

Current Baseline Technology: Each active pool cell has a water beta monitoring system that will detect that a capsule has failed and that radioactive materials have migrated into the water. The system, however, is not adequate to permit isolation of an individual leaking capsule.

Functional Performance Requirements: There is need for an easily deployable technology that will allow for rapid underwater identification of a single leaking capsule (there are approximately 1900 capsules stored in 5 pools). This technology must be operable in a high radiation environment. (The exposure rate of a single submerged cesium capsule, which contains 50 kiloCuries is 200 rems per second at contact and 11 rems per second at 24 inches.)

Schedule Requirements: Immediate - long term

Problem Description: WESF stores strontium and cesium capsules in pool cells that were constructed to provide shielding and cooling for approximately 1900 capsules. There are 5 pool cells that are actively storing capsules, each measuring approximately $6^{\prime} \times 20^{\prime} \times 13^{\prime}$ (deep). Each active pool cell has a water beta monitoring system to detect the loss of capsule integrity in that pool. Cesium chloride, and, to a lesser degree, strontium fluoride are soluble in water. A 
significant leak could contaminate the pool in the matter of hours. The current method of leak checking the capsules is to perform an inner capsule movement test that requires an individual operation for every capsule in the cell. Each capsule is lifted, shaken, and if there is no inclusion of water from the pool and the inner wall of the capsule is free to move against the external wall (as noted by impact), the integrity of the capsule is presumed to be intact. Identification of a leaking capsule by this technique could require several days.

$\begin{array}{lll}\text { ADS. No. } & \text { PBS No. } & \text { WBS No. } \\ \text { 6627-0. } & \text { RL-TP02 } & 7.1 .8\end{array}$

WESF Sub-Project

\section{Justification for Need:}

Technical: Rapid identification and removal of a leaking capsule would minimize pool cell contamination and the need for subsequent pool cell cleanup.

Regulatory: N/A

Environmental Safety and Health: Worker safety would be improved by the provision of an improved capsule leak detection system. Early leak detection would minimize the risk of worker exposure for pool cell decontamination.

Cost Savings Potential (Mortgage Reduction): N/A

Cultural/Stakeholder Concerns: Rapid identification would reduce the risk of employee exposure to any unexpected release of toxic and/or radioactive materials and it would reduce the quantities of materials handled, stored or disposed as a secondary waste product.

Other: None identified.

Consequences of Not Filling Need: Current baseline methods are labor intensive and tedious. The potential exists for a leaking capsule to contaminate a pool to the degree that worker entry is prohibited before the capsule can be identified and removed to an alternate shielded location.

Outsourcing Potential: N/A

End-User: EM-60

Site Technical Points of Contact: Gerry McCormick - BWHC (509) 372-8173, Robbin Duncan - BWHC (509) 373-2229, Paul Roege - BWHC (509) 372-0443

DOE End-User/Representative Points of Contact: David Evans - EM-60 (509) 373-9278 


\section{TECHNOLOGY NEEDS/OPPORTUNITIES \\ STATEMENT OUTLINE \\ GLOVE BOX VOLUME SIZE REDUCTION SYSTEM}

Identification No.: RL-DD02

Date: August 5, 1997

Program: Decontamination and Decommissioning

OPS Office/Site: Richland Operations Office/Hanford Site

Operable Unit (if applicable): N/A

Waste Stream: Alpha contamination that is 1) dispersible, 2) fixed, and 3) embedded

Waste Management Unit (if applicable): N/A

Facility: Plutonium Finishing Plant

Site Priority Ranking: High

Need Title: Glove Box Volume Size Reduction System

Need Description: A skid-mounted, possibly modular containment structure housing a final glovebox decontamination, NDA, and volume reduction system that would easily couple to a facility's support services, such as steam, water, air, and electricity. The system could potentially employ technology as identified in RL-DD03 and RL-DD04. The working surfaces include, but are not limited to, those found in glove boxes, piping, ducting, and metal surfaces, etc. The PFP glove boxes will be removed during deactivation. Without volume reduction, it becomes cost prohibitive to package and ship the transuranic (TRU) waste to the Waste Isolation Pilot Plant (WIPP). Presently, ongoing decontamination activities require intensive manpower, produce secondary waste, and are costly. There is minimal volume reduction capability at PFP at this time.

Current Baseline Technology: Metal - wipes, hydro-lancing, ice blasting, steam, acid washes, electropolishing; Glove boxes decontamination and volume reduction - wipes, strippable coatings/gels, shear balers, laser cutting, and mechanical shears.

Functional Performance Requirements: Lessons-learned from previous plutonium glovebox Deactivation/Decommissioning Projects indicate a preference to perform an initial gross decontamination in-situ to remove the majority of plutonium, focusing on ease of decontamination and high $\mathrm{Pu}$ holdup equipment. The glove box would then be packaged, disconnected from facility services and transported to the "structure" where final decontamination, NDA, volume reduction and potentially final packaging activities would take place. Readily deployable robotics may also be appropriate to minimize worker exposure and risk. Methods that clean to non-TRU levels are preferable. Specific applications include the following: 
a) Glove Boxes - The primary contaminant is plutonium oxide. Glove boxes contain multiple materials requiring decontamination such as metals in a variety of shapes and sizes. Many of these surfaces are inaccessible using manual decontamination techniques.

b) Piping and Ducting - The primary contaminant is plutonium oxide. The present method is to contain the piping/ducting and remove it for disposal (usually TRU). The "Decon/Volume Reduction Facility" could serve as a receiver of this type of material as well.

c) Metal Surfaces - The primary contaminant is plutonium oxide. Surfaces requiring decontamination include stainless-steel equipment of varying size but small enough to fit in a nominally-sized glovebox. Again, many of these surfaces are inaccessible using manual decontamination techniques.

Schedule Requirements: Immediate - long term

Problem Description: Contamination represents an immediate worker exposure and risk concern as well as a long-term environmental concern. Many surface decontamination technologies generate secondary waste streams, are labor intensive, and are costly.

a) Glove Boxes - Glove boxes have been used to handle radioactive materials for numerous activities. Present decontamination methods rely on personnel physically wiping surfaces. Worker fatigue, exposure, and risk are inherent in these methods. Complete decontamination of glove boxes using these methods is difficult because many surfaces are inaccessible using manual decontamination techniques.

b) Piping and Ducting - Plutonium exists in piping and ductwork in materials processing facilities. The current practice for removing and stabilizing plutonium in pipes and ductwork involves personnel physically cutting the materials, bagging them and transferring them to glove boxes for decontamination and size reduction. The process is time consuming, costly, and poses a risk of personnel exposure. Material removed must be managed as a transuranic waste, high level waste, and/or low level waste.

c) Metal Surfaces - There are many metal surfaces that require decontamination. These include glovebox equipment such as pipes, tanks, valves, motors, and flanges. Contaminants include plutonium oxide, other transuranics, and variety of tri-butyl phosphate-based organic compounds and degradation products.

$\begin{array}{llll}\text { ADS. No. } & \text { PBS No. } & \text { WBS No. } & \\ 6624-0(\mathrm{P}) & \text { RL-TP05 } & 7.13 . \mathrm{X} & \text { PFP Deactivation } \\ 6625-0 & & & \\ 6630-0 & & \end{array}$




\section{Justification for Need:}

Technical: As facilities are transitioned to stable conditions and decommissioned, they require decontamination of radioactively contaminated materials. Current decontamination methods increase worker exposure and risk and are often slow, coștly, and produce secondary waste.

Regulatory: TPA Milestone M-83-00: Complete Stabilization of Process Areas Resulting from EIS ROD [PFP (Date: TBD)]; TPA Milestone M-83-02, Complete Identified Interim Actions - PFP (December 1998); TPA Milestone M-83-02-T04, 234-5Z Duct Level Cleanout (December 1998); DNFSB 94-1: Completion of PFP terminal cleanout, 2002

Environmental Safety and Health: Radioactive contamination presents worker safety/exposure concerns.

Cost Savings Potential (Mortgage Reduction): Mortgage rates can be reduced through the implementation of cost effective methods for decontamination.

Cultural/Stakeholder Concerns: Decontaminating materials to free release can minimize the volume of material destined for onsite burial. This will help alleviate concerns expressed by several stakeholder groups.

Other: None identified.

Consequences of Not Filling Need: Current methods will be used which are costly and time consuming. These methods will slow Hanford cleanup progress.

Outsourcing Potential: There may be some outsourcing potential in developing decontamination and volume reduction technologies.

End-User: EM-60

Site Technical Points of Contact: Gerry McCormick - BWHC (509) 372-8173, Robbin Duncan (509) 373-2229, Darryl Nelson - BWHC (509) 373-2841

DOE End-User/Representative Points of Contact: James Mecca - EM-60 (509) 376-7471 


\section{TECHNOLOGY NEEDS/OPPORTUNITIES \\ STATEMENT OUTLINE \\ TRU WASTE DECONTAMINATION OF PFP}

Identification No.: RL-DD03

Date: August 5, 1997

Program: Decontamination and Decommissioning

OPS Office/Site: Richland Operations Office/Hanford Site

Operable Unit (if applicable): N/A

Waste Stream: Alpha contamination that is 1) dispersible, 2) fixed, and 3) embedded

Waste Management Unit (if applicable): N/A

Facility: Plutonium Finishing Plant

Site Priority Ranking: High

Need Title: TRU Waste Decontamination of PFP

Need Description: Fast acting, low life-cycle cost surface decontamination technologies, including those which can be remotely applied are needed immediately. Surfaces include, but are not limited to, those found in glove boxes, piping, ducting, metal surfaces, concrete surfaces, etc. Ongoing decontamination activities require intensive manpower, produce secondary waste, and are costly.

Current Baseline Technology: Concrete - scabbling, hydro-lancing; Metal - wipes, hydrolancing, ice blasting, steam, acid washes, electropolishing; Glove boxes - wipes, strippable coatings/gels

Functional Performance Requirements: Decontamination methods are needed that minimize worker exposure, secondary waste generation, costs, risk and are readily deployable. Methods that clean to free-release levels are preferable. Specific applications include the following:

a) Glove Boxes - The primary contaminant is plutonium oxide. Glove boxes contain multiple materials requiring decontamination such as glass, plastic, and metals in a variety of shapes and sizes. Many of these surfaces are inaccessible.

b) Piping and Ducting - The primary contaminant is plutonium oxide. A primary technology need is for improved methods for in situ decontamination in preparation for eventual removal.

c) Metal Surfaces - The primary contaminant is plutonium oxide. Surfaces requiring decontamination include cast iron cell walls, steel flooring systems, stainless-steel liners, and a range of equipment items of varying size. Some surfaces will require in situ decontamination, others may be transported to a central decontamination facility.

d) Concrete Surfaces - The primary contaminant is plutonium oxide. The contaminant exists as 1) deposits of varying thickness throughout the concrete, 2) as surface contamination, and 3) as contamination contained on painted or asphalt-coated surfaces. 
Schedule Requirements: Immediate - long term

Problem Description: Contamination represents an immediate worker exposure concern as well as a long-term environmental concern. Many surface decontamination technologies generate secondary waste streams, are labor intensive, and are costly.

a) Glove Boxes - Glove boxes have been used to handle radioactive materials for numerous activities. Present decontamination methods rely on personnel physically wiping surfaces. Worker fatigue and risk of exposure are inherent in these methods. Complete decontamination of glove boxes using these methods is difficult because many surfaces are inaccessible.

b) Piping and Ducting - Plutonium exists in piping and ductwork in materials processing facilities. The current practice for removing and stabilizing plutonium in pipes and ductwork involves personnel physically cutting the materials, bagging them and transferring them to glove boxes for decontamination and size reduction. The process is time consuming, costly, and poses a risk of personnel exposure. Material removed must be managed as a transuranic waste, high level waste, and/or low level waste.

c) Metal Surfaces . There are many metal surfaces that require decontamination. These include metal floors, stainless-steel hot cell liners, cast iron slabs, lead bricks, heavy equipment, tank systems, etc. Contaminants include plutonium oxide, other transuranics, and variety of organic compounds.

d) Concrete Surfaces - In addition to surface contamination, radioactive contamination associated with concrete surfaces may have penetrated to varying depths. Current practices include physical removal of the concrete surface (i.e., scabbling, sand blasting, etc.). Some contaminated concrete surfaces have been painted and/or coated with asphalt. Project requirements may require removal of such coatings prior to decontamination of the concrete.

$\begin{array}{llll}\text { ADS. No. } & \text { PBSNo. } & \text { WBS No. } & \\ 6624-0(\mathrm{P}) & \text { RL-TP05 } & \text { 7.13.X } & \text { PFP Deactivation } \\ 6625-0 & & & \\ 6630-0 & & & \end{array}$

\section{Justification for Need:}

Technical: As facilities are transitioned to stable conditions and decommissioned, they require decontamination of radioactively contaminated materials. Current decontamination methods are often slow, costly, and produce secondary waste.

Regulatory: TPA Milestone M-83-00: Complete Stabilization of Process Areas Resulting from EIS ROD [PFP (Date: TBD)] TPA Milestone M-83-02, Complete Identified Interim Actions - PFP (December 1998) TPA Milestone M-83-02-T04, 234-5Z Duct Level Cleanout (December 1998)

DNFSB 94-1: Completion of PFP terminal cleanout, 2002 
Environmental Safety and Health: Radioactive contamination presents safety/exposure concerns.

Cost Savings Potential (Mortgage Reduction): Mortgage rates can be reduced through the implementation of cost effective methods for decontamination.

Cultural/Stakeholder Concerns: Decontaminating materials to free release can minimize the volume of material destined for onsite burial. This will help alleviate concerns expressed by several stakeholder groups.

Other: None identified.

Consequences of Not Filling Need: Current methods will be used which are costly and time consuming. These methods will slow Hanford cleanup progress.

Outsourcing Potential: There may be some outsourcing potential in developing decontamination technologies.

End-User: EM-60

Site Technical Points of Contact: Gerry McCormick - BWHC (509) 372-8173, Robbin Duncan (509) 373-2229, Darryl Nelson - BWHC (509) 373-2841

DOE End-User/Representative Points of Contact: James Mecca - EM-60 (509) 376-7471 


\section{TECHNOLOGY NEEDS/OPPORTUNITIES \\ STATEMENT: OUTLINE \\ TRU WASTE FIXATIVES FOR PFP}

Identification No.: RL-DD04

Date: August 5, 1997

Program: Decontamination and Decommissioning

OPS Office/Site: Richland Operations Office/Hanford Site

Operable Unit (if applicable): N/A

Waste Stream: Radioactively contaminated surfaces with loose or dispersible contamination.

Waste Management Unit (if applicable): N/A

Facility: Plutonium Finishing Plant

Site Priority Ranking: Medium

Need Title: TRU Waste Fixatives for PFP

Need Description: Long-life fixatives to contain dispersible radioactive materials that are easily applied to and removed from surfaces are needed. Such fixatives could be used on a variety of surfaces such as those encountered in materials processing facilities, glove boxes, and ductwork.

Current Baseline Technology: Paint, tar, polymeric barrier systems, rustoleum

Functional Performance Requirements: The fixative may be used to contain dispersible alpha contamination. The fixative must be easily removable to allow for eventual decontamination. It needs to last $20-25$ years, and a thin film is preferred.

Schedule Requirements: Immediate - long term

Problem Description: Dispersible surface contamination is present in materials processing facilities. Such dispersible contamination often presents a worker exposure concern and a long term environmental concern. In areas where decontamination is not feasible, dispersible contamination is fixed in place.

$\begin{array}{llll}\text { ADS. No. } & \text { PBS No. } & \text { WBS No. } & \\ 6624-0(\mathrm{P}) & \text { RL-TP05 } & 7.13 . \mathrm{X} & \text { PFP Deactivation } \\ 6625-0 & & & \\ 6630-0 & & & \end{array}$

Justification for Need:

Technical: Dispersible radioactive contamination can present safety/exposure concerns. 
Regulatory: TPA Milestone M-83-00: Complete Stabilization of Process Areas Resulting from EIS ROD [PFP (Date: TBD)]; TPA Milestone M-83-02, Complete Identified Interim Actions - PFP (December 1998); TPA Milestone M-83-02-T04, 234-5Z Duct Level Cleanout (December 1998); DNFSB 94-1: Completion of PFP terminal cleanout, 2002

Environmental Safety and Health: Dispersible radioactive contamination can present safety/exposure concerns.

Cost Savings Potential (Mortgage Reduction): Current fixative methods require periodic replacement and increase life cycle costs.

Cultural/Stakeholder Concerns: Employee and public exposure to radioactive materials is a concern of Hanford stakeholders.

Other: None identified.

Consequences of Not Filling Need: Use current technology at high maintenance cost.

Outsourcing Potential: Unknown

End-User: EM-60

Site Technical Points of Contact: Gerry McCormick - BWHC (509) 372-8173, Robbin Duncan - BWHC (509) 373-2229, Darryl Nelson - BWHC (509) 373-2841

DOE End-User/Representative Points of Contact: James Mecca - EM-60 (509) 376-7471 


\section{TECHNOLOGY NEEDS/OPPORTUNITIES STATEMENT OUTLINE CHARACTERIZATION OF BUILDING 324}

Identification No.: RL-DD05

Date: August 11, 1997

Program: Decontamination and Decommissioning OPS Office/Site: Richland Operations Office/Hanford Site Operable Unit (if applicable): N/A

Waste Stream: Mixtures of contaminated and non-contaminated equipment and materials in or from materials processing facilities, reactors, and hot cells. The material and equipment may include radioactive/mixed wastes, equipment, tanks, pipes, concrete, etc.

Waste Management Unit (if applicable): N/A

Facility: Building 324

Site Priority Ranking: High

Need Title: Characterization of Building 324

Need Description: Characterization technologies are needed for determining radiation levels in situ. Differentiation between transuranic (TRU) waste and non-transuranic (non-TRU) waste is a primary concern. In addition, a verifiable method for determining that materials qualify for freerelease is necessary.

Current Baseline Technology: Wipes, laboratory samples, radiation detection - both general and energy specific such as the gamma spectral analyses, document searches, physical walk through, visual inspections and data recording, hand-held or cart-mounted survey equipment, and ad hoc sampling of representative surfaces, materials and spaces. Segregation activities involve the use of any of these techniques or material/equipment is managed as contaminated.

Functional Performance Requirements: A method is needed that will allow for the real-time differentiation between TRU and non-TRU waste and/or between low level waste and freerelease waste. Characterization is required for material contained in a variety of configurations including drums, plastic bags, equipment, processing facilities, etc.

a) Ducts/Piping - Improvements are needed for the remote in situ characterization of contamination levels in ducts and piping. Some ductwork has obstructions. Contaminants include cesium, strontium, uranium, and transuranics. The technology would need to be adaptable to a variety of configurations.

b) Remote Radiation Mapping - Remotely deployable radiation mapping techniques are required. Methods should permit the identification of hot spots within an area containing high radiation levels $(100,000-500,000 \mathrm{rad} / \mathrm{hr})$. 
c) Segregation Techniques - Techniques are needed that can differentiate between contaminated and non-contaminated material and equipment that have inaccessible surfaces. Decommissioning activities require the capability of survey equipment to be mounted on a conveyor belt that can identify and segregate radioactively contaminated versus clean material. Current technology allows crushed material on the order of 1 inch or less to be segregated in this manner. The improved technology. should permit the real-time characterization of materials larger than crushed materials.

Schedule Requirements: Immediate - long term

\section{Problem Description:}

a) Ducts/Piping - In situ characterization techniques are needed for determining levels of contamination within ducts and piping. In some instances there are obstructions that restrict the use of currently used methods.

b) Remote Radiation Mapping - It is difficult to determine where contamination hot spots are in high radiation areas (radiation levels on the order of $100,000-500,000 \mathrm{rad} / \mathrm{hr}$ in hot cells). A method that would provide point specific information is desired to optimize resources needed for accomplishing decontamination. Current methods for obtaining this data are labor intensive, long in duration, wasteful of personnel occupational radiation exposure, expensive and subject to a variety of random and systematic errors due to the use of multiple performers taking repetitive measurements over rather extended time periods.

c) Segregation techniques - It is often difficult to differentiate between radioactively contaminated and uncontaminated equipment and materials. Potentially contaminated surfaces are often inaccessible to current detection methods. Some materials are managed in their entirety as radioactive and/or mixed wastes, which adds unnecesșary costs for handling and disposal.

$\begin{array}{lll}\text { ADS. No. } & \text { PBS No. } & \text { WBS No. } \\ 6619-0 & \text { RL-TP08 } & 7.19\end{array}$
324/327 Facility Transition Project

\section{Justification for Need:}

Technical: Adequate characterization of wastes can lead to waste minimization.

Regulatory: TPA Milestone 89-02: Complete 324 building B-cell cleanout, May 31, 1999.

Environmental Safety and Health: Worker safety can be improved if characterization techniques can provide accurate indication of the presence of contamination.

Cost Savings Potential (Mortgage Reduction): Significant cost savings can be realized by confidently identifying contaminated versus noncontaminated materials, surfaces, and equipment. 
CulturaL/Stakeholder Concerns: Reduce employee exposure to toxic and/or radioactive materials. Better characterization data will lead to better and more cost effective decontamination/removal decisions, thus minimizing quantities of materials handled, stored or disposed as a waste product.

Other: None identified.

Consequences of Not Filling Need: Current baseline methods will be used that are labor intensive and very slow. The potential exists for clean materials to be managed as contaminated and disposed of at additional cost.

Outsourcing Potential: Unknown

End-User: EM-60

Site Technical Points of Contact: Gerry McCormick - BWHC (509) 372-8173, Robbin Duncan - BWHC (509) 2229, Rich Hobart - BWHC (509) 373-2316

DOE End-User/Representative Points of Contact: Larry Romine - EM-60 (509) 376-4747 


\section{TECHNOLOGY NEEDS/OPPORTUNITIES STATEMENT OUTLINE DECONTAMINATION OF BUILDING 324}

Identification No.: RL-DD06

Date: August 11, 1997

Program: Decontamination and Decommissioning

oPS Office/Site: Richland Operations Office/Hanford Site

Operable Unit (if applicable): N/A

Waste Stream: Alpha, Beta, and Gamma contamination that is 1) dispersible, 2) fixed, and 3) embedded

Waste Management Unit (if applicable): N/A

Facility: Building 324

Site Priority Ranking: High

Need Title: Decontamination of Building 324

Need Description: Fast acting, low life-cycle cost surface decontamination technologies, including those which can be remotely applied are needed immediately. Surfaces include, but are not limited to, those found in hot cells, piping, ducting, concrete basins, metal floors, etc. Ongoing decontamination activities require intensive manpower, produce secondary waste, and are costly.

Current Baseline Technology: Concrete - scabbling, hydro-lancing; Metal - wipes, hydrolancing, ice blasting, steam, acid washes, electropolishing; Glove boxes - wipes, strippable coatings/gels

Functional Performance Requirements: Decontamination methods are needed that minimize worker exposure, secondary waste generation, costs, risk and are readily deployable. Methods that clean to free-release levels are preferable. The specific need is for the decontamination of BCell. The cells typically contain stainless-steel liners over a concrete base. Contaminants may be restricted to the surfaces of these liners but also may have penetrated the stainiess steel and concrete to varying depths. Surfaces requiring decontamination include concrete cell walls, steel flooring systems, stainless-steel liners, and a range of equipment items of varying size. Some surfaces will require in situ decontamination, others may be transported to a central decontamination facility. The primary contaminants include strontium and cesium but may also include uranium and transuranic waste from spent fuel. Radiation levels range from several millirems to as high as 500,000 rad/hr. Waste minimization and remote handling methods are of prime importance.

Schedule Requirements: Immediate - long term 
Problem Description: Contamination represents an immediate worker exposure concern as well as a long-term environmental concern. Many surface decontamination technologies generate secondary waste streams, are labor intensive, and are costly.

$\begin{array}{llll}\text { ADS. No. } & \text { PBS No. } & \text { WBS No. } & \\ \text { 6618-0 } & \text { RL-TP08 } & 7.19 & \text { 324/327 Facility Transition Project } \\ 6619-0 & & & \end{array}$

\section{Justification for Need:}

Technical: As facilities are transitioned to stable conditions and decommissioned, they require decontamination of radioactively contaminated materials. Current decontamination methods are often slow, costly, and produce secondary waste.

Regulatory: TPA Milestone 89-02: Complete 324 building B-cell cleanout, May 31, 1999.

Environmental Safety and Health: Radioactive contamination presents safety/exposure concerns.

Cost Savings Potential (Mortgage Reduction): Mortgage rates can be reduced through the implementation of cost effective methods for decontamination.

Cultural/Stakeholder Concerns: Decontaminating materials to free release can minimize the volume of material destined for onsite burial. This will help alleviate concerns expressed by several stakeholder groups.

Other: None identified.

Consequences of Not Filling Need: Current methods will be used which are costly and time consuming. These methods will slow Hanford cleanup progress.

Outsourcing Potential: There may be some outsourcing potential in developing decontamination technologies.

End-User: EM-60

Site Technical Points of Contact: Gerry McCormick - BWHC (509) 372-8173, Robbin Duncan - BHWC (509)-2229, Rich Hobart - BWHC (509) 373-2316

DOE End-User/Representative Points of Contact: Larry Romine - EM-60 (509) 376-4747 


\section{TECHNOLOGY NEEDS/OPPORTUNITIES \\ STATEMENT OUTLINE \\ FIXATIVES FOR BUILDING 324}

Identification No.: RL-DD07

Date: August 11, 1997

Program: Decontamination and Decommissioning

OPS Office/Site: Richland Operations Office/Hanford Site

Operable Unit (if applicable): N/A

Waste Stream: Radioactively contaminated surfaces with loose or dispersible contamination.

Waste Management Unit (if applicable): N/A

Facility: Building 324

Site Priority Ranking: High

Need Title: Fixatives for Building 324

Need Description: Long-life fixatives to contain dispersible radioactive materiais that are easily applied to and removed from surfaces are needed. Such fixatives could be used on a variety of surfaces such as those encountered in materials processing facilities, glove boxes, hot cells, and ductwork.

Current Baseline Technology: Paint, tar, polymeric barrier system, rustoleum

Functional Performance Requirements: The fixative may be used to immobilize dispersible alpha, beta, and gamma contamination. The fixative must be easily removable to allow for eventual decontamination. It needs to last $20-25$ years, and a thin film is preferred.

Schedule Requirements: Immediate - long term

Problem Description: Dispersible surface contamination is present in hot cell facilities. Such dispersible contamination often presents a worker exposure concern and a long term environmental concern. In areas where decontamination is not feasible, dispersible contamination is fixed in place:
ADS. No.
PBS No.
WBS No.
6619-0
RL-TP08
7.19
324/327 Facility Transition Project

Justification for Need:

Technical: Dispersible radioactive contamination can present safety/exposure concerns. 
Regulatory: TPA Milestone 89-02 Complete 324 Building B-Cell cleanout, May 1, 1999

Environmental Safety and Health: Dispersible radioactive contamination can present safety/exposure concerns.

Cost Savings Potential (Mortgage Reduction): Current fixative methods require periodic replacement and increase life cycle costs.

Cultural/Stakeholder Concerns: Employee and public exposure to radioactive materials is a concern of Hanford stakeholders.

Other: None identified.

Consequences of Not Filling Need: Use current technology at high maintenance cost.

Outsourcing Potential: Unknown

End-User: EM-60

Site Technical Points of Contact: Gerry McCormick - BWHC (509) 372-8173, Robbin Duncan - BWHC (509)-2229, Rich Hobart - BWHC (509) 373-2316

DOE End-User/Representative Points of Contact: Larry Romine - EM-60 (509) 376-4747 


\section{TECHNOLOGY NEEDS/OPPORTUNITIES STATEMENT OUTLINE REMOTE CUTTING TECHNOLOGIES}

\section{Identification No.: RL-DD08}

Date: August 11, 1997

Program: Decontamination and Decommissioning

OPS Office/Site: Richland Operations Office/ Hanford Site

Operable Unit (if applicable): N/A

Waste Stream: Radioactively contaminated materials, equipment, tanks, pipes. Asbestos contaminated materials also require cutting.

Waste Management Unit (if applicable): N/A

Facility: Building 324

\section{Site Priority Ranking: High}

Need Title: Remote Cutting Technologies

Need Description: Low life-cycle cost, cutting technologies are needed immediately for radioactively contaminated materials, equipment, tanks, racks, pipes, etc. Some situations may require remote capabilities. Features of any such technology should include ease of set-up and operation, low waste generation, remote operation capabilities and reliability.

Current Baseline Technology: Metal - plasma torch, hydraulic shears, hack-saws, oxygenacetylene torch, diamond saws, circular saws; Glove boxes - nibblers and shears.

Functional Performance Requirements: The equipment should be easily set up, be reliable, have capability for remote operations, and have little or low generation of dust or other secondary waste. The methods should operate faster than the currentiy used methods. Technology may be deployed in locations having high radiation fields $(100,000-500,000 \mathrm{rad} / \mathrm{hr})$. Activities require remote cutting of radioactively contaminated equipment that does not generate excess waste material. Equipment requiring cutting in the hot cell environments include items with complex geometries such as equipment racks, fuel racks, pipes, tanks, etc.

Schedule Requirements: Immediate - long term

Problem Description: Deactivation activities require removal and size reduction of a variety of equipment and materials. Radiation concerns often prevent direct access. Current methods are time consuming, generate secondary wastes, cause a high degree of worker fatigue and are costly. 
ADS. No. PBSNo. WBSNo.

6619-0 RL-TP08 7.1.9 Facility Transition Project

\section{Justification for Need:}

Technical: Facility stabilization and decommissioning activities involve the removal and size reduction of equipment and materials. Current methods are often too slow and labor intensive. High radiation levels prevent direct worker access.

Regulatory: TPA.Milesțone 89-02: Complete 324 building B-cell cleanout, May 31, 1999.

Environmental Safety and Health: Occupational concerns in dealing with hot cells and materials with high levels of radioactive contamination.

Cost Savings Potential (Mortgage Reduction): Cost savings can be realized through the time savings due to faster cutting technology.

Cultural/Stakeholder Concerns: Stakeholders have expressed concerns with regard to the amount of waste destined for burial at Hanford and about the ultimate disposition of large processing facilities and reactors. Effective size reduction efforts can minimize waste volumes and help facilitate decontamination efforts. Size reduction of waste helps facilitate the removal of radioactively contaminated materials and equipment.

Other: None identified.

Consequences of Not Filling Need: Current cutting technologies will be deployed and may take longer than originally planned.

Outsourcing Potential: Unknown

End-User: EM-60

Site Technical Points of Contact: Gerry McCormick - BWHC (509) 372-8173, Robbin Duncan - BWHC (509) 373-2229, Rich Hobart - BWHC (509) 373-2316

DOE End-User/Representative Points of Contact: Larry Romine - EM-60 (509) 376-4747 


\section{TECHNOLOGY NEEDS/OPPORTUNITIES \\ STATEMENT OUTLINE \\ TANK REMEDIATION FOR BUILDING 324}

Identification No.: RL-DD09

Date: August 11, 1997

Program: Decontamination and Decommissioning

OPS Office/Site: Richland Operations Office/Hanford Site

Operable Unit (if applicable):

Waste Stream: High level radiation waste tank heels

Waste Management Unit (if applicable):

Facility: Building 324

Site Priority Ranking: Medium

Need Title: Tank Rernediation for Building 324

Need Description: Methods are needed for remediation of residual waste from tanks used for storing high level radioactive liquid waste associated with material processing facilities and hot cells.

Current Baseline Technology: Leave tanks in place until final disposal.

Functional Performance Requirements: Remote techniques are needed to remove tank heels or prevention of contamination dispersion upon cutting or disassembly. The residual material ranges from low level to high level material with potential for transuranic waste.

Schedule Requirements: Prior to hot cell cleanout scheduled for December 1998.

Problem Description: Residual material remains in high level radiation waste tanks that were used in materials processing facilities and hot cells. The residual materials are left in the tanks after they have been deactivated. The residues are in the form of liquids, liquid sludges, solids and dispersible material.

\section{ADS. No. PBSNo. WBSNo.}

6619-0 RL-TP08 7.1.9 324/327 Facility Transition Project

\section{Justification for Need:}

Technical: The current method of dealing with the tank heels are to leave them until final disposal at which time the tanks may be cut up and removed for disposal. 
Regulatory: TPA Milestone 89-02: Complete 324 building B-cell cleanout, May 31, 1999.

Environmental Safety and Health: There are potential worker safety concerns and potential for airborne releases.

Cost Savings Potential (Mortgage Reduction): Addressing the tank heels now will reduce surveillance and maintenance costs.

Cultural/Stakeholder Concerns: Tanks will be left until the Environmental Restoration program addresses them in the future. Methods of disposing of the tanks involve cutting them which may result in airborne release of radioactive contamination. This approach defers resolving the final disposition of the tanks or removal of the heel at time of decommissioning.

Other: None identified.

Consequences of Not Filling Need: Potential safety hazard.

Outsourcing Potential: N/A

End-User: EM-60

Site Technical Points of Contact: Gerry McCormick - BWHC (509) 372-8173, Robbin Duncan - BWHC (509) 373-2229, Rich Hobart - BWHC (509) 373-2316

DOE End-User/Representative Points of Contact: Larry Romine - EM-60 (509) 376-4747 


\section{TECHNOLOGY NEEDS/OPPORTUNITIES \\ STATEMENT OUTLINE \\ RADIATION HARDENED ROBOTICS}

Identification No.: RL-DD010

Date: August 11, 1997

Program: Decontamination and Decommissioning

OPS Office/Site: Richland Operations Office/Hanford Site

Operable Unit (if applicable): N/A

Waste Stream: Highly radioactive materials within hot cells

Waste Management Unit (if applicable): N/A

Facility: Building 324

Site Priority Ranking: Medium

Need Title: Radiation Hardened Robotics

Need Description: Remote handling methods are needed for high radiation areas such as hot cells. Automated systems are needed to survey contaminated areas and to deploy decontamination, characterization and cutting technologies.

Current Baseline Technology: Cranes and master slave manipulators

Functional Performance Requirements: Automated systems must be able to perform remote activities requiring a range of motions and weight requirements in high radiation fields (on the order of 100,000 to $500,000 \mathrm{rad} /$ hour) with a life expectancy of greater than one year. The systems need to have motor skills that allow them to deploy decontamination technologies, characterization techniques and perform cutting activities. The systems may be operated pneumatically, hydraulically or electrically but must be able withstand the harsh environments of the hot cells.

Schedule Requirements: Immediately

Problem Description: Hot cell cleanout activities require the decontamination and removal of equipment and debris. Activities are best performed remotely due to the high radiation field. In some cases, overhead cranes are the only equipment available to perform work. Such cranes often prove to not have the fine motor control necessary to accomplish a given task. Remote cutting operations are often tedious and labor intensive which may lead to worker fatigue and potential for dropping of equipment and other failures.
ADS. No.
PBS No.
WBS No.
6619-0
RL-TP08
7.1 .9

324/327 Facility Transition Project 


\section{Justification for Need:}

Technical: Activities in high radiation areas require remote operations.

Regulatory: TPA Milestone 89-02: Complete 324 building B-cell cleanout, May 31, 1999.

Environmental Safety and Health: Worker safety, exposure, and fatigue are the primary concerns.

Cost Savings Potential (Mortgage Reduction): Schedule acceleration due to more efficient remote operations may result in a cost saving.

Cultural/Stakeholder Concerns: Worker exposure can be significantly reduced by using remotely deployed systems that avoid putting workers at risk. Better characterization data will lead to better and more cost effective decontamination/removal decisions, thus minimizing quantities of materials handled, stored or disposed as a waste product.

Other: None identified.

Consequences of Not Filling Need: Will continue to use existing technology.

Outsourcing Potential: Unknown

End-User: EM-60

Site Technical Points of Contact: Gerry McCormick - BWHC (509) 372-8173, Robbin Duncan - BWHC (509) 373-2229, Rich Hobart - BWHC (509) 373-2316

DOE End-User/Representative Point of Contact: Larry Romine - EM-60 (509) 376-4747 


\section{TECHNOLOGY NEEDS/OPPORTUNITIES \\ STATEMENT OUTLINE \\ STRUCTURAL INTEGRITY INSPECTION TECHNOLOGIES}

Identification No.: RL-DD011

Date: August 11, 1997

Program: Decontamination and Decommissioning

OPS Office/Site: Richland Operations Office/Hanford

Operable Unit (if applicable): N/A

Waste Stream: Stainless-steel hot cell liners

Waste Management Unit (if applicable): N/A

Facility: Building 324

Site Priority Ranking: Low

Need Title: Structural Integrity Inspection Technologies

Need Description: A method is required for the reliable inspection of the integrity of hot cell liners to support the selection of an appropriate method for decontamination.

Current Baseline Technology: Visual inspection, camera

Functional Performance Requirements: The hot cell liner is composed of $1 / 4-1 / 2$ inch stainless-steel that has been welded into one piece. The cell liner must be thoroughly examined for cracks and other potential leak points. The technology must be able to withstand a high radioactive environment ( $<100,000 \mathrm{rad} /$ hour $)$, be remotely deployed, and must be able to operate in a variety of orientations and positions.

Schedule Requirements: Immediate

Problem Description: Objects penetrating and/or cracking of the hot cell liners may have resulted from past operations. There is low confidence in currently available methods to accurately determine the existence of flaws in the liner that would lead to the leaking of cleaning solutions and the spread of contamination. If it can be determined that the cell liner is intact, an aqueous decontamination method can be used. Otherwise, a dry method will need to be deployed at a significantly greater cost.
ADS. No.
PBS No.
WBS No. 6619-0 RL-TP08 7.1.9. 324/327 Facility Transition Project 


\section{Justification for Need:}

Technical: Decisions with regard to the decontamination method to be utilized are infiuenced by the integrity of the liner system. Simple, accurate methods to verify the integrity of such liners can positively influence these.decisions.

Regulatory: TPA Milestone 89-02: Complete 324 building B-cell cleanout, May 31, 1999.

Environmental Safety and Health: If the hot cell liner integrity has been compromised, an aqueous-based decontamination method could result in contamination release to the environment.

Cost Savings Potential (Mortgage Reduction): If the hot cell liner proves to be intact, significant cost savings could be realized if aqueous decontamination methods can be deployed.

Cultural:Stakeholder Concerns: Stakeholders are concerned about releases to the environment. Liner systems are often a primary barrier between any given source and the environment. Verifying the integrity of such liner systems can help alleviate such concerns.

Other: None identified.

Consequences of Not Filling Need: Uncertainty of the integrity of the liner will require more robust and expensive decontamination procedures.

Outsourcing Potential: N/A

End-User: EM-60

Site Technical Points of Contact: Gerry McCormick - BWHC (509) 372-8173, Robbin Duncan - BWHC (509) 373-2229, Rich Hobart - BWHC (509) 373-2316

DOE End-User/Representative Point of Contact: Larry Romine - EM-60 (509) 376-4747 


\section{TECHNOLOGY NEEDS/OPPORTUNITIES \\ STATEMENT OUTLINE \\ CONTAMINANT MAPPING OF K-BASIN}

Identification No.: RL-DD012

Date: August 1, 1997

Program: Decontamination and Decommissioning

OPS Office/Site: Richland Operations Office/Hanford Site

Operable Unit (if applicable): N/A

Waste Stream: Radioactively contaminated surfaces with loose or dispersible contamination.

Waste Management Unit (if applicable): N/A

Facility: K-Basins

Site Priority Ranking: Medium

Need Title: Contaminant Mapping of K-Basin

Need Description: A method to map the location and activity levels of radioactive contaminants on underwater vertical and horizontal surfaces is needed.

Current Baseline Technology: No appropriate technology has been identified.

Functional Performance Requirements: The mapping technology must be able to locate and identify the activity level of alpha, beta, and gamma contamination on both vertical and horizontal surfaces. The mapping must be performed remotely underwater. The surfaces are not uniform with sections that vary in width from an inch to 125 feet.

Schedule Requirements: The removal of fuel, debris, and sludge from the K-Basins is scheduled for completion in August 2001. Mapping of wall and floor contaminants is needed to support development of deactivation plans. Deactivation plans must be in place prior to initiation of decontamination activities. Completion of the $\mathrm{K}$-Basin Deactivation program is currently scheduled for December 2005.

Problem Description: Residual surface contamination may be present on KW Basin surfaces and will be present on $\mathrm{KE}$ Basin surfaces (basin walls and floors) and may also be present in the area surrounding the K-Basin fuel storage pools. Residual contamination presents a worker exposure concern. The location and activity level of contaminants needs to be identified to enable proper selection of a decontamination technology. Identification of the decontamination technology is necessary before project baselines can be developed.

ADS. No. PBSNo. $\quad$ WBSNo.

6628-0 RL-TP09 7.1.X

K-Basin Deactivation 


\section{Justification for Need:}

Technical: The location and activity level of contaminants needs to be identified to enable proper selection of a decontamination technology. Identification of the decontamination technology is necessary before project baselines can be developed. Residual radioactive contamination presents safety/exposure concerns.

Regulatory: TPA Milestones M-34-04 through M-34-11 have been proposed for K-Basin Deactivation and are out for public comment.

Environmental Safety and Health: Residual radioactive contamination presents safety/exposure concerns.

Cost Savings Potential (Mortgage Reduction): Current mapping methods may not be capable of remote operation or operation underwater.

Cultural/Stakeholder Concerns: Employee and public exposure to radioactive materials is a concern of Hanford stakeholders.

Other: None identified.

Consequences of Not Filling Need: A method has not been identified for the remote mapping of radioactive contaminants in a submerged location. Lack of appropriate technology will slow deactivation activity with the $\mathrm{K}-\mathrm{Basin}$ pools.

Outsourcing Potential: N/A

End-User: EM-60

Site Technical Points of Contact: Gerry McCormick - BWHC (509) 372-8173, Robbin Duncan - BWHC (509) 373-2229, Dennis Lund - BWHC (509) 372-3642

DOE End-User/Representative Points of Contact: Rick Gonzalez - EM-60 (509) 373-9922 


\title{
TECHNOLOGY NEEDS/OPPORTUNITIES \\ STATEMENT OUTLINE \\ DECONTAMINATION OF K-BASIN POOL
}

\author{
Identification No.: RL-DD013
}

Date: August 1, 1997

Program: Decontamination and Decommissioning

OPS Office/Site: Richland Operations Office/Hanford Site

Operable Unit (if applicable): N/A

Waste Stream: Beta and Gamma contamination that is embedded in concrete.

Waste Management Unit (if applicable): N/A.

Facility: KE-Basin

Site Priority Ranking: Medium

Need Title: Decontarnination of K-Basin Pool

Need Description: Method to remove radioactive contaminants that have migrated into the surface of the concrete of the KE-Basin fuel storage pool. The contamination exists as a "bathtub ring" and as deposits of varying thicknesses throughout the sides and bottom of the concrete pool. The primary contaminants are cesium and strontium. The upper level of the basin wall has been treated with epoxy and the water level has been raised to provide shielding during fuel and sludge removal. The basin can not be emptied of water until the contamination is either removed or additional shielding is provided. The water also acts as a contaminant containment barrier.

(No HEPA filtration system exists at either basin.)

Current Baseline Technology: No appropriate baseline technology has been identified.

Functional Performance Requirements: A decontamination method is needed that minimizes worker exposure, secondary waste generation, cost, and risk and it should be are readily deployable. Concrete decontamination technologies shall be capable of being remotely operated and mobile supplemental shielding must be provided to minimize worker exposure during setup. Underwater stripping technologies must minimize turbidity (maintaining water clarity is a major concern). If underwater stripping technology is not employed, some form of airborne contaminant containment is necessary. The decontamination technology must be capable of operation on both vertical and horizontal surfaces. These surfaces are not uniform with sections that vary in width from an inch to 125 feet. Removal of a fixative may also be required in some areas. The ability to collect and characterize contaminants as they are removed is also required.

Schedule Requirements: The removal of fuel, debris, and sludge from K-Basin is scheduled for completion in August 2001. Decontamination of the pool will proceed shortly thereafter. Completion of the K-Basin Deactivation program is currently scheduled for December 2005. 
Problem Description: Contamination represents an immediate worker exposure concern as well as a long-term environmental concern. The KE-Basin pool is contaminated with cesium, strontium, uranium, and transuranic components. The presence of these contaminants prevents drainage of the basin as the water serves as a radiation shield and containment barrier. There is a concentration of contaminants in a "bathtub ring" located near the surface of the water.

In addition to the "bathtub ring," radioactive contamination has penetrated to varying depths into the concrete wall and floor surfaces. Current decontamination practices include physical removal of the concrete surface (i.e., scabbling, sand blasting, etc.). None of these have been demonstrated underwater. Some contaminated concrete surfaces have also been painted and/or coated with a fixative. Project requirements may include removal of such coatings prior to decontamination of the concrete.

ADS. No. PBSNo. WBSNo. 6628-0
7.1.X

\section{Justification for Need:}

Technical: Decommissioning of the K-Basin pool to a stable condition requires the removal of the pool water. This can not occur until the level of residual contamination can be reduced or shielded to a safe level as the water in the pool currently serves as a radiation shield. Any remaining residual contaminants must be fixed in place after water removal since the basin does not have a HEPA filtration system.

Regulatory: TPA Milestones M-34-04 through M-34-11 have been proposed for K-Basin Deactivation and are out for public comment.

Environmental Safety and Health: Radioactive contamination presents safety/exposure concerns.

Cost Savings Potential (Mortgage Reduction): Mortgage rates can be reduced through the implementation of cost effective methods for decontamination and the transition of the facility into a stable condition that requires low surveillance and maintenance.

Cultural/Stakeholder Concerns: Decontamination of materials and equipment that are present in facilities near the Columbia river reduces the risk of offsite contamination.

Other: None identified.

Consequences of Not Filling Need: A method has not been identified for the decontamination of the KE-Basin pool. Lack of an appropriate method will slow completion of basin deactivation thereby slowing Hanford cleanup progress.

Outsourcing Potential: N/A 
End-User: EM- 60

Site Technical Points of Contact: Gerry McCormick - BWHC (509) 372-8173, Robbin Duncan - BWHC (509) 373-2229, Dennis Lund - BWHC (509) 372-3642.

DOE End-User/Representative Points of Contact: Rick Gonzalez - EM-60 (509) 373-9922 


\section{TECHNOLOGY NEEDS/OPPORTUNITIES \\ STATEMENT OUTLINE \\ FIXATIVES FOR K-BASIN}

\section{Identification No.: RL-DD014}

Date: August 1, 1997

Program: Decontamination and Decommissioning

OPS Office/Site: Richland Operations Office/Hanford Site

Operable Unit (if applicable): N/A

Waste Stream: Radioactively contaminated surfaces with loose or dispersible contamination.

Waste Management Unit (if applicable): N/A

Facility: K-Basins

Site Priority Ranking: Medium

Need Title: Fixatives for K-Basin

Need Description: Long-life fixatives to contain dispersible radioactive materials that are easily applied to and removed from surfaces are needed.

Current Baseline Technology: Paint, tar, polymeric barrier system, rustoleum

Functional Performance Requirements: The fixative must be able to immobilize dispersible alpha, beta, and gamma contamination. The fixative must be easily removable to allow for eventual decontamination. It needs to last $20-25$ years, and a thin film is preferred. At KE Basin, the fixative will need to be applied remotely, either in air or underwater. The fixative method must accommodate coating of both vertical and horizontal surfaces. The surfaces are not uniform with sections that vary in width from an inch to 125 feet.

Schedule Requirements: The removal of fuel, debris, and sludge from the K-Basins is scheduled for completion in August 2001. Decontamination of the pool will proceed shortly thereafter. Completion of the K-Basin Deactivation program is currently scheduled for December 2005.

Problem Description: Dispersible surface contamination may be present on KW Basin surfaces, will be present on KE Basin surfaces (basin walls and floors), and may also be present in the area surrounding the K-Basin fuel storage pools. Such dispersible contamination presents a worker exposure concern and constitutes a long term environmental concern since neither basin has HEPA filtration. In areas where decontamination is not feasible, dispersible contamination is fixed in place. 


$\begin{array}{llll}\text { ADS. No. } & P B S N o . & W B S N o . & \\ 6628-0 & \text { RL-TP09 } & \text { 7.1.X } & \text { K-Basin Deactivation }\end{array}$

Justification for Need:

Technical: Dispersible radioactive contamination presents safety/exposure concerns.

Regulatory: TPA Milestones M-34-04 through M-34-11 have been proposed for K-Basin Deactivation and are out for public comment.

Environmental Safety and Health: Dispersible radioactive contamination presents safety/exposure concerns.

Cost Savings Potential (Mortgage Reduction): Current fixative methods require periodic replacement and increase life cycle costs.

Cultural/Stakeholder Concerns: Employee and public exposure to radioactive materials is a concern of Hanford stakeholders.

Other: None identified.

Consequences of Not Filling Need: Use current technology at high maintenance cost.

Outsourcing Potential: N/A

End-User: EM-60

Site Technical Points of Contact: Gerry McCormick - BWHC (509) 372-8173, Robbin Duncan - BWHC (509) 373-2229, Dennis Lund - BWHC (509) 372-3642

DOE End-User/Representative Points of Contact: Rick Gonzalez - EM-60 (509) 373-9922 


\title{
TECHNOLOGY NEEDS/ OPPORTUNITIES STATEMENT OUTLINE CONCRETE FUEL BASIN DECONTAMINATION
}

\author{
Identification No.: $\underline{\mathrm{RL}-\mathrm{DD} 015}$
}

Date: September 9, 1997

Program: Decontamination and Decommissioning OPS Office/Site: Richland Operations Office/Hanford Site Operable Unit (if applicable): N/A

Waste Stream: Low level waste Waste Management Unit (if applicable): N/A

Facility: Fuel Basins

Site Priority Ranking: High

Need Title: Improved decontamination techniques for concrete fuel storage basins

Need Description: Current decontamination techniques for fuel storage basins, although very effective, produce large quantities of waste, are manpower intensive, and are costly.

\section{Current Baseline Technology: Scabbling}

Functional Performance Requirements: The primary contaminants are cesium and strontium. The contaminants exist: as a "bath tub ring", as deposits of varying thickness throughout the concrete, as surface contamination, and as contamination contained on painted or asphait-coated surfaces. The technology should be able to decontaminate concrete without surface removal up to a depth of $1 / 2$ inch or more, and should either not introduce hazardous materials or allow for ready removal of the hazardous constituents from the resultant waste. The technique should also be user friendly.

\section{Schedule Requirements: Immediate}

Problem Description: Fuel storage basins located at the Hanford Site are contaminated with cesium strontium, uranium, and transuranic components. The contamination has penetrated to various depths. Current practice includes physical removal of the concrete surface (e.g., scabbling or sand blasting), which creates large quantities of waste. Some contaminated concrete surfaces have been painted or coated with asphalt. Functional Requirements may include removal of coatings prior to decontamination of the concrete.

PBS Number: RL-ER06

Justification for Need: 
Technical: Current decontamination methods, although effective in removing contaminants, generate large quantities of waste, are manpower intensive and are costly.

Regulatory: Info needed from projects

Environmental Safety and Health: Radioactive contamination presents safety and exposure concerns.

Cost Savings Potential (Mortgage Reduction): Mortgage rates may be reduced through the implementation of coast effective methods for decontamination.

Cultural/Stakeholder Concerns: Decontamination of materials and equipment present in facilities near the river reduces the risk of offsite contamination. Decontamination of materials to free release can minimize the volume of material destined for onsite burial. This will help alleviate concerns of several stakeholder groups.

Other: None identified.

Consequences of Not Filling Need: Current methods will continue to be used.

Outsourcing Potential: There may be some outsourcing potential for developing and marketing decontamination techniques.

End-User: EM-40

Site Technical Points of Contact: Ken Jackson - BHI (509) 372-9295, Greg Eidam - BHI (509) 373-3818, Stephen Pulsford - BHI (509) 373-1769, Sue Garrett - PNNL, (509) 372-4266

DOE End-User/Representative Points of Contact: Jim Goodenough (509) 376-0893 


\section{TECHNOLOGY NEEDS/ OPPORTUNITIES STATEMENT OUTLINE CHARACTERIZATION TECHNOLOGIES}

Identification No.: $\underline{\text { RL-DD016 }}$

Date: September 9, 1997

Program: Decontamination and Decommissioning

OPS Office/Site: Richland Operations Office/Hanford Site

Operable Unit (if applicable): N/A

Waste Stream: Contaminated and non-contaminated equipment and materials from materials processing facilities. Contaminated materials may include radioactive or mixed wastes, equipment, tanks, pipes, concrete, etc.

Waste Management Unit (if applicable): N/A

Facility: Materials processing facilities

Site Priority Ranking: High

Need Title: Characterization technologies for materials processing facilities

Need Description: Characterization technologies are needed fro determining radiation levels in situ in materials processing facilities. Differentiation between transuranic and non-transuranic waste is a primary concern.

Current Baseline Technology: Wipes, laboratory analysis, radiation detection - both general and energy specific such as gamma spectral analyses, document searches, visual inspections and data recording, hand-held or cart-mounted survey equipment, and ad hoc sampling of representative surfaces, materials and spaces.

Functional Performance Requirements: A cost effective means of characterizing highly contaminated, highly congested, internally contaminated equipment with little or no exposure to personnel. Technology should all for mapping of dose rates and differentiation between TRU and non-TRU. Methods should allow for remote in situ characterization that permit identification of hot spots within a small area containing high radiation levels $(100,000-500,000$ $\mathrm{r} / \mathrm{hr}$ ).

Schedule Requirements: Immediate - long term

Problem Description: It is difficult to determine where contamination hot spots are in high radiation areas, especially when some of the contamination is TRU internal to equipment. A method that would provide point specific information is desired. Current methods are labor intensive, long in duration, wasteful of personnel occupational radiation exposure, expensive and subject to a variety of random and systematic errors. 
PBS Number: RL-ER06

Justification for Need:

Technical: Some areas within the materials processing facility can not be characterized using the current technologies.

Regulatory: Input from projects

Environmental Safety and Health: Improved worker safety could result with the use of remote systems.

Cost Savings Potential (Mortgage Reduction): Significant costs savings could result by being able to identify specific equipment/materials as contaminated with in a high dose field. Decontamination efforts could concentrate on removal/decontamination of specific locations versus blanket removal/decontamination.

CulturalStakeholder Concerns: Reduction of employee exposure. Decontamination' removal decisions would be more informed allowing for minimal treatment and waste disposal.

Other: None identified.

Consequences of Not Filling Need: Current labor intensive baseline technologies will be used resulting in high costs, and no mapping of contamination. Potential exists for clean materiais to be handled, and disposed or, as contaminated. There is an inability to characterize in some high radioactive areas using current techniques.

Outsourcing Potential: Unknown

End-User: EM-40

Site Technical Points of Contact: Ken Jackson - BHI (509) 372-9295, Jerry McGuire - BHI (509) 373-7253, Stephen Pulsford - BHI (509) 373-1769, Sue Garrett - PNNL (509) 372-4266

DOE End-User/Representative Points of Contact: Jim Goodenough (509) 376-0893 


\title{
TECHNOLOGY NEEDS/ OPPORTUNITIES \\ STATEMENT OUTLINE \\ SEGREGATION CHARACTERIZATION
}

\author{
Identification No.: RL-DD017
}

Date: September 9, 1997

Program: Decontamination and Decommissioning

OPS Office/Site: Richland Operations Office/Hanford Site

Operable Unit (if applicable): N/A

Waste Stream: Contaminated and non-contaminated equipment and materials from materials processing facilities, glove boxes reactors and hot cells. Contaminated materials may include radioactive or mixed wastes, equipment, tanks, pipes, concrete, etc.

Waste Management Unit (if applicable): N/A

Facility: Materials processing facilities, decontamination facilities, hot cells, fuel basins, reactors

Site Priority Ranking: High

Need Title: Characterization technologies for segregating contaminated versus noncontaminated, TRU versus non-TRU materials for disposal.

Need Description: Characterization technologies are needed for differentiating between transuranic and non-transuranic waste. In addition, a verifiable method for determining that materials qualify for free-release is necessary.

Current Baseline Technology: Wipes, laboratory analysis, radiation detection - both general and energy specific such as gamma spectral analyses, document searches, visual inspections and data recording, hand-held or cart-mounted survey equipment, and ad hoc sampling of representative surfaces, materials and spaces. Another alternative is management of material as contaminated without any characterization.

Functional Performance Requirements: A method is needed that will allow for the real-time differentiation between TRU and non-TRU waste and/or between low level and free-release waste. Characterization is needed for material contained in a variety of configurations including drums, plastic bags, equipment, concrete chunks, and gravel. The technology must work on material/equipment with inaccessible surfaces larger than crushed materials.

Decommissioning activities require the capability of survey equipment to be mounted on a conveyor belt that can identify and segregate radioactively contaminated versus clean material.

Schedule Requirements: Immediate 
Problem Description: It is difficult to differentiate between radioactively contaminated and noncontaminated equipment and materials. Potentially contaminated surfaces are often inaccessible to current detection methods. Some materials are managed in their entirety as radioactive and/or mixed wastes, which adds unnecessary costs for handling and disposal.

PBS Number: RL-ER06

Justification for Need:

Technical: Adequate characterization of wastes can lead to waste minimization.

Regulatory: Input from projects

Environmental Safety and Health: Improved worker safety could result with the use of remote systems.

Cost Savings Potential (Mortgage Reduction): Significant costs savings could result by being able to identify contaminated versus non-contaminated materials, surfaces and equipment.

Cultural/Stakeholder Concerns: Reduction in the amount of materials handled, stored or disposed as a waste product is desirable by the stakeholders.

other: None identified.

Consequences of Not Filling Need: The potential exists for clean materials to be handled and disposed of as contaminated, and therefore disposed of at additional cost.

Outsourcing Potential: Unknown

End-User: EM-40

Site Technical Points of Contact: Ken Jackson - BHI (509) 372-9295, Jerry McGuire - BHI (509) 373-7253, Stephen Pulsford - BHI (509) 373-1769, Sue Garrett - PNNL (509) 372-4266

DOE End-User/Representative Points of Contact: Jim Goodenough (509) 376-0893 


\section{TECHNOLOGY NEEDS/ OPPORTUNITIES \\ STATEMENT OUTLINE \\ REACTOR CORE STABILIZATION}

Identification No.: RL-DD018

Date: September 9, 1997

Program: Decontamination and Decommissioning

OPS Office/Site: Richland Operations Office/Hanford Site

Operable Unit (if applicable): N/A

Waste Stream: Radioactively contaminated reactor core surfaces with loose or dispersible contamination

Waste Management Unit (if applicable): N/A

Facility: Reactor facilities

Site Priority Ranking: High

Need Title: Stabilization techniques for the exterior or reactor cores.

Need Description: Long-life fixatives to contain dispersible radioactive material that are easily applied to and removed from surfaces with multiple geometries are needed.

\section{Current Baseline Technology: Rustoleum or nothing}

Functional Performance Requirements: Reactor core stabilization activities require a fixative that can survive radiation fields of a few to a few hundred $\mathrm{mr} / \mathrm{hr}$, be applicable (applied and removed) to geometries found on the core front and rear faces, be applicable to carbon steel, stainless steel, aluminum and lead, and have a design life of 50 years. Operating temperature are ambient temperatures for the Hanford Site. In addition, the fixative needs to be easily applied and removed, and be water and biota proof. The typical "biota" at the Hanford Site consists of rattle snakes, bull snakes, other reptiles and amphibians (11 species), black widow spiders, brown recluse spiders, other spiders, insects (more than 300 species), sea gulls, pigeons, starlings, other birds (more than 125 species), russian thistle, kocha, cheatgrass, sagebrush, rabbitbrush, and other weeds. There are also 27 species of mammals found on the Site that include the typical rodents.

Schedule Requirements: Immediate

Problem Description: Dispersible surface contamination exists on reactor cores: Such dispersible materials often present a worker exposure concern and a long term environmental concern. It is necessary to prevent the spread of contamination due to the degradation and bio intrusion of the reactor cores until it is time to move the cores to their final disposal site.

PBS Number: RL-ER06 
Justification for Need:

Technical: Dispersible radioactive contamination can present safety and exposure concerns.

Regulatory: Input needed from projects

Environmental Safety and Health: Dispersible radioactive contamination can present safety and exposure concerns.

Cost Savings Potential (Mortgage Reduction): Current methods are not applicable for 50 years, therefore requiring re application or additional clean up due to spread of contamination.

Cultural/Stakeholder Concerns: Employee and public exposure to radioactive materials is a concern of Hanford stakeholders.

Other: None identified.

Consequences of Not Filling Need: Continue using current techniques with a potential for high costs associated with decontaminating reactor cores.

Outsourcing Potential: Unknown

End-User: EM-40

Site Technical Points of Contact: Ken Jackson - BHI (509) 372-9295, Greg Eidam - BHI (509) 373-3818, Stephen Pulsford - BHI (509) 373-1769, Sue Garrett - PNNL (509) 372-4266

DOE End-User/Representative Points of Contact: Jim Goodenough (509) 376-0893 


\section{TECHNOLOGY NEEDS/ OPPORTUNITIES \\ STATEMENT OUTLINE \\ PHYSICAL STRESS MONITORS}

Identification No.: RL-DD019

Date: September 9, 1997

Program: Decontamination and Decommissioning

OPS Office/Site: Richland Operations Office/Hanford Site

Operable Unit (if applicable): N/A

Waste Stream: N/A

Waste Management Unit (if applicable): N/A

Facility: Any facility where heat or cold may be a factor in worker productivity and safety and there is a need for personnel protective equipment (e.g., in the presence of airborne contamination). This need is applicable to all the reactor facilities.

Site Priority Ranking: Medium

Need Title: Better physical stress monitoring system for use in conjunction with personnel protection equipment

Need Description: A better means of monitoring personnel vital signs in response to heat and cold is needed to increase worker safety.

Current Baseline Technology: Entry to and exit from the work area is administratively controlled.

Functional Performance Requirements: Must be able to determine worker physical stress levels (e.g., heat and cold related) on a real time basis without worker discomfort. Monitoring should be part of and compatible with personnel protection equipment.

Schedule Requirements: Immediate. The reactor deactivation program is ongoing and is to be completed in less than 10 years.

Problem Description: Not all contaminated facilities have active heating, ventilation and air conditioning (HVAC) systems resulting in workers working at ambient temperatures.

PBS Number: RL-ER06

Justification for Need:

Technical: In order to avoid potential safety problems, time at work is conservatively controlled to assure personnel safety resulting in frequent cycling of the work force. Better 
monitoring equipment would assure early detection of physical stress in order to reduce worker health problems.

Regulatory: OSHA Standards for worker safety

Environmental Safety and Health: People may suffer hypo- or hyper-thermia working under ambient conditions, even though conservative times are estimated for personnel work under the present miethods.

Cost Savings Potential (Mortgage Reduction): Health and safety costs for personnel would be reduced with better physical monitoring.

Cultural/Stakeholder Concerns: Reduce worker safety concerns.

Other: None identified.

Consequences of Not Filling Need: Use of current techniques with decreased worker safety and higher costs.

Outsourcing Potential: Unknown

End-User: EM-40

Site Technical Points of Contact: Ken Jackson - BHI (509) 372-9295, Greg Eidam - BHI (509) 373-3818, Stephen Pulsford - BHI (509) 373-1769, Sue Garrett - PNNL (509) 372-4266

DOE End-User/Representative Points of Contact: Jim Goodenough (509) 376-0893 


\section{TECHNOLOGY NEEDS/ OPPORTUNITIES STATEMENT OUTLINE BIO-CONTROL TECHNOLOGIES}

Identification No.: $\underline{\text { RL-DD020 }}$

Date: September 9, 1997

Program: Decontamination and Decommissioning

OPS Office/Site: Richland Operations Office/Hanford Site

Operable Unit (if applicable): N/A

Waste Stream: N/A

Waste Management Unit (if applicable): N/A

Facility: Any facility in S\&M (e.g., 9 reactor buildings, 5 canyon facilities)

Site Priority Ranking: Low

Need Title: Bio-control technologies

Need Description: Better methods for controlling biological entry are needed for facilities that are in a mode of long-term surveillance and maintenance. Current techniques will not stop varmint entry into controlled areas for extended periods of time. Animal intrusion has the potential to spread contamination and poses a hazard to workers.

Current Baseline Technology: Sticky mats and attractor traps. Other currently available techniques, such as ultrasound, decoy prey and streamers would also be inadequate.

Functional Performance Requirements: There is a need for bio-control technologies that pose no threat to humans or endangered species but will stop entry of all but authorized personnel. The methods need to be effective with little or no maintenance for a period of at least five years. The bio-control method should address animals specific to the Hanford Site (e.g., hornets, yellow jackets, rodents, snakes, spiders, some types of birds).

Schedule Requirements: Immediate

Problem Description: Snakes, birds, insects, rodents and spiders enter the vacant facilities on the Hanford Site on a regular basis. When the facility is contaminated, the entrant may become contaminated and spread radioactivity through its feces and its body at death. Many of the entrants (e.g., black widow spiders, aggressive brown house spiders, rattle snakes) are also dangerous to workers who must enter the facilities.

Current techniques of bio-control are not very effective and are not designed for prolonged use. The result is an increased probability of entry and potential spread of contamination inside and outside of the facilities. 
PBS Number: RL-ER07

Justification for Need:

Technical: Current methods are inadequate for stopping intrusion on a long-term basis, causing a potential for spread of contamination beyond the confines of a facility. Intruders also pose a potential for worker injury (e.g., rattle snake bites or hornet stings).

Regulatory: None known

Environmental Safety and Health: Inadequate control of intrusion may result in the spread of contamination beyond the facilities. This poses a higher risk in facilities closer to the river. Workers entering for monitoring are also at higher risk of injury from intruding species - directly from bites and stings, and indirectly from feces and contamination spread.

Cost Savings Potential (Mortgage Reduction): Potential cost of additional clean up is avoided if contamination can be contained within the facilities.

Cultural/Stakeholder Concerns: Spread of contamination to the environment is a stakeholder concern.

Other: None identified.

Consequences of Not Filling Need: There is increased risk for the spread of contamination and personnel injury.

Outsourcing Potential: Yes

End-User: EM-40

Site Technical Points of Contact: Ken Jackson - BHI (509) 372-9295, Greg Eidam - BHI (509) 373-3818, Stephen Pulsford - BHI (509) 373-1769, Sue Garrett - PNNL (509) 372-4266

DOE End-User/Representative Points of Contact: Jim Goodenough (509) 376-0893 


\section{TECHNOLOGY NEEDS/ OPPORTUNITIES STATEMENT OUTLINE METAL DECONTAMINATION AND RECYCLING}

Identification No.: RL-DD021

Date: September 9, 1997

Program: Decontamination and Decommissioning

OPS Office/Site: Richland Operations Office/Hanford Site

Operable Unit (if applicable): N/A

Waste Stream: Metals contaminated as low level waste

Waste Management Unit (if applicable): N/A

Facility: Hanford facilities undergoing final decontamination and decommissioning

Site Priority Ranking: Low

Need Title: Metal decontamination and recycling

Need Description: Current methods of handling contaminated materials don't cost-effectively reduce radioactive waste volumes nor allow for recycle/reuse of metals and equipment.

Current Baseline Technology: Piping and equipment suspected of internal contamination are usually disposed of as radioactive waste at extremely low cost (FY 1997 costs of $\$ 78 / \mathrm{m}^{3}$ for disposal, handling and transportation) in the ERDF. Characterization is insufficient for detailed qeometries, internals, and imbedded contamination. When suspect materials are to be decontaminated, chemical treatment or surface cleaning with high-pressure water jets are applied prior to the release of these materials.

Functional Performance Requirements: Methods are needed that can cost-effectively decontaminate materials to free-release levels for recycle or reuse. The requirements for the technology include :

- Decontaminate pipes and internal components to free-release levels to allow for unrestricted use or recycling.

- Quantitative verification that decontamination levels have been achieved. This includes methods for inspecting equipment and piping internals and other difficult geometries.

- The cost of decontamination and recycling must be cost competitive with the alternative of sending the materials to the Environmental Restoration Disposal Facility (ERDF).

- Minimize secondary waste generation and avoid any hazardous/mixed waste generation.

- Easily deployed.

- As a minimum, any technology should be applicable to the reuse/recycle of steel and carbon steel.

Schedule Requirements: Immediate 
Problem Description: The estimated total volume of metallic waste exceeds $150,000 \mathrm{~m}^{3}$. Current plans are to dispose of this waste at the ERDF. Disposal of contaminated materials and equipment results in loss of assets as well as the resources expended to dispose of the assets. An effective means of decontamination and verification of results is needed to avoid such losses.

\section{PBS Number: RL-ER06}

Justification for Need:

Technical: Current methods are not cost effective for reducing radioactive waste volumes.

Regulatory: None known

Environmental Safety and Health: Long term liability could be reduced with recycling and reuse of materials.

Cost Savings Potential (Mortgage Reduction): Potential areas of cost savings are: cost of disposal is avoided, cost of obtaining an asset is reduced (e.g., cost to make a drum is less costly than to buy a drum).

Cultural/Stakeholder Concerns: Reduced waste volumes placed in the ground resulting in reduced long-term liability.

Other: None identified.

Consequences of Not Filling Need: Continued loss of potentially "recyclable" materials to ERDF. D\&D projects within the DOE continue to be encumbered with disposal costs.

\section{Outsourcing Potential: Yes}

End-User: $\mathrm{EM}-40$

Site Technical Points of Contact: Ken Jackson - BHI (509) 372-9295, Jerry McGuire - BHI (509) 373-7253, Stephen Pulsford - BHI (509) 373-1769, Sue Garrett - PNNL (509) 372-4266 DOE End-User/Representative Points of Contact: Jim Goodenough (509) 376-0893 


\section{DECONTAMINATION \& DECOMMISSIONING SCIENCE NEEDS}

\begin{tabular}{|c|l|}
\hline ID \# & \multicolumn{1}{|c|}{ NEEDS TITLE } \\
\hline RL-DD022-S & Photon Assisted Decontamination Chemistry \\
\hline RL-DD023-S & Cesium Source Identification \\
\hline RL-DD024-S & Colloidal Chemistry of Basin Wastes \\
\hline RL-DD025-S & Effluent Capture \\
\hline RL-DD026-S & Contaminant Binding Science Need \\
\hline
\end{tabular}




\section{Hanford Site Science Need \\ Decontamination and Decommissioning Subgroup \\ PHOTON ASSISTED DECONTAMINATION CHEMISTRY}

Identification No.: RL-DD022-S

Site Priority Ranking: Medium

I. Functional Need:

A technology is required that will decontaminate both metal and concrete surfaces with and without fixatives without the use of liquid solvents. Laser technology has been explored in funded research from the $\mathrm{D} \& \mathrm{D}$ Focus Area that meets this functional need. The use of laser decontamination technology has the potential to minimize the creation of secondary waste and hazardous effluents.

\section{Problem Description:}

A significant effort has been made by DOE EM-50 to develop a decontamination system using laser technology to meet this functional need. The previous work has used $\mathrm{CO}_{2}$ and Nd:YAG laser systems that were commercially available. However, as these technology development programs have progressed, a lack of understanding of the fundamental laser ablation processes has been identified.

\section{Science Need Description:}

The photochemical and photomechanical mechanisms of laser ablation need to be analyzed and fundamental models developed. This includes photo-induced molecular bond dissociation and laser-induced plasma formation and shock propagation.

IV. Benefit:

Dry decontamination technologies will reduce worker exposures and contamination, secondary waste volumes, and the risk of contamination migration. Laser systems are a promising technology to meet these needs and require a better basic science foundation in order to select laser systems and implementation techniques.

$\checkmark$ Cost Savings $\checkmark$ Risk Reduction $\checkmark$ Enabling Knowledge

V. Corresponding Technology Needs

RL-DD03, RL-DD06, RL-DD013, RL-DD021 


\section{Hanford Site Science Need \\ Decontamination and Decommissioning Subgroup \\ CESIUM SOURCE IDENTIFICATION}

Identification Number: RL-DD023-S

Site Priority Ranking: High

I. Functional Need:

Underwater leaking cesium capsules must be identified so that a potential problem may be corrected.

II. Problem Description:

Cesium chloride is stored in double stainless steel containers (called capsules) in a basin of water for shielding and for cooling. A leaking capsule (there has been no leak to date) could cause contamination of the surrounding water and would be difficult to identify. The current method to identify a possible "leaker" (leaking capsule) is a "clunk" test where capsules are picked up off the basin floor and quickly raised and lowered so that an inner container clunks the outer container. Capsules that have lost integrity will not clunk because of water in the container. This method is time consuming and, in the presence of a leaking capsule, could involve high dose rates.

The containers that make up the capsules are constructed of the same stainless steel as is used for the basin liner.

III. Science Need Description:

An understanding of processes to locate a leak from the cesium chloride capsules is needed in order to develop a means of identifying leaking capsules quickly. Since cesium is highly soluble, some other material may act as a leaker identifying agent.

IV. Benefit:

The quicker a leaking capsule can be identified, the less contaminated material will leak into the basin. The result is less clean up at lower dose rates and lower costs.

$\checkmark$ Cost Savings $\quad \checkmark$ Risk Reduction Enabling Knowledge

V. Corresponding Technology Need

RL-DD01 


\section{Hanford Site Science Need \\ Decontamination and Decommissioning Subgroup \\ COLLOWAL CHEMISTRY OF BASIN WASTES}

Identification No.: RL-DD024-S

Site Priority Ranking: Medium

I. Functional Need:

A technology is needed to settle out or remove chelated metallic ions from fuel storage basins. Current methods address sludge resuspension.

\section{Problem Description:}

Only two Spent Fuel Storage Basins are operational and may, in the future, have a visibility problem due to chelated metallic ions. The Spent Fuel Storage Basins are to be cleaned, water removed and surfaces stabilized to ensure no airborne contamination is spread. As equipment and sludge are removed from the Basins, chelated metallic ions become suspended in the water, decreasing visibility and causing delays and increased worker exposure. Flocculents and filters have been used in the past.

Examples of materials making up the Basin sludge are: dust from the environment; corrosion products of zirconium alloys, stainless steel, spent nuclear fuel and carbon steel; algae; and spent nuclear fuel fragments. The sludge is also expected to contain any and all of the chemicals that have been added to the Basin water over the years to maintain water chemistry. A record is maintained of the chemicals added to the Basins.

\section{Science Need Description:}

The colloidal chemistry of the siudges in the two operational Spent Fuel Storage Basins needs to be defined in order to maintain visibility in an optimal manner.

IV. Benefit:

The delays and personnel exposure realized from poor vision would be avoided, thereby reducing the cost of clean out.

\section{$\checkmark$ Cost Savings $\checkmark$ Risk Reduction Enabling Knowledge}

\section{Corresponding Technology Need}

There is no corresponding technology need. However, the removal of fuel, debris, and sludge from the K-Basins is scheduled for completion in August 2001. 


\section{Hanford Site Science Need \\ Decontamination and Decommissioning Subgroup \\ EFFLUENT CAPTURE}

Identification Number: RL-DD025-S

Site Priority Ranking: High

\section{Functional Need:}

Smoke from cutting tools needs to be captured in a safe and efficient manner to maximize clarity in the cutting area and to minimize secondary contamination.

\section{Problem Description:}

Different cutting tools generate smoke and particles of different particle sizes. These smoke and particles have been known to foul High Efficiency Particulate (HEPA) filters very quickly resulting in the need to replace the HEPA filters. Some work arounds have been used, such as electrostatic precipitators and mini-cyclones. A better understanding of the particle size associated with the smoke from different cutting techniques would allow for the optimal capture technology to be employed.

\section{Science Need Description:}

An understanding is needed of the particle sizes associated with the smoke from alternative cutting methods (e.g., laser cutting, plasma torch, gasoline torch). As the particle size may vary with the material being cut, various metals (e.g., stainless steel and coated and uncoated carbon steel) may need to be tested for a full understanding of the particles sizes.

\section{Benefit:}

A better understanding of the particle sizes associated with the smoke from various cutting techniques would allow for optimal capture technologies to be used. This would reduce worker exposure, reduce cost, and reduce secondary contamination.

$\checkmark$ Cost Savings $\checkmark$ Risk Reduction Enabling Knowledge

V. Corresponding Technology Needs

RL-DD02, RL-DD08 


\section{Hanford Site Science Need \\ Decontamination and Decommissioning Subgroup \\ CONTAMINANT BINDING SCIENCE NEED}

Identification Number: RL-DD026-S

Site Priority Ranking: High

I. Functional Need:

Long-life, cost-effective, remotely applicable fixatives and decontaminants are needed for a variety of contaminants ( $\mathrm{Cs}, \mathrm{Sr}, \mathrm{Pu}, \mathrm{U}, \mathrm{Pb}$, and other RCRA metals) and surfaces (e.g., coated and uncoated concrete, cement covered with asphalt, coated and uncoated carbon steel and stainless steel glove boxes and ductwork). The products must be easy to apply and remove. Fixatives and decontaminants are needed for underwater application as well as for dry application.

\section{Problem Description:}

Loose, dispersible and fixed surface contamination (e.g., $\mathrm{Cs}, \mathrm{Sr}, \mathrm{Pu}, \mathrm{U}, \mathrm{Pb}$ and other RCRA metals) is present in high and low radiation areas on various surfaces (e.g., coated and uncoated concrete, coated and uncoated carbon steel, glass, plastics, rubber and stainless steel). The dispersible contamination presents an immediate worker exposure concern and a long-term environmental concern. Current fixative techniques are paint, tar, polymeric barrier systems, rustoleum or no fixative. Some of the current fixative techniques are ineffective (no fixative and rustoleum), allow leaching of radioactive material, allow for build up of hydrogen and/or helium over time, or are relatively high in cost to apply and remove.

Decontamination methods are needed that minimize worker exposures, waste generation, costs and risks and do not create mixed waste. Current methods for decontamination are costly and time consuming, and many of them create secondary waste. Baseline decontamination technologies are: scabbling and hydro-lancing for concrete; wipes, hydro lancing, ice blasting, steam, acid washes, and elctropolishing for metals; and wipes and strippable coatings/gels for glove boxes.

\section{Science Need Description:}

An understanding is needed of contamination chemistry and their binding mechanism to contaminated surfaces, decontaminants and fixatives to allow for optimal methods to be developed. 
IV. Benefit

Contamination would be contained where current fixatives are ineffective and worker safety and maintenance and decontamination costs and waste volumes would be reduced with improved fixatives and decontaminants.

$\checkmark$ Cost Savings $\checkmark$ Risk Reduction $\checkmark$ Enabling Knowledge

V. Corresponding Technology Needs

RL-DD02, RL-DD03, RL-DD04, RL-DD06, RL-DD07, RL-DD013, RL-DD014, RL-DD015, RL-DD021. 


\section{Decontamination \& Decommissioning Commentary on FY98 Technology Needs Process}

Each of the twenty-one technology needs for FY98 is linked to a specific project as defined by the Project Baseline Summary. Many of the consolidated needs from FY97 were expanded to generate a one-on-one relationship between needs and projects for the FY98 report. In addition, there were four deletions from the FY97 needs list. This is explained below and is illustrated in the FY97-FY98 Crosswalk table on the following page.

\section{Deleted Needs}

- Roofing Technologies - There are a number of commercially available technologies for the repair or replacement of roofs.

- Asbestos Remediation Technologies - This is a very low priority need for projects.

- $\quad N$ Reactor Spent Fuel Storage Basin Water Visibility - The use of $2 \mu$ filter media has resolved this problem.

- Liquid Metal Reactor Technologies - The FFTF has been placed on indefinite standby. There is no current need to deactivate this facility. 


\section{DECONTAMINATION \& DECOMMISSIONING TECHNOLOGY NEEDS \\ FY97 - FY98 CROSSWALK}

\begin{tabular}{|c|c|c|}
\hline ID \# FY97 & NEEDS TITLE (FY97) & ID \# FY98 \\
\hline RL-DD01 & Decontamination Technologies & $\begin{array}{l}\text { RL-DD02 } \\
\text { RL-DD03 } \\
\text { RL-DD06 } \\
\text { RL-DD013 } \\
\text { RL-DD015 }\end{array}$ \\
\hline RL-DD02 & Characterization Technologies & $\begin{array}{l}\text { RL-DD01 } \\
\text { RL-DD05 } \\
\text { RL-DD012 } \\
\text { RL-DD016 } \\
\text { RL-DD017 }\end{array}$ \\
\hline RL-DD03 & Cutting Technologies & RL-DD08 \\
\hline RL-DD04 & Fixatives & $\begin{array}{l}\text { RL-DD04 } \\
\text { RLDD-18 } \\
\text { RL-DD07 } \\
\text { RL-DD014 }\end{array}$ \\
\hline RL-DD05 & Roofing Technologies & Deleted \\
\hline RL-DD06 & $\begin{array}{l}\text { Better Physical Stress Monitoring System for Use in } \\
\text { Conjunction with Personnel Protection Equipment }\end{array}$ & RL-DD019 \\
\hline RL-DD07 & Radiation Hardened Automated Deployment Systems & RL-DD010 \\
\hline RL-DD08 & High Level Waste Tank Heel Remediation & RL-DD09 \\
\hline RL-DD09 & Asbestos Remediation Technologies & Deleted \\
\hline RL-DD010 & N Reactor Spent Fuel Storage Basin Water Visibility & Deleted \\
\hline RL-DD011 & Bio.-Control Technologies & RL-DD020 \\
\hline RL-DD012 & Liquid Metal Reactor Technologies & Deleted \\
\hline RL-DD013 & Structural Integrity Inspection Technologies & RL-DD011 \\
\hline RL-DD014 & Metal and Concrete Recycling Technologies & RL-DD021 \\
\hline
\end{tabular}




\section{DECONTAMINATION \& DECOMMISSIONING SCIENCE NEEDS \\ FY97 - FY98 CROSSWALK}

\begin{tabular}{|l|l|l|}
\hline \multicolumn{1}{|c|}{ ID \# FY97 } & \multicolumn{1}{|c|}{ NEEDS TITLE (FY97) } & \multicolumn{1}{c|}{ ID \# FY98 } \\
\hline RL-DD015-S & Photon-Assisted Decontamination Chemistry & RL-DD022-S \\
\hline RL-DD016-S & Sodium Potassium Passivation Chemistry & \\
\hline RL-DD017-S & Fixative Binding Chemistry & RL-DD026-S \\
\hline RL-DD018-S & Contaminant Binding Chemistry & RL-DD026-S \\
\hline \multirow{2}{*}{ RL-DD019-S } & $\begin{array}{l}\text { Non-Destructive Characterization Mapping } \\
\text { Methods }\end{array}$ & \\
\hline \multirow{2}{*}{ RL-DD020-S } & Colloidal Chemistry of Basin Wastes & RL-DD024-S \\
\cline { 2 - 4 } & Cesium Source Identification & RL-DD023-S \\
\cline { 2 - 4 } & Effluent Capture & RL-DD025-S \\
\hline
\end{tabular}




\section{MIXED WASTE TECHNOLOGY NEEDS}

\begin{tabular}{|c|l|}
\hline ID \# & \multicolumn{1}{|c|}{ NEEDS TITLE } \\
\hline RL-MW01 & Remote Treatment of RH-LLMW Debris \\
\hline RL-MW02 & $\begin{array}{l}\text { Remotely Controlled Volume Reduction Techniques for RH-LLMW and } \\
\text { RH-TRU/TRUM }\end{array}$ \\
\hline RL-MW03 & $\begin{array}{l}\text { Remote Characterization to Distinguish TRU from Non-TRU Portions or } \\
\text { Sections of Various-Sized Debris in a High Beta/Gamma Field }\end{array}$ \\
\hline RL-MW04 & $\begin{array}{l}\text { Remote Decontamination of RH-TRU Debris to Support Reclassification } \\
\text { into Non-TRU Category }\end{array}$ \\
\hline RL-MW05 & $\begin{array}{l}\text { Remote Treatment of RH Soils and Other Solid Wastes Contaminated } \\
\text { with Organics }\end{array}$ \\
\hline RL-MW06 & $\begin{array}{l}\text { Treatment of Contact Handled CH-TRU Liquid Wastes Contaminated } \\
\text { with PCBs and Ignitables }\end{array}$ \\
\hline Appendix A & Basis for Waste Volumes \\
\hline
\end{tabular}




\section{TECHNOLOGY NEEDS/OPPORTUNITIES STATEMENT OUTLINE}

Identification No.: RL-MW01 (previously RL-MW01)

Date: September 1997

OPS Office/Site: Richland Operations Office/Hanford

Operable Unit (if applicable): N/A

Waste Stream: RH-LLMW

Waste Management Unit (if applicable): N/A

Facility: T Plant and/or a future RH treatment facility

Site Priority Ranking: Very High

Need Title: Remote Treatment of RH-LLMW Debris (e.g. Macroencapsulation for RH Debris)

Need Description: Develop and demonstrate remote treatment systems for remote handled (RH) debris contaminated with low-level mixed waste. Converting existing treatment technologies, such as macroencapsulation, to remote handling mode may require substantial design modification or may not be successful, thus leading to development of system that may need regulatory review and/or approval.

Functional Performance Requirements: The technology must be able to treat remotehandled low-level mixed waste to meet LDR standards; and must have a high degree of reliability and ease of maintenance.

Schedule Requirements: One to three years.

Problem Description: The TWRS program is projecting a large volume of long-length equipment that will be removed from the tanks during waste recovery. In addition, the $D \& D$ program generated $9.5 \mathrm{~m}^{3}$ of RH-LLMW equipment and debris in calendar year (CY) 1995. The future waste streams will include items currently in the tanks as well as new equipment that will be used during waste retrieval dismantling operations. A major portion of these items will be classified as remote-handled debris. Remote treatment processes for this debris have not been demonstrated or developed.

$\begin{array}{lccl}\text { ADS No. } & \text { RDS No. } & \text { WBS No. } & \\ 2200-0 & \text { R96N0015 } & \text { 1A1209 } & \text { M-91 Treatment } \\ 2200-0 & \text { R96N0225 } & \text { 1A1206 } & \text { MW Characterization }\end{array}$

Justification For Need:

Technical - Whereas treatment technologies for contact-handled (CH) debris exist, they have not been developed or demonstrated to treat RH-LLMW debris.

Regulatory - The M-91 Milestone covers RH-LLMW treatment in a Project Management Plan which is to be completed in June 1999. M-91 also targets the award of a comrnercial contract for RH and Large Sized LLMW in October 2003, and requires on-site facilities and initiation of treatment by June 2008. 
Environmental Safety \& Health - Occupational Health concerns associated with processing RH waste.

Cost Savings Potential (Mortgage Reduction) - Not yet established. After defining the $\mathrm{RH}$ treatment system and its regulatory impact, costs and schedules can be determined and minimized.

CulturalStakeholder Concerns - Facilitate the cleanup effort and reduce worker exposure to radiation.

Other - None identified

Consequences Of Not Filling Need: Higher total cost to manage RH-LLMW large-sized waste storage.

Outsourcing Potential: Good candidate.

Current Baseline Technology: Macroencapsulation exists only for $\mathrm{CH}$ debris. Extensive shielding is required for debris removal from waste tanks. Significant modifications will be needed for RH capability.

Cost: \$216 million

Waste: RH-LLMW

How Long It Will Take: 24 years

End-User: Waste Management and Strategic Planning

Site Technical Point(s)-of-Contact: Larbi Bounini, WMH, (509) 376-4650; Mike Coony, WMH, (509) 376-9774; Wayne Ross, PNNL, (509)372-4684

DOE End-User/Representative Point(s)-of-Contact: Joe Waring, DOE, (509) 373-7687

\begin{tabular}{||l|r|}
\hline Waste Volume, $\mathrm{m} 3$ & \multicolumn{1}{|c|}{$\begin{array}{c}\text { Existing: } 127 \mathrm{~m}^{3} \\
\text { Projected: }+22,518 \mathrm{~m}^{3}\end{array}$} \\
& \multicolumn{1}{|c|}{ Total } \\
\hline Waste Form & $22,645 \mathrm{~m}^{3}$ \\
\hline $\begin{array}{l}\text { Waste Stream Numbers } \\
\text { from MWIR }\end{array}$ & $\begin{array}{l}\text { RL-W498, RL-W716, RL-W717, RL- } \\
\text { W718, RL-W719, RL-W720, RL-W721. }\end{array}$ \\
\hline $\begin{array}{l}\text { Contaminants and } \\
\text { co-contaminants }\end{array}$ & High alpha, beta, and gamma radiation \\
\hline Function of technology & Processing (Meet LDR) \\
\hline \hline Source Category & Remediation (TWRS) \\
\hline
\end{tabular}




\section{TECHNOLOGY NEEDS/OPPORTUNITIES \\ STATEMENT OUTLINE}

Identification: RL-MW02 (previously RL-MW03 and RLMW04)

Date: September 1997

OPS Office/Site: Richland Operations Office/Hanford

Operable Unit (if applicable): N/A

Waste Stream: RH-LLMW

Waste Management Unit (if applicable): N/A

Facility: T Plant and/or a future RH treatment facility

Site Priority Ranking: High

Need Title: Remotely Controlled Volume Reduction Techniques for RH-LLMW and RHTRU/TRUM.

Need Description: Develop a remotely controlled robust volume/size reduction system for remote-handled (RH) LLMW and transuranic/mixed-transuranic (TRU/TRUM) items over a wide range of sizes, shapes, weights, materials of construction and types/levels of contamination. This technology will be used to reduce the large void volume associated with debris and with the long-length equipment removed from Hanford's underground waste tanks. Selecting a volume reduction technology from existing technologies such as compaction, metal melting, and shredding, and converting it to remote operation may require substantial development as well as regulatory review and/or approval.

Functional Performance Requirements: Provide volume reduction capability for RHLLMW and RH-TRU such as compaction, metal melting or shredding. The system should be highly reliable, and easy to maintain and clean.

Schedule Requirements: One to three years.

Problem Description: TWRS and other generators have generated and have forecasted to generate large-sized RH-LLMW and RH-TRU. In CY95, ten boxes of RH-LLMW with a total volume of $127 \mathrm{~m}^{3}$ were generated from TWRS and D\&D combined, and an additional $29,216 \mathrm{~m}^{3}$ are forecast. At present there are $179 \mathrm{~m}^{3}$ of RH-TRU debris in storage and an additional $3,467 \mathrm{~m}^{3}$ are forecast. A volume reduction technology could reduce these quantities significantly.

$\begin{array}{lrrr}A D S N o . & R D S N o . & \text { WBSNo. } & \\ 2200-0 & \text { R96N0015 } & 1 \mathrm{~A} 1209 & \text { M-91 Treatment }\end{array}$

\section{Justification For Need:}

Technical: No remotely controlled system exists to reduce the volume and treatment cost of remote handled RH-LLMW and RH-TRU/TRUM debris.

Regulatory: The M-91 Milestone covers remote controlled treatment in a Project Management Plan which is to be completed in June 1999. M-19 also targets the award 
of a commercial contract for RH and Large Size LLMW and TRU in October 2003, and requires on-site facilities and initiation of treatment by June 2008 .

Environmental Safety \& Health: Occupational Health concerns associated with processing RH waste.

Cost Savings Potential (Mortgage Reduction): Life cycle cost reduction of $\$ 72.4$ million based on an estimated volume and treatment cost reduction of $20 \%$.

Cultural/Stakeholder Concerns: Facilitate cleanup and increase the cost effectiveness of the cleanup effort.

Other: None identified

Consequences Of Not Filling Need: Higher cost to treat a greater volume of RH waste.

Outsourcing Potential: Good candidate.

Current Baseline Technology: Treat/dispose of RH-LLMW and RH-TRU will be treated and disposed of without reduction in volume.

Cost: $\$ 280$ million for RH-LLMW and $\$ 82$ million for RH-TRU

Waste: RHILLMW, RH-TRU

How Long It Will Take: 30 years

End-User: Waste Management and Strategic Planning

Site Technical Point(s)-of-Contact: Larbi Bounini, WMH, (509) 376-4650; Mike Coony, WMH, (509) 376-9774; Wayne Ross, PNNL, (509) 372.4684

DOE End-User/Representative Point(s)-of-Contact: Joe Waring, DOE, (509) 373-7687

\begin{tabular}{||l|r|r||}
\hline & RH-LLMW & RH-TRU \\
\hline Waste Volume, m3 & $\begin{array}{l}\text { Existing: } \begin{array}{r}128 \mathrm{~m}^{3} \\
\text { Projected: }+29,216 \mathrm{~m}^{3} \\
\text { Total }\end{array} \\
29,344 \mathrm{~m}^{3}\end{array}$ & $\begin{array}{l}\text { Existing: } \\
\text { Projected: }+3,467 \mathrm{~m}^{3} \\
\text { Total }\end{array}$ \\
\hline Waste Form & Heterogeneous & Heterogeneous \\
\hline $\begin{array}{l}\text { Waste Stream Numbers } \\
\text { from MWIR }\end{array}$ & $\begin{array}{l}\text { All RH-LLMW waste streams } \\
\text { (See Appendix A) }\end{array}$ & $\begin{array}{l}\text { All RH-TRU forecasted waste } \\
\text { streams (see Appendix A) }\end{array}$ \\
\hline $\begin{array}{l}\text { Contaminants and } \\
\text { co-contaminants }\end{array}$ & $\begin{array}{l}\text { High alpha, beta, and gamma } \\
\text { radiation }\end{array}$ & $\begin{array}{l}\text { High alpha, beta, and gamma } \\
\text { radiation }\end{array}$ \\
\hline Function of technology & Volume Reduction & Volume Reduction \\
\hline Source Category & Remediation (TWRS) Waste & Remediation (TWRS) Waste \\
\hline
\end{tabular}




\section{TECHNOLOGY NEEDS/OPPORTUNITIES STATEMENT OUTLINE}

Identification: RL-MW03 (previously RL-MW05 and RLMW06)

Date: September 1997

OPS Office/Site: Richland Operations Office/Hanford

Operable Unit (if applicable): N/A

Waste Stream: RH-TRU Tank Waste

Waste Management Unit (if applicable): N/A

Facility: T Plant and/or a future RH treatment facility

Site Priority Ranking: Very High

Need Title: Remote Characterization to Distinguish TRU from Non-TRU Portions or Sections of Various-Sized Debris (up to 22 meters in length) in a High Beta/Gamma Field

Need Description: A large volume of debris generated from the Hanford tanks remediation activities is expected to be a mixture of TRU and non-TRU contaminated items. Developing a detection capability for TRU waste will allow separation and consolidation of TRU items, parts or sections of long-length equipment from the non-TRU portion. As a consequence, the total processing cost may be reduced since the treatment cost for non-TRU is significantly lower than that TRU processing. In addition, reducing TRU debris volume will help keep the total volume of Hanford TRU waste within the planned disposal capacity at WIPP.

Functional Performance Requirements: The TRU non-destructive assay (NDA) capability must be able to determine TRU contamination levels in a high beta-gamma dose rate environment and remotely handle TRU items over a wide range of sizes, shapes, weights, materials of construction and types and levels of contamination. Debris may include pieces up to 22 meters long. The system must generate high quality data (precise and accurate) to allow identification of TRU items with a high degree of confidence. Near real-time detection capability would be a plus, as it could support segregation during equipment removal/retrieval operations.

Schedule Requirements: Three to five years.

Problem Description: Much of the equipment and other debris from some facilities has been or may be categorized as RH-TRU waste upon retrieval. It is likely that the total volume of RH-TRU waste from Hanford (including tank waste) may approach the RH capacity at WiPP.

$\begin{array}{llll}\text { ADS No. } & \text { RDS No. } & \text { WBS No. } & \\ 2200-0 & \text { R96N0015 } & \text { 1A1209 } & \text { M-91 Treatment } \\ 2200-0 & \text { R96N0225 } & \text { 1A1206 } & \text { MW Characterization }\end{array}$

\section{Justification For Need:}

Technical: Presently no fast and safe characterization system exists to reduce volume and cost of treating RH-TRU, and reduce the likelihood that total volume of RH-TRU waste from Hanford (including tank waste) exceeds the planned RH shipment to WIPP. 
Regulatory: M-91 Milestone requires that a TRU/TRUM Project Management Plan be completed by June 2000, and specifies a target date of September 2003 for award of commercial contracts to process RH and large size TRU/TRUM.

Environmental Safety \& Health: Occupational Health concerns associated with processing $\mathrm{RH}$ waste.

Cost Savings Potential (Mortgage Reduction): Estimated life cycle cost reduction of $\$ 10.8$ million for large-length debris and $\$ 12.3$ million for other debris assuming that $30 \%$ of the RH-TRU can be segregated and treated as RH-LLMW. Additional cost savings potential at the disposal facility (WIPP).

Cultural/Stakeholder Concerns: Increase the cost effectiveness of the cleanup. Recycle and/or reuse materials and equipment.

Other: None identified

Consequences of Not Filling Need: Higher cost to treat a greater volume of RH-TRU waste.

Outsourcing Potential: Good candidate.

Current Baseline Technology: RH-TRU is presently not (nor planned to be) segregated to concentrate the volume of the RH-TRU fraction. Some RH-LLMW and CH-LLMW will be treated and disposed along with the RH-TRU.

Cost: $\$ 62.6$ million assuming $2,780 \mathrm{~m}^{3}$ of RH-TRU is actually retrieved from tanks.

Waste: RH-TRU

$\$ 71.2$ million for non Long-Length debris

How Long It Will Take: 30 years

End-User: Waste Management and Strategic Planning

Site Technical Point(s)-of-Contact: Larbi Bounini, WMH, (509) 376-4650; Mike Coony, WMH, (509) 376-9774; Wayne Ross, PNNL, (509) 372-4684

DOE End-User/Representative Point(s)-of-Contact: Joe Waring, DOE, (509) 373-7687 


\begin{tabular}{|c|c|c|c|}
\hline \multirow{3}{*}{ Waste Volume, m3 } & Long-length & \multicolumn{2}{|c|}{ Non-long-Length } \\
\hline & $\begin{array}{c}\text { Existing: } \quad 0 \mathrm{~m}^{3} \\
\text { Projected: } 480 \text { to } 22,998 \mathrm{~m}^{3}\end{array}$ & $\begin{array}{l}\text { Existing } \\
\text { Projected: }\end{array}$ & $\begin{array}{r}175 \mathrm{~m}^{3} \\
+2,987 \mathrm{~m}^{3}\end{array}$ \\
\hline & $\begin{array}{l}\text { Total: } 480 \text { to } 22,998 \mathrm{~m}^{3} \\
\text { Volume is reported as a range } \\
\text { as some of the long-length } \\
\text { equipment, presently } \\
\text { forecasted as RH-LLMW, may } \\
\text { be characterized as RH-TRU } \\
\text { upon retrieval from the tanks. }\end{array}$ & Total & $3,162 \mathrm{~m}^{3}$ \\
\hline Waste Form & Heterogeneous & Heterogeneous & \\
\hline $\begin{array}{l}\text { Waste Stream } \\
\text { Numbers from } \\
\text { MWIR }\end{array}$ & $\begin{array}{l}\text { RL-W436 and possibly } \\
\text { some of RL-W498 }\end{array}$ & $\begin{array}{l}\text { All forecast RL } \\
\text { waste streams } \\
\text { RL-W436), an } \\
\text { inventory in R } \\
\text { RL-W256, RL } \\
\text { RL-W273, RL } \\
\text { RL-W275. }\end{array}$ & $\begin{array}{l}\text { H-TRU } \\
\text { (except } \\
\text { d existing } \\
\text { L-W253, } \\
\text {-W271, } \\
\text {-W274 and }\end{array}$ \\
\hline $\begin{array}{l}\text { Contaminants and } \\
\text { co-contaminants }\end{array}$ & $\begin{array}{l}\text { High alpha, beta, and } \\
\text { gamma radiation }\end{array}$ & $\begin{array}{l}\text { High alpha, be } \\
\text { gamma radiati }\end{array}$ & ta, and \\
\hline $\begin{array}{l}\text { Function of } \\
\text { technology }\end{array}$ & Assay & Assay & \\
\hline Source Category & Remediation (TWRS) & $\begin{array}{l}\text { Remediation } \\
\text { D\&D }\end{array}$ & TWRS) and \\
\hline
\end{tabular}




\section{TECHNOLOGY NEEDS/OPPORTUNITIES \\ STATEMENT OUTLINE}

Identification: RL-MW04 (previously RL-MW07)

Date: September 1997

OPS Office/Site: Richland Operations Office/Hanford

Operable Unit (if applicable): N/A

Waste Stream: RH-TRU

Waste Management Unit (if applicable): N/A

Facility: T Plant and/or a future RH treatment facility

Site Priority Ranking: High

Need Title: Remote Decontamination of RH-TRU Debris to Support Reclassification into NonTRU Category

Need Description: Another approach to the volume reduction of RH-TRU materials is to decontaminate the items and concentrate the TRU materials into a much smaller volume. Selecting a decontamination technology from existing technologies and converting it to remote operation may require substantial development as well as regulatory review and/or approval.

Decontamination techniques focusing on radionuclides removal from RH-TRU debris may allow recategorization of the debris into non-TRU waste. In addition, some decontaminated materials may be recycled.

Functional Performance Requirements: The decontamination system for RH-TRU must effectively remove radionuclides from the debris and generate minimal amount of secondary waste preferably in the solid form. Decontamination processes which produce liquid secondary waste streams would be inconsistent with the site-wide effort to eliminate liquid waste. The system/equipment should have a high degree of reliability and must be easy to maintain and clean.

Schedule Requirements: Three to five years

Problem Description: A volume of $179 \mathrm{~m}^{3}$ of RH-TRU is currently in storage and an additional $3,467 \mathrm{~m}^{3}$ is forecast. The anticipated sources of RH-TRU are the long-length equipment from Hanford HLW tanks (transfer piping, pumps, jumpers and other ancillary equipment), tank waste disposal program and $R \& D$ waste.

$\begin{array}{llll}\text { ADS No. } & \text { RDS No. } & \text { WBSNo. } & \\ 2200-0 & \text { R96N0015 } & \text { 1A1209 } & \text { M-91 Treatment } \\ 2320-0 & \text { R96N0023 } & \text { 1A3104 } & \text { 221-T Canyon Decon Operations }\end{array}$

\section{Justification For Need:}

Technical: Remote handling decontamination does not exist, and development of a system is needed.

Regulatory: M-91 Milestone requires that a TRU/TRUM Project Management Plan be completed by June 2000, and specifies a target date of September 2003 for award of commercial contracts to process RH and large size TRU/TRUM. 
Environmental Safety \& Health: Occupational Health concerns associated with processin $\mathrm{RH}$ waste.

Cost Savings Potential (Mortgage Reduction): Estimated life cycle cost reduction of $\$ 9.6$ million assuming that $15 \%$ of previously RH-TRU could be treated as CH-LLMW. Additional cost savings potential at the disposal facility (WIPP).

Cultural/Stakeholder Concerns: Increase the cost effectiveness of the cleanup. Recycle and/or reuse materials and equipment.

Other - none identified

Consequences Of Not Filling Need: Higher cost to treat a greater volume of $\mathrm{RH}$ waste.

Outsourcing Potential: Good candidate.

Current Baseline Technology: RH-TRU waste will not be decontaminated to remove radionuclides that could allow RH-TRU waste to be disposed at WIPP as CH-TRU or recategorized as non-TRU.

Cost: $\$ 82$ million

Waste: RH-TRU

How Long It Will Take: 30 years

End-User: Waste Management and Strategic Planning

Site Technical Point(s)-of-Contact: Larbi Bounini, WMH, (509) 376-1009; Mike Coony, WMFr (509) 376-9774; Wayne Ross, PNNL, (509) 372-4684

DOE End-User/Representative Point(s)-of-Contact: Joe Waring, DOE, (509) 373-7687

\begin{tabular}{|l|l|}
\hline Waste Volume, m3 & \multicolumn{1}{|c|}{$\begin{array}{c}\text { Existing: } \\
\text { Projected: }+3,467 \mathrm{~m}^{3} \\
\text { Total }\end{array}$} \\
\hline Waste Form & Heterogeneous \\
\hline $\begin{array}{l}\text { Waste Stream Numbers } \\
\text { from MWR }\end{array}$ & $\begin{array}{l}\text { All waste streams with forecasted RH-TRU waste, } \\
\text { and existing inventory in RL-W253, RL-W256, } \\
\text { RL-W271, RL-W272, RL-W274 and RL-W275. }\end{array}$ \\
\hline $\begin{array}{l}\text { Contaminants and } \\
\text { co-contaminants }\end{array}$ & High alpha, beta, and gamma radiation \\
\hline Function of technology & Decontamination \\
\hline Source Category & Remediation (TWRS)/D\&D Waste/R\&D Waste \\
\hline
\end{tabular}




\section{TECHNOLOGY NEEDS/OPPORTUNITIES STATEMENT OUTLINE}

Identification: RL-MW05 (previously RL-MW08)

Date: September 1997

OPS Office/Site: Richland Operations Office/Hanford

Operable Unit (if applicable): N/A

Waste Stream: RH-LLMW Organic Wastes

Waste Management Unit (if applicable): N/A

Facility: A future organics treatment facility for RH mixed wastes.

Site Priority Ranking: High

Need Title: Remote Treatment of RH Soils and Other Solid Wastes Contaminated With Organics.

Need Description: Develop technologies to treat $\mathrm{RH}$ soils and other granular materials contaminated with hazardous organic compounds. Low cost remote thermal or non-thermal treatment methods will be needed to process the wastes to meet the land disposal- restrictions (LDR). Adding the remote handling capability to existing or emerging organic treatment technologies will require substantial additional development.

Functional Performance Requirements: The technology must be able to remotely handle and treat RH solids, such as organic contaminated soils and lab packs, to applicable LDR standards. Generation of secondary wastes is discouraged and if unavoidable, the secondary must be minimized and preferably in the solid form. The technology must be readily acceptable by the public and the regulators. The process must have a high degree of reliability and must be easy to maintain and clean. The system design should allow for construction of a mobile treatment unit.

Schedule Requirements: Five years or greater.

Problem Description: Small volumes of homogeneous soils, lab packs and soils with organics are expected. Since the wastes are remote handled and the volumes are low, it is unlikely that there will be a commercial capacity for treatment of the wastes.
ADS No.
RDS No.
WBS No.
2200-0
R96N0015
$1 \mathrm{~A} 1209$
M-91 Treatment

\section{Justification For Need:}

Technical: No technology to treat remote handled wastes exists.

Regulatory: TPA Milestone M-91 requires a Project Management Plan for treatment of this LDR waste by June 1999 .

Environmental Safety \& Health: Occupational and Health concerns associated with storing and handling the RH-LLMW organic waste.

Cost Savings Potential (Mortgage Reduction): Not yet available. There is no baseline plan to treat RH-LLMW organic waste. 
Cultural/Stakeholder Concerns: Complete the cleanup of Hanford, including small difficu waste streams.

Other: None identified.

Consequences of Not Filling Need: The RH-LLMW Organic Waste will remain untreated and in storage.

Outsourcing Potential: Good candidate.

Current Baseline Technology: At present there is no baseline plan to treat this waste. Likely technologies will be thermal treatment or an alternative organic removal or destruction technique.

Cost: There is no baseline plan to treat this waste.

Waste: RH-LLMW Organic Waste

How Long It Will Take: 30 years

End-User: Waste Management and Strategic Planning

Site Technical Point(s)-of-Contact: Larbi Bounini, WMH, (509) 376-4650; Wayne Ross, PNNL, (509) $372-4684$

DOE End-User/Representative Point(s)-of-Contact: Joe Waring, DOE, (509) 373-7687

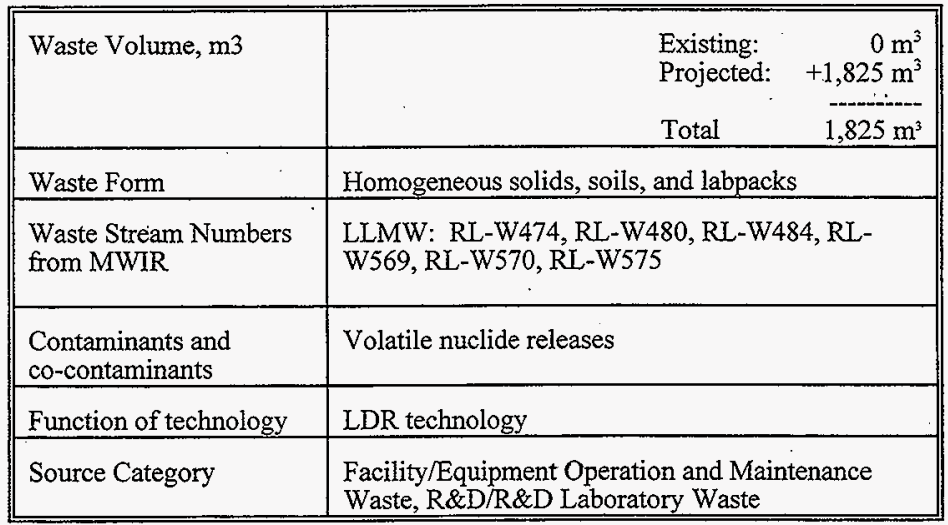




\section{TECHNOLOGY NEEDS/OPPORTUNITIES \\ STATEMENT OUTLINE}

Identification: RL-MW06 (previously RL-MW09)

Date: September 1997

OPS Office/Site: Richland Operations Office/Hanford

Operable Unit (if applicable): N/A

Waste Stream: Contact Handled (CH) TRU Waste with PCBs and Ignitables (D001 waste codes)

Waste Management Unit (if applicable): N/A

Facility: A future treatment facility.

Site Priority Ranking: High

Need Title: Treatment of CH-TRU Liquid Wastes Contaminated With PCBs and Ignitables.

Need Description: Develop a technology to treat organic liquid TRU wastes (mostly hydraulic fluids) to destroy PCBs, remove the ignitable characteristic, and safely contain transuranic . radionuclides. Adapting existing or emerging thermal or chemical organic destruction technologies to handle TRU wastes may require substantial development.

Functional Performance Requirements: The technology must be able to remove the Ignitable Characteristic from ignitable wastes and must destroy PCBs to $99.9999 \%$ destruction efficiency and contain TRU radionuclides. The technology must be readily acceptable by the regulators (as equivalent to incineration) and the public.

Schedule Requirements: Three to five years.

Problem Description: The WIPP Waste Acceptance Criteria prohibits the disposal of TRU waste that contains either PCBs or ignitable characteristics (D001) and therefore wastes with these characteristics must be processed to remove the PCBs or ignitables prior to packaging and transporting to WIPP. The bulk of these wastes are PCB-contaminated hydraulic fluids which were generated in 1989 from the Plutonium Finishing Plant.

$\begin{array}{lrcr}\text { ADSNo. } & \text { RDS No. } & \text { WBS No. } & \\ 2200-0 & \text { R96N0015 } & 1 \mathrm{~A} 1209 & \text { M-91 Treatment }\end{array}$

Justification For Need:

Technical: No treatment capacity exists for TRU ignitable or PCB wastes.

Regulatory: WIPP Waste Acceptance Criteria does not allow PCBs and ignitables. TPA Milestone M-91 requires a Project Management Plan for treatment by June 1999 .

Environmental Safety \& Health: Occupational and Health concerns associated with storing and handling the TRU waste.

Cost Savings Potential (Mortgage Reduction): Not yet available. There is no baseline plan to treat this waste. 
Cultural/Stakeholder Concerns: Complete the cleanup of Hanford, including small difficu waste streams.

Other: None identified.

Consequences of Not Filling Need: The TRU Waste with PCBs and ignitables will remain untreated and cannot go to WIPP.

Outsourcing Potential: Good candidate.

Current Baseline Technology: At present there is no baseline plan to treat this waste. Likely technologies will be thermal treatment or an alternative organic destruction technique.

Cost: There is no baseline plan to treat this waste.

Waste: TRU Waste with PCBs and ignitables (D001 waste codes)

How Long It Will Take: 30 years

End-User: Waste Management and Strategic Planning

Site Technical Point(s)-of-Contact: Larbi Bounini, (509) 376-4650; Wayne Ross, PNNL, (509) $372-4684$

DOE End-User/Representative Point(s)-of-Contact: Joe Waring, DOE, (509) 373-7687

\begin{tabular}{||l|l||}
\hline Waste Volume, m3 & \multicolumn{1}{|c|}{$\begin{array}{c}\text { Existing: } \\
\text { Projected: } \\
\text { Total }\end{array}$} \\
$\begin{array}{l}-77 \mathrm{~m}^{3} \\
0 \mathrm{~m}^{3}\end{array}$ \\
\hline Waste Form & Mostly.PCB contaminated hydraulic fluids \\
\hline $\begin{array}{l}\text { Waste Stream Numbers } \\
\text { from MWIR }\end{array}$ & $\begin{array}{l}\text { LLMW: RL-W281, RL-W285, RL-W310, RL- } \\
\text { W315, RL-W326, RL-W327, RL-W329, RL- } \\
\text { W333, RL-W515, RL-W516, RL-W517 }\end{array}$ \\
\hline $\begin{array}{l}\text { Contaminants and } \\
\text { co-contaminants }\end{array}$ & Volatile nuclide releases \\
\hline Function of technology & Destroy PCB's and remove ignitables \\
\hline Source Category & $\begin{array}{l}\text { Facility/Equipment Operation and Maintenance } \\
\text { Waste, R\&D/R\&D Laboratory Waste }\end{array}$ \\
\hline
\end{tabular}




\section{Appendix A: Basis for waste volumes}

Overall inventories and Forecasts

\subsection{Stored Mixed Low-level Waste}

\subsection{Inventories}

Inventories are based on SWITS. The inventories exclude MLLW that has been legally disposed. The inventories all exclude submarine reactor compartments.

\subsubsection{Inventory basis}

RCRA/State Regulated, through 12/31/95

RCRA/St Regulated, CY 96 thru 6/30

Volume (m3)

RCRA/State Stored through 6/30/96

LLW/TSCA(PCB) thru 12/31/96

$$
\begin{aligned}
& 8,009.5 \\
& +\quad 153.0 \\
& 8,162.5 \\
& +\quad 102.5 \\
& 8,265.0
\end{aligned}
$$

Total Stored/regulated LLW

Less treated in Sept 96 to final form

Total remaining to be treated

(Basis for mixed waste needs)

1.1.2 Inventory by radiation characteristics (m3)

$$
\mathrm{CH} \quad \mathrm{RH}(*) \quad \text { Total }
$$

$\begin{array}{lrrr}\text { RCRA/State } & 7,969.5 & 128.0 & 8,097.5 \\ \text { TSCA (PCB) } & +102.5 & 0.0 & 102.5 \\ & -10 .- & -128.0 & 8,200.0\end{array}$

* $127 \mathrm{~m} 3$ in boxes and $1 \mathrm{~m} 3$ in drums

\subsection{Forecasts}

For compilation of forecasts into the Mixed Waste Inventory Report, forecasts are subdivided into three categories: Group A, existing generation, Group B, future generation, and Offsite, representing expected waste from offsite. Group A was comprised of generators who forecast to generate waste with similar characteristics as in the past. Group $\mathrm{B}$ represents new or relatively large volumes of waste that typically have not been generated in the past. 
The following data has been obtained from the Life Cycle Solid Waste Forecast of 1997 $\mathrm{CH}(\mathrm{m} 3) \quad \mathrm{RH}(\mathrm{m} 3) \quad$ Total (m3)

\begin{tabular}{|c|c|c|c|}
\hline $\begin{array}{l}\text { Group A } \\
\text { Group B } \\
\text { Offsite }\end{array}$ & $\begin{array}{r}8,891.7 \\
21,341.3 \\
+\quad 174.7\end{array}$ & $\begin{array}{r}993.3 \\
28,222.7 \\
4.6\end{array}$ & $\begin{array}{r}9,885.0 \\
49,564.0 \\
179.3\end{array}$ \\
\hline Total Forecast & $30,407.7$ & $29,220.6$ & $59,628.3$ \\
\hline $\begin{array}{l}\text { Adjustments } \\
\text { Less Offsite (a) } \\
\text { Plus FY96 (b) }\end{array}$ & $\begin{array}{c}(174.7) \\
117.7\end{array}$ & $\begin{array}{c}(4.6) \\
0.0\end{array}$ & $\begin{array}{c}(179.3) \\
117.7\end{array}$ \\
\hline Basis for MW needs & $30,350.7$ & $29,216.0$ & $59,566.7$ \\
\hline
\end{tabular}

(a) Each off-site generator is responsible for maintaining mixed waste inventories and forecasts through their Site Treatment Plans.

(b) Value represents the period from $7 / 1$ to $9 / 30 / 96$, and is one-fourth of the.FY 1996 forecast for CH-LLMW.

Group B forecasts include 22,518.0 m3 of RH-LLMW long-length equipment from the tanks.

1.3 Inventories + Forecasts

$$
\mathrm{CH}(\mathrm{m} 3) \quad \mathrm{RH}(\mathrm{m} 3) \quad \text { Total (m3) }
$$

\begin{tabular}{|c|c|c|c|}
\hline $\begin{array}{l}\text { Cnve } \\
\text { Core }\end{array}$ & $8,072.0$ & 128.0 & $\begin{array}{r}8,200.0 \\
59,566.7\end{array}$ \\
\hline & & & \\
\hline Basis for MW needs & 38,422 . & $9,344.0$ & , \\
\hline
\end{tabular}

The inventory above does not include $65 \mathrm{~m} 3$ that has been treated to final form.

\subsection{TRU Waste Inventories}

The TRU waste inventories are directly from the WIPP Baseline Inventory Report, Rev 4, which is expected to be published within the next 90 days. This data was submitted from Hanford to WIPP in April 1996. 
2.1 Inventories

\begin{tabular}{lrrr} 
& $\mathrm{CH}(\mathrm{m} 3)$ & $\mathrm{RH}(\mathrm{m} 3)$ & Total $(\mathrm{m} 3)$ \\
Certifiable TRU & $11,079.0$ & 203.0 & $11,282.0$ \\
Estimated to be LLW & $4,935.0$ & 0.0 & $4,935.0$ \\
\hline Basis for MW needs & $16,014.0$ & 203.0 & $16,217.0$
\end{tabular}

The volume of $16,217 \mathrm{~m} 3$ is the volume currently managed as stored TRU waste (per DOE Order $5820.2 \mathrm{~A}$ ) at the Hanford Site.

A break-down of existing RH-TRU is as follows:

$\begin{array}{lc} & \text { Volume }(\mathrm{m} 3) \\ \text { Waste in trenches } & 175.0 \\ \text { Waste in caissons } & 24.0 \\ \text { Waste in above ground storage } & +\quad 4.0 \\ & -1 .-0 \\ \text { Total } & 203.0\end{array}$

\subsection{Forecasts}

The forecast for TRU waste is based on the FY 1996 Life Cycle forecast and is intended to be consistent with the data that are nationally available through WIPP.

$$
\mathrm{CH}(\mathrm{m} 3) \quad \mathrm{RH}(\mathrm{m} 3) \quad \text { Total (m3) }
$$

Forecast total

$$
9,638.0 \quad 3,467.0 \quad 13,105.0
$$

The forecast includes $480.0 \mathrm{~m} 3$ of $\mathrm{RH}$ long-length equipment from the tanks.

2.2 Inventories + Forecasts

$$
\mathrm{CH}(\mathrm{m} 3) \quad \mathrm{RH}(\mathrm{m} 3) \quad \text { Total (m3) }
$$

$\begin{array}{lrrr}\text { Inventories } & 16,014.0 & 203.0 & 16,217.0 \\ \text { Forecasts } & 9,638.0 & 3,467.0 & 13,105.0 \\ \text { Basis for MW needs } & 25,652.0 & 3,670.0 & 29,322.0\end{array}$


3.0 Combined LLMW and TRU waste inventories

\begin{tabular}{lrrr} 
& $\mathrm{CH}(\mathrm{m} 3)$ & $\mathrm{RH}(\mathrm{m} 3)$ & \multicolumn{1}{c}{ Total $(\mathrm{m} 3)$} \\
& & & \\
Inventory LLMW & $8,072.0$ & 128.0 & $8,200.0$ \\
Forecasted LLMW & $30,350.7$ & $29,216.0$ & $59,566.7$ \\
Inventory TRU & $16,014.0$ & 203.0 & $16,217.0$ \\
Forecasted TRU & $9,638.0$ & $3,467.0$ & $13,105.0$ \\
& $-1,-.$. & $-13,014.0$ & $97,088.7$
\end{tabular}

\subsection{Waste Volumes Per Individual MW Need}

1. Processing/treatment of RH-LLMW large-sized waste

Basis: Existing large box waste RH waste and forecasted long-length equipment

Existing large RH-LLMW boxes

$127.0 \mathrm{~m} 3$

(Sec 1.1.2)

Forecasted long-length equip LLMW

(Sec 1.2)

Total

$22,518.0 \mathrm{~m} 3$

$22,645.0 \mathrm{~m} 3$

2. Cost Effective characterization/verification technologies for MLLW shipped offsite

Assumption: All existing and forecasted CH-LLMW will be shipped offsite for treatment (although a minor quantity will not be treated under a petition arrangement).

Basis: Existing, Sec 1.1.2

Projected, Sec 1.2

$8200.0 \mathrm{~m} 3$

$59,566.7$

Total

$67,766.7 \mathrm{~m} 3$

The existing inventory does not include $42 \mathrm{~m} 3$ of long-length equipment and $23 \mathrm{~m} 3$ of thermocouple LLMW, for a total of $65 \mathrm{~m} 3$. These wastes were treated into a final form by macroencapsulation in September, 1996. 
3. Volume reduction techniques for RH-LLMW.

Existing

RH-LLMW in drums (Sec 1.1.2)

RH-LLMW in boxes ( $\operatorname{Sec} 1.1 .2$ )

Total

1.0

127.0

$128.0 \mathrm{~m} 3$

Forecasted

RH LLMW (Sec 1.2)

$29,216.0$

-...-...-

$29,216.0 \mathrm{~m} 3$

Total

$29,344.0 \mathrm{~m} 3$

4. Volume reduction techniques for RH-TRU

Existing

Waste in above grd storage

4.0

Waste in trenches (Sec 2.1)

175.0

Total

$179.0 \mathrm{~m} 3$

Forecasted

RH TRU (Sec 2.2)

$3,467.0$

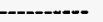

$3,467.0 \mathrm{~m} 3$

Total

$3,646.0 \mathrm{~m} 3$

5. Segregation of RH-TRU tank waste into TRU and non-TRU

In FY 1996, 10,276 $\mathrm{m} 3$ of the long-length equipment from Tank Farms was assumed to be RH-TRU. For FY 1997, nearly all of this waste has been judged to be RH-MLLW, and is included with the forecast for RH-MLLW. However, until further characterization is performed a fraction of this waste may still be TRU waste upon waste generation. Therefore, the volumes to support segregation of RH-TRU waste into TRU and non-TRU is reported as a range. 
Lower range

Forecasted long-length equip expected to be RH-TRU

$480.0 \mathrm{~m} 3$

Total

$480.0 \mathrm{~m} 3$

Upper range

Forecasted long-length equip expected to be RH-TRU

$480.0 \mathrm{~m} 3$

Forecasted long-length equip presently assumed RH-LLMW $22,518.0 \mathrm{~m} 3$ but could be characterized as RH-TRU

$22,998.0 \mathrm{~m} 3$

6. Segregation of RH-TRU non-tank waste into TRU and non-TRU

Existing RH-TRU in trenches

Forecasted RH-TRU

$175.0 \mathrm{~m} 3$

$3,467.0 \mathrm{~m} 3$

Subtotal

Less long-length equipment

$3,642.0$

$480.0 \mathrm{~m} 3$

Net

$3,162.0 \mathrm{~m} 3$

7. Decontamination of RH-TRU waste

Basis: All RH-TRU volume, inventories + forecast

Existing RH-TRU in trenches

Existing RH-TRU in above grade storage

$175.0 \mathrm{~m} 3$

Forecasted RH-TRU

$4.0 \mathrm{~m} 3$

$3,467.0 \mathrm{~m} 3$

Total

$3,646.0 \mathrm{~m} 3$

8. Treatment of organic contaminated $\mathrm{RH}$ waste

The assumption is that RH-LLMW consisting of homogeneous solids, lab packs, or soils w/organics will receive thermal treatment (where volumes are small, e.g RL-W480, thermal treatment is assumed regardless of organics)

RL-W570 Homo solid

RL-W474

“

$1,329.0 \mathrm{~m} 3$

RL-W575 Soils

408.2

RL-W480 Homo solid

79.4

RL-W484 Soils

RL-W569 Lab packs

2.5

2.5

$1,824.6 \mathrm{~m} 3$ 
9. Treatment of TRU waste contaminated with PCB's and ignitables:

MWIR ID

RL-W281
RL-W285
RL-W310
RL-W315
RL-W326
RL-W327
RL-W329
RL-W333
RL-W515
RL-W516
RL-W517

Total
CPC Code

$\mathrm{RC}-\mathrm{O} 90-\mathrm{M} 90-\mathrm{C} 11$

$\mathrm{RC}-\mathrm{O} 11-\mathrm{M} 90-\mathrm{C} 11$

$\mathrm{RC}-\mathrm{O} 11-\mathrm{M} 90-\mathrm{C} 11$

RC-090-M11-C11

RC-O11-M90-C11

RT-O90-M12-C90

RT-O90-M90-C11

TS-O90-M90-C90

RT-O90-M12-C90

TS-O90-M90-C90

TS-O90-M90-C90
Total Inventory (m3)
0.3218
1.2120
0.2830
0.2080
1.8738
26.4310
2.1000
0.4200
43.3460
0.8400
0.2100

Note: $R C=R C R A, R T=R C R A T S C A(P C B), T S=T S C A$ only $(P C B), O 11=$ w/organics, $\mathrm{O} 90=$ w/o organics, $\mathrm{M} 11=\mathrm{RCRA}$ metals w/o Hg, M12 $=\mathrm{RCRA}$ metals w/Hg, $\mathrm{M} 90=\mathrm{No}$ RCRA metals, C11 = D001 (ignitables), $\mathrm{C} 90=$ not regulated for D001, D002, or D003 (no ignitables, corrosives, reactives).

MWIR ID

RL-W281

RL-W285

RL-W310

RL-W315

RL-W326

RL-W327

RL-W329

RL-W333

RL-W515

RL-W516

RL-W517
Waste Stream Name

$183 \mathrm{H}$ aqueous lab packs MTRU/CH RCRA/IGN

202A predominantly organic debris MTRU/CH RCRA/ORG/IGN

$2345 Z$ unknown/other solids MTRU/CH RCRA/ORG/IGN

2345Z predominantly organic debris MTRU/CHRCRA/MET/IGN

$2345 Z$ organic lab packs MTRU/CH RCRA/ORG/IGN

2345Z metal debris MTRU/CH RC/TS/MHG

$2345 Z$ predominantly organic debris MTRU/CH RC/TS/IGN

$2345 Z$ predominantly organic debris MTRU/CH TSCA

$2345 Z$ predominantly inorganic debris MTRU/CH

$2345 \mathrm{Z}$ unknown/other debris MTRU/CH type 2

$2345 Z$ inorganic particulate MTRU/CH

$183 \mathrm{H}=$ Dewatered fuel fabrication sludge $202 \mathrm{~A}=$ PUREX Canyon and Process Facility

$2345 Z=$ Plutonium Finishing Plant 
10. Fast/effective surveying of transportation packages

All CH-LLMW, RH-LLMW, TRU-CH, and TRU-RH waste streams.

11. Cost effective storage techniques for RH-TRU and RH-LLMW

Basis: All future generated RH TRU and RH LLMW.

$\begin{array}{ll}\text { RH TRU } & 3,467.0 \mathrm{~m} 3 \\ \text { RH LLMW } & 29,216.0 \\ \text { Total } & 32,683.0 \mathrm{~m} 3\end{array}$

\subsection{Waste Streams}

See attached tables. 
Table 5-1. Remote-handled mixed low-level waste streams

Th RL-W716 CY95 Hanford M\&O RH RCRA/LLW Sandblasting Media w/o org w/met RL-W717 CY95 Hanford M\&O RH RCRALLW/ inorg Debr w/ org w/ met RL-W718 CY95 Hanford M\&O RH RCRALLW Composite Fitters w/ org w/ met RL-W719 CY95 Hanford M\&O RH RCRALLLW Pred Inorg debr w/ org w/ met RL-WT20 CY95 Hanford M\&O RH RCPALLW Pred Inorg debr w/ org w/o met RL-W721 CY95 Hanford M\&O RH RCRAVLLW UnkJoth Debris w/ org w/met

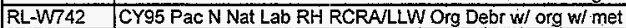
RL-W743 CY95 Pac N Nat Lab RH RCRA/LLW Pred Org Debr w/ org w/ met \begin{tabular}{|l|l}
\hline RL-W744 & CY95 Pac N Nat Lab RH RCRALLW Unk/oth Debris w/o org w/ met
\end{tabular} \begin{tabular}{|l|l}
\hline RL-W745 & Future routine onsite RHRCRALLLW Homo Solids
\end{tabular} \begin{tabular}{l|l} 
RL-W746 & Future routine onsite RH·RCRA/LLW Metal Debris \\
\hline
\end{tabular} \begin{tabular}{|l|l}
\hline RL-W747 & Future routine onsite RH RCRAVLLW Non-metal Debris \\
\hline
\end{tabular} \begin{tabular}{|l|l|}
\hline RL-W748 & Future routine onsite RH RCRALLLW Org Debris \\
\hline
\end{tabular} \begin{tabular}{l|l} 
RL-W749 & Future routine onsite RH RCRA/LLW Heter debris \\
\hline
\end{tabular} \begin{tabular}{l|l}
\hline RL-W750 & Future routine onsite RH RCRALLWW Lead waste \\
\hline RL
\end{tabular} \begin{tabular}{|l|l}
\hline RL-W474 & Dbl-shl tank retrieval MLLW/RH inorg homo solids w/org \\
\hline
\end{tabular}

\begin{tabular}{l|l}
\hline RL-W475 & Sgl-shl tank retrieval MLLW/RH inorg debris \\
\hline
\end{tabular}

\begin{tabular}{|l|l}
\hline RL-W477 & Dbl-shl tank retrieval MLLW/RH het debris \\
\hline
\end{tabular}

\begin{tabular}{l|l}
\hline RL-W480 & Decontam fac MLLW/RH inorg homo solids \\
\hline
\end{tabular}

\begin{tabular}{|l|l|l}
\hline RL-W481 Decontam fac MLLW/RH metal debris & \\
\hline
\end{tabular}

\begin{tabular}{l|l}
\hline RL.-W482 & Decontam fac MLLW/RH org debris \\
\hline RL
\end{tabular}

\begin{tabular}{l|l}
\hline RL-W483 Decontam fac MLLW/RH het debris \\
\hline RL-W484
\end{tabular}

\begin{tabular}{|l|l}
\hline RL-W484 & Decontam fac MLLW/RH soils \\
\hline RL
\end{tabular}

\begin{tabular}{|l|l}
\hline RL-W485 & Decontam fac MLLW/RH lead \\
\hline
\end{tabular}

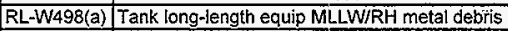

\begin{tabular}{|l|l|}
\hline RL-W566 & Fuel stab MLLW/RH metal debris \\
\hline
\end{tabular}

\begin{tabular}{|l|l|}
\hline RL-W567 & Decontam fac MLLW/RH batteries \\
\hline
\end{tabular}

\begin{tabular}{|l|l}
\hline RL-W568 & Decontam fac MLLW/RH elemental mercury \\
\hline
\end{tabular}

\begin{tabular}{|l|l}
\hline RL-W569 & Decontam fac MLLW/RH lab packs \\
\hline
\end{tabular}

\begin{tabular}{|l|l}
\hline RL-W570 & Init tank retrieval project MLLW/RH inorg homo solids w/org \\
\hline RL
\end{tabular}

\begin{tabular}{|l|l}
\hline RL-W571 & Init tank retrieval project MLLW/RH metal debris \\
\hline RLW
\end{tabular}

\begin{tabular}{|l|l}
\hline RL-W572 & Init tank retrieval project MLLW/RH het debris \\
\hline RLW
\end{tabular}

\begin{tabular}{|l|l}
\hline RL-W573 & Tank farm upgrade project MLLW/RH pred inorg debris \\
\hline
\end{tabular}

\begin{tabular}{|l|l|}
\hline RL-W574 & Tank farm upgrade project MLLW/RH org debris \\
\hline
\end{tabular}

\begin{tabular}{|l|l}
\hline RL-W575 & Tank farm upgrade project MLLW/RH soils \\
\hline RL
\end{tabular}

\begin{tabular}{|l|l}
\hline RL-W577 & Dbl-shl tank retrieval MLLW/RH inorg homo solids w/met
\end{tabular}

\begin{tabular}{|l|l}
\hline RL-W578 & init tank retrieval project MLLW/RH inorg homo solids w/met
\end{tabular} Total

(a) This waste stream represents the long-length equipment from the tanks.

\begin{tabular}{|c|c|c|c|c|c|}
\hline 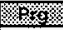 & 1) & 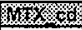 & 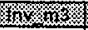 & Wox & 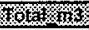 \\
\hline LLMW & $\mathrm{RH}$ & 53112 & 9.48 & 0 & 9.48 \\
\hline LLMW & RH & S5190 & 77.62 & 이 & 77.62 \\
\hline LLMW & $\mathrm{RH}$ & $\$ 5410$ & 6.7 & 야 & 6.7 \\
\hline LLMW & $\mathrm{RH}$ & $\$ 5420$ & 11.62 & 0 & 11.62 \\
\hline LLMW & $\mathrm{RH}$ & S5420 & 8.3 & 0 & 8.3 \\
\hline LLMW & $\mathrm{RH}$ & 55900 & 8.5082 & 0 & 8.5082 \\
\hline LLMW & $\mathrm{RH}$ & $\$ 5390$ & 0.2082 & 0 & 0.2082 \\
\hline LLMW & RH & 55440 & 0.2082 & 0 & 0.2082 \\
\hline LLMW & $\mathrm{RH}$ & 55900 & 5.3 & 0 & 5.3 \\
\hline LLMW & RH & 53900 & 0 & 96.84 & 96.84 \\
\hline LLMW & $\mathrm{RH}$ & 55119 & 0) & 253.63 & 253.63 \\
\hline LLMW & $\mathrm{RH}$ & $\$ 5129$ & 0 . & 176.508 & 176.508 \\
\hline LLMW & $\mathrm{RH}$ & 55390 & 0] & 343.622 & 343.622 \\
\hline LLMW & $\mathrm{RH}$ & $\$ 5490$ & D & 5.918 & 5.918 \\
\hline LLMW & $\mathrm{RH}$ & $\times 7290$ & 0 & 116.824 & 116.824 \\
\hline LLMW & $\mathrm{RH}$ & 53190 & of & 408.191 & 408.191 \\
\hline LLMW & $\mathrm{RH}$ & $\$ 5190$ & 0 & 1596.889 & 1596.889 \\
\hline LLMW & $\mathrm{RH}$ & $\$ 5490$ & 0 & 100.725 & 100.725 \\
\hline LLMW & $\mathrm{RH}$ & $\$ 3190$ & 요 & 3.024 & 3.024 \\
\hline LLMW & RH & 55119 & - 01 & 15.4 & 15.4 \\
\hline LLMW & $\mathrm{RH}$ & 55390 & 0) & 11.2 & 11.2 \\
\hline LLMW & $\mathrm{RH}$ & 55490 & 0) & 17.024 & 17.024 \\
\hline LLMW & $\mathrm{RH}$ & $\$ 4200$ & 0] & 2.52 & 2.52 \\
\hline LLMW & $\mathrm{RH}$ & $\times 7219$ & 0 & 3.304 & 3.304 \\
\hline LLMW & $\mathrm{RH}$ & 55119 & D) & 22517.96 & 22517.96 \\
\hline LLMW & RH & S5119 & 0 & 65.8 & 65.8 \\
\hline LLMW & RH & $\times 7490$ & 0) & 0.504 & 0.504 \\
\hline LLMW & $\mathrm{RH}$ & $\times 7100$ & 우 & 0.504 & 0.504 \\
\hline LLMW & $\overline{\mathrm{RH}}$ & $\times 6100$ & 0 & 2.52 & 2.52 \\
\hline LLMW & $\mathrm{RH}$ & 53190 & 이 & 1329.043 & 1329.043 \\
\hline LLMW & $\mathrm{RH}$ & 55119 & 0 & 1517.726 & 1517.726 \\
\hline LLMW & RH & $S 5490$ & 0 & 59.25 & 59.25 \\
\hline LLMW & $\mathrm{RH}$ & 55420 & 0 & 170.1 & 170.1 \\
\hline LIMW & $\overline{\mathrm{RH}}$ & 55390 & 아 & 128.52 & 128.52 \\
\hline LLMW & RH & 54200 & 0 & 79.38 & 79.38 \\
\hline LLMW & RH & $\$ 3190$ & 0 & 45.355 & 45.355 \\
\hline LLMW & $\mathrm{RH}$ & $\$ 3190$ & 이 & 147.671 & 147.671 \\
\hline
\end{tabular}


Table 5-2. Remote-handled TRU waste streams

\begin{tabular}{|l|l|l|r|r|r|}
\hline & & & \\
\hline
\end{tabular}

(a) This waste stream consists of long-length equipment from the tanks.

(b) This RH waste is stored in either trenches or caissons. 


\section{MIXED WASTE SCIENCE NEEDS}

\begin{tabular}{|c|l|}
\hline ID \# & \multicolumn{1}{c|}{ NEEDS TITLE } \\
\hline RL-MW07-S & $\begin{array}{l}\text { Nonintrusive, Nondestructive Characterization Methods for } \\
\text { Nonradioactive Hazardous Chemical Components of Mixed Low-Level } \\
\text { Waste }\end{array}$ \\
\hline RL-MW08-S & $\begin{array}{l}\text { Develop Nondestructive TRU/Non-TRU Characterization/Radionuclide } \\
\text { Mapping Methods for Contaminated Remotely Handled (RH) TRU } \\
\text { Waste }\end{array}$ \\
\hline RL-MW09-S & $\begin{array}{l}\text { Fundamental Understanding of the Mechanism for Encapsulation of } \\
\text { Radionuclides and Hazardous Components } \\
\text { during Microencapsulation or Stabilization }\end{array}$ \\
\hline RL-MW10-S & $\begin{array}{l}\text { Development of Analytical Techniques that Extract Information about a } \\
\text { Waste Stream or Sample without Extracting Any Material }\end{array}$ \\
\hline RL-MW11-S & Methods to Remove Ingested or Inhaled Radioactivity from an Individual \\
\hline RL-MW12-S & $\begin{array}{l}\text { Concepts/Methods for the Prevention of Migration of Radionuclides and } \\
\text { Hazardous Components from Buried Radioactive Wastes }\end{array}$ \\
\hline
\end{tabular}




\section{Listing of Science Needs \\ For the Mixed Waste Subgroup}

\section{High Priority Mixed Waste Needs}

1. Non-intrusive, non-destructive characterization methods for non-radionuclide hazardous chemical components of mixed low-level waste

2. Develop non-destructive TRU/non-TRU characterization/radionuclide mapping methods for contaminated remotely handled (RH) TRU waste

\section{Medium Priority Mixed Waste Needs}

1. Fundamental understanding of the mechanism for encapsulation of radionuclides and hazardous components during microencapsulation or stabilization

General Needs Broader than Mixed Waste Treatment, but that could Significantly Impact Mixed Waste Management

\section{High Priority General Needs}

1. Development of analytical techniques that extract information about a waste stream or sample without extracting any material

2. Methods to remove ingested or inhaled radioactivity from an individual

\section{Medium Priority General Needs}

Concepts/methods for the prevention of migration of radionuclides and hazardous components from buried radioactive wastes 


\section{Hanford Site Science Need \\ Mixed Waste Subgroup}

Identification No.: $\underline{\text { RL-MW07-S }}$

Need Title: Non-intrusive, non-destructive characterization methods for non-radionuclide hazardous chemical components of mixed low-level waste.

Site Priority Ranking: High

I. Functional Need:

Cost-effective characterization/verification methods for MLLW prior to LDR treatment.

\section{Problem Description:}

Much of Hanford's MLLW will be treated by off-site commercial vendors. There is a high cost associated with the present baseline of opening drums for sampling and characterizing the waste prior to treatment.

\section{Science Need Description:}

Development of non-intrusive, non-destructive methods to identify and measure nonradionuclide, RCRA hazardous components of mixed low-level. Non-destructive, non-intrusive methods exist for measuring radionuclide components, but currently no known technique exists for detection and quantification of non-radionuclide, hazardous components within a waste drum. There is a special need for the measurement of volatiles and semi-volatile organic compounds and for PCBs in solid materials at RCRA hazard levels. Contaminates that are of primary interest include: acretonitrile, acrolein, aluminum, barium, cadmium, calcium oxide, carbon disulfide, chlorine gas, chloroform, chromium III, copper ion, cyanide ion, dichloromethane, fluorine (gas), fluoride ion, hydrogen chloride, hydrogen fluoride, kerosene, lead, mercury, nickel, nitric acid, nitrobenzene, polystyrene, potassium hydroxide, pyridine, silver chloride, sodium cyanide, sodium, hydroxide, toluene, tributyl phosphate, and triethylamine.

Timing of Need: $1-3$ Years

\section{Benefit:}

Minimize the cost for waste characterization prior to treatment and verification of treated waste. Estimated cost reduction of $\$ 3.8$ million through FY 2006 based upon a $30 \%$ decrease in sampling and analysis costs. There would also be a reduction in the exposure risk to worker as a result of the avoidance of drum opening. 
Benefit code: check all that apply:

$\checkmark$ Cost Savings $\checkmark$ Risk Reduction $\checkmark$ Enabling Knowledge (i.e., solves a problem that cannot be remediated by current science/technology)

V. Contacts:

Joe Waring, DOE-RL

(509) $373-7687$

(509) $372-4684$

joseph_j_waring@rl.gov

Wayne Ross, PNNL wa_ross@pnl.gov 


\section{Hanford Site Science Need \\ Mixed Waste Subgroup}

Identification No.: RL-MW08-S

Need Title: Develop non-destructive TRU/non-TRU characterization/radionuclide mapping methods for contaminated remotely handled $(\mathrm{RH}) \mathrm{TRU}$ waste.

Site Priority Ranking: High

\section{Functional Need:}

Development of a robust TRU NDA detection capability to 1) map TRU contamination levels in a high beta-garnma dose rate environment, and 2) handle segregated pieces of remote-handled TRU items over a wide range of sizes, shapes, weights, materials of construction and types and levels of contamination.

\section{Problem Description:}

Much of the equipment and other waste from certain facilities has been or will be categorized as RH-TRU waste upon retrieval or classification as a waste. In addition to volume reduction methods, the segregation of items or parts of items may make it possible to separate the RH-TRU fraction, leaving some proportion as RH-LLMW and/or CH-LLMW. Total processing cost could be reduced accordingly because the cost of processing RH or CH-LLMW is significantly less than RH-TRU processing. In addition, reducing RH-TRU waste volumes from TWRS tanks will reduce the likelihood that the total volume of RH-TRU waste from Hanford will approach the RH capacity at WIPP.

\section{Science Need Description:}

Development of robust non-destructive TRU/non-TRU characterization/radionuclide mapping methods for contaminated remotely handled (RH) TRU waste in a high beta-gamma dose rate environment. High beta-gamma dose rates interfere with existing non-destructive methods for TRU characterization.

Timing of Need: 4-10 Years

IV. Benefit:

The major benefits are 1) the reduction of the volume and cost of treating of RH-TRU, and 2) the likelihood that the volume of RH-TRU waste from Hanford (including tank waste) exceeds the RH capacity at WIPP. Estimated life cycle cost reduction of $\$ 10.8$ million assuming that $30 \%$ of the RH-TRU from TWRS tanks can be segregated and treated as RH-LLMW. Additional cost savings potential are from the difference in disposal costs (WIPP vs. the Mixed waste trench) and transportation costs to the disposal site. 
Benefit code: check all that apply:

$\checkmark$ Cost Savings $\checkmark$ Risk Reduction $\checkmark$ Enabling Knowledge (i.e., solves a problem that cannot be remediated by current science/technology)

\section{Contacts:}

For more information, contact:

Joe Waring, DOE-RL

Wayne Ross, PNNL

(509) $373-7687$

(509) $372-4684$ joseph_j_waring@rl.gov wa_ross@pnl.gov 


\section{Hanford Site Science Need Mixed Waste Subgroup}

\section{Identification No.: $\underline{\text { RL-MW09-S }}$}

Need Title: Fundamental understanding of the mechanism for encapsulation of radionuclides and hazardous components during microencapsulation or stabilization.

Site Priority Ranking: Medium

\section{Functional Need:}

Fundamental information on the long-term stability and durability of waste constitutions within waste forms is needed to aid in projections of the impacts of disposal of waste materials and to provide greater understanding of how to further improve the immobilization of radioactive and hazardous components within waste materials.

\section{Problem Description:}

Continued incremental progress is being made on the ability to make meaningful projections of the long-term performance of various waste materials and waste forms. However, there is not universal agreement on how various waste constituents will behave in the environment over the long term and in how the variation of waste components within a waste form can change its behavior. A fundamental understanding of the materials involved and the release and migration of hazarcous and radioactive components should increase the confidence in the long term success of waste management activities.

\section{Science Need Description:}

The identification of fundamental behavior of various radioactive and hazardous components so that their release and migration from waste forms and disposal environments can be more accurately projected and defended. There is also a need to provide further reduction in the impacts of waste disposal on the environment through better understanding of how wastes can be retained within waste forms and within waste containment barriers.

Timing of Need: 4-10 Years

IV. Benefit:

The availability of a stronger science base on the behavior of radioactive and hazardous constitutions should increase the acceptance of projections of the waste management impact on the environment and on public. This could increase the acceptance of waste management activities by the general public. This could lead to reduced costs for waste management, since more extreme measures may not be needed. 
Benefit code: check all that apply:

$\checkmark$ Cost Savings $\checkmark$ Risk Reduction

$\checkmark$ Enabling Knowledge (i.e., solves a problem that cannot be remediated by current science/technology)

V. Contacts:

For more information, contact:

Joe Waring, DOE-RL

(509) 373-7687_joseph_j_waring@rl.gov

Wayne Ross, PNNL

(509) $376-3638$ wa_ross@pnl.gov 


\section{Hanford Site Science Need \\ Mixed Waste Subgroup}

Identification No.: RL-MW10-S

Need Title: Development of analytical techniques that extract information about a waste stream or sample without extracting any material.

Site Priority Ranking: High

\section{Functional Need:}

Analytical techniques that function by analyzing the bulk material without the need for extraction of a sample of material for analysis.

\section{Problem Description:}

Typically, samples of waste or material must be extracted from the bulk material to allow analysis in the laboratory. An ideal analytical method would be able to analyze the material in the bulk form without the need for sampling. This avoids the costs of sampling and reduces the secondary waste that is generated from the sampling operations and the analysis activities. It also avoids changes in the sample that may occur between the time of sampling and the time of analysis.

\section{Science Need Description:}

Analytical techniques or methods that can be taken to the field, placed into or near the solid waste materials, and that can provide information on chemical composition without the need for extracting physical samples of the material from the bulk material. The special needs are for the detection of volatile and semivolatile organic materials that exceed the RCRA regulatory minimal levels. Some of the important RCRA components that need detection include: acretonitrile, acrolein, aluminum, barium, cadmium, calcium oxide, carbon disulfide, chlorine gas, chloroform, chromium III, copper ion, cyanide ion, dichloromethane, fluorine (gas), fluoride ion, hydrogen chloride, hydrogen fluoride, kerosene, lead, mercury, nickel, nitric acid, nitrobenzene, polystyrene, potassium hydroxide, pyridine, silver chloride, sodium cyanide, sodium, hydroxide, toluene, tributyl phosphate, and triethylamine.

Timing of Need: 4-10 Years

\section{Benefit:}

The avoidance of sampling provides many benefits. In increases the representativeness of the sample, allows sampling of more material, and avoid the generation of additional wastes with all of its associated costs and needs. With the secondary benefits in-place analysis could offer cost savings as well. 
Benefit code: check all that apply:

$\checkmark$ Cost Savings $\quad \checkmark$ Risk Reduction $\checkmark$ Enabling Knowledge (i.e., solves a problem that cannot be remediated by current

V. Contacts: science/technology)

For more information, contact:

Joe Waring, DOE-RI

Ted Anderson, BHI
(509) $373-7687$

(509) $376-3638$ joseph_j_waring@rl.gov

Theodore_D_Anderson@apec.ri.gov 


\section{Hanford Site Science Need \\ Mixed Waste Subgroup}

Identification No.: RL-MW11-S

Need Title: Methods to remove ingested or inhaled radioactivity from an individual.

Site Priority Ranking: High

\section{Functional Need:}

Additional methods are needed that will remove radioactive materials from an individual.

II. Problem Description:

During the increased handling and waste management activities with a large number of waste containers, it becomes increasing likely that an individual will be exposed to radioactive materials. Historical methods have been developed that can remove some of these material from the skin surface, but removal of ingested or inhaled materials from the body is still a difficuit activity.

\section{Science Need Description:}

Identify the location and varying degree of strength by which different isotopes are held within the body, and identify how to remove isotopes in the case of accidental inhalation or ingestion.

Timing of Need: 4-10 Years

IV. Benefit:

This will reduce the risk to the individual in the case of accidental exposure during waste management activities.

Benefit code: check all that apply:

$\checkmark$ Cost Savings $\checkmark$ Risk Reduction

V. Contacts:

For more information, contact:

Joe Waring, DOE-RL

Wayne Ross, PNNL
(509) 373-7687

(509) $376-3638$ $\checkmark$ Enabling Knowledge (i.e., solves a problem that cannot be remediated by current science/technology) 


\section{Hanford Site Science Need \\ Mixed Waste Subgroup}

Identification No.: RL-MW12-S

Need Title: Concepts/methods for the prevention of migration of radionuclides and hazardous components from buried radioactive wastes.

Site Priority Ranking: Medium

\section{Functional Need:}

Materials or systems that can reduce or prevent the migration of radionuclides and/or hazardous components in the waste.

\section{Problem Description:}

Large quantities of radioactive and mixed wastes have previously been buried at Hanford and other DOE sites. Many of these materials are to be left in their current locations for permanent disposal. The impacts of the wastes on future generations may be reduced if the mobility of the radioactive and hazardous components in the wastes is reduced to allow the radioactivity to decay in place. Surface barriers have been designed and developed for capping of the waste sites and appear to be generally effective. Alternative designs or approaches may be more effective or may be implemented at lower cost.

\section{Science Need Description:}

The identification and development of approaches that will further enhance the stability of wastes in their current disposal environment.

The highest risk appears to be from the leaching of radionuclides by rain or ground water and then the migration of that radionuclides in the ground water to the public environments. Approaches that have been typically considered 1) eliminate or reduce the water that can penetrate the wastes, 2) increasing the leach resistance of the wastes by treating with a materials such a grout or polymers, or 3 ) limiting the flow of radionuclides by inclusion of an ion exchange media or other physical barrier to reduce migration of the water containing the radionuclides. As noted above the first approach (capping) is the currently planned method for Hanford disposal sites. Methods or materials that can enhance the stability and performance of the caps can be given special attention.

Timing of Need: $4-10$ Years

IV. Benefit:

The reduction of the migration of the radionuclides from the burial grounds will reduce the risk to the public from any migration of radionuclides. The current caps are anticipated to cost in 
excess of $\$ 0.5$ million per acre, with an estimated total area in excess of 2000 acres of waste sites to cover at Hanford. Thus, there may be some opportunities to reduce the costs of barriers by evaluating of alternative designs or modifications in waste form.

If a sufficiently effective method is identified and developed, it may allow the disposal of GTCIII or TRU wastes at the current DOE sites.

Benefit code: check all that apply:

$\checkmark$ Cost Savings $\checkmark$ Risk Reduction

V. Contacts:

For more information, contact:

Joe Waring, DOE-RL Glendon Gee, PNNL
(509) $373-7687$ (509) $372-6096$ joseph_j_waring@rl.gov glendon.gee@pnl.gov $\checkmark$ Enabling Knowledge (i.e., solves a problem that cannot be remediated by current . science/technology) 


\section{Mixed Waste \\ Commentary on FY98 Technology Needs Process}

The FY97 technology needs were thoroughly reviewed by Fluor Daniel Hanford, Inc. (FDH), and Waste Management Federal Services of Hanford, Inc. (WMH). Suggested revisions to the needs statements were then reviewed, and endorsed by Hanford's Mixed Waste Subgroup of the Site Technology Coordination Group. Four of the FY97 needs were consolidated into two needs statements. One of the FY97 needs was reclassified as a Science Need. One of the FY97 needs was deleted, and one need was tabled for future consideration. The FY97-FY98 Crosswalk Table below summarizes these changes.

MIXED WASTE TECHNOLOGY NEEDS

FY97 - FY98 CROSSWALK

\begin{tabular}{|c|c|c|c|}
\hline $\begin{array}{l}\text { ID \# } \\
\text { FY97 }\end{array}$ & Technology Need $(12 / 96)$ & Changes in FY98 Revision & $\begin{array}{l}\text { D\# \# } \\
\text { FY98 }\end{array}$ \\
\hline $\begin{array}{l}\text { RL- } \\
\text { MW01 }\end{array}$ & $\begin{array}{l}\text { Processing/Treatment of RH-LLMW large- } \\
\text { sized waste }\end{array}$ & $\begin{array}{l}\text { Upgraded. New focus on } \mathrm{RH} \\
\text { treatment. }\end{array}$ & RL-MW01 \\
\hline $\begin{array}{l}\text { RL- } \\
\text { MW02 }\end{array}$ & $\begin{array}{l}\text { Cost Effective Characterization/Verification } \\
\text { Technologies for MLLW Treated by } \\
\text { Commercial Vendor }\end{array}$ & $\begin{array}{l}\text { Transfered to "Science Need" } \\
\text { with new focus on non- } \\
\text { instrusive characterization of } \\
\text { hazardous chemicals. WRAP } \\
\text { provides NDE/NDA for } \\
\text { radionuclides. }\end{array}$ & $\mathrm{N} / \mathrm{A}$ \\
\hline $\begin{array}{l}\text { RL- } \\
\text { MW03 }\end{array}$ & $\begin{array}{l}\text { Volume Reduction Techniques for RH- } \\
\text { LLMW }\end{array}$ & Upgraded & RL-MW02 \\
\hline $\begin{array}{l}\text { RL- } \\
\text { MW04 }\end{array}$ & Volume reduction for RH-TRU & Merged with RL-MW03 & RL-MW02 \\
\hline $\begin{array}{l}\text { RL- } \\
\text { MW05 }\end{array}$ & $\begin{array}{l}\text { Segregation of RH-TRU Waste from TWRS } \\
\text { Tanks into TRU and Non-TRU (long-length } \\
\text { equipment) }\end{array}$ & $\begin{array}{l}\text { Upgraded. Focus on } \\
\text { characterization. Segregation } \\
\text { technology exists. }\end{array}$ & RL-MW03 \\
\hline $\begin{array}{l}\text { RL- } \\
\text { MW06 }\end{array}$ & $\begin{array}{l}\text { Segregation of RH-TRU Waste (other than } \\
\text { long-length equipment) Into TRU and Non- } \\
\text { TRU }\end{array}$ & Merged with RL-MW05 & RL-MW03 \\
\hline $\begin{array}{l}\text { RL- } \\
\text { MW07 }\end{array}$ & Decontamination of RH-TRU Waste & Upgraded & RL-MW04 \\
\hline $\begin{array}{l}\text { RL- } \\
\text { MW08 }\end{array}$ & $\begin{array}{l}\text { Treatment of Organic Contaminated RH } \\
\text { Waste }\end{array}$ & Upgraded & RL-MW05 \\
\hline $\begin{array}{l}\text { RL- } \\
\text { MW09 }\end{array}$ & $\begin{array}{l}\text { Treatment of TRU Waste Contaminated } \\
\text { with PCBs and Ignitables }\end{array}$ & Upgraded & RL-MW06 \\
\hline $\begin{array}{l}\text { RL- } \\
\text { MW10 }\end{array}$ & $\begin{array}{l}\text { Fast, Effective Surveying of Transportation } \\
\text { Packages }\end{array}$ & $\begin{array}{l}\text { Tabled. WMH deemed current } \\
\text { baseline effective. }\end{array}$ & N/A \\
\hline $\begin{array}{l}\text { RL- } \\
\text { MW11 }\end{array}$ & $\begin{array}{l}\text { Cost-effective Storage Techniques for RH- } \\
\text { LLMW \& RH-TRU waste }\end{array}$ & $\begin{array}{l}\text { Deleted. Space optimization } \\
\text { study needed, not technology. }\end{array}$ & N/A \\
\hline
\end{tabular}


FY 1998 MLLW SCIENCE NEEDS CROSSWALK

\begin{tabular}{|c|c|c|c|c|c|}
\hline $\begin{array}{l}\text { New (FY98) } \\
\text { RL-WT } \\
\text { Number }\end{array}$ & $\begin{array}{c}\text { Old } \\
\text { (FY97) } \\
\text { RL-WT } \\
\text { Number }\end{array}$ & Need Title & $\begin{array}{l}\text { STCG } \\
\text { FY97 } \\
\text { Priority }\end{array}$ & $\begin{array}{c}\text { STCG } \\
\text { FY98 } \\
\text { Priority }\end{array}$ & Notes \\
\hline RL-MW07-S & $\begin{array}{l}\text { RL- } \\
\text { MW012-S }\end{array}$ & $\begin{array}{l}\text { Non-intrusive, non-destructive } \\
\text { characterization methods for } \\
\text { non-radionuclide hazardous } \\
\text { chemical components of mixed } \\
\text { low-level waste }\end{array}$ & $\mathrm{H}$ & $\mathrm{H}$ & $\begin{array}{l}\text { Need } \\
\text { Continues }\end{array}$ \\
\hline \multirow[t]{2}{*}{ RL-MW08-S } & $\begin{array}{l}\text { RL- } \\
\text { MW013-S }\end{array}$ & $\begin{array}{l}\text { Develop of non-destructive } \\
\text { TRU/non-TRU } \\
\text { characterization/radionuclide } \\
\text { mapping methods for } \\
\text { contaminated remotely handled } \\
\text { (RH) TRU waste }\end{array}$ & $\mathrm{H}$ & $\mathrm{H}$ & \\
\hline & $\begin{array}{l}\text { RL- } \\
\text { MW014-S }\end{array}$ & $\begin{array}{l}\text { Development of effluent-free, } \\
\text { cost-effective, organic } \\
\text { destruction methods }\end{array}$ & & Unranked & $\begin{array}{l}\text { Contract } \\
\text { established for } \\
\text { treatment of } \\
\text { organic } \\
\text { wastes. }\end{array}$ \\
\hline RL-MW09-S & & $\begin{array}{l}\text { Fundamental understanding of } \\
\text { the mechanism for encapsulation } \\
\text { of radionuclides and hazardous } \\
\text { components during } \\
\text { microencapsulation or } \\
\text { stabilization }\end{array}$ & $\bar{M}$ & & $\begin{array}{l}\text { Similar need } \\
\text { noted from the } \\
\text { Tanks STCG. }\end{array}$ \\
\hline RL-MW10-S & & $\begin{array}{l}\text { Development of analytical } \\
\text { techniques that extract } \\
\text { information about a waste stream } \\
\text { or sample without extracting any } \\
\text { material }\end{array}$ & $\mathrm{H}$ & & $\begin{array}{l}\text { Broad-based } \\
\text { need identified } \\
\text { from group. }\end{array}$ \\
\hline RL-MW11-S & & $\begin{array}{l}\text { Methods to remove ingested or } \\
\text { inhaled radioactivity from an } \\
\text { individual }\end{array}$ & $\mathrm{H}$ & & $\begin{array}{l}\text { Broad-based } \\
\text { need identified } \\
\text { from group. }\end{array}$ \\
\hline RL-MW12-S & & $\begin{array}{l}\text { Concepts/methods for the } \\
\text { prevention of migration of } \\
\text { radionuclides and bazardous } \\
\text { components from buried } \\
\text { radioactive wastes }\end{array}$ & $\mathrm{M}$ & & $\begin{array}{l}\text { Long range } \\
\text { need identified } \\
\text { in life-cycle } \\
\text { planning. }\end{array}$ \\
\hline
\end{tabular}




\section{Fiscal Year 1998 Subsurface Contaminant Priority Technology Needs}

\begin{tabular}{|c|c|}
\hline ID No. & Needs Title \\
\hline \multicolumn{2}{|r|}{ Groundwater Project } \\
\hline RL-SSO1 & Cost-Effective, In-Situ Remediation of Carbon Tetrachloride in the Vadose Zone and Groundwater \\
\hline $\mathrm{RL}-\mathrm{SSO} 2$ & Improved, Real-Time, In-Line Detection of Carbon Tetrachloride in Process Water \\
\hline $\mathrm{RL}-\mathrm{SSO} 3$ & Improved, Real-Time, In Situ Detection of Carbon Tetrachloride in Groundwater \\
\hline RL-SS04 & Cost-Effective, In Situ Remediation of Hexavalent Chromium in Groundwater \\
\hline RL-SSO5 & Improved, Real-Time, In-Line Detection of Hexavalent Chromium in Process Water \\
\hline RL-SSO6 & Improved, Real-Time, In Situ Detection of Hexavalent Chromium in Groundwater \\
\hline $\mathrm{RL}-\mathrm{SS} 07$ & Cost-Effective, In Situ Remediation of Strontium-90 in Groundwater \\
\hline RL-SSO8 & Improved, Real-Time, In-Line Detection of Strontium-90 in Process Water \\
\hline RL-SS09 & Improved, Real-Time, In Situ Detection of Strontium-90 in Groundwater \\
\hline \multicolumn{2}{|r|}{ Remedial Action and Waste Disposal Project } \\
\hline RL-SS10 & $\begin{array}{l}\text { Improved Technologies for Detection/Delineation of Burial Ground Contents and Subsurface } \\
\text { Geological Boundaries }\end{array}$ \\
\hline RL-SSH & $\begin{array}{l}\text { Cost-Effective, In Siti Remediation in the Vadose Zone of One or More of the Following Heavy } \\
\text { Metals: Hexavalent Chromium, Mercury, and Lead }\end{array}$ \\
\hline RL-SS12 & $\begin{array}{l}\text { Cost-Effective, In Situ Remediation in the Vadose Zone of One or More of the Following } \\
\text { Radionuclides: Uranium, Plutonium, Cesium, Cobalt, and Strontium-90 }\end{array}$ \\
\hline RL-SSI3 & $\begin{array}{l}\text { Improved, Real-Time Field Screening During Excavation for One or More of the Following Heavy } \\
\text { Metals: Hexavalent Chromium, Mercury, and Lead }\end{array}$ \\
\hline RL-SSI4 & $\begin{array}{l}\text { Improved, Real-Time Field Screening During Excavation for One or More of the Following } \\
\text { Radionuclides: Uranium, Plutonium, Cesium, Cobalt, and Strontium-90 }\end{array}$ \\
\hline RL-SS15 & $\begin{array}{l}\text { Improved, In Situ Characterization to Determine the Extent of Soil Contamination of One or More of } \\
\text { the Following Heavy Metals: Hexavalent Chromium, Mercury, and Lead }\end{array}$ \\
\hline RL-SS16 & $\begin{array}{l}\text { Improved, In Situ Characterization to Determine the Extent of Soil Contamination of One or More of } \\
\text { the Following Radionuclides: Uranium, Plutonium, Cesium, Cobalt, and Strontium-90 }\end{array}$ \\
\hline RL-SS17 & Long-Life Waste Isolation Surface Barrier \\
\hline RL-SS18 & Improved Handling and Segregation of TRU Waste (Debris) \\
\hline RL-SS19 & Detection and Handling of Pyrophoric Materials in Burial Grounds \\
\hline RL-SS20 & Improved Methods for Debris Handling and Segregation \\
\hline \multicolumn{2}{|r|}{ TWRS } \\
\hline RL-SS21 & Contaminant Mobility Beneath Tank Farm \\
\hline $\mathrm{RL}-\mathrm{SS} 22$ & Data and Tools for Performance Assessments \\
\hline
\end{tabular}




\section{TECHNOLOGY NEEDS/OPPORTUNITIES \\ STATEMENT OUTLINE}

Identification No.: RL-SSO1

Date: October 15, 1997

OPS Office/Site: DOE-RL/Hanford

Operable Unit(s): 200-ZP-1, 200-ZP-2

Waste Stream: Groundwater (200-ZP-1), Soils (200-ZP-2)

Waste Management Unit: N/A

Facility: N/A

Site Priority Ranking: High

Need Title: Cost-effective, In Situ Remediation of Carbon Tetrachloride in the Vadose Zone and Groundwater

Need Description: In situ remediation of carbon tetrachloride (CCl4) into simpler elements or compounds to reduce the risk to human health and the environment. In situ processes need to be more efficient than current baseline operations.

Functional Performance Requirements: Concentration of carbon tetrachloride in groundwater is not to exceed $5 \mathrm{ppb}$ at the 200 Area Plateau boundary.

Schedule Requirements: Pump and treat operations are ongoing for groundwater. The interim record of decision (ROD) will be reviewed in FYO0 for the potential identification of a final remedy. Soil vapor extraction (SVE) operations are ongoing for vadose zone. The SVE system is currently being reviewed and further enhancements/requirements are being identified.

Technology Insertion Point: Potential alternative technology for groundwater remediation must be identified and evaluated prior to reevaluation of the interim ROD in FYOO for potential subsequent deployment.

Problem Description: Operable unit 200-ZP-1 underlies the Z Plant and T Plant Aggregate Areas located in the northern half of the 200 West Area. This operable unit addresses contamination in the groundwater and saturated zone soils. Carbon tetrachloride, the contaminant of concern, extends in groundwater over a 3.5 square mile area. Depth to the water table is 270 feet. The ultimate remediation goal for the $\mathrm{CCl} 4$ plume is to eliminate a sufficient amount of contamination so that the plume concentration will not exceed $5 \mathrm{ppb}$ at the 200 Area plateau boundary.

An interim ROD has been issued requiring an interim remedial measure (IRM) to start treating the 2000-3000 ppb portion of the carbon tetrachloride plume northwest of $Z$ Plant (excluding the I Plant plume). Contaminated groundwater within the operable unit is being pumped from the 
aquifer, then treated with an air-stripping unit followed by vapor phase granular activated carbon polishing. However, initial modeling indicates that pump and treat will need to be expanded and operated for 33 to 56 years to meet stated objectives.

Operable unit 200-ZP-2 represents the source sites and underlying unsaturated soils in the northern balf of the 200 West Area. Co-contaminants include $\mathrm{Pu}, \mathrm{Am}$, and other radionuclides. The 200-ZP-2 soil vapor extraction system was an expedited response action that extracts carbon tetrachloride vapor from the vadose zone, and treats the off gas with granular activated carbon. Although this action has successfully removed a large mass of CCl4, SVE removal efficiencies are declining while as much as $50 \%$ of the estimated initial inventory remains in the soil.

Dense non-aqueous phase liquid (DNAPL) has not been positively identified in the 200 Area, but estimates of initial disposal quantities of $\mathrm{CCl} 4$ indicate that free phase is possible. Therefore, DNAPL detection and treatment in both the vadose zone and aquifer are also potential concerns.

ADS/RDS/WBS No.: $\quad$ ADS: 3210

RDS: Found in Table 4-3. Risk Data Sheet Results of DOE/RL-96-09 Rev. 1.

WBS: 1.4.10.1.1.08.06.17.01 (Groundwater)

1.4.10.1.1.08.06.17.01 (Soils)

Justification For Need:

Technical - In situ remediation could potentially reduce time and cost of the current soil vapor extraction and groundwater pump and treat processes.

Regulatory - If not addressed, carbon tetrachloride in groundwater is expected to migrate and exceed the Safe Drinking Water Act standard of $5 \mathrm{ppb}$ at compliance wells at 200 Area Plateau boundary.

Environmental Safety and Health - Possible exposure to carbon tetrachloride.

Cost Savings Potential (Mortgage Reduction) - Eliminate O\&M costs of the existing groundwater pump and treat, and soil vapor extraction systems.

CulturaL/Stakeholder Concerns - Stakeholders may be sensitive to introduction of chemicals into the subsurface to accomplish in situ remediation.

Other - None.

Consequences Of Not Filling Need: Continued operation of groundwater pump and treat, and soil vapor extraction systems to remediate carbon tetrachloride contamination.

Outsourcing Potential: Potential may exist to employ in situ technology at other carbon tetrachloride-contaminated sites nationwide. 
Current Baseline Technology: Contaminated groundwater is being pumped to the surface, then treated with an air-stripping unit followed by vapor phase granular activated carbon polishing.

Soil vapor is being extracted from the vadose zone with collection of carbon tetrachloride on granular activated carbon; the carbon is regenerated off-site.

Cost: Pump and treat IRM budget forecast is: FY98, $\$ 1.0 \mathrm{M} ; \mathrm{FY} 99, \$ 1.8 \mathrm{M}$. Costs for complete remediation have not been calculated. However, initial modeling indicates that complete remediation will require 33 to 56 years and significant expansion of the IRM. Rough estimates for building and operating the expanded pump and treat system for this length of time range from $\$ 50 \mathrm{M}$ to $\$ 70 \mathrm{M}$.

Soil vapor extraction budget forecast is: FY98, $\$ 770 \mathrm{~K} ; \mathrm{FY} 99, \$ 790 \mathrm{~K}$.

Waste: Spent carbon adsorption material which is regenerated off-site:

How Long It Will Take: Initial modeling indicates complete remediation with pump and treat will take 33 to 56 years.

End-User: Richland Environmental Restoration Project

Site Technical Point(s)-of-Contact: Kim Koegler, BHI, (509) 372-9294; Jared D. Isaacs, BHI, (509) 372-9162; George C. Henckel III, BHI, (509) 372-9381

DOE End-User/Representative Point(s)-of-Contact: Fred R. Serier DOE, (509) 372-8517;

Arlene C. Tortoso DOE, (509) 373-9631; K. M. (Mike) Thompson, DOE, (509) 373-0750 


\section{TECHNOLOGY NEEDS/OPPORTUNITIES \\ STATEMENT OUTLINE}

Identification No.: RL-SS02

Date: October 15, 1997

OPS Office/Site: DOE-RL/Hanford

Operable Unit(s): 200-ZP-1

Waste Stream: Water (process)

Waste Management Unit: N/A

Facility: N/A

\section{Site Priority Ranking: High}

Need Title: Improved, Real-Time, In-line Detection of Carbon Tetrachloride in Process Water

Need Description: Monitoring carbon tetrachloride by discrete sampling is costly and slow. Inline sampling with real-time monitoring of contaminant concentrations may support the construction of fully automated treatment systems that could substantially reduce operating costs.

Functional Performance Requirements: The new technology must measure contaminant concentrations as process water passes through pipes at the in fluent and/or effluent ends of treatment processes. Results must be real-time and output must be transmittable through standard computer connections. In-line carbon tetrachloride detection must be sensitive to less than $5 \mathrm{ppb}$, which is the regulatory standard.

Schedule Requirements: Pump and treat operations are ongoing. The interim record of decision (ROD) will be reviewed in FY00 for the potential identification of a final remedy for groundwater.

Technology Insertion Point: Consideration of new detection technology is ongoing.

Problem Description: There are two operable units (200-ZP-1 and 200-ZP-2) in the 200 Area at the Z Plant and T Plant Aggregate Areas. Operable unit 200-ZP-1 underlies the Z Plant and T Plant Aggregate Areas located in the northern half of the 200 West Area. Source operable unit 200-ZP-2 addresses contaminated soils. Contaminants of concern in the operable units are carbon tetrachloride, chloroform, and trichlorethylene. A groundwater pump and treat system is in operation at $200-\mathrm{ZP}-1$ and a vapor extraction system is in operation at $200-\mathrm{ZP}-2$.

At present, concentrations of carbon tetrachloride are measured by discrete sampling and analysis in field laboratories. These methods require approximately 24 hours for turn around. In general, laboratory analytical work is highly accurate, but time delays and high cost are considered to be significant drawbacks. In-line monitoring.would lower the analytical chemistry cost of the pump and treat projects and would support design changes to allow fully automated operation of the air 
stripping/carbon adsorption treatment systems.

ADS/RDS/WBS No.: $\quad$ ADS: 3210

RDS: Found in Table 4-3. Risk Data Sheet Results of DOE/RL96-09 Rev. 1 .

WBS: 1.4 .10 .1 .1 .08 .06 .17 .01

Justification For Need:

Technical - In-line sampling with real-time monitoring of contaminant concentrations may support the construction of fully automated treatment systems that would not require the continued presence of human operators, thus potentially reducing operating costs.

Regulatory - There is no regulatory requirement for this technology need.

Environmental Safety and Health - There are no environmental safety and health issues of concern with this technology need.

Cost Savings Potential (Mortgage Reduction) - Improved analytical techniques may reduce baseline laboratory costs and would support fully automated treatment systems.

Cultural/Stakeholder Concerns - None.

Other - None.

Consequences of Nor Filling Need: Continued use of quick-turnaround laboratory analytical methods. At present, these methods are produced satisfactory analytical results but are time consuming and expensive and do not support design changes to allow for fully automated operation of the pump-and-treat systems.

Outsourcing Potential: Potentially high.

Current Baseline Technology: Laboratory analysis.

Cost: Pump and treat sampling costs for carbon tetrachloride are less than $\$ 50 \mathrm{~K}$ per year. Waste: None.

How Long It Will Take: Operations scheduled beyond FY00.

End-User: Richland Environmental Restoration Project

Site Technical Point(s)-of-Contact: Kim Koegler, BHI, (509) 372-9294; George C. Henckel III, BHI, (509) 372-9381; Jared D. Isaacs, BHI, (509) 372-9162

DOE End-User/Representative Point(s)-of-Contact: Fred R. Serier DOE, (509) 372-85i7; Arlene C. Tortoso DOE, (509) 373-9631; K. M. (Mike) Thompson, DOE, (509) 373-0750 


\section{TECHNOLOGY NEEDS/OPPORTUNITIES \\ STATEMENT OUTLINE}

Identification No.: RL-SS03

Date: October 15, 1997

OPS Office/Site: DOE-RL/Hanford

Operable Unit(s): 200-ZP-1

Waste Stream: Groundwater

Waste Management Unit: N/A

Facility: N/A

\section{Site Priority Ranking: High}

Need Title: Improved, Real-Time, In-Situ Detection of Carbon Tetrachloride in Groundwater

Need Description: Monitoring carbon tetrachloride by discrete sampling is costly and time consuming. In situ monitoring would reduce the labor-intensive process of sampling, handling, and shipping samples for analysis. Purge water production and associated disposal or treatment requirements would be minimized or eliminated. In situ monitoring would also aid in situations where monitoring site access is difficult and costly, or where conditions may pose safety hazards to samplers. In situ measurement in extraction, injection or monitoring wells would provide realtime monitoring of contaminant concentrations. In combinations of horizontal and vertical profiling, this will provide highly accurate isopleths of contaminant concentrations to aid in fate and transport modeling and construction of remediation systems.

Functional Performance Requirements: The new technology must measure contaminant concentrations in situ in extraction, injection or monitoring wells. Results must be near real-time and output must be transmittable by hardwire or telemetry to standard computer connections for data reduction and processing. In situ carbon tetrachloride detection must be sensitive to less than $5 \mathrm{ppb}$, which is the regulatory standard. In situ detectors must be of robust design and capable of operating for long periods without maintenance in the specified environments.

Schedule Requirements: Pump and treat systems are presently in operation. The interim record of decision (ROD) will be reviewed in FY00 for the potential identification of a final remedy. Initial modeling indicates that pump and treat will need to be expanded and operated for 33 to 56 years to meet stated objectives. Long-term monitoring will be required to support either pump and treat continuation or alternate technologies.

Technology Insertion Point: Consideration of new detection technology is ongoing.

Problem Description: The central portion of the Hanford Site where the 200 East and 200 West Areas are located was used for chemical separation of plutonium, processing, and waste management. There are two operable units (200-ZP-1 and 200-ZP-2) in the 200 Area at the $Z$ 
Plant and T Plant Aggregate Areas. Operable unit 200-ZP-1 underlies the Z Plant and T Plant Aggregate Areas located in the northern half of the 200 West Area. The operable unit addresses contamination in the groundwater and saturated zone soils. Source operable unit 200-ZP-2 addresses contaminated unsaturated soils associated with $Z$ Plant operations. Contaminants of concern in the operable units are carbon tetrachloride, chloroform, and trichlorethylene. Carbon tetrachloride concentrations of $2,000-3,000 \mathrm{ppb}$ occur in the groundwater plume northwest of the $Z$ Plant. Depth to the water table in this area is about 270 feet: A groundwater pump and treat system is in operation at $200-\mathrm{ZP}-1$ and a vapor extraction system is in operation at $200-\mathrm{ZP}-$ 2.

At present, concentrations of carbon tetrachloride are measured by discrete sampling from wells with analysis in analytical laboratories. Time for receipt of analytical results vary, but can extend to several weeks. Laboratory analytical work is highly accurate, but time delays and high cost are considered to be significant drawbacks. In situ monitoring could lower the analytical chemistry cost of remediation projects and fate and transport studies. The possibility also exists to incorporate in situ monitoring with existing pump and treat remediation systems. This would support design changes to allow fully automated operation of the pump and treat systems.

ADS/RDS/WBS No.: $\quad$ ADS: 3210

RDS: Found in Table 4-3. Risk Data Sheet Results of DOE/RL-96-09 Rev. 1.

WBS: $200-Z \mathrm{P}-1=1 \cdot 4 \cdot 10 \cdot 1 \cdot 1 \cdot 08.06 \cdot 17.01$

$200-\mathrm{ZP}-2=1 \cdot 4 \cdot 10 \cdot 1 \cdot 1 \cdot 08 \cdot 06 \cdot 17.02$

\section{Justification For Need:}

Technical - In situ measurement in extraction, injection or monitoring wells would provide real-time monitoring of contaminant concentrations. Combinations of horizontal and vertical profiling could provide highly accurate isopleths of contaminant concentrations to aid in fate and transport modeling and construction of remediation systems. In situ monitoring will also negate the present requirement of human samplers to purge wells, collect samples and transport to a certified laboratory, and dispose of waste.

Regulatory - There is no regulatory requirement for this technology need.

Environmental Safety and Health - There are no environmental safety and health issues of concern with this technology need.

Cost Savings Potential (Mortgage Reduction) - Cost benefit analysis of increased capital costs versus lower operating costs should be performed.

Cultural/Stakeholder Concerns - In situ monitoring could reduce the Atraffice around monitoring locations situated in or near culturally and environmentally sensitive areas.

Other - None. 
Consequences of Not Filling Need: Continued use of laboratory analytical methods. At present, these methods are producing satisfactory analytical results but are time consuming and expensive.

Outsourcing Potential: Potentially high.

Current Baseline Technology: Laboratory analysis.

Cost: Budget forecast is: FY98, $\$ 100 \mathrm{~K}$; FY99, $\$ 100 \mathrm{~K}$. Although there are no current baseline plans to fund extensive plume mapping, advanced characterization techniques that allowed near real time monitoring of plume concentration changes would be supported by the groundwater project.

Cost per unit: $\$ 300$ per sample for collection and field screening analysis. $\$ 500$ per sample for collection and laboratory analysis.

Waste: None.

How Long It Will Take: Beyond FY00.

End-User: Richiand Environmental Restoration Project

Site Technical Point(s)-of-Contact: Kim Koegler, BHI, (509) 372-9294; Jared D. Isaacs, BHI, (509) 372-9162; George C. Henckel III, BHI, (509) 372-9381

DOE End-User/Representative Point(s)-of-Contact: Fred R. Serier DOE, (509) 372-8517;

Arlene C. Tortoso DOE, (509) 373-9631; K. M. (Mike) Thompson, DOE, (509) 373-0750 


\section{TECHNOLOGY NEEDS/OPPORTUNITIES \\ STATEMENT OUTLINE}

Identification No: RL-SS04

Date: October 15, 1997

OPS Office/Site: DOE-RL/Hanford

Operable Unit(s): 100-HR-3, 100-KR-4

Waste Stream: Groundwater

Waste Management Unit: N/A

Facility: N/A

Site Priority Ranking: High

Need Title: Cost-Effective, In Situ Remediation of Hexavalent Chromium in Groundwater

Need Description: Cost-effective, environmentally safe and compliant in situ remediation of Hexavalent chromium to reduce the risk to juvenile salmon in the Columbia River

Functional Performance Requirements: 40 CFR 141 drinking water standard of $100 \mathrm{ppb}$; Clean Water Act Ambient Water Quality Criteria of $11 \mathrm{vg} / \mathrm{L}$ measured in the pore spaces of sediment in the Columbia River.

Schedule Requirements: Pump and treat operations are ongoing. The interim record of decision (ROD) will be reviewed in FY02 for the potential identification of a final remedy.

Technology Insertion Point: Potential alternative technology for groundwater remediation must be identified and evaluated prior to reevaluation of the interim ROD in FY02 for potential subsequent deployment.

Problem Description: The 100- $\mathrm{H}$ and $100-\mathrm{K}$ Areas are located along the horn of the Columbia River, in the northern portion of the Hanford Site, and include three nuclear reactors previously used for plutonium production. Primary sources of contamination in groundwater are cribs, french drains, trenches, ponds, retention basins, pipelines, and waste disposal sites. Groundwater in the 100 Area ultimately discharges into the Columbia River. The principal contaminant is chromium which occurs in two main plumes. The north plume is about $2,000^{\prime} \times 4,000^{\prime}$ and a south plume of about $2,000^{\prime} \times 2,000^{\prime}$. Both plumes have an average thickness of about 15 feet with concentrations ranging from 60 to $600 \mathrm{ppb}$. Depth to the water table is 85 feet.

Hexavalent chromium has been identified as a contaminant of concern for juvenile salmon in the Columbia River. A Focused Feasibility Study/Proposed Plan (August, 1995) recommended a pump and treat Interin Remedial Measure to address chromate migration from groundwater to the river. An interim ROD (April, 1996) for the operable units 100-HR-3 and 100-KR-4 specified installation of a pump-and-treat systems in operable units $100-\mathrm{HR}-3$ and $100-\mathrm{KR}-4$ to 
intercept chromate plumes that impact the Columbia River. The objective of the Interim Remedial Measure (IRM) is protection of juvenile salmon in the river substrate from exposure to hexavalent chromium.

A technology that is currently under development to deal with this need is the In Situ Redox Manipulation technology that injects dithionite into the aquifer to modify the oxidation/reduction potential and immobilize the chromium. The ongoing treatability study for this technology has recently undergone a peer review that recommends further testing. Tests will be carefully monitored over the next several years to confirm it effectiveness. If the testing proves successful, this technology will be available to help address this need.

Chromium treatment in the vadose zone is a related need. (See also Need Title: Cost Effective, in Situ Remediation in the Vadose Zone of One or More of the Following Heavy Metals: Hexavalent Chromium, Mercury, and Lead.)

ADS/RDS/WBS No.: $\quad$ ADS: 3110

RDS: Found in Table 4-3. Risk Data Sheet Results of DOE/RL-96-09 Rev. 1

WBS: $100-H R-3=1 \cdot 4 \cdot 10 \cdot 1 \cdot 1 \cdot 08 \cdot 02.08 .03$

$100-K R-4=1 \cdot 4 \cdot 10 \cdot 1 \cdot 1 \cdot 08 \cdot 02 \cdot 06.04$

\section{Justification For Need}

Technical - Testing has shown that hexavalent chromium is migrating to the Columbia River in sufficient concentration to pose a risk to juvenile salmon; in situ treatment will negate the requirement and current process of groundwater extraction and ex situ treatment to remove hexavalent chromium (in chromate form).

Regulatory - Federal Clean Water Act Ambient Water Quality Criteria of $11 \mathrm{vg} / \mathrm{L} ; 40 \mathrm{CFR}$ 141 drinking water standard of $100 \mathrm{ppb}$.

Environmental Safety and Health - Possible worker safety issues regarding handling of reducing chemicals, etc., although proper safety protocols should mitigate these concerns.

Cost Savings Potential (Mortgage Reduction) - Eliminate O\&M costs of the pump and treat system.

Cultural/Stakeholder Concerns - Stakeholders are sensitive to introduction of chemicals into the vadose zone and groundwater to accomplish in situ hexavalent chromium remediation. Ecotoxicity and bio-uptake are also stakeholder concerns.

Other - None.

Consequences of Not Filling Need: Continued operation of groundwater pump and treat systems to remediate hexavalent chromium contamination. 
Outsourcing Potential: Potentially high.

Current Baseline Technology: Extraction of groundwater and ex situ ion exchange treatment.

Cost: Combined Budget forecast for pump and treat IRMs at 100-HR-3 and 100-KR-4 is: FY98, \$5.0M; FY99, \$5.0M. Complete cost estimates for out years have not been completed. However, current cost estimates developed for comparison purposes were based on annual O\&M costs for pump \& treat of about $\$ 5.0 \mathrm{M}$ per year for a period of 5 years. Thus, if discounted at a rate of $5 \%$, the cost of the IRM is on the order of $\$ 22 \mathrm{M}$. Although the IRM pump and treat system is removing significant quantities of $\mathrm{Cr}$, the planned 5 year period will probably need to be extended to reduce the inventory to the point that this would represent a permanent solution.

Waste: Exhausted ion exchange resin disposed on site.

How Long It Will Take: Pump and treat operations are scheduled beyond FY00.

End-User: Richland Environmental Restoration Project

Site Technical Point(s)-of-Contact: Kim Koegler, BHI, (509) 372-9294; Jared D. Isaacs, BHI, (509) 372-9162; George C. Henckel III, BHI, (509) 372-9381

DOE End-User/Representative Point(s)-of-Contact: Fred R. Serier DOE, (509) 372-85.17; Arlene C. Tortoso DOE, (509) 373-9631; K. M. (Mike) Thompson, DOE, (509) 373-0750 


\section{TECHNOLOGY NEEDS/OPPORTUNITIES \\ STATEMENT OUTLINE}

Identification No.: RL-SS05

Date: October 15, 1997

OPS Office/Site: DOE-RL/Hanford

Operable Unit(s): 100-HR-3, 100-KR-4

Waste Stream: Water (process)

Waste Management Unit: N/A

Facility: N/A

Site Priority Ranking: High

Need Title: Improved, Real-Time, In-line Detection of Hexavalent Chromium in Process Water

Need Description: Monitoring hexavalent chromium by discrete sampling is costly and slow. In-line sampling with real-time monitoring of contaminant concentrations may support the construction of fully automated treatment systems that could substantially reduce operating costs.

Functional Performance Requirements: The new technology must measure contaminant concentrations as process water passes through pipes at the influent and/or effluent ends of treatment processes. Results must be real-time and output must be transmittable through standard computer connections. In-line chromium detection must be sensitive to less than 50 micrograms total chromium per liter.

Schedule Requirements: Pump and treat operations are ongoing. The interim record of decision (ROD) will be reviewed in FY02 for the potential identification of a final remedy for groundwater.

Technology Insertion Point: Consideration of new detection technology is ongoing.

Problem Description: The 100- $\mathrm{H}$ and $100-\mathrm{K}$ Areas are located along the horn of the Columbia River, in the northern portion of the Hanford Site, and includes three nuclear reactors previously used for plutonium production. Primary sources of contamination in groundwater are cribs, french drains, trenches, ponds, retention basins, pipelines, and waste disposal sites.

Groundwater in the 100 Area ultimately discharges into the Columbia River. The principal contaminant is chromium. To mitigate this contamination, interim remedial measures were initiated at operable units $100 \mathrm{KR}-4$, and 100-HR-3. Pump-and-treat operations are very costly, hence the desire to investigate the potential for advanced technologies to improve efficiency.

At present, chromium concentrations are measured by discrete sampling and analysis in field laboratories. These methods require approximately 24 hours for turn around. In general, 
laboratory analytical work is highly accurate, but time delays and high cost are considered to be significant drawbacks. In-line monitoring would lower the analytical chemistry cost of the pump and treat projects and would support design changes to allow fully automated operation of the ion exchange treatment systems.

ADS/RDS/WBS No: $\quad$ ADS: 3110

RDS: Found in Table 4-3. Risk Data Sheet Results of DOE/RL-96-09 Rev. 1.

WBS: $100-K R-4=1.4 .10 .1 .1 .08 .02 .06 .04$

$100-$ HR $-3=1.4 .10 .1 .1 .08 .02 .08 .03$

Justification For Need:

Technical - In-line sampling with real-time monitoring of contaminant concentrations may support the construction of fully automated treatment systems that would not require the continued presence of human operators, thus potentially reducing operating costs. In addition, closer monitoring of contaminant concentrations in the process streams would allow operators to accurately identify contaminant breakthrough of lead columns in the treatment systems. This increased efficiency could ultimately reduce the amount of ion exchange resin used, saving money.

Regulatory - There is no regulatory requirement for this technology need.

Environmental Safety and Health - There are no environmental safety and health issues of concern with this technology need.

Cost Savings Potential (Mortgage Reduction) - Improved analytical techniques may reduce baseline laboratory costs and could support fully automated treatment systems.

CulturalStakeholder Concerns - There are serious stakeholder concerns that 50 micrograms per liter is not protective of the ambient water quality standard.

Other - None.

Consequences of Not Filling Need: Continued use of quick-turnaround laboratory analytical methods. At present, these methods are produced satisfactory analytical results but are time consuming and expensive and do not support design changes to allow for fully automated operation of the pump-and-treat systems.

Outsourcing Potential: Potentially high.

Current Baseline Technology: Laboratory analysis.

Cost: Pump and treat sampling costs for chromium are less than $\$ 50 \mathrm{~K}$ per year.

Waste: None.

How Long It Will Take: Operations scheduled beyond FY00. 
End-User: Richland Environmental Restoration Project

Site Technical Point(s)-of-Contact: Kim Koegler, BHI, (509) 372-9294; Jared D. Isaacs, BHI, (509) 372-9162; George C. Henckel III, BHI, (509) 372-9381

DOE End-User/Representative Point(s)-of-Contact: Fred R. Serier DOE, (509) 372-8517; Arlene C. Tortoso DOE, (509) 373-9631; K. M. (Mike) Thompson, DOE, (509) 373-0750 


\section{TECHNOLOGY NEEDS/OPPORTUNITIES \\ STATEMENT OUTLINE}

Identification No.: RL-SS06

Date: October 15, 1997

OPS Office/Site: DOE-RL/Hanford

Operable Unit(s): 100-HR-3, 100-KR-4

Waste Stream: Groundwater

Waste Management Unit: N/A

Facility: N/A

Site Priority Ranking: High

\section{Need Title:}

Improved, Real-Time; In-Situ Detection of Hexavalent Chromium in Groundwater

Need Description: Monitoring hexavalent chromium by discrete sampling is costly and time consuming. In situ monitoring would reduce the labor-intensive process of sampling, handling, and shipping samples for analysis. Purge water production and associated disposal or treatment requirements would be minimized or eliminated. In situ monitoring would also aid in situations where monitoring site access is difficult and costly, or where conditions may pose safety hazards to samplers. In situ measurement in extraction, injection or monitoring wells, well points, or in river substrate would provide real-time monitoring of contaminant concentrations. In combinations of horizontal and vertical profiling, this will provide highly accurate isopleths of contaminant concentrations to aid in fate and transport modeling and construction of remediation systems.

Functional Performance Requirements: The new technology must measure contaminant concentrations in situ in extraction, injection or monitoring wells, well points, or in river substrate. Results must be near real-time and output must be transmittable by hardwire or telemetry to standard computer connections for data reduction and processing. In situ chromium detection must be sensitive to less than $11 \mathrm{vg} / \mathrm{L}$. In situ detectors must be of robust design and capable of operating for long periods without maintenance in the specified environments.

Schedule Requirements: Pump and treat operations are ongoing. The interim record of decision (ROD) will be reviewed in FY02 for the potential identification of a final remedy. Long-term. monitoring will be required to support either pump and treat continuation or alternate technologies.

Technology Insertion Point: Consideration of new detection technology is ongoing.

Problem Description: The 100-H and 100-K Areas are located along the horn of the Columbia River, in the northern portion of the Hanford Site, and includes three nuclear reactors previously 
used for plutonium production. Primary sources of contamination in groundwater are cribs, french drains, trenches, ponds, retention basins, pipelines, and waste disposal sites. Groundwater in the 100 Area ultimately discharges into the Columbia River. The principal contaminant is chromium. Depth to the water table in these areas is approximately 85 feet. To mitigate this contamination, interim remedial measures were initiated at operable units $100 \mathrm{KR}-4$, and 100-HR-3.

At present, concentrations of chromium are measured by discrete sampling from wells or river substrate with analysis in analytical laboratories. Time for receipt of analytical results vary, but can extend to several weeks. Laboratory analytical work is highly accurate, but time delays and high cost are considered to be significant drawbacks. In situ monitoring would lower the analytical chemistry cost of remediation projects and fate and transport studies. The possibility also exists to incorporate in situ monitoring with existing pump-and-treat remediation systems. This objective would support design changes to allow fully automated operation of the pumpand-treat systems.

ADS/RDS/WBS No.: $\quad$ ADS: 3110

RDS: Found in Table 4-3. Risk Data Sheet Results of DOE/RL-96-09 Rev. 1.

WBS: $100-K R-4=1.4 .10 .1 .1 .08 .02 .06 .04$

$100-$ HR-3 $=1.4 .10 .1 .1 .08 .02 .08 .03$

\section{Justification For Need:}

Technical - In situ measurement in extraction, injection or monitoring wells, well points, or in river substrate would provide real-time monitoring of contaminant concentrations.

Combinations of horizontal and vertical profiling could provide highly accurate isopleths of contaminant concentrations to aid in fate and transport modeling and construction of remediation systems. In situ monitoring will also negate the present requirement of human samplers to purge wells, collect samples and transport to a certified laboratory, and dispose of waste.

Regulatory - There is no regulatory requirement for this technology need.

Environmental Safety and Health - There are no environmental safety and health issues of concern with this technology need.

Cost Savings Potential (Mortgage Reduction) - Cost benefit analysis of increased capital costs versus lower operating costs should be performed.

Cultural/Stakeholder Concerns - In situ monitoring could reduce the "traffic" around monitoring locations situated in or near culturally and environmentally sensitive areas.

Other - None.

Consequences of Not Filling Need: Continued use of laboratory analytical methods. At 
present, these methods are producing satisfactory analytical results but are time consuming and expensive.

Outsourcing Potential: Potentially high.

Current Baseline Technology: Laboratory analysis.

Cost: Although there are no current baseline plans to fund extensive plume mapping, advanced characterization techniques that allowed near real time monitoring of plume concentration changes would be supported by the groundwater project.

Waste: None.

How Long It Will Take: Beyond FY00.

End-User: Richland Environmental Restoration Project

Site Technical Point((s)-of-Contact: Kim Koegler, BHI, (509) 372-9294; Jared D. Isaacs, BHI, (509) 372-9162; George C. Henckel III, BHI, (509) 372-9381

DOE End-User/Representative Point(s) of-Contact: Fred R. Serier DOE, (509) 372-8517; Arlene C. Tortoso DOE, (509) 373-9631; K. M. (Mike) Thompson, DOE, (509) 373-0750 


\section{TECHNOLOGY NEEDS/OPPORTUNITIES \\ STATEMENT OUTLINE}

Identification No.: RJ--SS07

Date: October 15, 1997

OPS Office/Site: DOE-RL/Hanford

Operable Unit(s): 100-NR-2

Waste Stream: Groundwater

Waste Management Unit: N/A

Facility: N/A

Site Priority Ranking: High

Need Titte: Cost-Effective, In Situ Remediation of Strontium-90 in Groundwater

Need Description: Remediation of soluble strontium-90 in the groundwater to reduce risk to human health and the environment.

Functional Performance Requirements: Reduce strontium-90 activity to the Safe Drinking Water Act criteria of $8 \mathrm{pCi} / \mathrm{L}$.

Schedule Requirements: Pump and treat operations are ongoing as an expedited action. An interim record of decision (ROD) is expected to be issued in late 1997 to early 1998 selecting an interim remedy. The interim ROD is expected to include a requirement to continue evaluation of other technologies. The interim ROD will be reviewed in FY02 for the potential identification of a final remedy.

Technology Insertion Point: Potential alternative technology for groundwater remediation must be identified and evaluated prior to reevaluation of the interim ROD in FY02 for potential subsequent deployment.

Problem Description: The 100-N Area is located near the Columbia River and includes one nuclear reactor previously used for plutonium production. In the 100-NR-2 operable unit, the primary sources of contamination are ditches and cribs. Groundwater in the 100 Area ultimately discharges to the Columbia River. The principal contaminant, strontium-90 (half-life 29.3 years), is present in groundwater at activities up to $6000 \mathrm{pCi} / \mathrm{L}$. Maximum concentrations of the plume range from 4,000-6,000 pCi per liter with depth to the water table of 70-80 feet at the source. Plume thickness ranges from 13 to 40 feet. The estimated total inventory of contaminant in both the groundwater and soils ranges from 75 to 89 curies.

The immediate objective is to prevent further migration of St-90 into the Columbia River. The long-term objective is to reduce Sr-90 levels to below drinking water standards. An existing pump \& treat expedited response action (ERA) has been implemented to help reduce the flux of 
Sr-90 to the river. The low mobility of the strontium-90 reduces the removal effectiveness to the point that natural radioactive decay removes the contamination almost as fast as the pump and treat operation combined with radioactive decay. Thus, the main purpose of the pump and treat system is for containment while natural decay reduces the source. If containment must be maintained until the highest concentrations in the plume $(6,000 \mathrm{pCi} /$ liter $)$ decay to the Safe Drinking Water Act Standard of $8 \mathrm{pCi} /$ liter, the aquifer will need to be contained for 280 years.

One containment approach being evaluated for this application is an in situ permeable strontium adsorption barrier. Implementation of this approach has been stalled due to concerns over the effectiveness of long-term containment strategies. A main concern is that high concentrations of Sr-90 will accumulate in the barrier and result in a catastrophic release into the Columbia River if the barrier is washed out during a major flooding event.

A stated desire of the Hanford Advisory Board is to develop technologies to remove strontium90 in the groundwater near the river with an in situ process. There is a strong preference towards contaminant removal. An important consideration with any contaminant removal process is to assure complete capture of any mobilized contaminant.

ADS/RDS/WBS No: $\quad$ ADS: 3125

RDS: Found in Table 4-3. Risk Data Sheet Results of DOE/RL-96-09 Rev. 1.

WBS: 1.4.10.1.1.08.03.09.02

\section{Justification For Need:}

Technical - Remediation of strontium-90 in the groundwater is presently in progress at 100$\mathrm{N}$ Area with an ion exchange process accomplished via pump and treat. An in situ remediation process will negate the need for ex situ extraction and treatment.

Regulatory - Strontium-90 in groundwater exceeds the Safe Drinking Water Act standard of $8 \mathrm{pCi} / \mathrm{L}$.

Environmental Safety and Health - Possible exposure to strontium-90

Cost Savings Potential (Mortgage Reduction) - Reduce operating costs of the existing pump and treat system.

Cultural/Stakeholder Concerns - Stakeholders may not accept immobilization or precipitation methods that do not actually remove strontium- 90 from the aquifer. It is not possible to eliminate strontium- 90 with in situ methods as strontium-90 is a metallic element, although immobilization or precipitation of strontium-90 will effectively eliminate risk to human health and the environment.

Other - None.

Consequences of Not Filling Need: Continued operation of groundwater pump and treat to 
remove strontium-90 from groundwater.

Outsourcing Potential: Potentially high.

Current Baseline Technology: Extraction of groundwater and ex situ ion exchange treatment. Clean process water is reinjected into the aquifer.

Cost: Budget forecast for pump and treat at 100-NR-2 is: FY98, \$630K; FY99, \$630K. Cost estimates for out years have not been completed. Assuming the pump and treat system must contain the plume for 280 years and the O\&M costs remain constant, the total cost for remediation (discounted at a rate of $5 \%$ ) is in excess of $\$ 13 \mathrm{M}$.

Waste: Exhausted ion exchange resin disposed on site.

How Long It Will Take: Interim remediation measures have commenced and will continue for several years or until alternate treatment strategies/technologies are approved.

End-User: Richland Environmental Restoration Project

Site Technical Point(s)-of-Contact: Kim Koegler, BHI, (509) 372-9294; Jared D. Isaacs, BHI, (509) 372-9162; George C. Henckel III, BHI, (509) 372-9381

DOE End-User/Representative Point(s)-of-Contact: Fred R. Serier DOE, (509) 372-8517;

David E. Olson, DOE, (509) 376-7142; K. M. (Mike) Thompson, DOE, (509) 373-0750 


\section{TECHNOLOGY NEEDS/OPPORTUNITIES STATEMENT OUTLINE}

Identification No.: RL-SS08

Date: October 15, 1997

OPS Office/Site: DOE-RL/Hanford

Operable Unit(s): 100-NR-2

Waste Stream: Water (process)

Waste Management Unit: N/A

Facility: N/A

Site Priority Ranking: High

Need Title: Improved, Real-Time, In-line Detection of Strontium-90 in Process Water

Need Description: Monitoring Strontium-90 by discrete sampling is costly and slow. In-line sampling with real-time monitoring of contaminant concentrations may support the construction of fully automated treatment systems that could substantially reduce operating costs.

Functional Performance Requirements: The new technology must measure contaminant concentrations as process water passes through pipes at the in fluent and/or effluent ends of treatment processes. Results must be real-time and output must be transmittable through standard computer connections. In-line strontium-90 detection must be sensitive to concentrations on the order of $5-50 \mathrm{pCi} / \mathrm{L}$ to support $90 \%$ removal rate requirements.

Schedule Requirements: Pump and treat operations are ongoing as an expedited action. An interim record of decision (ROD) is expected to be issued in late 1997 to early 1998 selecting an interim remedy. The interim $R O D$ is expected to include a requirement to continue evaluation of other technologies. The interim record ROD will be reviewed in FY02 for the potential identification of a final remedy.

Technology Insertion Point: Consideration of new detection technology is ongoing.

Problem Description: The 100-N Area is located along the horn of the Columbia River in the northern portion of the Hanford Site and includes one nuclear reactor previously used for plutonium production.

The primary sources of contamination in the 100-NR-2 operable unit are cribs. Groundwater in the 100 Area ultimately discharges to the Columbia River. The principal contaminant is . strontium. Activity of Strontium-90 (half-ife 29.3 years) in groundwater is up to $6000 \mathrm{pCi} / \mathrm{L}$.

At present, concentrations of strontium- 90 is measured by discrete sampling and analysis in field laboratories. These methods require approximately 24 hours for turn around. In general, 
laboratory analytical work is highly accurate, but time delays and high cost are considered to be significant drawbacks. In-line monitoring would lower the analytical chemistry cost of the pump and treat projects and would support design changes to allow fully automated operation of the ion exchange treatment systems.

ADS/RDS/WBS No.: $\quad$ ADS: 3110

RDS: Found in Table 4-3. Risk Data Sheet Results of DOE/RL-96-09 Rev. 1.

WBS: $100-N R-2=1.4 .10 .1 .1 .08 .02 .09 .02$

\section{Justification For Need:}

Technical - In-line sampling with real-time monitoring of contaminant concentrations may support the construction of fully automated treatment systems that would not require the continued presence of human operators, thus potentially reducing operating costs. In addition, closer monitoring of contaminant concentrations in the process streams would allow operators to accurately identify contaminant breakthrough of lead columns in the treatment systems. This increased efficiency could ultimately reduce the amount of ion exchange resin used, saving money.

Regulatory - There is no regulatory requirement for this technology need.

Environmental Safety and Health - There are no environmental safety and health issues of concern with this technology need.

Cost Savings Potential (Mortgage Reduction) - Improved analytical techniques may reduce baseline laboratory costs and would support fully automated treatment systems.

Cultural/Stakeholder Concerns - There are serious stakeholder concerns that detection limits above the regulatory standard may not be protective of the. ambient water quality standard.

Other - None.

Consequences of Not Filling Need: Continued use of quick-turnaround laboratory analytical methods. At present, these methods are produced satisfactory analytical results but are time consuming and expensive and do not support design changes to allow for fully automated operation of the pump-and-treat systems.

Outsourcing Potential: Potentially high.

Current Baseline Technology: Laboratory analysis.

Cost: Pump and treat sampling costs for strontium are less than $\$ 50 \mathrm{~K}$ per year.

Waste: None.

How Long It Will Take: Operations scheduled beyond FYOO. 
End-User: Richland Environmental Restoration Project

Site Technical Point(\$)-of-Contact: Kim Koegler, BHI, (509) 372-9294; Jared D. Isaacs, BHI, (509) 372-9162; George C. Henckel IIL, BHI, (509) 372-9381

DOE End-User/Representative Point(s)-of-Contact: Fred R. Serier DOE, (509) 372-8517;

David E. Olson, DOE, (509) 376-7142; K. M. (Mike) Thompson, DOE, (509) 373-0750 


\section{TECHNOLOGY NEEDS/OPPORTUNITIES \\ STATEMENT OUTLINE}

Identification No.: RL-SS09

Date: October 15, 1997

OPS Office/Site: DOE-RL/Hanford

Operable Unit(s): 100-NR-2

Waste Stream: Groundwater

Waste Management Unit: N/A

Facility: N/A

Site Priority Ranking: High

Need Title: Improved, Real-Time, In-Situ Detection of Strontium-90 in Groundwater

Need Description: Monitoring strontium-90 by discrete sampling is costly and time consuming. In situ monitoring would reduce the labor-intensive process of sampling, handling, and shipping samples for analysis. Purge water production and associated disposal or treatment requirements would be minimized or eliminated. In situ monitoring would also aid in situations where monitoring site access is difficult and costly, or where conditions may pose safety hazards to samplers. In situ measurement in extraction, injection or monitoring wells, well points, or in river substrate would provide real-time monitoring of contaminant concentrations. In combinations of horizontal and vertical profiling, this will provide highly accurate isopleths of contaminant concentrations to aid in fate and transport modeling and construction of remediation systems.

Functional Performance Requirements: The new technology must measure contaminant concentrations in situ in extraction, injection or monitoring wells, well points, or in river substrate. Depth to water table is $60-80$ feet with maximum ground water concentrations ranging from $4,000-6,000$ pCi per liter. Results must be near real-time and output must be transmittable by hardwire or telemetry to standard computer connections for data reduction and processing. In situ strontium-90 detection must be sensitive to less than $8 \mathrm{pCi} / \mathrm{L}$. In situ detectors must be of robust design and capable of operating for long periods without maintenance in the specified environments.

Schedule Requirements: Pump and treat operations are ongoing as an expedited action. An interim record of decision (ROD) is expected to be issued in late 1997 to early 1998 selecting an interim remedy. The interim ROD is expected to include a requirement to continue evaluation of other technologies. The interim ROD will be reviewed in FY02 for the potential identification of a final remedy. Long-term monitoring will be required to support either pump and treat continuation or alternate technologies.

Technology Insertion Point: Consideration of new detection technology is ongoing. 
Problem Description: The 100-N Area is located along the horn of the Columbia River in the northern portion of the Hanford Site and includes one nuclear reactor previously used for plutonium production. Maximum groundwater concentrations range from $4,000-6,000 \mathrm{pCi}$ per liter. Depth to water table ranges from $60-80$ feet at the source.

At present, concentrations of strontium-90 is measured by discrete sampling from wells or river substrate with analysis in analytical laboratories. Time for receipt of analytical results vary, but can extend to several weeks. Laboratory analytical work is highly accurate, but time delays and high cost are considered to be significant drawbacks. In situ monitoring would lower the analytical chemistry cost of remediation projects and fate and transport studies. The possibility also exists to incorporate in situ monitoring with existing pump-and-treat remediation systems. This objective would support design changes to allow fully automated operation of the pumpand-treat systems.

ADS/RDS/WBS No.: $\quad$ ADS: 3110

RDS: Found in Table 4-3. Risk Data Sheet Results of DOE/RL-96-09 Rev. 1.

WBS: $100-\mathrm{NR}-2=1.4 .10 .1 .1 .08 .02 .09 .02$

\section{Justification For Need:}

Technical - In situ measurement in extraction, injection or monitoring wells, well points, or in river substrate would provide real-time monitoring of contaminant concentrations.

Combinations of horizontal and vertical profiling could provide highly accurate isopleths of contaminant concentrations to aid in fate and transport modeling and construction of remediation systems. In situ monitoring will also negate the present requirement of human samplers to purge wells, collect samples and transport to a certified laboratory, and dispose of waste.

Regulatory - There is no regulatory requirement for this technology need.

Environmental Safety and Health - There are no environmental safety and health issues of concern with this technology need.

Cost Savings Potential (Mortgage Reduction) - Cost benefit analysis of increased capital costs versus lower operating costs should be performed.

Cultural/Stakeholder Concerns - In situ monitoring could reduce the "traffic" around monitoring locations situated in or near culturally and environmentally sensitive areas.

Other - None.

Consequences of Not Filling Need: Continued use of laboratory analytical methods. At present, these methods are producing satisfactory analytical results but are time consuming and expensive. 
Outsourcing Potential: Potentially high.

Current Baseline Technology: Laboratory analysis.

Cost: Although there are no current baseline plans to fund extensive plume mapping, advanced characterization techniques that allowed near real time monitoring of plume concentration changes would be supported by the groundwater project.

How Long It Will Take: Beyond FY00.

End-User: Richland Environmental Restoration Project

Site Technical Point(s)-of-Contact: Kim Koegler, BHI, (509) 372-9294; Jared D. Isaacs, BHI, (509) 372-9162; George C. Henckel III, BHI, (509) 372-9381

DOE End-User/Representative Point(s)-of-Contact: Fred R. Sexier DOE, (509) 372-8517; David E. Olson, DOE, (509) 376-7142; K. M. (Mike) Thompson, DOE, (509) 373-0750 


\section{TECHNOLOGY NEEDS/OPPORTUNITIES \\ STATEMENT OUTLINE}

Identification No.: RL-SS10

Date: October 15, 1997

OPS Office/Site: DOE-RL/Hanford

Operable Unit: All burial ground sites in the 100,200 and 300 Areas and liquid waste disposal sites in the 200 Areas

Waste Stream: Soil

Waste Management Unit: N/A

Facility: N/A

Site Priority Ranking: High

Need Title: Improved Technologies for Detection/Delineation of Burial Ground Contents and Subsurface Geological Boundaries.

Need Description: Improved technologies are needed for non-intrusive or minimally intrusive methods for identifying burial ground contents and delineating difficult to find waste sites. A large number of burial grounds and liquid waste disposal sites were created during fifty years of defense plutonium production. Documentation of materials that were placed in the burial grounds and exact location of some sites is incomplete. These non-intrusive or minimally intrusive methods are also needed to identify geological boundaries prior to characterization/remediation activities for the 200 Area liquid waste sites. A significant number of the 200 Area's liquid waste disposal sites have been interim stabilized prior to characterization. As a result, 5 to 15 feet of stabilized fill material (either imported fill or material pushed in from the sides of the trenches or ditches) now exists above the original contours of the liquid waste sites. Characterization of these waste sites require a clear delineation of the original contours. Performing this delineation in a non-intrusive manner is needed.

Functional Performance Requirements: Technology must be a remote-sensing design capable of non-intrusive or minimally-intrusive methods for physical and radiological identification of burial ground contents. Also, sensing of different soil characteristics and features of liquid waste disposal sites waste site contours are also required. Some items may be located as deep as $50 \mathrm{ft}$ from the surface but much of the buried waste at Hanford is at depths of less than 15 feet. Also, high resolution, real-time imaging systems would be useful (even if the penetration depth was only 4-5 feet) to support lift-by-lift excavation planning. Physical determination of objects should be sensitive enough to accurately differentiate small items, such as pipes, bricks, machinery, etc. Radiological sensing should be directed toward segregation of transuranic debris from non-transuranic debris and identification of other radionuclides if possible. While several technologies are available to detect different types of features in the subsurface, ways to integrate the geophysical data from these various technologies are also needed. 
Schedule Requirements: Variable. Burial grounds and liquid waste disposal sites exist in the 100,200 , and 300 Areas. The first burial ground (located in the 300 Area) excavation is scheduled for early FY98. Goals established in the Hanford Ten Year Challenge would have all soil sites and burial grounds in the 100 Area and 300 Area completed by 2006 . Strategies for characterization and remediation of the 200 Area burial ground sites are being revised but are scheduled to begin in 2003 and will extend several years past 2006. Characterization and remediation of the 200 Area liquid waste sites are scheduled to start FY99 and extend several years past 2006 .

Technology Insertion Point: Consideration of new technology is ongoing. Mature technologies would support near term actions but development of innovative technologies could support actions that extend several years past 2006 .

Problem Description: Fifty years of defense plutonium production resulted in the creation of a large number of solid waste burial ground sites in Hanford's 100, 200, and 300 Areas. The 100 Areas are located along the Columbia River and include nine nuclear reactors previously used for plutonium production. The 300 Area is also located along the Columbia River and contains the fuel fabrication facilities. The 200 Area is located on the central plateau and contains the spent fuel extraction and processing facilities, and the radioactive waste storage tanks. Hanford's burial grounds contain a variety of solid waste debris including construction waste, discarded equipment, and protective clothing. Much of this waste is contaminated with low-level radioactive materials. The baseline for the 100 and 300 area sites is excavation and disposal on site. The 200 Area remediation includes a combination of removal and leave in-place with in situ treatment and/or barrier placement strategies. Non-intrusive or minimally-intrusive investigation and determination of burial ground contents will aid the development of remedial action plans and will reduce exposure to workers involved in removal operations. These tools are also necessary to support decisions to leave some burial grounds in place with caps or other measures to control exposures. Leaving selected 100 and 300 area burial grounds in place could result in a cost savings of over $\$ 500 \mathrm{M}$. Improved detection techniques would also allow for hot spot/selective removal alternatives and help locate soil sites covered with clean fill material.

At present, gross burial ground delineation and assessment is accomplished with various remote sensing instruments, including ground penetrating radar, magnetic anomaly detection, and remote roving vehicles to measure gamma ray emissions. These methods are effective to identify certain types of debris, contaminants, and changes in subsurface conditions. For example, ground penetrating radar effectively detects physical objects that present a distinctly different reflectively than the surrounding matrix, such as metal drums or pipes. The remote measurement of gamma radiation can identify the presence of certain radionuclides such as cobalt-60 that are high energy gamma emitters. Other radioactive contaminants, such as strontium-90 and uranium, are beta and alpha particle emitters that cannot be detected with surface remote detection because of matrix interference of the overlying soils. 
ADS: $3100,3200,3300$

RDS: Found in Table 4-3. Risk Data Sheet Results of DOE/RL-96-09 Rev. 1.

WBS: ADS: $3100=$ WBS 1.4.10.1.1.01.01

ADS: $3200=$ WBS 1.4.10.1.1.02.05

ADS: $3300=$ WBS 1.4.10.1.1.03.07

\section{Justification For Need:}

Technical - Enhanced detection and delineation methods could provide accurate information for characterization and remedial action planning and negate the requirement for invasive sampling.

Regulatory - There is no regulatory requirement for this technology.

Environmental Safety and Health - Successful non-invasive, or minimally-invasive, detection and delineation technologies could reduce risk to remediation workers by negating the requirement for invasive sampling to adequately characterize burial grounds or the contents of liquid waste sites.

Cost Savings Potential (Mortgage Reduction) - Substantial cost savings could result if select burial grounds can be treated in place instead of excavated and disposed. Savings could also result if intrusive activities are not required to locate disposal sites prior to characterization.

Cultural/Stakeholder Concerns - There are serious concerns that inadequate waste site characterization will be used to support decisions to leave waste in place.

Other - None.

Consequences of Not Filling Need: Continued use of ground penetrating radar and other remote detection methods, along with invasive sampling as required.

Outsourcing Potential: Possible high potential in Department of Energy, Department of Defense, and private applications.

Current Baseline Technology: Ground penetrating radar, electric magnetic induction, trenching, and visual examination.

Cost: Budget forecast for 300 Area burial ground activities is: FY98, \$3.2M, FY99, \$3.1M. Estimates to complete excavation and disposal of all the burial grounds in the 100 and 300 Areas is nearly $\$ 700 \mathrm{M}$. Characterization activities in the 200 Areas are estimated to be $\$ 70 \mathrm{M}$.

Waste: None 
How Long It Will Take: Burial ground and soil remediation activities in the 100 and 300 Areas are planned for next ten years. Characterization and remediation activities in the 200 Area will begin in FY99 and are likely to extend well beyond the ten year time period.

End-User: Richland Environmental Restoration Project

Site Technical Point(s)-of-Contact: Kim Koegler, BHI, (509) 372-9294; Greg B. Mitchem (509) 372-9632; Ashur R. Michael, BHI, (509) 372-9074; V. R. (Vern) Dronen, BHI, (509) $372-9096$

DOE End-User/Representative Point(s)-of-Contact: Fred R. Serier DOE, (509) 372-8517; Bryan L. Foley, DOE, (509) 376-7087; Owen Robertson, DOE, (509) 373-6295 


\section{TECHNOLOGY NEEDS/OPPORTUNITIES \\ STATEMENT OUTLINE}

Identification No.: RL-SS11

Date: October 15, 1997

OPS Office/Site: DOE-RL/Hanford

Operable Unit: Selected soil sites in 100 Area

Waste Stream: Soil

Waste Management Unit: N/A

Facility: N/A

Site Priority Ranking: High

Need Title: Cost Effective, In Situ Remediation in the Vadose Zone of One or More of the Following Heavy Metals: Hexavalent Chromium, Mercury, and Lead

Need Description: Numerous contaminated soil sites exist at the Hanford Site as a result of liquid effluent discharge to the soil column. Cost effective in situ remediation technologies are required to deal with heavy metal contamination. In situ technologies that are more cost effective than the baseline excavation/disposal costs (\$105/cubic meter) are needed to treat the top 15 feet of soil. In situ treatment technologies may also be required if soil contamination extends beyond the 15 feet to depths were excavation costs become prohibitive. Primary metal contaminants of concem include hexavalent chromium, mercury, and lead.

Functional Performance Requirements: Reduce concentrations or mobilities of metal contaminants to the point that remediation goals are met. The following remediation goals can be found in the Remedial Design Report/Remedial Action Work Plan for the 100 Area (DOE/RL-96-17): $\mathrm{Cr}(\mathrm{VI}), 2.2 \mathrm{mg} / \mathrm{kg} ; \mathrm{Hg}, 24 \mathrm{mg} / \mathrm{kg}$; and $\mathrm{Pb}, 250 \mathrm{mg} / \mathrm{kg}$.

Schedule Requirements: Soil Remediation is ongoing. Goals established in the Hanford Ten Year Challenge would have all soil sites and burial grounds in the 100 Area completed by 2006 .

Technology Insertion Point: Consideration of new technology is ongoing. Mature technologies would support near term actions. Technology must be available to support completion of remedial actions in the 100 Area by 2006.

Prablem Description: The 100 Area has over 3.9 million cubic yards of soil and debris in 340 contaminated soil sites and 50 buried waste sites that will require remediation. Soil units include cribs, french drains, trenches, ponds, and retention basins that received radiologically and chemically contaminated liquid effluent from reactor and support operations. The 100 Area sites are located close to the Columbia River and therefore are also scheduled for completion prior to 2006. These areas will be cleaned up to meet residential land-use requirements. Soils with contamination in the top 15 feet that exceed established cleanup goals must be treated to reduce the risk potential from the direct exposure pathway. The baseline strategy for soil sites is to 
excavate the top 15 feet of contaminated soil and ship to on site disposal. If contamination extends beyond 15 feet, soil contaminant concentrations and/or mobilities must be low enough to prevent future groundwater problems. If concentrations exceed these levels, additional remedial measures (removal, containment or treatment) may be required. In situ technologies that are more cost effective than the baseline excavation/disposal costs ( $\$ 105 /$ cubic meter) are needed to treat the top 15 feet of soil. In situ treatment technologies may also be required if soil contamination extends beyond the 15 feet to depths were excavation costs become prohibitive. Chromium contamination in the $100-\mathrm{H}$ and $100-\mathrm{K}$ Areas is known to have reached groundwater and resulted in concentrations that require remedial measures. Although the vadose zone source of this contamination has not been positively identified, it is likely that chromium contamination extends deep into the vadose zone were excavation is not practical. Lead and mercury are other heavy metals of concern.

ADS/RDS/WBS No.: $\quad$ ADS: 3100

RDS: Found in Table 4-3. Risk Data Sheet Results of DOE/RL-96-09 Rev. 1.

WBS: 1.4.10.1.1.01.01

Justification For Need:

Technical - Demonstrate that a technology is implementable and effective at reducing contaminant concentrations and/or mobilities.

Regulatory - Soil concentrations currently exceed preliminary remediation goals as defined in various RODs.

Environmental Safety and Health - The contaminants pose a potential risk to human health and the environment. Remediation by conventional methods such as excavation and capping may result in exposure to workers. There is also the potential for offsite releases during soil handling operations.

Cost Savings Potential (Mortgage Reduction) - In situ treatments could (1) reduce excavation/disposal costs (especially for deeper soils), (2) allow less costly, hot spot treatment/capping alternatives and (3) prevent future groundwater contamination problems.

Cultural/Stakeholder Concerns - High exposures to remediation workers and potential for off-site releases are a concern. Stakeholders are sensitive to introduction of chemicals into the vadose zone to accomplish in situ remediation. Stakeholders are also concerned that in situ immobilization strategies that reduce human heath risk from groundwater pathways may not be fully protective for food chain pathways, particularly under acid conditions.

Other - None.

Consequences of Not Filling Need: Limited options for deeper soil contamination and treatment of hot spots. Also potential for groundwater contamination. 
Outsourcing Potential: Potentially high. These types of wastes are common at DOE, DoD, and industrial sites.

Current Baseline Technology: Excavate and dispose.

Cost: Estimated cost to excavate and dispose is $\$ 105 / \mathrm{Cubic}$ meter.

Waste: Excavated soil would be disposed on site.

How Long It Will Take: Soil remediation activities in the 100 Areas are planned for the next ten years.

End-User: Richland Environmental Restoration Project

Site Technical Point(s)-of-Contact: Kim Koegler, BHI, (509) 372-9294; Ashur R. Michael, BHI, (509) 372-9074; V. R. (Vern) Dronen, BHI, (509) 372-9096

DOE End-User/Representative Point(s)-of-Contact: Fred R. Serier DOE, (509) 372-8517; Owen Robertson, DOE, (509) 373-6295 


\section{TECHNOLOGY NEEDS/OPPORTUNITIES \\ STATEMENT OUTLINE}

Identification No.: RL-SS12

Date: October 15, 1997

OPS Office/Site: DOE-RL/Hanford

Operable Unit: All soil sites

Waste Stream: Soil

Waste Management Unit: N/A

Facility: N/A

Site Priority Ranking: High

Need Title: Cost Effective, In Situ Remediation in the Vadose Zone of One or More of the Following Radionuclides: Uranium, Plutonium, Cesium, Cobalt, or Strontium-90

Need Description: Numerous contaminated soil sites exist at the Hanford site as a result of liquid effluent discharge to the soil column. Cost effective in situ remediation technologies are required to deal with radioactive contamination. In situ technologies that are more cost effective than the baseline excavation/disposal costs ( $\$ 105 /$ cubic meter) are needed to treat the top 15 feet of soil. In situ treatment technologies may also be required if soil contamination extends beyond the 15 feet to depths were excavation costs become prohibitive. Primary radionuclides of concern include Uranium, Plutonium, Cesium, Cobalt, and Strontium-90.

Functional Performance Requirements: Reduce concentrations or mobilities of radioactive contaminants to the point that remediation goals are met. The following remediation goals can be found in the Remedial Design Report/Remedial Action Work Plan for the 100 Area (DOE/RL-96-17): U, 1 pCi/g; Pu, 34 pCi/g; Cs, $6.2 \mathrm{pCi} / \mathrm{g}$; Co, $1.4 \mathrm{pCi} / \mathrm{g}$; and $\mathrm{Sr}, 4.5 \mathrm{pCi} / \mathrm{g}$. The 200 Area sites do not currently have specific remediation goals, but goals are anticipated to be no more stringent than the ones presented for the 100 Area sites.

Schedule Requirements: Soil Remediation is ongoing. Goals established in the Hanford Ten Year Challenge would have all soil sites and burial grounds in the 100 Area and 300 Area completed by 2006. Characterization and remediation of the 200 Area sites will begin in FY99 and will extend several years past 2006.

Technology Insertion Point: Consideration of new technology is ongoing. Mature technologies would support near term actions but development of innovative technologies could support actions that extend several years past 2006 .

Problem Description: Fifty years of defense plutonium production at Hanford resulted in the creation of a large number of contaminated soil sites. The Hanford site is essentially divided into three areas: the 100 Area along the Columbia River where the plutonium production reactors were located, the 300 Area at the south end of the site where fuel fabrication facilities were 
located and the 200 Area located near the center of the site where the reactor-fuel processing and waste management facilities were located. The approximate total volumes of soil requiring remediation at the Hanford Site (liquid waste disposal sites and burial grounds) are: 3.9 million cubic yards in the 100 Areas, approximately 10 million cubic yards in the 200 Areas, and 0.8 million cubic yards in the 300 Area. Remediation schedules and requirements for these sites differ due to several factors including the types of contaminants present, the location of the area relative to the river, and the potential future land use for each area.

The 300 Area has several soil sites that resulted from liquid disposal in ponds and trenches. The 300 Area sites are located close to the Columbia River and therefore are scheduled for completion prior to 2006 . These areas will be cleaned up to meet industrial land-use requirements. Uranium is used as an indicator contaminant and soils with concentrations greater than 350 picocuries/gram in the top 15 feet are removed to reduce the risk potential from the direct exposure pathway. The baseline strategy for soil sites is to excavate the top 15 feet of contaminated soil and ship to on site disposal facilities. If contamination extends beyond 15 feet, soil contaminant concentrations and/or mobilities must be low enough to prevent future groundwater problems. If concentrations exceed these levels, additional remedial measures (removal, containment or treatment) may be required. In situ technologies that are more cost effective than the baseline excavation/disposal costs ( $\$ 105 /$ cubic meter) are needed to treat the top 15 feet of soil. In situ treatment technologies may also be required if soil contamination extends beyond the 15 feet to depths where excavation costs become prohibitive.

The 100 Area has over 340 contaminated soil sites that are expected to require remediation. Soil waste disposal units including cribs, french drains, trenches, ponds, and retention basins received radiologically and chemically contaminated liquid effluent from reactor and support operations. The 100 Area sites are located close to the Columbia River and therefore are also scheduled for completion prior to 2006. These areas will be cleaned up to meet residential land-use requirements. Soils with contamination in the top 15 feet that result in a dose of greater than 15 millirem must be treated to reduce the risk potential from the direct exposure pathway. Cobalt and Strontium-90 are the main radioactive contaminants of concern. The baseline strategy for soil sites is to excavate the top 15 feet of contaminated soil and ship to on site disposal facilities. If contamination extends beyond 15 feet, soil contaminant concentrations and/or mobilities must be low enough to prevent future groundwater problems. If concentrations exceed these levels, additional remedial measures (removal, containment or treatment) may be required. In situ technologies that are more cost effective than the baseline excavation/disposal costs $(\$ 105 /$ cubic meter) are needed to treat the top 15 feet of soil. In situ treatment technologies may also be required if soil contamination extends beyond the 15 feet to depths were excavation costs become prohibitive.

The 200 Area contains approximately 1000 different soil and burial ground sites. Soil waste sites were predominantly the result of liquid discharge to cribs, ponds and ditches. This area is located furthest from the Columbia River and is scheduled for remediation after the 300 and 100 Areas. This area will probably have an industrial future land use designation. The 200 Area remediation includes a combination of removal and leave in-place with in situ treatment and/or barrier placement strategies. The target/indicator contaminants will be developed for the 200 
Area as part of the characterization activities. Excavation strategies will generally be similar to the other areas but the depth and target/indicator contaminants have not been identified.

However, plutonium, uranium, cesium, cobalt, and strontium are all likely to be the key indicator. contaminants for many of the contaminated sites. In situ technologies that are more cost effective than the baseline excavation/disposal costs ( $\$ 105 /$ cubic meter) are needed to treat surface soils. Other potential concerns in the 200 Area include contamination (primarily uranium) that has been driven into low permeability layers deep ( $>150 \mathrm{ft}$ ) in the vadose zone, and near surface hot spots that prevent capping of some sites due to inadvertent intruder scenarios. In situ treatment technologies that can treat contamination at depth or treat hot spots to reduce health risks associated with intruder scenarios are required.

ADS/RDS/WBS No.: $\quad$ ADS: $3100,3200,3300$

RDS: Found in Table 4-3. Risk Data Sheet Results of DOE/RL-96-09 Rev. 1.

WBS: ADS: $3100=$ WBS 1.4.10.1.1.01.01

ADS: $3200=$ WBS 1.4.10.1.1.02.05

ADS: $3300=$ WBS 1.4.10.1.1.03.07

\section{Justification For Need:}

Technical - Demonstrate that a technology is implementable and effective at reducing contaminant concentrations and/or mobilities.

Regulatory - Soil concentrations currently exceed preliminary remediation goals as defined in various RODs.

Environmental Safety and Health - The contaminants pose a potential risk to human health and the environment. Remediation by conventional methods such as excavation and capping may result in exposure to workers. There is also the potential for offsite releases during soil handling operations.

Cost Savings Potential (Mortgage Reduction) - In situ treatments could (1) reduce excavation/disposal costs (especially for deeper soils), (2) allow less costly, hot spot treatment/capping alternatives and (3) prevent future groundwater contamination problems.

CulturalStakeholder Concerns: High exposures to remediation workers and potential for off-site releases are a concern. Stakeholders are sensitive to introduction of chemicals into the vadose zone to accomplish in situ remediation.

Other: None.

Consequences of Not Filling Need: Limited options for deeper soil contamination and treatment of hot spots. Also potential for groundwater contamination.

Outsourcing Potential: Potentially high. These types of wastes typically occur at DOE sites. 
Current Baseline Technology: Excavate and dispose.

Cost: Estimated cost to excavate and dispose is $\$ 105 /$ Cubic meter.

Waste: Excavated soil would be disposed in on site disposal facilities.

How Long It Will Take: Soil remediation activities in the 100 and 300 Areas are planned for the next ten years. Soil activities in the 200 Area are likely to extend well beyond the ten year time period.

End-User: Richland Environmental Restoration Project

Site Technical Point(s)-of-Contact: Kim Koegler, BHI, (509) 372-9294; Ashur R. Michael, BHI, (509) 372-9074; V. R. (Vern) Dronen, BHI, (509) 372-9096

DOE End-User/Representative Point(s)-of-Contact: Fred R. Serier DOE, (509) 372-8517; Owen Robertson, DOE, (509) 373-6295 


\section{TECHNOLOGY NEEDS/OPPORTUNITIES \\ STATEMENT OUTLINE}

Identification No: $: \mathrm{RL}-\mathrm{SS} 13$

Date: October 15, 1997

OPS Office/Site: DOE-RL/Hanford

Operable Unit: Selected soil sites in the 100 Area

Waste Stream: Soil

Waste Management Unit: N/A

Facility: N/A

Site Priority Ranking: High

Need Title: Improved, Real-Time Field Screening During Excavation for One or More of the Following Heavy Metals: Hexavalent Chromium, Mercury and Lead

Need Description: Rapid, field screening techniques are needed to direct excavation operations and to assure that excavated materials meet waste acceptance criteria prior to disposal. Primary metal contaminants of concern include hexavalent chromium, mercury, and lead.

Functional Performance Requirements: Detection technologies must be portable, easy to use, produce little or no secondary waste and provide real-time field screening. Detection levels must be comparable to cleanup requirements. The following remediation goals can be found in the Remedial Design Report/Remedial Action Work Plan for the 100 Area (DOE/RL-96-17): $\mathrm{Cr}(\mathrm{VI}), 2.2 \mathrm{mg} / \mathrm{kg} ; \mathrm{Hg}, 24 \mathrm{mg} / \mathrm{kg}$; and Pb, $250 \mathrm{mg} / \mathrm{kg}$. Detection to lower levels that would allow for real time Land Disposal Restricted (LDR) determinations (e.g., 20 times Toxic Characteristic Leaching Procedure (TCLP) limits) would also be useful for these metal contaminants.

Schedule Requirements: Soil Remediation is ongoing. Goals established in the Hanford Ten Year Challenge would have all soil sites and burial grounds in the 100 Area completed by 2006 .

Technology Insertion Point: Consideration of new technology is ongoing. Mature technologies would support near term actions. Technology must be available to support completion of remedial actions in the 100 Area by 2006 .

Problem Description: The 100 Area has over 3.9 million cubic yards of soil and debris in 340 contaminated soil sites and 50 buried waste sites that will require remediation. Soil units include cribs, french drains, trenches, ponds, and retention basins that received radiologically and chemically contaminated liquid effluent from reactor and support operations. The effluent to many of these sites contained sodium dichromate, lead, and mercury. The boundaries for some of these liquid waste disposal sites are poorly defined. Also, other sites may have significantly different contaminant concentrations throughout the site. The baseline strategy for soil sites is to excavate the top 15 feet of contaminated soil and ship to on site disposal. Rapid field screening 
techniques are required to help direct excavation operations so that all soils contaminated above required levels can be removed.

ADS/RDS/WBS No.: $\quad$ ADS: 3100

RDS: Found in Table 4-3. Risk Data Sheet Results of DOE/RL-96-09 Rev. 1.

WBS: 1.4 .10 .1 .1 .01 .01

\section{Justification For Need:}

Technical - Current technology (XRF technology) can measure high end concentrations but new technology is needed to accurately measure the low end concentrations.

Regulatory - None.

Environmental Safety and Health - Rapid screening techniques will reduce worker exposure times and help assure that all soil contaminated above regulatory limits is removed.

Cost Savings Potential (Mortgage Reduction) - Rapid field screening techniques would improve excavation efficiency and reduce costs. Accurate field screening may also reduce the amount of soil that must be removed to assure that all contaminated soils are excavated thereby reducing disposal volumes and costs.

Cultural/Stakeholder Concerns - None.

Other - None.

Consequences of Not Filling Need: Continued reliance on XRF technology for screening and discrete sampling.

Outsourcing Potential: Good potential, common industry and government contaminants.

Current Baseline Technology: XRF and discrete sampling.

Cost: Cost of equipment and analyses are minimal but hidden costs related to reduced excavation efficiency could be substantial.

Cost per unit: Not determined.

Waste: Laboratory waste generated from discrete sampling.

How Long It Will Take: Soil remediation activities in the 100 Areas are planned for the next ten years.

End-User: Richland Environmental Restoration Project 
Site Technical Point(s)-of-Contact: Kim Koegler, BHI, (509) 372-9294; Ashur R. Michael, BHI, (509) 372-9074; V. R. (Vern) Dronen, BHI, (509) 372-9096

DOE End-User/Representative Point(s)-of-Contact: Fred R. Serier DOE, (509) 372-8517; Owen Robertson, DOE, (509) 373-6295 


\section{TECHNOLOGY NEEDS/OPPORTUNITIES \\ STATEMENT OUTLINE}

Identification No.: RL-SS14

Date: October 15, 1997

OPS Office/Site: DOE-RL/Hanford

Operable Unit: All soil sites

Waste Stream: Soil

Waste Management Unit: N/A

Facility: N/A

Site Priority Ranking: High

Need Title:

Improved, Real-Time Field Screening During Excavation for One or More of the Following Radionuclides: Uranium, Plutonium, Cesium, Cobalt , or Strontium-90

Need Description: Rapid, field screening techniques are needed to direct characterization, delineation, and excavation operations. Field screening techniques for characterization and delineation will assure that high cost, site characterization laboratory analyses are optimized. These techniques will also help assure that operations at excavation sites remove all contaminated material and that excavated materials meet waste acceptance criteria prior to disposal. Primary radioactive contaminants of concern include Uranium, Plutonium, Cesium, Cobalt , and Strontium-90.

Functional Performance Requirements: Detection technologies must be portable, easy to use, produce little or no secondary waste and provide real-time field screening. Detection levels must be comparable to cleanup requirements or levels at which remediation alternative decisions can be made. If possible, the technique should support the eventual elimination of the requirement for sample collection and analysis. The following remediation goals can be found in the Remedial Design Report/Remedial Action Work Plan for the 100 Area (DOE/RL-96-17): U, 1 $\mathrm{pCi} / \mathrm{g}$; Pu, $34 \mathrm{pCi} / \mathrm{g}$; Cs, $6.2 \mathrm{pCi} / \mathrm{g} ; \mathrm{Co}, 1.4 \mathrm{pCi} / \mathrm{g}$; and Sr, $4.5 \mathrm{pCi} / \mathrm{g}$. The 200 Area sites do not currently have specific remediation goals, but goals are anticipated to be no more stringent than the ones presented for the 100 Area sites.

Schedule Requirements: Soil Remediation is ongoing. Goals established in the Hanford Ten Year Challenge would have all soil sites and burial grounds in the 100 Area and 300 Area completed by 2006 . Characterization and remediation of the 200 Area sites will begin in FY99 and will extend several years past 2006.

Technology Insertion Point: Consideration of new technology is ongoing. Mature technologies would support near term actions but development of innovative technologies could support actions that extend several years past 2006. 
Problem Description: The approximate total volumes of soil requiring remediation at the Hanford Site (liquid waste disposal sites and burial grounds) are: 3.9 million cubic yards in the 100 Areas, approximately 10 million cubic yards in the 200 Areas, and 0.8 million cubic yards in the 300 Area. The 100 Area has over 340 contaminated soil sites that are expected to require remediation. Soil units include cribs, french drains, trenches, ponds, and retention basins that received radiologically and chemically contaminated liquid effluent from reactor and support operations. Cobalt and Strontium- 90 are the main radioactive contaminants of concern. The 300 Area has several soil sites that resulted from liquid disposal in ponds and trenches. Uranium is used as an indicator contaminant and soils with concentrations greater than 350 picocuries/gram in the top 15 feet are removed. The 200 Area contains approximately 1000 different soil and burial ground sites. Soil waste sites are predominantly the result of liquid discharges to cribs, ponds and ditches. The 200 Area remediation include a combination of removal and leave inplace with in situ treatment and/or barrier placement strategies. The target/indicator contaminants will be developed for the 200 Area as part of the characterization activities. However, plutonium, uranium, cesium, cobalt, and strontium are likely to be the key indicator contaminants for many of the contaminated sites.

The boundaries for some of these liquid waste disposal sites are poorly defined. Also, other sites may have significantly different contaminant concentrations throughout the site. The baseline strategy for soil sites in the 100 and 300 Areas is to excavate the top 15 feet of contaminated soil and dispose on site. A portion of the 200 area sites are also anticipated to be excavated and disposed on site. Rapid field screening techniques are required to help direct excavation operations so that all soils contaminated above required levels can be removed. Field screening techniques that support characterization and delineation will also assure that high cost, site characterization laboratory analyses are optimized.

ADS/RDS/WBS No.:' ADS: $3100,3200,3300$

RDS: Found in Table 4-3. Risk Data Sheet Results of DOE/RL-96-09 Rev. 1.

WBS: ADS: $3100=$ WBS 1.4.10.1.1.01.01

ADS: $3200=$ WBS 1.4.10.1.1.02.05

ADS: $3300=$ WBS 1.4.10.1.1.03.07

\section{Justification For Need:}

Technical - Current technology can measure high end concentrations of gamma emitters but new technology is needed to accurately measure the low end concentrations of alpha and beta emitters.

Regulatory - None.

Environmental Safety and Health - Rapid screening techniques will reduce worker exposure times and help assure that all soil contaminated above regulatory limits is removed and all contaminated sites are located. 
Cost Savings Potential (Mortgage Reduction) - Rapid field screening techniques would improve excavation efficiency and reduce costs. Accurate field screening may also reduce the amount of soil that must be removed to assure that all contaminated soils are excavated thereby reducing disposal volumes and costs. Substantial cost savings could result if site characterization activities are optimized to reduce the number of full suite laboratory analyses required to fully characterize soil sites.

CulturalStakeholder Concerns - None.

Other - None.

Consequences of Not Filling Need: Continued reliance on gamma detectors and discrete sampling.

Outsourcing Potential: Good potential, common DOE contaminants.

Current Baseline Technology: Gamma detectors and discrete sampling.

Cost: Cost of equipment and analyses to support excavation are minimal but hidden costs related to reduced excavation efficiency could be substantial. Baseline characterization activities in the 200 Areas are estimated to be $\$ 70 \mathrm{M}$.

Cost per unit: Not determined.

Waste: Laboratory waste generated from discrete sampling.

How Long It Will Take: Soil remediation activities in the 100 and 300 Areas are planned for the next ten years. Soil activities in the 200 Area are likely to extend well beyond the ten year time period.

End-User: Richland Environmental Restoration Project

Site Technical Point(s)-of-Contact: Kim Koegler, BHI, (509) 372-9294; Ashur R. Michael, BHI, (509) 372-9074; V. R. (Vern) Dronen, BHI, (509) 372-9096

DOE End-User/Representative Point(s)-of-Contact: Fred R. Serier DOE, (509) 372-8517;

Owen Robertson, DOE, (509) 373-6295 


\section{TECHNOLOGY NEEDS/OPPORTUNITIES STATEMENT OUTLINE}

Identification No.: RJ-SS15

Date: October 15, 1997

OPS Office/Site: DOE-RL/Hanford

Operable Unit(s): 100, 200, and 300 Areas

Waste Stream: Soil

Waste Management Unit: N/A

Facility: N/A

Site Priority Ranking: High

\section{Need Title:}

Improved, In Situ Characterization to Determine the Extent of Soil Contamination of One or More of the Following Heavy Metals: Hexavalent Chromium, Mercury, and Lead

Need Description: The extent of contamination in soil and burial ground sites is often poorly defined. A cost effective technology that provides real-time, in situ measurement of heavy metals (hexavalent chromium, mercury, and lead) at depth is required.

Functional Performance Requirements: The cost effective technology needs to provide realtime, in situ measurement of heavy metals with field deployable instruments. Data must be easily downloaded into computer systems for analysis and retrieval. Detection limits down to required remediation levels would be preferable but higher detection level instruments that could be deployed economically at depth are also of interest. The following remediation goals can be found in the Remedial Design Report/Remedial Action Work Plan for the 100 Area (DOE/RL-96-17): $\mathrm{Cr}(\mathrm{VI}), 2.2 \mathrm{mg} / \mathrm{kg} ; \mathrm{Hg}, 24 \mathrm{mg} / \mathrm{kg}$; and $\mathrm{Pb}, 250 \mathrm{mg} / \mathrm{kg}$. Analyses down to $200+$ feet would be useful in some areas, but deployment to depths of greater than $15 \mathrm{ft}$ is required. If possible, the technique should support the eventual elimination of the requirement for sample collection and analysis.

Schedule Requirements: Soil Remediation is ongoing. Goals established in the Hanford Ten Year Challenge would have all soil sites and burial grounds in the 100 . Area completed by 2006 .

Technology Insertion Point: Consideration of new technology is ongoing. Mature technologies would support near term actions. Technology must be available to support completion of remedial actions in the 100 Area by 2006 .

Problem Description: The 100 Area has over 3.9 million cubic yards of soil and debris in 340 contaminated soil sites and 50 buried waste sites that will require remediation. The baseline strategy for soil sites is to excavate the top 15 feet of contaminated soil and ship to on site disposal. If contamination extends beyond 15 feet, soil contaminant concentrations and/or mobilities must be low enough to prevent future groundwater problems. If concentrations exceed 
these levels, additional remedial measures (removal, containment or treatment) may be required. In situ detection techniques would help make this determination prior to excavation. In situ characterization technologies may also help support decisions to leave some burial grounds and portions of select soils sites in place.

A specific near term need for in situ chromium detection exists in the $100-\mathrm{H}$ and $100-\mathrm{K}$ Areas. Chromium is known to have reached groundwater and resulted in concentrations that require remedial measures but the vadose zone source of this contamination has not been positively identified. Identification and treatment of this contaminant source is an important part of meeting and maintaining groundwater cleanup objectives. Lead and mercury are other potential contaminants of concern.

\section{ADS/RDS/WBS No.: $\quad$ ADS: 3100}

RDS: Found in Table 4-3. Risk Data Sheet Results of DOE/RL-96-09 Rev. 1.

WBS: 1.4.10.1.1.01.01

\section{Justification For Need:}

Technical - Highly accurate and easily operated instrumentation to measure the concentrations of heavy metals will facilitate accurate soil remediation planning and will reduce exposure to workers involved in characterization work.

Regulatory - There is no regulatory requirement for soils remediation at this time.

Environmental Safety and Health - There are no specific environmental safety and health issues with respect to this technology need.

Cost Savings Potential (Mortgage Reduction) - Substantial cost savings could result if select burial grounds and portions of soil sites could be treated in place instead of excavated and disposed.

\section{CulturalStakeholder Concerns - None}

Other - None

Consequences of Not Filling Need: Continued use of current methods which includes costly boring, labor intensive sampling, and laboratory analysis.

Outsourcing Potential: Potentially high.

Current Baseline Technology: Borehole, cone penetrometer, cased wells, and test pits are used to gain access to the subsurface. Depending on the contaminant of concern, soil samples from the drill cuttings may be subjected to laboratory analysis.

Cost: Varied. 
Waste: Drill cuttings and laboratory wastes.

How Long It Will Take: Soil remediation activities in the 100 Areas are planned for the next ten years.

End-User: Richland Environmental Restoration Project

Site Technical Point(s)-of-Contact: Kim Koegler, BHI, (509) 372-9294; Ashur R. Michael, BHI, (509) 372-9074; V. R. (Vern) Dronen, BHI, (509) 372-9096

DOE End-User/Representative Point(s)-of-Contact: Fred R. Serier DOE, (509) 372-8517; Owen Robertson, DOE, (509) 373-6295 


\section{TECHNOLOGY NEEDS/OPPORTUNITIES \\ STATEMENT OUTLINE}

Identification No.: RL-SS16

Date: October 15, 1997

oPS Office/Site: DOE-RL/Hanford

Operable Unit(s): All soil sites

Waste Stream: Soil

Waste Management Unit: N/A

Facility: N/A

Site Priority Ranking: High

\section{Need Title:}

Improved, In Situ Characterization to Determine the Extent of Soil Contamination of One or More of the Following Radionuclides: Uranium, Plutonium, Cesium, Cobalt, or Strontium-90

Need Description: The extent of contamination in soil and burial ground sites is often poorly defined. A cost effective technology that provides real-time, in situ measurement of radioactive contaminants (uraniurn, plutonium, cesium, cobalt, and strontium-90) in soils at depth is required.

Functional Performance Requirements: The cost effective technology needs to provide realtime, in situ measurement of radioactive contaminants with field deployable instruments. Data must be easily downloaded into computer systems for analysis and retrieval. Detection limits down to required remediation levels or levels at which remediation alternative decisions can be made would be preferable, but higher detection level instruments that could be deployed economically at depth are also of interest. If possible, the technique should support the eventual elimination of the requirement for sample collection and analysis. The following remediation goals can be found in the Remedial Design Report/Remedial Action Work Plan for the 100 Area (DOE/RL-96-17): U, $1 \mathrm{pCi} / \mathrm{g} ; \mathrm{Pu}, 34 \mathrm{pCi} / \mathrm{g} ; \mathrm{Cs}, 6.2 \mathrm{pCi} / \mathrm{g} ; \mathrm{Co}, 1.4 \mathrm{pCi} / \mathrm{g}$; and $\mathrm{Sr}, 4.5 \mathrm{pCi} / \mathrm{g}$. Analyses down to $200+$ feet would be useful in some areas but deployment to depths of greater than $15 \mathrm{ft}$ would help supply missing information. The 200 Area sites do not currently have specific remediation goals, but goals are anticipated to be no more stringent than the ones presented for the 100 Área sites.

Schedule Requirements: Soil Remediation is ongoing and 200 Area site characterization activities are planned for FY99. Goals established in the Hanford Ten Year Challenge would have all soil sites and burial grounds in the 100 Area and 300 Area completed by 2006 . Characterization and remediation of the 200 Area sites will begin in FY99 and will extend several years past 2006 .

Technology Insertion Point: Consideration of new technology is ongoing. Mature technologies would support near term actions but development of innovative technologies could support 
actions that extend several years past 2006 .

Problem Description: The approximate total volumes of soil requiring remediation at the Hanford Site (liquid waste disposal sites and burial grounds) are: 3.9 million cubic yards in the 100 Areas, approximately 10 million cubic yards in the 200 Areas, and 0.8 million cubic yards in the 300 Area. The 100 Area has over 340 contaminated soil sites that are expected to require remediation. Soil units include cribs, french drains, trenches, ponds, and retention basins that received radiologically and chemically contaminated liquid effluent from reactor and support operations. Cobalt and Strontium-90 are the main radioactive contaminants of concern. The 300 Area has several soil sites that resulted from liquid disposal in ponds and trenches. Uranium is used as an indicator contaminant and soils with concentrations greater than 350 picocuries/gram in the top 15 feet are removed. The 200 Area contains approximately 1000 different soil and burial ground sites. Soil waste sites are predominantly the result of liquid discharges to cribs, ponds and ditches. The 200 Area remediation includes a combination of removal and leave inplace with in situ treatment and/or barrier placement strategies. The target/indicator contaminants will be developed for the 200 Area as part of the characterization activities. However, plutonium, uranium, cesium, cobalt, and strontium are likely to be the key indicator contaminants for many of the contaminated sites.

The boundaries for some of these liquid waste disposal sites are poorly defined. Also, other sites may have significantly different contaminant concentrations throughout the site. The baseline strategy for soil sites in the 100 and 300 Areas is to excavate the top 15 feet of contaminated soil and dispose on site. A portion of the 200 area sites are also anticipated to be excavated and disposed on site. If contamination extends beyond 15 feet, soil contaminant concentrations and/or mobilities must be low enough to prevent future groundwater problems. If concentrations exceed these levels, additional remedial measures (removal, containment or treatment) may be required. In situ detection techniques would help make this determination prior to excavation. In situ characterization technologies may also help support cost effective means of making remedial alternative decisions including whether burial grounds and portions of soil sites can be left in place.

ADS/RDS/WBS No.: $\quad$ ADS: $3100,3200,3300$

RDS: Found in Table 4-3. Risk Data Sheet Results of DOE/RL-96-09 Rev. 1.

WBS: ADS: $3100=$ WBS 1.4.10.1.1.01.01

ADS: $3200=$ WBS $1.4 \cdot 10.1 \cdot 1 \cdot 02.05$

ADS: $3300=$ WBS 1.4.10.1.1.03.07

\section{Justification For Need:}

Technical - Highly accurate and easily operated instrumentation to measure the concentrations of radioactive contaminants in situ will facilitate accurate remedial alternative decision making and soil remediation planning. In situ techniques will also reduce exposure to workers involved in characterization work.

Regulatory - There is no regulatory requirement for soils remediation at this time. 
Environmental Safety and Health - There are no specific environmental safety and health issues with respect to this technology need.

Cost Savings Potential (Mortgage Reduction) - Substantial cost savings could result if select burial grounds and portions of soil sites could be treated in place instead of excavated and disposed. Substantial cost savings could result if site characterization activities can be performed without the need to conduct full suite laboratory analyses on soil samples.

Cultural/Stakeholder Concerns - None

Other - None

Consequences of Not Filling Need: Continued use of current methods which includes costly boring, labor intensive sampling, and laboratory analysis.

Outsourcing Potential: Potentially high.

Current Baseline Technology: Borehole, cone penetrometer, cased wells and test pits, are used to gain access to the subsurface. A sensitive hyper-pure germanium gamma detector adapted for bore hole use gathers radiation spectrums as it is lowered through a casing. Depending on the contaminant of concern, soil samples from the drill cuttings may be subjected to laboratory analysis.

Cost: Varied. Baseline characterization activities in the 200 Areas are estimated to be $\$ 70 \mathrm{M}$.

Waste: Drill cuttings and laboratory wastes.

How Long It Will Take: The remediation effort is ongoing and will last for at least the next 20 years.

End-User: Richland Environmental Restoration Project

Site Technical Point(s)-of-Contact: Kim Koegler, BHI, (509) 372-9294; Ashur R. Michael, BHI, (509) 372-9074; V. R. (Vern) Dronen, BHI, (509) 372-9096

DOE End-User/Representative Point(s)-of-Contact: Fred R. Serier DOE, (509) 372-8517;

Owen Robertson, DOE, (509) 373-6295 


\section{TECHNOLOGY NEEDS/OPPORTUNITIES \\ STATEMENT OUTLINE}

Identification No.: RL-SS17

Date: October 15, 1997

OPS Office/Site: DOE-RL/Hanford

Operable Unit(s): 200 Area Remedial Action and Waste Management Units and Burial Grounds in 100 and 300 Areas

Waste Stream: Soil

Waste Management Unit: N/A

Facility: N/A

Site Priority Ranking: High

Need Title:

Long-Life Waste Isolation Surface Barrier

Need Description: Surface barriers are remediation options for Hanford waste sites contaminated with low-level radionuclides and chemical contaminants below hazardous/dangerous waste levels. In some cases, the radioactive contaminants have half-lives of thousands of years. Concern exists regarding the integrity of barrier designs and the definition of adequate testing to verify barrier performance. This technology need relates to the generation and subsequent regulatory acceptance of adequate design, selection, validation, and monitoring results. Acceptance of these results will allow an environmentally sound, cost-effective, graded design approach for barrier implementation at the Hanford site.

Functional Performance Requirements: Major regulatory drivers for cover design are 10 CFR 61 (NRC), 40 CFR 264 and 265 (RCRA), and 40 CFR 191 (EPA). Performance criteria for barrier designs depend on waste categories. DOE/RL has identified four conceptual design options for various waste compositions and radioactive activities (DOE/RL-93-33, Rev. 0). The most robust barrier design presently identified is the "Hanford Barrier" with a design life of 1,000 years, water infiltration limits to less than $0.05 \mathrm{~cm} / \mathrm{yr}$ and erosion limits of less than 4,500 $\mathrm{kg} / \mathrm{ha}$ ( 2 tons/acre).

Schedule Requirements: Variable. The viability of barrier technology affects decisions for burial grounds in the 100 and 300 Areas and burial ground and liquid waste disposal sites in the 200 Area. The first burial ground (located in the $300 \mathrm{Area}$ ) is scheduled for excavation in early FY98. Goals established in the Hanford Ten Year Challenge would have all burial grounds in the 100 Area and 300 Area completed by 2006 . The acceptance of barriers as a remedial alternative is needed to support decisions to utilize barriers for selected burial grounds in the 100/300 Areas and selected burial ground and liquid waste disposal sites in the 200 Area. 200 Area remedial alternative decision making will require barrier performance data in the FY98 FY00 time frame. 
Technology Insertion Point: Acceptable barrier designs need to be available by FY00 to support 100 and 300 Area schedules. Performance data are required in the FY98 - FY00 time frame to support 200 area remedial alternative decision making.

Problem Description: Fifty years of defense plutonium production resulted in the creation of a large number of solid waste burial ground sites in Hanford's 100, 200, and 300 Areas. The 100 Areas are located along the Columbia River and include nine nuclear reactors previously used for plutonium production. The 300 Area is also located along the Columbia River and contains the fuel fabrication facilities. The 200 Area is located on the central plateau and contains the spent fuel extraction and processing facilities and the radioactive waste storage tanks. Hanford's burial grounds contain a variety of solid waste debris, including construction waste, discarded equipment, and protective clothing. Much of this waste is contaminated with low-level radioactive materials. The baseline for the 100 and 300 area sites is excavation and disposal in on site facilities. However, acceptable long-life surface barriers would help support decisions to cap some burial grounds in place. Capping selected 100 and 300 area burial grounds in place could result in a cost savings of over $\$ 500 \mathrm{M}$.

The 200 Area remediation includes a combination of removal and leave in-place with in situ treatment and/or barrier placement strategies. Sites within areas that will be used for waste management and other industrial uses or sites where capping provides better, more cost effective protection of human health and the environment are the main candidates for surface barriers. Failure to establish an acceptable long-life surface barrier could result in excavation requirements that would be cost prohibitive.

In FY97, Bechtel Hanford Inc. and Pacific Northwest National Laboratory completed three-years worth of field performance testing and monitoring for the Hanford Prototype Barrier as part of a treatability test. The purpose of this treatability test was to demonstrate the effectiveness of construction techniques and barrier performance. Data from this test could also be used to demonstrate acceptability of less robust barriers for use at the Hanford Site. Data collected during this three year period showed that the barrier worked as designed but an acceptable methodology for extrapolating short term data into long term performance is still required.

The areas that are currently planned to be completed within the ER Project during FY98-FY00 to finalize the treatability test report are:

(1) Confirming the longevity of the asphalt layer through literature searches or by conducting accelerated aging tests and stress/strain analysis of asphaltic or asphaltic concrete mixtures to assure that this component will not degrade during its proposed design life;

(2) Evaluating the differential settlement of soils beneath the surface barrier and the impacts of this differential settlement on barrier integrity are required to establish maximum allowable settlement criteria;

(3) Performing and documenting in the treatability test report an independent technical peer review of the results obtained throughout the treatability test.

As barrier deployment enters the detailed design phase, considerations relating to performance of 
adjacent barriers (and interconnected barriers), side-slope stability, and waste site identification/warning systems will need to be addressed.

Areas that are presently unfunded that require further study (FY98-FY00 preferably) prior to deployment of barriers at waste sites include:

(1) Development of a model for extrapolating short-term data to address long-term performance that is acceptable to the DOE and regulators;

(2) Evaluation of alternate materials and reduced thicknesses including altematives to fluid applied asphalt and the use of geoclay to allow a graded approach to barrier application;

(3) Side slopes that use large rocks for slope stability might increase infiltration in those areas.

This issue needs to be analyzed to determine if this is a significant issue that requires design changes;

(4) Evaluation of long term monitoring techniques, including a long term, easy to use, soil moisture measurement device to monitor the cap performance. These techniques would ideally be non-intrusive with minimal potential for creating a preferential pathway circumventing the barrier integrity.

ADS/RDS/WBS No.: $\quad$ ADS: $3100,3200,3300$

RDS: Found in Table 4-3. Risk Data Sheet Results of DOE/RL-96-09 Rev. 1.

WBS: ADS: $3100=$ WBS 1.4.10.1.1.01.01

ADS: $3200=$ WBS 1.4.10.1.1.02.05

ADS: $3300=$ WBS 1.4.10.1.1.03.07

\section{Justification For Need:}

Technical - Installation of long-term barrier options with design lives of hundreds or more years requires very high quality testing to confidently predict design performance.

Regulatory - CERCLA, RCRA, MTCA requirements for environmental remediation. DOE Order 5820.2A for tank waste performance assessment.

Environmental Safety and Health - A properly installed barrier will significantly reduce risk to human health and the environment at uncontrolled surface waste sites.

Cost Savings Potential (Mortgage Reduction) - Information from the 10-year plan indicates a potential saving of $\$ 500 \mathrm{M}$ based on successful deployment of a Long-Life Waste Isolation Surface Barrier technology that enables in place remediation of selected landfills and buried waste sites in the 100 and 300 Areas instead of the baseline of excavation and disposal in on site facilities. Barriers are a significant part of the baseline strategy for many sites in the 200 area. 
Cultural/Stakeholder Concerns - Hanford stakeholders have expressed the desire for highly predictive performance testing of barrier designs prior to selection of barriers as remediation options at waste sites.

Other - This need is DOE complex wide for remedial action and waste management units. This need is also applicable to other US government agencies, as well as private environmental restoration activities.

Consequences of Not Filling Need: Reliance on existing testing programs to assess barrier performance. Potential for capping options to be rejected, thus requiring more expensive remediation methods.

Outsourcing Potential: Potentially high.

Current Baseline Technology: Excavate and dispose.

Cost: Budget forecast for 300 Area burial ground activities is: FY98, $\$ 3.2 \mathrm{M} ; \mathrm{FY} 99, \$ 3.1 \mathrm{M}$. Estimates to complete excavation and disposal of all the burial grounds in the 100 and 300 Areas is nearly $\$ 700 \mathrm{M}$.

Waste: None

How Long It Will Take: Burial ground remediation activities in the 100 and 300 Areas are planned for next ten years. Burial ground remediation activities in the 200 Area are likely to extend well beyond the ten year time period.

End-User: Richland Environmental Restoration Project

Site Technical Point(s)-of-Contact: Kim Koegler, BHI, (509) 372-9294; Greg B. Mitchem (509) 372-9632; Ashur R. Michael, BHI, (509) 372-9074; V. R. (Vern) Dronen, BHI, (509) $372-9096$

DOE End-User/Representative Point(s)-of-Contact: Fred R. Serier DOE, (509) 372-8517; Bryan L. Foley, DOE, (509) 376-7087; Owen Robertson, DOE, (509) 373-6295 


\section{TECHNOLOGY NEEDS/OPPORTUNITIES \\ STATEMENT OUTLINE}

Identification No.: RL-SS18

Date: October 15, 1997

OPS Office/Site: DOE-RL/Hanford

Operable Unit: Selected burial ground sites in the 200 and 300 Areas

Waste Stream: Soil

Waste Management Unit: N/A

Facility: N/A

Site Priority Ranking: High

\section{Need Title:}

Improved Detection and Segregation of TRU Waste (Debris)

Need Description: Burial grounds in the 200 and 300 Areas received waste contaminated with plutonium and other TRU constituents. Many of these burial grounds will be excavated and disposed on site but waste with more than $100 \mathrm{nCi}$ of TRU contamination per gram of waste does not meet current waste acceptance criteria. Improved methods for detecting and segregating TRU waste are required.

Functional Performance Requirements: Technologies must be able to rapidly detect and segregate TRU contarninants at concentrations greater than $100 \mathrm{nCi}$ per gram of waste on a variety of different waste geometries.

Schedule Requirements: Variable. Goals established in the Hanford Ten Year Challenge would have all burial grounds in the 300 Area completed by 2006. Strategies for remediation of the 200 Area burial ground sites are being revised but are scheduled to begin in 2003 and will extend several years past 2006 .

Technology Insertion Point: Consideration of new technology is ongoing. Mature technologies would support near term actions in the 300 Area but development of innovative technologies could support actions that extend several years past 2006.

Problem Description: Fifty years of defense plutonium production resulted in the creation of a large number of solid waste burial ground sites in Hanford's 100, 200, and 300 Areas. The 100 Areas are located along the Columbia River and include nine nuclear reactors previously used for plutonium production. No TRU materials are known to have been disposed in the 100 Area burial grounds. The 300 Area is also located along the Columbia River and contains the fuel fabrication facilities. The 200 Area is located on the central plateau and contains the spent fuel extraction and processing facilities and the radioactive waste storage tanks. Selected burial grounds in both the 200 and 300 Areas have received waste contaminated with plutonium and other TRU constituents. The baseline for the 300 area burial ground sites is excavation and 
disposal on site. Strategies for remediation of the 200 Area burial ground sites are being revised. Hanford's burial grounds contain a variety of solid waste debris that may require size reduction and/or further characterization to confirm that the item should not be classified as TRU waste prior to disposal. Plans are to use conventional excavation equipment and grizzlies to remove and separate the debris. The separated material will then be staged until determination of the TRU contaminant concentrations is complete. There are concerns that these operations will reduce excavation efficiencies and increase costs.

ADS/RDS/WBS No.: $\quad$ ADS: 3200,3300

RDS: Found in Table 4-3. Risk Data Sheet Results of DOE/RL-96-09 Rev. 1.

WBS: ADS: $3200=$ WBS 1.4.10.1.1.02.05

ADS: $3300=$ WBS 1.4.10.1.1.03.07

\section{Justification For Need:}

Technical - Rapid field methods for detection and segregation of TRU materials are not available.

Regulatory - TRU waste does not meet the current waste acceptance criteria and must be stored in approved facilities until a permanent TRU disposal site (i.e., WIPP) become available.

Environmental Safety and Health - Improved handling of waste debris may reduce the potential for worker exposures and contaminant releases.

Cost Savings Potential (Mortgage Reduction): Potential savings depend on excavation inefficiencies introduced by baseline handling strategy.

CulturaLStakeholder Concerns - No stakeholder concerns are likely.

Other - None.

Consequences of Not Filling Need: Continued use of baseline handling strategy for suspected TRU waste.

Outsourcing Potential: Possible high potential in Department of Energy, Department of Defense, and private applications.

Current Baseline Technology: Conventional excavation equipment for removal with grizzlies for separation.

Cost: Estimates to complete excavation and disposal of 300 Area burial grounds that contain TRU waste is nearly $\$ 100 \mathrm{M}$. Occurrence of inefficiencies during the excavation process could have substantial cost impacts. 
Waste: None

How Long It Will Take: Burial ground remediation activities in the 300 Area are planned for next ten years. Burial ground remediation activities in the 200 Area are likely to extend well beyond the ten year time period.

End-User: Richland Environmental Restoration Project

Site Technical Point(s)-of-Contact: Kim Koegler, BHI, (509) 372-9294; Ashur R. Michael, BHI, (509) 372-9074; V. R. (Vern) Dronen, BHI, (509) 372-9096

DOE End-User/Representative Point(s)-of-Contact: Fred R. Serier DOE, (509) 372-8517; Owen Robertson, DOE, (509) 373-6295 


\section{TECHNOLOGY NEEDS/OPPORTUNITIES STATEMENT OUTLINE}

Identification No.: RL-SS19

Date: October 15, 1997

OPS Office/Site: DOE-RL/Hanford

Operable Unit: Selected burial grounds in the 300 Area

Waste Stream: Soil

Waste Management Unit: N/A

Facility: N/A

Site Priority Ranking: High

Need Title: Detection and Handling of Pyrophoric Materials in Burial Grounds

Need Description: Several different pyrophoric materials were used in 300 Area production processes. Some or all of these materials may have been placed in 300 Area burial grounds. Improved methods for detecting and handling suspect pyrophoric materials during excavation operations are required.

Functional Performance Requirements: Technology must improve detection and/or handling techniques for suspect pyrophoric materials.

Schedule Requirements: The first burial ground in the 300 Area is scheduled for excavation in early FY98. Goals established in the Hanford Ten Year Challenge would have all burial grounds in the 300 Area completed by 2006 .

Technology Insertion Point: Consideration of new technology is ongoing.

Problem Description: Fifty years of defense plutonium production resulted in the creation of a large number of solid waste burial ground sites in Hanford's 100, 200, and 300 Areas. The 300 Area contained the fuel fabrication facilities where uranium and zircaloy were machined. These. processes generated scrap machining chips/filings which can have pyrophoric tendencies. Uranium was also recovered in pyrometallurgical processes that used magnesium and calcium metals which can also have pyrophoric tendencies. There are records that indicate that drums of zircaloy chips were placed in some 300 Area burial grounds. The other pyrophoric materials may or may not be present in burial grounds. There is no baseline for dealing with suspect pyrophoric materials. Techniques to detect for these materials and safely handle the materials once they are discovered are required.

ADS/RDS/WBS No: $\quad$ ADS: 3300

RDS: Found in Table 4-3. Risk Data Sheet Results of DOE/RL-96-09 Rev. 1.

WBS: 1.4 .10 .1 .1 .03 .07 


\section{Justification For Need:}

Technical - Current methods would require all containers in selected burial grounds to be treated as suspect pyrophoric material. This will reduce excavation efficiencies and increase costs.

Regulatory - There is no regulatory requirement for this technology need.

Environmental Safety and Health - Improved handling of suspect pyrophoric materials may reduce the potential for worker exposures and contaminant releases.

Cost Savings Potential (Mortgage Reduction) - Cost saving will be minor unless discovery of pyrophoric materials disrupts excavation operations.

Cultural/Stakeholder Concerns - No stakeholder concerns are likely.

Other - None.

Consequences of Nor Filling Need: Discover of pyrophoric materials may delay excavation operations until methods for dealing with the materials are approved.

Outsourcing Potential: Possible high potential in Department of Energy, Department of Defense, and private applications.

Current Baseline Technology: Conventional excavation equipment for removal with grizzlies for separation.

Cost: Budget forecast for 300 Area burial ground activities is: FY98, $\$ 3.2 \mathrm{M} ; \mathrm{FY} 99, \$ 3.1 \mathrm{M}$. Estimates to complete excavation and disposal of all the burial grounds in the 100 and 300 Areas is nearly $\$ 700 \mathrm{M}$. Occurrence of inefficiencies during the excavation process could have substantial cost impacts.

Waste: None

How Long It Will Take: Burial ground remediation activities in the 100 and 300 Areas are planned for next ten years. Burial ground remediation activities in the 200 Area are likely to extend well beyond the ten year time period.

End-User: Richland Environmental Restoration Project

Site Technical Point(s)-of-Contact: Kim Koegler, BHI, (509) 372-9294; Ashur R. Michael, BHI, (509) 372-9074; V. R. (Vern) Dronen, BHI, (509) 372-9096

DOE End-User/Representative Point(s)-of-Contact: Fred R. Serier DOE, (509) 372-8517; Owen Robertson, DOE, (509) 373-6295 


\section{TECHNOLOGY NEEDS/OPPORTUNITIES STATEMENT OUTLINE}

Identification No.: RL-SS20

Date: October 15, 1997

OPS Office/Site: DOE-RL/Hanford

Operable Unit: All burial ground sites in the 100,200, and 300 Areas

Waste Stream: Soil

Waste Management Unit: N/A

Facility: N/A

Site Priority Ranking: High

Need Title: Improved Methods for Debris Handling and Segregation

Need Description: A large number of waste burial grounds will be excavated and disposed on site. Improved methods are needed for handling and segregating waste debris that requires further characterization or size reduction prior to disposal required.

Functional Performance Requirements: Technology must reduce inefficiencies and costs associated with handling solid debris.

Schedule Requirements: Variable. Burial grounds exist in the 100, 200, and 300 Areas. The first burial ground (located in the 300 Area) excavation is scheduled for early FY98. Goals established in the Hanford Ten Year Challenge would have all burial grounds in the 100 Area and 300 Area completed by 2006. Strategies for remediation of the 200 Area burial ground sites are being revised but are scheduled to begin in 2003 and will extend several years past 2006 .

Technology Insertion Point: Consideration of new technology is ongoing. Mature technologies would support near term actions but development of innovative technologies could support actions that extend several years past 2006.

Problem Description: Fifty years of defense plutonium production resulted in the creation of a large number of solid waste burial ground sites in Hanford's 100, 200, and 300 Areas. The 100 Areas are located along the Columbia River and include nine nuclear reactors previously used for plutonium production. The 300 Area is also located along the Columbia River and contains the fuel fabrication facilities. The 200 Area is located on the central plateau and contains the spent fuel extraction and processing facilities and the radioactive waste storage tanks. The baseline for the 100 and 300 area burial ground sites is excavation and on site disposal.

Hanford's burial grounds contain a variety of solid waste debris that may require size reduction and/or further characterization (e.g., to confirm that the item should not be classified as TRU waste) prior to disposal. The first burial ground is scheduled for excavation in early FY98. 
Plans are to use conventional excavation equipment and grizzlies to remove and separate the debris. The separated material will then be staged until any required characterization is complete. There are concerns that these operations will reduce excavation efficiencies and increase costs. Breaching sealed containers and spreading contamination during removal operations is another potential concem. Experience gained during excavation of the first burial ground in FY98 is expected to help establish the importance of this need.

ADS/RDS/WBS No:: $\quad$ ADS: $3100,3200,3300$

RDS: Found in Table 4-3. Risk Data Sheet Results of DOE/RL-96-09 Rev. 1.

WBS: ADS: $3100=$ WBS 1.4.10.1.1.01.01

ADS: $3200=$ WBS 1.4.10.1.1.02.05

ADS: $3300=$ WBS 1.4.10.1.1.03.07

\section{Justification For Need:}

Technical - Wide variety of wastes placed in burial grounds are likely to require several different or very robust handling/segregation technologies.

Regulatory - There is no regulatory requirement for this technology need.

Environmental Safety and Health - Improved handling of waste debris may reduce the potential for worker exposures and contaminant releases.

Cost Savings Potential (Mortgage Reduction) - Potential savings depend on excavation inefficiencies introduced by baseline debris handling strategy.

Cultural/Stakeholder Concerns - No stakeholder concerns are likely.

Other: None.

Consequences of Not Filling Need: Continued use of baseline debris handling strategy.

Outsourcing Potential: Possible high potential in Department of Energy, Department of Defense, and private applications.

Current Baseline Technology: Conventional excavation equipment for removal with grizzlies for separation.

Cost: Budget forecast for 300 Area burial ground activities is: FY98, $\$ 3.2 \mathrm{M}$; FY99, $\$ 3.1 \mathrm{M}$. Estimates to complete excavation and disposal of all the burial grounds in the 100 and 300 Areas is nearly $\$ 700 \mathrm{M}$. Occurrence of inefficiencies during the excavation process could have substantial cost impacts.

Waste: None 
How Long It Will Take: Burial ground remediation activities in the 100 and 300 Areas are planned for next ten years. Burial ground remediation activities in the 200 Area are likely to extend well beyond the ten year time period.

End-User: Richland Environmental Restoration Project

Site Technical Point(s)-of-Contact: Kim Koegler, BHI, (509) 372-9294; Ashur R. Michael, BHI, (509) 372-9074; V. R. (Vern) Dronen, BHI, (509) 372-9096

DOE End-User/Representative Point(s)-of-Contact: Fred R. Serier DOE, (509) 372-8517; Owen Robertson, DOE, (509) 373-6295 


\section{TECHNOLOGY NEEDS/OPPORTUNITIES STATEMENT OUTLINE}

Identification No: : RL-SS21

Date: October 15, 1997

OPS Office/Site: Richland

Operable Unit (if applicable): Tank Farms and ZP-1

Waste Stream: Past-practice PFP and tank farm discharges to ground

Waste Management Unit (if applicable): N/A

Facility: Tank Farms and PFP cribs

Site Priority Ranking: high

Need Title: Contaminant Mobility Beneath Tank Farms and TRU Soil Column Disposal Sites

Need Description: Tank farm leak sites and TRU soil column disposal sites are the two most significant vadose sources of potential groundwater contamination at the Hanford Site. Assessment of contaminant mobility of these sources requires site-specific information.

Tank Farms. Recent borehole spectral gamma data at the Hanford Site indicate that cesium137 has migrated deeper than previously expected at both the SX and BX tank farms.

Groundwater data for several tank farm waste management areas also suggest that pathways through the vadose zone exist and could impact groundwater quality. These observation suggest that fundamental assumptions about contaminant mobility that support single shell tank cleanup options and schedules may be incorrect, a finding echoed by a recent peer review and the National Academy of Sciences. The transport mechanisms and pathways involved are of concern since other waste components not detectable by spectral gamma logging (e.g., plutonium, technetium- 99 , strontium- 90 , chromate, nitrate) may also have migrated farther than anticipated and could still be moving. Revised conceptual models coupled with supplemental geophysical and sorption (mobility) data, are needed to:

1) quantify and understand the evolution of the present distribution of contaminants and

2) to evaluate the potential mobility of the individual contaminants under all "leave or retrieve" options.

Soil Column disposal Sites (PFP Cribs). Similar needs exist for PFP soil column disposal sites that received large quantities $(-20,000 \mathrm{Ci})$ of transuranics in both a highly acidic aqueous phase and as an organic complex dissolved in an organic phase (carbon tetrachloride). The total contaminated soil volume beneath the PFP cribs is about 1,000,000 cubic meters and may extend to a depth of $40 \mathrm{~m}$ or more below ground surface. Some TRU may have migrated deep in the vadose zone in association with the DNAPL. The cost to package, handle and dispose of this volume of TRU (or near TRU) waste (>100 nCi/g) could easily exceed 1 billion dollars. Excavation and personnel safety related costs would be in 
addition. Thus stabilization in place, to the extent possible, would be a significant cost savings. Be that as it may, evaluation of either leave or retrieve options will require detailed knowledge of the sorptive status (degree of natural soil "fixation") of the deeply distributed plutonium and americium beneath PFP cribs and trenches.

Functional Performance Requirements: The most cost efficient approach to acquisition of the needed data is to conduct the work as one integrated study of vadose zone contaminant mobility. However, there are specific requirements for the two primary study areas, noted as follows.

Tank Farms. Each tank farm is a highly complex facility consisting of many underground structures, piping, and conduits. All technology solutions must be able to work within this environment and be compatible with tank farm safety operations. Any solution seeking to quantify contaminants and temporal changes must be able to measure the entire range of chemical concentrations (i.e., as high as the $10 \mathrm{M}$ in the original tank liquor) and radionuclide levels (e.g., 0.1 to $107 \mathrm{pCi} / \mathrm{g}$ cesium-137). Spectral gamma logging or geophysical methods must also be able to distinguish between interior/exterior borehole contamination versus contamination in the surrounding formation. Sample media dependent methods (e.g., laboratory sorption and pore fluid extraction and analysis on core samples) must be capable of recovering contaminated, semi-continuous core with minimai disturbance (e.g., no drilling fluids and minimal compaction) down to a depth of $200+\mathrm{ft}$.

TRU Soil Column Disposal Sites (PFP Cribs). Selected new core samples from beneath the PFP disposal sites are needed to address the TRU mobility issue. A building over one of the main sites (Z-9 trench) precludes direct drilling and coring through the disposal site. Thus angle drilling and coring methods must be used. The core samples must be semicontinuous all the way to groundwater and must be from directly beneath the structure to ensure passing through the main soil column contaminant plume down to groundwater. Drilling and coring operations must be compatible with on-going activities in the area (soil vapor extraction). Core samples must be minimally disturbed (no drilling fluids) and radiological containment and handling of TRU waste (cuttings and core samples) is required. Evaluation of the sorptive status of transuranics must include "desorption" or leachability testing for which radiologically contained test equipment is required (e.g., ultracentrifuge, core sectioning glove box, etc.). Trained personnel and equipment to conduct this specialized work are unique to the Hanford Site. Thus expensive shipping and handling of TRU contaminated sample media can be avoided by conducting the work on site.

Schedule Requirements: The ER program is scheduled to begin vadose zone characterization and remediation in the 200 Areas (where the tank farms and PFP cribs are located) in 2003. The mobility data is needed at an early date to support technically sound cleanup decisions. A recent U.S. senate inquiry (Senator Wyden, Oregon) on the same subject underscores these concerns. Requirements for long-term stabilization and/or cleanup of residual waste left in the tanks, or in the soil column beneath tanks and soil column disposal sites, are included in a recent stakeholder-prepared document (Requirements for the 
Columbia River Comprehensive Impact Assessment, Part II, TPA milestone M-15-80A and B). In addition, because of uncertainty about the mobility of the contaminants, stakeholders such as the states of Oregon and Washington and Native American tribes are concerned about what is moving now.

Problem Description: Inadequate in situ contaminant mobility data exists for single shell tank leaks and major soil column transuranic disposal sites to support cleanup, closure or performance assessment related decisions.
ADS No. 1250
RDS No.
WBS No.

\section{Justification For Need:}

Technical - In situ contaminant mobility data for tank leak and TRU disposal sites is not currently available, and currently available tools for in situ characterization are inadequate.

Environmental Safety \& Health - Contaminant mobility data is fundamental to prediction of environmental and human health effects (dose) due to groundwater and Columbia River exposure pathways, as called for in the CERCLA requirements document and cleanup related risk assessments.

Cost Savings Potential (Mortgage Reduction) - Stabilization in place option for TRU beneath PFP cribs alone could result in a savings of over 1 billion dollars. Potential return on investment is $\sim 1000: 1$.

Cultural/Stakeholder Concerns - Lack of contaminant mobility data is a major concern among stakeholders as expressed in $\mathrm{HAB}$ communications and the CERCLA requirements document.

Regulatory - Needed for on-going tank farm RCRA assessments of nature and extent of the cause of groundwater contamination at nearly half the tank farm sites.

Consequences of Not Filling Need: Without knowledge about the distribution of contaminants beneath the tank farms, and without the ability in hand to predict contaminant movement, it will be impossible to assure the public that the DOE can predict:

a) the impact of leaks during sluicing of the tanks during cleanup, and

b) the impact of leaving the tanks (and their associated subsurface contamination) in place.

Furthermore, the vadose zone cleanup schedule for the 200 Areas could be delayed if the mobility status of deeply distributed transuranics is unknown, or inadequately characterized, well enough in advance. For example, if it is eventually determined that retrieval of TRUcontaminated soil down to $40 \mathrm{~m}$ or more beneath PFP cribs is required, the cleanup schedule could be greatly impacted due to inadequate financial planning for excavation and handling costs 
that could approach 1 billion dollars or more. The sooner this issue is resolved the sooner more accurate financial and schedule forecasts can be made.

Outsourcing Potential: aspects that do not require recovery and handling of highly contaminated sample media may have outsourcing potential (e.g., advanced geophysical logging). A CRADA with Schlumberger was previously in place for some of the advanced geophysical logging needs.

Current Baseline Technology: Existing tools and approaches and improvements needed are described as follows.

Geophysical methods. Logging methods currently employed in the tank farms (e.g., HPGe) cannot quantify radionuclide concentrations at high levels. Tools are needed that are capable of both high resolution and quantification over a range of $\sim 1 \mathrm{pCi} / \mathrm{g}$ to $108 \mathrm{pCi} / \mathrm{g}$. Additional needs not currently available include methods that can measure soil salinity through steel cased boreholes along with reliable soil moisture contents. The latter are needed to:

1) compare the depth distribution of the salt matrix (due to sodium nitrate, etc.) from a tank leak with cesium-137 and

2) to determine the extent of dilution of the original tank liquor.

This would allow use of existing boreholes to assess the relative mobility of cesium-137 and the salt matrix (assumed to be completely mobile) around those tanks that have leaked. In addition, current methods do not distinguish strontium-90 (due to bremsstrahlung radiation from the beta decays) from other gamma emitters. This capability would greatly expand in situ detection/quantification for the two dominant components of tank waste (Sr-90 and Cs137).

Soil fixation/binding mechanisms. Current predictive models of contaminant transport beneath single shell tanks rely on general $\mathrm{Kd}$ information derived from laboratory sorption stadies in synthetic media. The extreme chemical conditions associated with tank liquor ( $\mathrm{pH}$ up to 14) and PFP crib discharges ( $\mathrm{pH}$ to -1), and the associated changes in sorptive properties of the porous media, are difficult if not impossible to simulate. Prior characterization studies (mid 70's) provided valuable information to build on. However, due to moderately slow changes in conditions over time (e.g., silicate hydrolysis) the $\mathrm{pH}$ and other chemical conditions in the soil column beneath receiving sites may be different today than 20-25 years ago. Thus contemporary contaminated media is needed to assess the existing field mobility status of major contaminants in the soil column. The sorptive mechanisms need to be studied to determine how tightly bound Sr-90, Cs-137, Pu and Am are today. This involves:

1) extraction of pore fluid (free fraction) and the "reverse" of laboratory sorption studies (i.e., leaching or desorption studies) using actual contaminated media and 
2) assessment of the role of potential chemical reactions induced by the soil mineral fraction.

For example, what is the role of iron (II) rich silicate minerals (pyroxenes) present in Hanford soils on reduction-sorption of transuranics? Acid hydrolysis due to the acidity of the effluent may have enhanced the reducing capability of iron (II) rich minerals and resulted in irreversible sorption of transuranics (Johnson and Hodges, 1997 -Second Symposium on Hydrogeology of Washington, abstracts). Hot, high $\mathrm{pH}$ media (original tank waste) also modified the soil matrix in unpredictable ways. Silicate minerals dissolve and reprecipitate, colloids may form, etc. Actual modified media is needed to evaluate existing conditions. Some work of the latter type is planned for FY98 (TWRS Vadose Characterization Program). Additional or supplemental work is needed for a comprehensive assessment of 200 Area soil column disposal and tank farm sites.

End-User: DOE: 1) TWRS Vadose Characterization Program (David Shafer) 2) ER vadose/groundwater program, Mike Thompson

Site Technical Point(s)-of-Contact: V. G. Johnson (PNNL), R. J. Serne (PNNL), M. Fayer (PNNL)

DOE End-User/Representative Point(s)-of-Contact: David Shafer (DOE-RI)/David Myers (IT); Mike Thompson (DOE-RL) 


\section{TECHNOLOGY NEEDS/OPPORTUNITIES \\ STATEMENT OUTLINE}

Identification No.: RL-SS22

Date: October 15, 1997

OPS Office/Site: Richland

Operable Unit (if applicable): N/A

Waste Stream: Immobilized Low-Activity Tank Waste

Waste Management Unit (if applicable): N/A

Facility: Tank Farms

Site Priority Ranking:

Need Title: Data and Tools for Performance Assessments

Need Description: Performance assessments must be developed for all disposal actions, and the models that are used for these assessments require a defensible basis for the movement of water. Most databases describe recharge and distribution of water for non-arid conditions. The arid conditions at Hanford are not accurately represented by the existing data. This need is comprised of two elements:

1) Recharge water is the primary means for dissolution and release of contaminants from the buried waste and transport of those contaminants to the groundwater. Estimation of these rates is difficult under arid conditions because the rates are very low. In addition, there are significant questions about the adequacy of the estimated recharge rates given the heterogeneity of the environmental processes, the effect of facility features, the uncertainty of climate, and the influence of humans. Furthermore, no attempt has been made to quantify the distribution of recharge rates to enable sounder estimates of the mean and range of rates to be expected during the time of compliance of the facility.

2) Assessments of waste disposal require the knowledge of hydraulic properties in the unsaturated sediments (the vadose zone). Typically, these properties are inferred or estimated from small cores or particle size distributions obtained from a drilled borehole. Field measurements of hydraulic properties will eliminate the uncertainty when extrapolating small-scale laboratory measurements.

\section{Functional Performance Requirements:}

For recharge issues:

1) Identify range of factors that affect recharge

2) Develop new and innovative methods to determine recharge rates in and around subsurface disposal facilities

3) Estimate recharge rates for a subset of the range of factors and correlate estimates from multiple methods. 
4) Use estimates to quantify spatial and temporal distribution of recharge rates for the spatial and temporal extent of the disposal facility.

Factors of interest that can contribute to variable recharge rates include soil type, vegetation, facility and surface cover design, human activity, climate, and time.

For hydraulic properties:

Design, construct, and operate a device to measure hydraulic properties in the vadose zone.

Measurement of variables such as water content and matric potential, which are used to calculate conductivity, must be accurate and quick. The device must be portable and reusable.

Schedule Requirements: For use in the Hanford Low-Level Tank Waste Performance Assessments, such data and testing are needed by September 2000. Preliminary versions of the performance assessments will need data by September 1998.

Problem Description: Computer codes, hydraulic measurements, and tracer movement can be used to estimate recharge rates. These techniques are not often used in conjunction, and hardly ever to characterize the spatial distribution of recharge rates.

ADS No.

RDS No.: 1250

WBS No.: 1.1.1.3.04.01.03

\section{Justification For Need:}

Technical - Provide technical basis for characterizing the distribution of hydraulic properties and recharge rates in and around the Hanford Low-Level Tank Waste Disposal System. Such information will also be required for other waste management actions involving subsurface disposal.

Regulatory - Performance assessments are required by DOE Order $5820.2 \mathrm{~A}$, soon to be revised and issued as DOE Order 435.1. Composite analyses, which also require knowledge of recharge, are required under separate guidance and are related to the soon to be issued 10 CFR 834, Radiation Protection of the Public and the Environment.

Environmental Health and Safety - Recharge water is the main means for dissolution/release of contaminants from waste and the transport of those contaminants to groundwater.

Cost Savings Potential - Less conservative values for hydraulic properties and recharge rates in and around disposal facilities will allow less stringent release contaminant specifications for the Phase II immobilization Request for proposals (and hence lower product costs to $\mathrm{DOE}$ ) as well as less stringent requirements for waste disposal facility design. 
Cultural/Stakeholder Concerns - Disposal of low-activity tank waste has the largest environmental impact of any intentional Hanford action.

Other - Achieve better understanding of magnitude and variability of recharge rates in dry environments.

Consequences of Not Filling Need: Conservative methods and data will be used in the performance assessment, likely requiring more stringent contaminant release specifications in the waste product request for proposal and requiring more expensive disposal facilities.

Outsourcing Potential: Information and technology are likely to be used at other arid DOE sites and other waste management sites (e.g., commercial sites) in the Western United States where wastes are present, or will be disposed, in the subsurface. The data gathering could be contracted, but the development of correlations among data describing the physical processes is not easily privatizable. Following successful development and testing of a device to measure vadose zone hydraulic properties, there would be significant potential for outsourcing of the device for commercial and DOE applications involving either hazardous or radioactive waste or both in the arid Western States.

Current Baseline Technology: Point estimates of recharge and laboratory measurements of hydraulic properties on small cores.

Cost:

Waste:

How Long It Will Take:

End-User: TWRS Storage and Disposal Project

Site Technical Point-of-Contact: Fred Mann, Fluor Daniel Northwest, phone: (509)376-5728; fax: (509)376-1293; email: frederick_m_mann@rl.gov or v92515@ffep0.rl.gov

DOE Representative Point of Contact: Phil LaMont, RL/TWRS, phone (509)376-6117; fax: (509)372-1350; email: philip_e_lamont@rl.gov 


\section{Fiscal Year 1998 Subsurface Contaminant Science Needs}

\begin{tabular}{|c|c|}
\hline \multirow[t]{2}{*}{ ID No. } & Needs Title \\
\hline & Detection/Distribution of Contaminants \\
\hline RL-SS23-S & Chemical Speciation and Complexation in Site-Specific Groundwaters \\
\hline RL-SS24-S & Chemical Binding on Site-Specific Mineral Surfaces \\
\hline RL-SS25-S & $\begin{array}{l}\text { Chemical Form and Mobility of Dense, Non-Aqueous Phase Liquids in Hanford } \\
\text { Subsurface }\end{array}$ \\
\hline \multicolumn{2}{|r|}{ Transport of Contaminants } \\
\hline RL-SS26-S & $\begin{array}{l}\text { Reaction Rates for Key Contaminant Species and Complexes in Site-Specific } \\
\text { Groundwaters }\end{array}$ \\
\hline RL-SS27-S & $\begin{array}{l}\text { Rates of Coupled Abiotic and Biogeochemical Reactions Involving Contaminants in } \\
\text { Hanford Subsurface }\end{array}$ \\
\hline RL-SS28-S & $\begin{array}{l}\text { Rates of Colloid Formation and Colloidal Transport of Contaminants in Site-Specific } \\
\text { Groundwaters }\end{array}$ \\
\hline RL-SS29-S & Effect of Subsurface Heterogeneities on Chemical Reaction and Transport \\
\hline RL-SS30-S & Cs Migration Beneath Tanks \\
\hline \multicolumn{2}{|r|}{ Remediation } \\
\hline RL-SS31-S & Mathematical Formulations of Chemical Reaction/Material Transport \\
\hline RL-SS32-S & Reactivity of Organics in the Hanford Subsurface \\
\hline RL-SS33-S & Interaction of Remedial Processes with Hanford Subsurface \\
\hline RL-SS34-S & Selectivity for Contaminants in the Hanford Subsurface \\
\hline \multicolumn{2}{|r|}{ Monitoring of Contaminants } \\
\hline RL-SS35-S & Use of Chemical Surrogates for Contaminants \\
\hline RL-SS36-S & Chemical Indicators of Remedial Technology Processes \\
\hline RL-SS37-S & Chemical Sensor Principles \\
\hline
\end{tabular}




\section{Hanford Site Science Need -- FY 1998 Subsurface Contaminant Subgroup}

Site Background Information Relevant for All Science Needs: The Hanford Site covers 1450 square kilometers along the Columbia River in the southeastern Washington State. The primary mission of the Hanford Site for nearly 50 years was to produce plutonium for national defense. Since 1943, nine plutonium production reactors, seven chemical separations plants, and various ancillary facilities were constructed and operated at the Hanford Site, with peak defense production activities occurring in the 1950s and early 1960s during the Cold War. Plutonium production, fuel processing, and fuel fabrication had a significant effect on the environment. The Hanford Site contains over 1600 contaminated waste sites; 670 occur within one half mile of the Columbia River. Defense production created over 625,000 cubic meters of solid liquid wastes containing both radioactive and chemical contamination. Early waste disposal practices have resulted in groundwater contamination levels exceeding federal drinking water standards (DWS). The Department of Energy established the environmental restoration mission in 1987 with the goal of returning the site to other beneficial uses.

There is significant soil contamination at 100,200, and 300 areas of the Hanford Site. The approximate total volumes of soil requiring remediation (liquid waste disposal sites and burial grounds) are:

3.9 million cubic yards in the 100 Areas, 10 million cubic yards in the 200 Areas, and 0.8 million cubic yards in the 300 Area.

The 100 Area, located along the Columbia River at the inactive production reactors, has over 70 contaminated soil sites that will require remediation. Soil units include cribs, french drains, trenches, ponds, and retention basins that received radiologically and chemically contaminated liquid effluent from reactor and support operations. Cobalt and Strontium-90 are the main radioactive contaminants of concern in 100 area soils. The 300 Area, located along the Columbia River on the southeastern side of the Site, has several soil sites that resulted from liquid disposal in ponds and trenches. Uranium is used as an indicator contaminant and soils with concentrations greater than 350 picocuries/gram in the top 15 feet are removed. The 200 Area contains approximately 1000 different soil and burial ground sites. Soil waste sites are the result of liquid discharge to cribs, ponds and ditches. Remediation strategies and target/indicator contaminants are currently being developed for the 200 Area, located on a plateau several miles from the Columbia River. However, plutonium, uranium, cesium, cobalt, and strontium are likely to be the key indicator contaminants. for many of the contaminated sites.

The boundaries for some of these liquid waste disposal sites are poorly defined. Also, other sites may have significantly different contaminant concentrations throughout the site. The baseline strategy for soil sites in the 100 and 300 Areas is to excavate the top 15 feet of contaminated soil and dispose on site. A portion of the 200 area sites may also be excavated and disposed on site. If contamination extends beyond 15 feet, soil contaminant concentrations and/or mobilities must 
be low enough to prevent future groundwater problems. If concentrations exceed these levels, additional remedial measures (removal, containment or treatment) may be required. In situ detection techniques would help make this determination prior to excavation. In situ characterization technologies may also help support decisions to leave some burial grounds and portions of soils sites in place.

The central portion of the Hanford Site, where the 200 East and 200 West Areas are located, was used for chemical separation of plutonium, processing, and waste management. Soils within the vadose zone at the 200-ZP-2 operable unit are contaminated with elevated concentrations of carbon tetrachloride. An Expedited Response Action (ERA) is being conducted using vapor extraction to remove carbon tetrachloride from the soil beneath the operable unit. A final remedial strategy has not yet been developed to mitigate the soil contamination.

Groundwater plumes are located in the 100,200 , and 300 areas. Tritium has been found in groundwater in all three locations. Other plumes are specific to the function of the area. For example, the $100-\mathrm{H}$ and $100-\mathrm{K}$ Areas are located along the horn of the Columbia River in the northern portion of the Hanford Site, and include three nuclear reactors previously used for plutonium production. Primary sources of contamination in groundwater are cribs, french drains, trenches, ponds, retention basins, pipelines, and waste disposal sites. Groundwater in the 100 Area ultimately discharges into the Columbia River. The principal groundwater contaminant is hexavalent chromium, which occurs in two main plumes. The north plume is about 2,000 feet by 4,000 feet and a south plume of about 2,000 feet by 2,000 feet. Both plumes have an average thickness of about 15 feet with concentrations ranging from 60 to $600 \mathrm{ppb}$. Depth to the water table is approximately 85 feet. Hexavalent chromium has been identified as a contaminant of concern for juvenile salmon in the Columbia River. A Focused Feasibility Study/Proposed Plan (August 1995) recommended a pump and treat Interim Remedial Measure to address chromate migration from groundwater to the river. An interim ROD (April 1996) for the 100-HR-3 and $100-K R-4$ operable units specified installation of a pump-and-treat systems to intercept chromate plumes that impact the Columbia River. The objective of the Interim Remedial Measure (IRM) is protection of juvenile salmon in the river substrate from exposure to hexavalent chromium.

The 100-N Area is located along the horn of the Columbia River in the northern portion of the Hanford Site and includes one nuclear reactor previously used for plutonium production. In the 100-NR-2 operable unit, the primary sources of contamination are ditches and cribs. Groundwater in the 100 Area ultimately discharges to the Columbia River. The principal contaminant, strontium-90 (half-life 29.3 years), is present in groundwater at activities up to $6000 \mathrm{pCi} / \mathrm{L}$. Maximum concentrations of the plume range from 4,000-6,000 $\mathrm{pCi}$ per liter with depth to the water table of 70-80 feet at the source. Plume thickness ranges from 13 to 40 feet. The estimated total inventory of contaminant in both the groundwater and soils ranges from 75 to 89 curies.

The immediate objective is to prevent further migration of Sr-90 into the Columbia River. The long-term objective is to reduce $\mathrm{Sr}-90$ levels to below drinking water standards. An existing pump \& treat interim remedial measure (IRM) has been implemented to help reduce the flux of Sr-90 to the river. The low mobility of the strontium-90 reduces the removal effectiveness to the 
point that natural radioactive decay removes the contamination almost as fast as the pump and treat operation combined with radioactive decay. Thus, the main purpose of the pump and treat system is for containment while natural decay reduces the source. If containment must be maintained until the highest concentrations in the plume $(6,000 \mathrm{pCi} /$ liter $)$ decay to the Safe Drinking Water Act Standard of $8 \mathrm{pCi} /$ liter, the aquifer will need to be contained for 280 years. One containment approach being evaluated for this application is an in situ permeable strontium adsorption barrier. Implementation of this approach has been stalled due to regulators concerns over the effectiveness of long-term containment strategies. A main concern is that high concentrations of Sr-90 will accumulate in the barrier and result in a catastrophic release into the Columbia River if the barrier is washed out during a major flooding event.

Groundwater in the 200 Areas has been contaminated by carbon tetrachloride, trichloroethylene, and degradation products of these compounds have also been detected in groundwater. Concentrations of carbon tetrachloride, chloroform, and trichloroethylene in groundwater at the 200-ZP-1 operable unit exceed the regulatory limit. Remediation must meet a functional requirement of less than $5 \mathrm{ppb}$ of carbon tetrachloride. Current remedial actions include pumping contaminated water from the aquifer and treating it with an air-stripping action followed by vapor-phase GAC polishing.

The current approach of using ex-situ ion exchange treatment of contaminated water and air is considered to be relatively expensive. The length of time required to operate the system to meet functional requirements is not well constrained because of uncertainty associated with data used in models of ex-situ treatment. In situ treatment of the contaminants may result in reduced costs for remediation, but requires reduction of the uncertainty associated with the chemical form and mobility of DNAPLs in the subsurface.

Additional challenges to restoration of the Hanford Site involve timely and accurate monitoring and assessment of remedial technology performance. At present, concentrations of chromium, strontium-90, and carbon tetrachloride are measured by discrete sampling from wells or river substrate with analysis in analytical laboratories. Time for receipt of analytical results vary, but require approximately 24 hours for turn around time for strontium-90, and can extend to several weeks for hexavalent chromium and carbon tetrachloride. Laboratory analytical work is highly accurate, but time delays and high cost are considered to be significant drawbacks. In situ monitoring would lower the analytical chemistry cost of remediation projects and fate and transport studies. The possibility also exists to incorporate in situ monitoring with existing pump-and-treat remediation systems. This objective would support design changes to allow fully automated operation of the pump-and-treat systems. In-line monitoring would lower the analytical chemistry cost of the pump and treat projects and would support design changes to allow fully automated operation of the ion exchange treatment systems.

Nature of the Problem and Long-Term Potential Remedial Solutions: A summary of the contaminants of highest interest is given below:

Groundwater Contaminants

Carbon tetrachloride, trichloroethylene 
Hexavalent Chromium

Radionuclides: Tritium, 90Sr, 99Tc, 129I

\section{Vadose Zone Contaminants}

Carbon tetrachloride

Chromium, Lead, Mercury, Cobalt

Radionuclides; Tritium, Uranium, Plutonium, 90Sr, 99Tc, 129I, 137Cs

The potential for cesium to become a groundwater contaminant is recognized.

Several long-term remedial technologies are being considered for these waste plumes at Hanford; additional scientific information is needed to make them effective for environmental restoration. These technologies are considered generally representative of technologies that could be effective at Hanford; the list is not considered to be limiting. Technologies requiring additional scientific basis include:

Reactive and passive in-situ remediation technologies: The basic science is needed to refine those approaches currently being evaluated under EM support, such as in-situ redox manipulation and use of passive containment barriers made of material such as zero-valent iron or zeolites. These technologies address remediation of deep aquifer systems.

Reactive chemical transport models: Models and codes that couple chemical information with transport are needed to conduct the assessment of contaminant reactivity and migration needed to select among remedial alternatives. The models are also needed for performance assessments of remedial technologies, where results of models are compared to postremediation monitoring data to assess how well a remedial technology met functional performance requirements.

Semi- or real-time chemical and radiological groundwater monitoring techniques: These capabilities are needed to cut the costs of analyses where post-remediation monitoring of ground water aquifers may be required for years into the future, and to support performance assessment using reactive chemical transport models. 


\section{Hanford Site Science Need -- FY 1998 \\ Subsurface Contaminant Subgroup}

Identification No: : RL-SS23-S

Science Need Title: Detection/Distribution of Contaminants--Chemical Speciation and Complexation in Site-specific Groundwaters

Site Priority Ranking: Soil and Groundwater Science Need--High

I. Functional Need:

Determine the speciation and complexation of contaminants of interest in an aqueous phase distributed in (1) the vadose zone (pristine and contacted by tank waste liquids) and (2) the aquifer.

\section{Problem Description:}

The Hanford Site is underlain by a vadose zone that ranges from less than 40 feet thick at the 100 Areas near the Columbia River to greater than 300 feet thick at the 200 Area. Recharge rates in pristine parts of the site are very low. Liquid waste disposal within the vadose zone has introduced numerous sources of contamination to the soil pore waters. High-level waste tanks have leaked varying amounts of sodium nitrate-hydroxide liquids contaminated with soluble radionuclides such as cesium and technetium. The chemistry of groundwater in the vadose zone will reflect the heterogeneity of waste streams that have been disposed. Likewise, the suprabasalt sediments beneath the Hanford site have several different facies, and therefore varying mineralogical, chemical, and hydraulic properties. The nature of the chemical reactions in this hydrogeologic setting will be specific to the types of pore waters, contamination, and primary/secondary minerals encountered, and data for the specific species and complexes encountered are a necessary prerequisite to adequate design of.remedial technologies.

\section{Science Need Description:}

In order to detect and delineate the distribution of contaminants accurately in different media in a variety of hydrogeological settings at Hanford (e.g-, vadose zone, aquifer), several aspects of science need to be addressed. It is important for design and selection of remedial alternatives to determine the inventory of the different contaminants at a given contaminated site: what contaminants are present, in what different forms, and in what amounts? The in-situ chemical speciation of important contaminants (listed in the background section) as a function of the hydrochemical conditions of the Site is important to determining which dissolution/precipitation or oxidation/reduction reactions will immobilize or release contaminants. Measures are needed for solubilities of the different species as a function of the concentration of important cations and anions in uncontaminated and contaminated groundwater. While speciation can be modeled from bulk groundwater analyses, some direct measure of speciation, such as optical or emission 
spectroscopy, is needed to confirm models and assist in establishing contaminant mass balance. Basic scientific information on speciation contributes to the assessment of remedial alternatives.

Science needs also include knowing the range of aqueous complexes that contaminants form with common groundwater cations and anions. Can contaminants be expected to occur as hydroxides, carbonates, sulfates, oxyanions, or as organic complexes? Knowledge of the solubility limits for these species in site-specific groundwaters assists in determining if aqueous complexes form surface complexes with secondary mineral surfaces.

A secondary need for information on contaminant speciation and complexation supports the development of accelerated analytical methods that can provide data on in-situ chemistry remotely and non-invasively. Some of the constraints include the need for these approaches to be remote, real-time, and either on-line or in-situ methods.

\section{Benefit:}

If the science needs are filled, then alternative technologies may be developed and deployed to enhance the rate of remediation of the groundwater plumes at the Hanford site. Use of in-situ remedial technology rather than ex-situ treatment will reduce risk and provide cost savings

Benefit code: check all that apply:

$\checkmark$ Cost Savings $\checkmark$ Risk Reduction $\checkmark$ Enabling Knowledge (i.e., solves a problem that cannot be remediated by current science/technology)

This Science Need also supports the following Hanford Subsurface Contaminant Technology Needs:

RL-SS01 Cost-effective, In-situ Remediation of Carbon Tetrachloride in the Vadose Zone and Groundwater

RL-SS03 Improved, Real-time, In-situ Detection of Carbon Tetrachloride in Groundwater

RL-SS04 Cost-effective, In-situ Remediation of Hexavalent Chromium in Groundwater

RL-SS06 Improved, Real-time, In-situ Detection of Hexavalent Chromium in Groundwater

RL-SS07 Cost-effective, In-situ Remediation of Strontium-90 in Groundwater

RL-SS09 Improved, Real-time, In-situ Detection of Strontium-90 in Groundwater

RL-SS11 Cost-effective, In-situ Remediation in the Vadose Zone of One or More of the Following Heavy Metals: Hexavalent Chromium, Mercury, Lead 
RL-SS12 Cost-effective, In-situ Remediation in the Vadose Zone of One or More of the Following Radionuclides: Uranium, Plutonium, Cesium, Cobalt, and Strontium-90

RL-SS15 Improved, In-situ Characterization to Determine the Extent of Soil Contamination of One or More of the Following Heavy Metals: Hexavalent Chromium, Mercury, Lead

RL-SS16 Improved, In-situ Characterization to Determine the Extent of Soil Contamination of One or More of the Following Radionuclides: Uranium, Plutonium, Cesium, Cobalt, and Strontium-90

RL-SS21 Contaminant Mobility Beneath Tank Farms

V. Contacts:

For more information, contact:

Fred Serier, DOE

(509) $376-8517$

Shirley Rawson, PNNL

(509) 376-0223

sa_rawson@pnl.gov 


\section{Hanford Site Science Need -- FY 1998 \\ Subsurface Contaminant Subgroup}

Identification No.: RL-SS24-S

Science Need Title: Detection/Distribution of Contaminants--Chemical Binding on SiteSpecific Mineral Surfaces

Site Priority Ranking: Soil and Groundwater Science Need--High

\section{Functional Need:}

For Hanford site conditions, determine the reactions that will affect the binding of contaminants in solution on secondary mineral surfaces, and on primary phases, if relevant.

\section{Problem Description:}

Significant geologic heterogeneity exists in the suprabasalt sediments underlying Hanford production facilities, and the unconfined aquifer at Hanford occurs in two different formations. The aquifer beneath facilities sited near the Columbia river occurs within flood gravels of the Hanford Formation; beneath the 200 area, the aquifer occurs within coarse- to medium sands and gravels of the Ringold Formation. The secondary mineralogy of these units differs, with significant amounts of 2:1 layer silicates in the finer-grained members of the Ringold Formation and fewer layer silicates in the Hanford Formation. The types of mineral surfaces will include edge sites on layer silicates.

\section{Science Need Description:}

The binding of contaminants on secondary mineral surfaces occurs primarily through adsorption. Adsorption processes affect potentially all metals and organics, and occur primarily with selected adsorbing surfaces (i.e., $\mathrm{Fe}$ and $\mathrm{Mn}$ oxides, clay minerals, humics, microbial cells). Science needs for a better understanding of adsorption include the need to incorporate the effects of surface heterogeneity into macroscopic models of adsorption. To better determine the effects of competitive adsorption processes and ligand complexation, it is necessary to have free energy relations for surface adsorption processes. Many of these properties require that measurements be made on ideal surfaces and surfaces with selected defects for mechanistic studies of surface heterogeneity. When microbial processes are important, it will be important to determine the stabilities of microbial exopolymers and the complexes it forms with metal ions. Research is needed to characterize the chemical composition of microbially-produced metal-binding ligands, which are large, chemically heterogeneous biomolecules. Potentially metal/radionuclide binding selectivity can be related to microbial ligand chemical composition, which may in turn be developed into remedial alternatives. 
Geochemically and microbially mediated processes such as precipitation/dissolution affect all the metals of interest with the possible exception of mercury and technetium. Many of the contaminants of interest are abiotically precipitated, with the possible exception of uranium. Microorganisms can also participate either actively or passively in the precipitation or dissolution of metals (e.g., production of $\mathrm{CO} 2$, sulfide from respiration). Additional science is needed to describe the incorporation of trace components into important mineral phases; such information supports assessment of how trace components be selectively removed by remediation. When there is microbial reductive dissolution of oxide minerals, it becomes important to know the fate of trace components that are released.

IV. Benefit:

The science needs for understanding contaminant binding enable the development of in-situ remedial schemes that can replace existing pump/treat approaches.

Benefit code: check all that apply:

$\checkmark$ Cost Savings $\checkmark$ Risk Reduction Enabling Knowledge (i.e., solves a problem that cannot be remediated by current science/technology)

This Science Need also supports the following Hanford Subsurface Contaminant Technology Needs: 


\begin{tabular}{||l|l||}
\hline RL-SS01 & $\begin{array}{l}\text { Cost-effective, In-situ Remediation of Carbon Tetrachloride in the Vadose Zone } \\
\text { and Groundwater }\end{array}$ \\
\hline RL-SS03 & Improved, Real-time, In-situ Detection of Carbon Tetrachloride in Groundwater \\
\hline RL-SS04 & Cost-effective, In-situ Remediation of Hexavalent Chromium in Groundwater \\
\hline RL-SS06 & $\begin{array}{l}\text { Improved, Real-time, In-situ Detection of Hexavalent Chromium in } \\
\text { Groundwater }\end{array}$ \\
\hline RL-SS07 & Cost-effective, In-situ Remediation of Strontium-90 in Groundwater \\
\hline RL-SS09 & \begin{tabular}{l} 
Improved, Real-time, In-situ Detection of Strontium-90 in Groundwater \\
\hline RL-SS11
\end{tabular} $\begin{array}{l}\text { Cost-effective, In-situ Remediation in the Vadose Zone of One or More of the } \\
\text { Following Heavy Metals: Hexavalent Chromium, Mercury, Lead }\end{array}$ \\
\hline RL-SS12 & $\begin{array}{l}\text { Cost-effective, In-situ Remediation in the Vadose Zone of One or More of the } \\
\text { Following Radionuclides: Uranium, Plutonium, Cesium, Cobalt, and Strontium- } \\
90\end{array}$ \\
\hline RL-SS15 & $\begin{array}{l}\text { Improved, In-situ Characterization to Determine the Extent of Soil } \\
\text { Contamination of One or More of the Following Heavy Metals: Hexavalent } \\
\text { Chromium, Mercury, Lead }\end{array}$ \\
\hline RL-SS16 & $\begin{array}{l}\text { Improved, In-situ Characterization to Determine the Extent of Soil } \\
\text { Contamination of One or More of the Following Radionuclides: Uranium, } \\
\text { Plutonium, Cesium, Cobalt, and Strontium-90 }\end{array}$ \\
\hline RL-SS21 & \begin{tabular}{l} 
Contaminant Mobility Beneath Tank Farms \\
\hline
\end{tabular}
\end{tabular}

\section{Contacts:}

For more information, contact:

Fred Serier, DOE (509) $376-8517$

Shirley Rawson, PNNL

(509) 376-0223 sa_rawson@pnl.gov 


\section{Hanford Site Science Need -- FY 1998 \\ Subsurface Contaminant Subgroup}

\section{Identification No.: RL-SS25-S}

Science Need Title: Detection/Distribution of Contaminants--Chemical Form and Mobility of Dense, Non-Aqueous Phase Liquids in Hanford Subsurface

Site Priority Ranking: Soil and Groundwater Science Need--High

\section{Functional Need:}

For Hanford vadose zone and aquifer, determine the chemical form and mobility of dense, nonaqueous phase liquids such as chlorinated solvents in contact with (1) pore water and groundwater, (2) secondary minerals.

\section{Problem Description:}

There is known contamination of groundwater in the vadose and saturated zones at the 200 West Area by carbon tetrachloride, a dense non-aqueous phase liquid (DNAPL). Current remedial actions for groundwater plumes include pumping contaminated water from the aquifer and treating it with an air-stripping action followed by vapor-phase GAC polishing. An Expedited Response Action (ERA) is being conducted to remove carbon tetrachloride from the soil beneath the operable unit; vapor extraction is currently being used in the ERA, but a final remedial strategy has not yet been developed to mitigate the soil contamination at 200-ZP-2. The current approach of using ex-situ ion exchange treatment of contaminated water and air is considered to be relatively expensive and the length of time required to operate the system to meet functional requirements is not well constrained because of uncertainty associated with data used in models of ex-situ treatment. In situ treatment of the contaminants may result in reduced costs for remediation, but requires reduction of the uncertainty associated with the chemical form and mobility of DNAPLs in the subsurface.

\section{Science Need Description:}

Free-phase DNAPL can constitute a major secondary contaminant source so its chemical form and mobility need to be established. Science needs include the solubility and speciation of DNAPL in Hanford groundwaters, as well as the possibility of free product DNAPL.

Constitutive properties (e.g., interfacial tension, entry pressure) of multiple fluids (air, water, free product DNAPL) are needed to model the form and potential mobility of DNAPLs in the subsurface. The interaction of DNAPL with mineral surfaces or with naturally occurring organic matter should be determined to gain additional information on chemical form. The subsurface itself is physically heterogeneous at a variety of scales; this heterogeneity must be incorporated in any model of DNAPL mobility and is addressed by another science need, Effect of Subsurface Heterogeneities on Chemical Reaction and Transport (RL-SS29-S). Key science needs on 
DNAPL form and mobility also include determining how NAPLs are distributed with regard to specific pore geometries and how the physical setting affects their extractability. Additional information is also needed about the role of surfactants and other agents on the basic physical properties (solubility, interfacial tensions) of NAPLs or dissolved organics and how these relations can be exploited to mobilize such contaminants. Science is also needed to extend the theoretical and computational basis for the physics of subsurface multiple phase fluid flow and transport, a corollary science need, Mathematical Formulations of Chemical Reaction/Material Transport (RL-SS31-S).

Subsurface processes which can lead to the in-situ degradation or transformation of the chemical form of DNAPLs can include abiotic or biotic dechlorination. In-situ remediation requires knowledge of the mechanisms and rates of these processes. Different remedial options will incorporate different science needs. For example, selection of a bioremediation option that uses metabolic dechlorinating microorganisms requires knowledge of (1) subsurface microbial ecology (are dechlorinators present or must they be introduced?), (2) microbial nutrient requirements, (3) biochemistry of dechlorination (e.g., electron donors, metabolic pathways and rates, byproducts, enzymology), and (4) bacterial injection/transport issues (e.g., biofouling; exopolymer production). Selection of a remedial option that uses manipulation of aquifer oxidation-reduction potential to cause dechlorination requires knowledge of (1) aquifer hydraulics, (2) mechanisms and rates for electron transfer reactions involving aquifer minerals, and (3) colloid mobilization/transport issues. Other subsurface processes can lead to the enhanced mobilization or immobilization of contaminants in the subsurface. For example, in the case of carbon tetrachloride, for example, science needs include (1) cosolvency of carbon tetrachloride in aquifer organic matter or introduced materials (e.g., surfactants, alcohol, vegetable oil), and (2) effects of surfactants on carbon tetrachloride mobility (e.g., viscosity, interfacial tension). Knowledge of the sorption capacity of the ion exchange resin can also be used to improve current pump/treat methods.

To understand DNAPL mobility, it may also be necessary to detect the location of DNAPLs, and remote interrogation methods require additional refinement. Science needs based for subsurface detection of DNAPL include identifying which properties of the DNAPL and the subsurface sediments will provide the most indicative signal of DNAPL presence. Seismic signals can be used to locate DNAPL; knowledge of the effects of site-specific physical and chemical properties on seismic attenuation can assist in determining if such interrogation methods are viable. Knowledge of the chemical composition of the disposed DNAPL may allow use of chemical tracers that can be used to constrain DNAPL location. Combining measurement techniques with a numerical model of DNAPL migration in the subsurface can further constrain its location.

\section{Benefit:}

If the science needs are filled, then alternative technologies may be developed and deployed to locate and remediate subsurface DNAPL acting as a long-term source for groundwater contamination. Knowledge of chemical form and mobility make it possible to design the necessary remedial approach. Rapid location of DNAPL leads to the ability to plan and implement appropriate remedial technologies. 
Benefit code: check all that apply:

$\checkmark$ Cost Savings $\checkmark$ Risk Reduction $\checkmark$ Enabling Knowledge (i.e., solves a problem that cannot be remediated by current science/technology)

This Science Need also supports the following Hanford Subsurface Contaminant Technology Needs:

\begin{tabular}{||l|l|}
\hline \hline RL-SS01 & $\begin{array}{l}\text { Cost-effective, In-situ Remediation of Carbon Tetrachloride in the Vadose Zone } \\
\text { and Groundwater }\end{array}$ \\
\hline RL-SS02 & $\begin{array}{l}\text { Improved, Real-time, In-Line Detection of Carbon Tetrachloride in Process } \\
\text { Water }\end{array}$ \\
\hline RL-SS03 & $\begin{array}{l}\text { Improved, Real-time, In-Line Detection of Carbon Tetrachloride in } \\
\text { Groundwater }\end{array}$ \\
\hline RL-SS21 & Contaminant Mobility Beneath Tank Farms \\
\hline
\end{tabular}

\section{Contacts:}

For more information, contact:

Fred Serier, DOE

Shirley Rawson, PNNL
(509) $376-8517$

(509) $376-0223$ sa_rawson@pnl.gov 


\section{Hanford Site Science Need -- FY 1998 \\ Subsurface Contaminant Subgroup}

\section{Identification No.: RL-SS26-S}

Science Need Title: Transport of Contaminants--Reaction Rates for Key Contaminant Species and Complexes in Site-Specific Groundwaters

Site Priority Ranking: Soil and Groundwater Science Need-High

\section{Functional Need:}

For Hanford site conditions, determine the reaction rates and the key reaction steps that control the speed with which a contaminant changes chemical form (e.g., speciation, complexation) and/or interacts with the surfaces of secondary minerals. For waste streams associated with implemented restoration technologies, establish the important reactions and associated rates of contaminant transformation.

\section{Problem Description:}

Growth of contaminant plumes and their response to remedial actions both involve the transport of contaminants, which in turn depends on the interplay between hydraulics of subsurface systems and groundwater chemistry. The dissolved species concentrations in many groundwater systems may remain constant with time, implying either equilibrium or steady-state chemical conditions, controlled by slow dissolution/precipitation or adsorption/desorption reactions. Detailed analyses of such systems can reveal that many of the chemical reactions that occur consist of initially fast and then slower reaction steps, with the latter reactions being strongly affected by diffusion of species. For many species, ions must diffuse into the matrix of sediments before binding by adsoprtion or incorporation by secondary mineral precipitation can occur. Knowledge of the reaction rates within the aquifer system must be combined with information on hydraulic properties to understand plume growth and mobility in such environments, which is prerequisite to remedial technology selection and design. Once a technology is implemented, it becomes important to know both the reaction mechanisms and the rates of reactions that control the transformation of the contaminant, in order to assess accurately the longevity of remedial treatments.

\section{Science Need Description:}

Kinetic treatments of groundwater chemistry are usually required for chemical systems where reactions are slow, irreversible, or heterogeneous. The rates of reactions between minerals and groundwater are difficult to predict because of the dependence of the rate on the surface characteristics of the mineral grains, any adsorbed trace substances, and the possible presence of microorganisms that could catalyze reactions. Reactions of interest will involve reactions. between mineral surfaces and an aqueous solution. Science needs include direct determination of 
the rates of reactions for Hanford contaminants on secondary minerals important in Hanford subsurface environments, e.g., iron oxyhydroxides, calcium carbonates, or 2:1 layer silicates such as smectite or vermiculite or illite.

The mechanisms and reaction rates for the adsorption of metals and ligands on mineral surfaces are required. The role of surface reaction control vs. transport reaction control on specific reactions will be important. Groundwater systems in the Hanford and Ringold formations contain variable amounts of primary minerals such as plagioclase, quartz, and mafics associated with basaltic fragments which are thermodynamically unstable at low temperatures. Rates of primary mineral dissolution and secondary mineral precipitation are needed, as well as geochemical models for the incorporation of trace contaminants (metals, radionuclides) into secondary phases via co-precipitation.

\section{Benefit:}

If the science needs are filled, then accurate information is available for use in tools associated with the design and selection of appropriate remedial technologies. Using accurate geochemical models of subsurface contaminant reactions assists in the design of technologies that address the problem in a timely fashion with minimal impact on human health and the environment.

Benefit code: check all that apply:

$\checkmark$ Cost Savings $\checkmark$ Cost Risk Reduction Enabling Knowledge (i.e., solves a problem that cannot be remediated by current science/technology)

This Science Need also supports the following Hanford Subsurface Contaminant Technology Needs: 


\begin{tabular}{|c|c|}
\hline RL-SS01 & $\begin{array}{l}\text { Cost-effective, In-situ Remediation of Carbon Tetrachloride in the Vadose Zone } \\
\text { and Groundwater }\end{array}$ \\
\hline RL-SS03 & Improved, Real-time, In-situ Detection of Carbon Tetrachloride in Groundwater \\
\hline RL-SS04 & Cost-effective, In-situ Remediation of Hexavalent Chromium in Groundwater \\
\hline RL-SS06 & $\begin{array}{l}\text { Improved, Real-time, In-situ Detection of Hexavalent Chromium in } \\
\text { Groundwater }\end{array}$ \\
\hline RL-SS07 & Cost-effective, In-situ Remediation of Strontium-90 in Groundwater \\
\hline RL-SS09 & Improved, Real-time, In-situ Detection of Strontium-90 in Groundwater \\
\hline RL-SS11 & $\begin{array}{l}\text { Cost-effective, In-situ Remediation in the Vadose Zone of One or More of the } \\
\text { Following Heavy Metals: Hexavalent Chromium, Mercury, Lead }\end{array}$ \\
\hline RL-SS12 & $\begin{array}{l}\text { Cost-effective, In-situ Remediation in the Vadose Zone of One or More of the } \\
\text { Following Radionuclides: Uranium, Plutonium, Cesium, Cobalt, and Strontium- } \\
90\end{array}$ \\
\hline RL-SS15 & $\begin{array}{l}\text { Improved, In-situ Characterization to Determine the Extent of Soil } \\
\text { Contamination of One or More of the Following Heavy Metals: Hexavalent } \\
\text { Chromium, Mercury, Lead }\end{array}$ \\
\hline RL-SS16 & $\begin{array}{l}\text { Improved, In-situ Characterization to Determine the Extent of Soil } \\
\text { Contamination of One or More of the Following Radionuclides: Uranium, } \\
\text { Plutonium, Cesium, Cobalt, and Strontium-90 }\end{array}$ \\
\hline RL-SS21 & Contaminant Mobility Beneath Tank Farms \\
\hline
\end{tabular}

\section{Contacts:}

For more information, contact:

Fred Serier, DOE

(509) $376-8517$

Shirley Rawson, PNNL

(509) $376-0223$

sa_rawson@pnl.gov 


\section{Hanford Site Science Need -- FY 1998 \\ Subsurface Contaminant Subgroup}

Identification No.: RL-SS27-S

Science Need Title: Transport of Contaminants--Rates of Coupled Abiotic and Biogeochemical Reactions Involving Contaminants in Hanford Subsurface

Site Priority Ranking: Soil and Groundwater Science Need--High

\section{Functional Need:}

For Hanford site conditions, determine the effect on contaminant form (e.g., speciation/complexation/reaction) of coupling important abiotic and biogeochemical reactions for which independent rates of reaction are known.

\section{Problem Description:}

Numerous abiotic and biogeochemical reactions occur in complex geochemical systems. Individual rates can be determined in laboratories; in natural settings, these rates may not adequately describe the behavior of contaminant plume because coupling between chemical reactions and transport processes occurs. Depending on groundwater velocities, reactions that are transport-controlled may become more or less favored in the natural setting, and relative contributions of different reactions to buffering the chemical system could change. The potential for coupling of abiotic and biogeochemical reactions for Hanford contaminants must be assessed as part of selection of appropriate remedial alternatives.

\section{Science Need Description:}

In systems where reaction coupling may occur, it becomes important to determine how movement of a fluid of reactive components affects oxidation/reduction, aqueous and surface complexation, precipitation/dissolution, and interphase mass transfer. Coupling with convective and dispersive transport processes may result in different reaction pathways for the system, and science is needed to quantify these effects. Science is needed to understand the response of the biogeochemical system to the presence of zones ranging from transport-limited to reaction ratelimited conditions. Multiphase transport in heterogeneous media may need to incorporated in a broader understanding of a subsurface system. It will be important to establish how the biogeochemical system behaves under remediation stresses (chemical, hydraulic, thermal, phase changes).

IV. Benefit:

If the science needs are filled, then the relative importance of transport limitations vs. reactionrate limitations for important Hanford plumes will be known and incorporated into 
appropriate remedial technologies. Such information could affect the selection of technologies because the rate information is important to technology performance.

Benefit code: check all that apply:

$\checkmark$ Cost Savings $\checkmark$ Risk Reduction

$\checkmark$ Enabling Knowledge (i.e., solves a problem that cannot be remediated by current science/technology)

This Science Need also supports the following Hanford Subsurface Contaminant Technology Needs:

\begin{tabular}{||l|l||}
\hline RL-SS01 & $\begin{array}{l}\text { Cost-effective, In-situ Remediation of Carbon Tetrachloride in the Vadose Zone } \\
\text { and Groundwater }\end{array}$ \\
\hline RL-SS03 & Improved, Real-time, In-situ Detection of Carbon Tetrachloride in Groundwater \\
\hline RL-SS04 & Cost-effective, In-situ Remediation of Hexavalent Chromium in Groundwater \\
\hline RL-SS06 & $\begin{array}{l}\text { Improved, Real-time, In-situ Detection of Hexavalent Chromium in } \\
\text { Groundwater }\end{array}$ \\
\hline RL-SS07 & Cost-effective, In-situ Remediation of Strontium-90 in Groundwater \\
\hline RL-SS09 & \begin{tabular}{l} 
Improved, Real-time, In-situ Detection of Strontium-90 in Groundwater \\
\hline RL-SS11
\end{tabular} $\begin{array}{l}\text { Cost-effective, In-situ Remediation in the Vadose Zone of One or More of the } \\
\text { Following Heavy Metals: Hexavalent Chromium, Mercury, Lead }\end{array}$ \\
\hline RL-SS12 & $\begin{array}{l}\text { Cost-effective, In-situ Remediation in the Vadose Zone of One or More of the } \\
\text { Following Radionuclides: Uranium, Plutonium, Cesium, Cobalt, and } \\
\text { Strontium-90 }\end{array}$ \\
\hline RL-SS15 & $\begin{array}{l}\text { Improved, In-situ Characterization to Determine the Extent of Soil } \\
\text { Contamination of One or More of the Following Heavy Metals: Hexavalent } \\
\text { Chromium, Mercury, Lead }\end{array}$ \\
\hline RL-SS16 & $\begin{array}{l}\text { Improved, In-situ Characterization to Determine the Extent of Soil } \\
\text { Contamination of One or More of the Following Radionuclides: Uranium, } \\
\text { Plutonium, Cesium, Cobalt, and Strontium-90 }\end{array}$ \\
\hline RI-SS21 & \begin{tabular}{l} 
Contaminant Mobility Beneath Tank Farms \\
\hline \hline
\end{tabular}
\end{tabular}




\section{Contacts:}

For more information, contact:

Fred Serier, DOE

Shirley Rawson, PNNL
(509) $376-8517$

(509) 376-0223 sa_rawson@pnl.gov 


\section{Hanford Site Science Need -- FY 1998 \\ Subsurface Contaminant Subgroup}

Identification No.: RL-SS28-S

Science Need Title: Transport of Contaminants--Rates of Colloid Formation and Colloidal Transport of Contaminants in Site-Specific Groundwaters

Site Priority Ranking: Soil and Groundwater Science Need--High

\section{Functional Need:}

For Hanford site conditions, determine what secondary minerals form as colloids in groundwater, determine the importance of biosorption, and establish the nature of the chemical interactions between contaminants of interest and the surfaces of inorganic and organic colloids.

\section{Problem Description:}

Colloid-facilitated transport is not uncommon in the movement of low solubility contaminants in arid environments. Radionuclides such as plutonium have been demonstrated to move on silicate colloids at other arid sites, and organic contaminants can be adsorbed or co-solvated with both naturally-occurring and synthetic organic colloids. Metals can be adsorbed on inorganic colloids, complexed by organic colloids, or adsorbed on microbial surfaces. Such colloids are often charge-neutral and travel more quickly through groundwater systems than ions or complexes. Such behavior must be accounted for in the design and selection of appropriate remedial technologies.

\section{Science Need Description:}

The physical and chemical behavior of colloids in the subsurface can dramatically affect how the contaminants are transported, so it becomes important to know if Hanford subsurface environmental conditions are conducive to the formation of stable suspensions of mobile colloids. Science needs include the determination of mechanisms and rates of production of inorganic and organic colloids in Hanford groundwaters, the rates of adsorption of contaminants onto colloids, and the effect of colloid-facilitated transport on contaminant migration. In those part of the aquifer where there may be subsurface microbial communities, issues of microbial transport become important. Science needs also include the determination of important controls on biosorption of contaminants and bacterial/ colloid transport processes (e.g.the role of microbial transport processes such as growth, active attachment to surfaces, filtration by pores, settling within pores, on the ultimate dispersal and distribution of biosorbed contaminants). 
IV. Benefit:

If the science needs are filled, then understanding of the role of colloid-facilitated transport in the dispersal of Hanford contaminants will be possible. Better knowledge of the subsurface chemical systems supports selection of the most appropriate remedial technologies for the types of plumes being remediated.

Benefit code: check all that apply:
$\checkmark$ Cost Savings $\quad \checkmark$ Risk Reduction
$\checkmark$ Enabling Knowledge (i.e., solves a problem that cannot be remediated by current science/technology)

This Science Need also supports the following Hanford Subsurface Contaminant Technology Needs:

\begin{tabular}{||l|l||}
\hline RL-SS01 & $\begin{array}{l}\text { Cost-effective, In-situ Remediation of Carbon Tetrachloride in the Vadose Zone } \\
\text { and Groundwater }\end{array}$ \\
\hline RL-SS03 & Improved, Real-time, In-situ Detection of Carbon Tetrachloride in Groundwater \\
\hline RL-SS04 & Cost-effective, In-situ Remediation of Hexavalent Chromium in Groundwater \\
\hline RL-SS06 & $\begin{array}{l}\text { Improved, Real-time, In-situ Detection of Hexavalent Chromium in } \\
\text { Groundwater }\end{array}$ \\
\hline RL-SS07 & Cost-effective, In-situ Remediation of Strontium-90 in Groundwater \\
\hline RL-SS09 & \begin{tabular}{l} 
Improved, Real-time, In-situ Detection of Strontium-90 in Groundwater \\
\hline RL-SS11
\end{tabular} $\begin{array}{l}\text { Cost-effective, In-situ Remediation in the Vadose Zone of One or More of the } \\
\text { Following Heavy Metals: Hexavalent Chromium, Mercury, Lead }\end{array}$ \\
\hline RL-SS12 & $\begin{array}{l}\text { Cost-effective, In-situ Remediation in the Vadose Zone of One or More of the } \\
\text { Following Radionuclides: Uranium, Plutonium, Cesium, Cobalt, and Strontium- } \\
90\end{array}$ \\
\hline RL-SS15 & $\begin{array}{l}\text { Improved, In-situ Characterization to Determine the Extent of Soil } \\
\text { Contamination of One or More of the Following Heavy Metals: Hexavalent } \\
\text { Chromium, Mercury, Lead }\end{array}$ \\
\hline RL-SS16 & $\begin{array}{l}\text { Improved, In-situ Characterization to Determine the Extent of Soil } \\
\text { Contamination of One or More of the Following Radionuclides: Uranium, } \\
\text { Plutonium, Cesium, Cobalt, and Strontium-90 }\end{array}$ \\
\hline RL-SS21 & $\begin{array}{l}\text { Contaminant Mobility Beneath Tank Farms } \\
\text {. }\end{array}$ \\
\hline
\end{tabular}


V. Contacts:

For more information, contact:

Fred Serier, DOE

Shirley Rawson, PNNL
(509) 376-8517

(509) 376-0223 sa_rawson@pnl.gov 


\section{Hanford Site Science Need -- FY 1998 \\ Subsurface Contaminant Subgroup}

Identification No.: RL-SS29-S

Science Need Title: Transport of Contaminants--Effect of Subsurface Heterogeneities on Chemical Reaction and Transport

Site Priority Ranking: Soil and Groundwater Science Need--High

\section{Functional Need:}

Determine how the physical and chemical properties of the specific Hanford formations affect the transport of chemical solutes and colloids.

\section{Problem Description:}

Subsurface environments are heterogeneous in their physical and chemical properties at a variety of scales. Heterogeneities in surface areas of minerals can have significant impacts on reaction rates, whereas heterogeneous distributions of formation permeability affects transport velocities. Knowledge of how heterogeneous physical and chemical properties affect chemical solute and colloidal transport is important to the design of appropriate remedial technologies.

\section{Science Need Description:}

The science needed to elucidate the role of physical and chemical heterogeneities on subsurface transport of solutes and colloids can be focused on both (1) developing a more thorough understanding of the relative contributions of these heterogeneities to contaminant transport through controlled experimentation, and (2) rapidly and accurately characterizing the presence of these heterogeneities. Key science issues related to how physical properties affect transport include determining the effect of multidomain pore structures on solute, NAPL, and other contaminant transport rates under controlled pressure gradients, determining the role of pore structure on the movement of water in unsaturated porous media, and relating this information to convective and diffusive transport of contaminants. Key scientific issues related to the coupling of chemical reaction to physical transport include accounting for changes in the hydraulics due to precipitation/dissolution and/or biomass accumulation/destruction, determining the availability of sites for surface complexation based on chemical changes in the mineral surface area, and representing fully coupled bioreactive transport processes, where constituent reactions affect transport properties and vice versa.

Science is needed to characterize physical and chemical heterogeneity rapidly and remotely. Most remote sensing technologies (e.g., ground-penetrating radar, shallow seismic, electromagnetics) are sensitive to differences in the physical properties of the subsurface, such as sediment density, moisture content, physical structure, and clay content. Many of the 
technologies are also sensitive to thickness of different sediment layers or to depth of signal penetration into sediment. Science needs to address these issues include developing detection methods that provide adequate signal penetration and reflection/refraction and account for sediment moisture, grain size, and clay content. Science is needed to determine chemical information in situ as well.

\section{Benefit:}

If the science needs are filled, then alternative technologies may be developed and deployed to enhance the rate of remediation of different types of plumes. Use of in-situ remedial technology rather than ex-situ treatment will reduce risk and provide cost savings

Benefit code: check all that apply:

$\checkmark$ Cost Savings $\checkmark$ Risk Reduction $\checkmark$ Enabling Kniowledge (i.e., solves a problem that cannot be remediated by current science/technology)

This Science Need also supports the following Hanford Subsurface Contaminant Technology Needs: 


\begin{tabular}{|l|l||}
\hline RL-SS01 & $\begin{array}{l}\text { Cost-effective, In-situ Remediation of Carbon Tetrachloride in the Vadose Zone } \\
\text { and Groundwater }\end{array}$ \\
\hline RL-SS03 & Improved, Real-time, In-situ Detection of Carbon Tetrachloride in Groundwater \\
\hline RL-SS04 & Cost-effective, In-situ Remediation of Hexavalent Chromium in Groundwater \\
\hline RL-SS06 & $\begin{array}{l}\text { Improved, Real-time, In-situ Detection of Hexavalent Chromium in } \\
\text { Groundwater }\end{array}$ \\
\hline RL-SS07 & Cost-effective, In-situ Remediation of Strontium-90 in Groundwater \\
\hline RL-SS09 & \begin{tabular}{l} 
Improved, Real-time, In-situ Detection of Strontium-90 in Groundwater \\
\hline RL-SS11
\end{tabular} $\begin{array}{l}\text { Cost-effective, In-situ Remediation in the Vadose Zone of One or More of the } \\
\text { Following Heavy Metals: Hexavalent Chromium, Mercury, Lead }\end{array}$ \\
\hline RL-SS12 & $\begin{array}{l}\text { Cost-effective, In-situ Remediation in the Vadose Zone of One or More of the } \\
\text { Following Radionuclides: Uranium, Plutonium, Cesium, Cobalt, and Strontium- } \\
90\end{array}$ \\
\hline RL-SS15 & $\begin{array}{l}\text { Improved, In-situ Characterization to Determine the Extent of Soil } \\
\text { Contamination of One or More of the Following Heavy Metals: Hexavalent } \\
\text { Chromium, Mercury, Lead }\end{array}$ \\
\hline RL-SS16 & $\begin{array}{l}\text { Improved, In-situ Characterization to Determine the Extent of Soil } \\
\text { Contamination of One or More of the Following Radionuclides: Uranium, } \\
\text { Plutonium, Cesium, Cobalt, and Strontium-90 }\end{array}$ \\
\hline RL-SS21 & \begin{tabular}{l} 
Contaminant Mobility Beneath Tank Farms \\
\hline
\end{tabular}
\end{tabular}

\section{Contacts:}

For more information, contact:

Fred Serier, DOE

Shirley Rawson, PNNL
(509) 376-8517

(509) $376-0223$ sa_rawson@pnl.gov 


\section{Hanford Site Science Need -- FY 1998 \\ Subsurface Contaminant Subgroup}

Identification No.: RL-SS30-S

Science Need Title: Transport of Contaminants--Cs Migration Beneath Tanks

Site Priority Ranking: Soil and Groundwater Science Need--High

\section{Functional Need:}

For migration of $\mathrm{Cs}$ beneath Hanford waste tanks, determine the reaction rates affecting cesium adsorption on micaceous secondary minerals exposed to chemical conditions similar to those generated by leaking high-level waste.

\section{Problem Description:}

High-level wastes generated during special nuclear material production at the Hanford Site were stored in 177 underground storage tanks. Many of the single-shelled tanks have leaked, discharging up to 1 million gallons of waste to the subsurface. Much of the radioactivity in the leaking wastes is ascribed to highly soluble constituents, such as cesium-137. Cesium-137 generally adsorbs strongly to the types of micaceous secondary minerals found in the Hanford subsurface.

However, the wastes themselves have high concentrations of base (hydroxyl), aluminate, sodium, and nitrite/nitrate. These wastes are likely to react with Hanford subsurface minerals, causing dissolution and reprecipitation of material. The reactions of the waste on Hanford subsurface micaceous materials may be affecting the geochemical behavior of radiological constituents such as cesium-137. Preliminary characterization data for the unsaturated zone beneath SX tank farm in Hanford's 200 West area suggests the effect is to cause significant remobilization of cesium137 to deeper sections of the subsurface profile. Information is needed to assess the velocity of cesium-137 in the unsaturated zone beneath Hanford tanks.

\section{Science Need Description:}

Current geochemical understanding of the adsorption of cesium-137 on secondary micaceous minerals is based on measurements of phenomenological distribution coefficients in systems with a dilute aqueous phase. There are no direct measurements of the adsorption reactions of cesium on Hanford micaceous materials that have been exposed to solutions with high concentrations of base, salt, and aluminate. Science is needed to develop an improved understanding of the ion-exchange and surface adsorption processes affecting cesium on micaceous minerals in the presence of solutions similar to high-level tank wastes. Science is also needed to develop an accurate geochemical model that describes the molecular mechanisms and rates of cesium adsorption on micaceous minerals as a function of relevant solution and solid 
phased properties. These data are needed to design and select an appropriate remedial technology for cesium migration in the Hanford unsaturated zone.

\section{Benefit:}

If the science needs are filled, then alternative technologies may be developed and deployed to remediate cesium migration in the Hanford unsaturated zone. Use of in-situ remedial technology rather than ex-situ treatment will reduce risk and provide cost savings

Benefit code: check all that apply:

Cost Savings $\checkmark$ Risk Reduction $\checkmark$ Enabling Knowledge (i.e., solves a problem that cannot be remediated by current science/technology)

This Science Need also supports the following Hanford Subsurface Contaminant Technology Needs:

\begin{tabular}{|l|l|}
\hline RL-SS01 & $\begin{array}{l}\text { Cost-effective, In-situ Remediation of Carbon Tetrachloride in the Vadose Zone } \\
\text { and Groundwater }\end{array}$ \\
\hline RL-SS03 & Improved, Real-time, In-situ Detection of Carbon Tetrachloride in Groundwater \\
\hline RL-SS04 & Cost-effective, In-situ Remediation of Hexavalent Chromium in Groundwater \\
\hline RL-SS06 & $\begin{array}{l}\text { Improved, Real-time, In-situ Detection of Hexavalent Chromium in } \\
\text { Groundwater }\end{array}$ \\
\hline RL-SS07 & Cost-effective, In-situ Remediation of Strontium-90 in Groundwater \\
\hline RL-SS09 & Improved, Real-time, In-situ Detection of Strontium-90 in Groundwater \\
\hline RL-SS11 & $\begin{array}{l}\text { Cost-effective, In-situ Remediation in the Vadose Zone of One or More of the } \\
\text { Following Heavy Metals: Hexavalent Chromium, Mercury, Lead }\end{array}$ \\
\hline RL-SS12 & $\begin{array}{l}\text { Cost-effective, In-situ Remediation in the Vadose Zone of One or More of the } \\
\text { Following Radionuclides: Uranium, Plutonium, Cesium, Cobalt, and } \\
\text { Strontium-90 }\end{array}$ \\
\hline RL-SS15 & $\begin{array}{l}\text { Improved, In-situ Characterization to Determine the Extent of Soil } \\
\text { Contarnination of One or More of the Following Heavy Metals: Hexavalent } \\
\text { Chromium, Mercury, Lead }\end{array}$ \\
\hline RL-SS16 & $\begin{array}{l}\text { Improved, In-situ Characterization to Determine the Extent of Soil } \\
\text { Contarnination of One or More of the Following Radionuclides: Uranium, } \\
\text { Plutonium, Cesium, Cobalt, and Strontium-90 }\end{array}$ \\
\hline
\end{tabular}




\section{Contacts:}

For more information, contact:

Fred Serier, DOE

Shirley Rawson, PNNL
(509) $376-8517$

(509) 376-0223 sa_rawson@pnl.gov 


\section{Hanford Site Science Need -- FY 1998 \\ Subsurface Contaminant Subgroup}

\section{Identification No.: RL-SS31-S}

Science Need Title: Remediation--Mathematical Formulations of Chemical Reaction/Material Transport

Site Priority Ranking: Remedial Action--High

\section{Functional Need:}

For site conditions, contaminant chemistry and reactivity, and hydraulic properties at Hanford, formulate the chemistry and physics needed to describe the dispersal and longevity of subsurface contaminant plumes.

\section{Problem Description:}

As part of the design and selection of remedial technologies, the longevity and performance of different remedial alternatives will be addressed. Simple engineering models exist to assess technology performance. The assumptions of subsurface physical and chemical homogeneity, of chemical equilibrium, and of steady-state hydraulics in these models result in large uncertainties in the computed assessments of technology performance. Once remedial technologies are implemented, the longevity and performance of the technology can be monitored through direct measurements of the associated transformations of contaminants. The use of monitoring data in conjunction with accurate physical and chemical models of technology behavior will substantially increase the accuracy of longevity predictions. Improved accuracy of physical and chemical models of the processes involved in the technology will also require knowledge of the effect of spatial and temporal process scales.

\section{Science Need Description:}

Key scientific issues for the mathematical formulation of coupled multicomponent reactions and mass transfer include methods for incorporating and accommodating very different rates of chemical transformation (e.g., milliseconds to microseconds for homogenous acid -base transformations, to seconds to hours for adsorption/desorption reactions, to years for isotopic exchange or certain mineral-water reactions.) Science needs include determining the formulation of chemical reaction when coupled with steady-state and transient velocity fields for physical transport at a variety of length scales. Such needs point out the requirement of understanding the relationship among processes that occur on different temporal and length scales. Scaling is often addressed empirically. To incorporate information across a variety of temporal and spatial scales, it is important to know the physical and temporal scales at which biogeochemical processes, particularly nonlinear processes, occur in heterogeneous media. This need relates to the need for characterizing physical and chemical heterogeneity in the subsurface (RL-SS29-2: 
Transport of Contaminants--Effect of Subsurface Heterogeneities on Chemical Reaction and Transport), and determining the appropriate statistical descriptors of properties important to prediction of reactive transport at the field-scale. Science is also needed to improve the speed, accuracy, and resolution of codes that model multicomponent three-dimensional bioreactive transport processes.

IV. Benefit:

If the science needs are filled, the appropriate mathematic formulations of physical and chemical subsurface processes will be available for use in design and development of remedial alternatives. The longevity and performance of different remedial technologies can be screened to assure the best in-situ remedial technology or ex-situ treatment will be implemented at reduced risks to workers and at cost savings to the government.

Benefit code: check all that apply:

$\checkmark$ Cost Savings $\quad \checkmark$ Risk Reduction $\quad \checkmark$ Enabling Knowledge (i.e., solves a problem that
cannot be remediated by current science/technology)

This Science Need also supports the following Hanford Subsurface Contaminant Technology Needs: 


\begin{tabular}{|l|l||}
\hline RL-SS01 & $\begin{array}{l}\text { Cost-effective, In-situ Remediation of Carbon Tetrachloride in the Vadose Zone } \\
\text { and Groundwater }\end{array}$ \\
\hline RL-SS03 & Improved, Real-time, In-situ Detection of Carbon Tetrachloride in Groundwater \\
\hline RL-SS04 & Cost-effective, In-situ Remediation of Hexavalent Chromium in Groundwater \\
\hline RL-SS06 & $\begin{array}{l}\text { Improved, Real-time, In-situ Detection of Hexavalent Chromium in } \\
\text { Groundwater }\end{array}$ \\
\hline RL-SS07 & Cost-effective, In-situ Remediation of Strontium-90 in Groundwater \\
\hline RL-SS09 & Improved, Real-time, In-situ Detection of Strontium-90 in Groundwater \\
\hline RL-SS11 & $\begin{array}{l}\text { Cost-effective, In-situ Remediation in the Vadose Zone of One or More of the } \\
\text { Following Heavy Metals: Hexavalent Chromium, Mercury, Lead }\end{array}$ \\
\hline RL-SS12 & $\begin{array}{l}\text { Cost-effective, In-situ Remediation in the Vadose Zone of One or More of the } \\
\text { Following Radionuclides: Uranium, Plutonium, Cesium, Cobalt, and } \\
\text { Strontium-90 }\end{array}$ \\
\hline RL-SS15 & $\begin{array}{l}\text { Improved, In-situ Characterization to Determine the Extent of Soil } \\
\text { Contarnination of One or More of the Following Heavy Metals: Hexavalent } \\
\text { Chromium, Mercury, Lead }\end{array}$ \\
\hline RL-SS16 & $\begin{array}{l}\text { Improved, In-situ Characterization to Determine the Extent of Soil } \\
\text { Contamination of One or More of the Following Radionuclides: Uranium, } \\
\text { Plutonium, Cesium, Cobalt, and Strontium-90 }\end{array}$ \\
\hline RL-SS21 & \begin{tabular}{l} 
Contaminant Mobility Beneath Tank Farms \\
\hline \hline
\end{tabular} \\
\hline
\end{tabular}

\section{Contacts:}

For more information, contact:

Fred Serier, DOE

Shirley Rawson, PNNL
(509) 376-8517

(509) 376-0223 sa_rawson@pnl.gov 


\section{Hanford Site Science Need -- FY 1998 \\ Subsurface Contaminant Subgroup}

Identification No.: RL-SS32-S

Science Need Title: Remediation--Reactivity of Organics in the Hanford Subsurface

Site Priority Ranking: Remedial Action--High

\section{Functional Need:}

For naturally occurring organic matter and synthetic organic compounds in the Hanford subsurface, determine the rates of degradation reactions that supply energy to subsurface biological consortia that participate in dechlorination of halogenated solvents.

\section{Problem Description:}

Natural organic matter constitutes a fraction of the minerals in most subsurface hydrogeologic environments. Synthetic organic compounds, such as organic acids or chelating agents, and chlorinated solvents, also occur in contaminated parts of the subsurface. These compounds can undergo biodegradation by subsurface microbial communities. The biodegradation of the different compounds occurs at varying rates, and in the case of certain chlorinated hydrocarbons, involves cometabolic processes. The reactivity of these organics depends on the chemistry of the groundwater system (oxic, anoxic) and the nature of the subsurface microbial consortia and its degradative abilities.

\section{Science Need Description:}

The biodegradation of halogenated organic compounds (TCE, PCE, DCE, TCA, DCA--CC14, PCBs--primarily anaerobic) and metal/radionuclide organic complexes (EDTA, ED3A, citrate-aerobic or anaerobic) requires knowledge of the biochemical mechanisms/enzymes involved in the transformations. Potentially, the halogenated organic compounds undergo reductive dehalogenation by anaerobic bacteria. It will be important to determine the molecular phylogeny of these organisms and how they interact physiologically to degrade halogenated organics. The kinetics of the individual reactions must be known to determine whether pathways/enzymes can be engineered to overcome kinetic limitations. Science needs also include determining the electron donors that drive microbial dehalogenation and the stoichiometries required for complete dehalogenation of chlorinated organic compounds. For biodegradation of chelating agents, it will be important to know the speciation of contaminants with these agents, the metabolic pathways and enzymes involved, and the molecular basis for the substrate selectivity exhibited by transport and catabolic enzymes. Likewise, it will be important to determine the fate of the radionuclide or metal after the organic moiety has been degraded. 
Scientific issues associated with the nature of in-situ microbial consortia and their potential role in the transformation of contaminants include knowing the endogenous rates of microbial metabolism and how they relate to contaminant attenuation. It will be important to determine the spatial distributions of microorganisms, the composition of the microbial community and its nutrient requirements, and the in-situ microbial degradative capabilities in order to understand the scale, range, and distribution of kinetic rates for contaminant degradation. Science will be required to address whether the chemical composition of the aqueous phase could be manipulated to facilitate the desired reactions in situ.

\section{Benefit:}

If the science needs are filled, then alternative technologies may be developed and deployed to enhance the rate of remediation of different organic compounds in the subsurface. Use of in-situ remedial technology rather than ex-situ treatment will reduce risk and provide cost savings

Benefit code: check all that apply:

$\checkmark$ Cost Savings $\checkmark$ Risk Reduction $\checkmark$ Enabling Knowledge (i.e., solves a problem that cannot be remediated by current science/technology)

This Science Need also supports the following Hanford Subsurface Contaminant Technology Needs: 


\begin{tabular}{|c|c|}
\hline RL-SS01 & $\begin{array}{l}\text { Cost-effective, In-situ Remediation of Carbon Tetrachloride in the Vadose Zone } \\
\text { and Groundwater }\end{array}$ \\
\hline $\mathrm{RL}-\mathrm{SS} 03$ & Improved, Real-time, In-situ Detection of Carbon Tetrachloride in Groundwater \\
\hline $\mathrm{RL}-\mathrm{SS} 04$ & Cost-effective, In-situ Remediation of Hexavalent Chromium in Groundwater \\
\hline $\mathrm{RL}-\mathrm{SSO} 6$ & $\begin{array}{l}\text { Improved, Real-time, In-situ Detection of Hexavalent Chromium in } \\
\text { Groundwater }\end{array}$ \\
\hline RL-SS07 & Cost-effective, In-situ Remediation of Strontium-90 in Groundwater \\
\hline RL-SS09 & Improved, Real-time, In-situ Detection of Strontium-90 in Groundwater \\
\hline RL-SS11 & $\begin{array}{l}\text { Cost-effective, In-situ Remediation in the Vadose Zone of One or More of the } \\
\text { Following Heavy Metals: Hexavalent Chromium, Mercury, Lead }\end{array}$ \\
\hline RL-SS12 & $\begin{array}{l}\text { Cost-effective, In-situ Remediation in the Vadose Zone of One or More of the } \\
\text { Following Radionuclides: Uranium, Plutonium, Cesium, Cobalt, and } \\
\text { Strontium-90 }\end{array}$ \\
\hline RL-SS15 & $\begin{array}{l}\text { Improved, In-situ Characterization to Determine the Extent of Soil } \\
\text { Contanination of One or More of the Following Heavy Metals: Hexavalent } \\
\text { Chromium, Mercury, Lead }\end{array}$ \\
\hline RL-SS16 & $\begin{array}{l}\text { Improved, In-situ Characterization to Determine the Extent of Soil } \\
\text { Contarnination of One or More of the Following Radionuclides: Uranium, } \\
\text { Plutonium, Cesium, Cobalt, and Strontium-90 }\end{array}$ \\
\hline RL-SS21 & Contarninant Mobility Beneath Tank Farms \\
\hline
\end{tabular}

\section{Contacts:}

For more information, contact:

Fred Serier, DOE

Shirley Rawson, PNNL
(509) 376-8517

(509) 376-0223 sa_rawson@pnl.gov 


\section{Hanford Site Science Need -- FY 1998 \\ Subsurface Contaminant Subgroup}

Identification No.: RL-SS33-S

Science Need Title: Remediation--Interaction of Remedial Processes with Hanford Subsurface

Site Priority Ranking: Remedial Action--High

\section{Functional Need:}

For technologies implemented under Hanford conditions, determine the interactions and reactions between materials used in the remedial process, and dissolved, adsorbed, and/or precipitated contaminants associated with native mineral surfaces.

\section{Problem Description:}

Many of the remedial alternatives under consideration for implementation at Hanford require the manipulation of subsurface conditions, either passively as in the emplacement of zeolite containment barriers or actively as in pump/treat solutions or manipulation of the oxidation/reduction potential of the aquifer. The materials that will be introduced to the Hanford subsurface may have a noticeable effect on the existing steady-state chemistry. The types of interactions and their mechanisms and rates must be established to assess the effect on dissolved, adsorbed, or coprecipitated contaminant species. Likewise any competition for mineral surface sites must be examined.

\section{Science Need Description:}

For different implemented or proposed technologies, there will be information required to address the effect of the remediation process on the environment. Currently implemented technologies include pump/treat systems for the ex-situ removal of carbon tetrachloride from groundwater, and pump/treat systems for the reduction of chromate in groundwater. Technologies under testing and evaluation for possible implementation include redox manipulation of the subsurface using sodium dithionite. Science needs include the measurement of reaction rates involving contaminants being remediated and those solids, liquids, and/or gases introduced as part of remedial technologies.

\section{Benefit:}

If the science needs are filled, then a more accurate estimation of the performance and effectiveness of different alternative technologies may be assessed, supporting selection of the safest and most cost-effective remediation. More in-situ remedial technologies potentially could be implemented, thereby reducing human health risk and providing cost savings. 
Benefit code: check all that apply:

$\checkmark$ Cost Savings $\checkmark$ Risk Reduction $\checkmark$ Enabling Knowledge (i.e., solves a problem that cannot be remediated by current science/technology)

This Science Need also supports the following Hanford Subsurface Contaminant Technology Needs:

\begin{tabular}{|l|l|}
\hline RL-SS01 & $\begin{array}{l}\text { Cost-effective, In-situ Remediation of Carbon Tetrachloride in the Vadose Zone } \\
\text { and Groundwater }\end{array}$ \\
\hline RL-SS03 & Improved, Real-time, In-situ Detection of Carbon Tetrachloride in Groundwater \\
\hline RL-SS04 & Cost-effective, In-situ Remediation of Hexavalent Chromium in Groundwater \\
\hline RL-SS06 & $\begin{array}{l}\text { Improved, Real-time, In-situ Detection of Hexavalent Chromium in } \\
\text { Groundwater }\end{array}$ \\
\hline RL-SS07 & Cost-effective, In-situ Remediation of Strontium-90 in Groundwater \\
\hline RL-SS09 & \begin{tabular}{l} 
Improved, Real-time, In-situ Detection of Strontium-90 in Groundwater \\
\hline RL-SS11
\end{tabular} $\begin{array}{l}\text { Cost-effective, In-situ Remediation in the Vadose Zone of One or More of the } \\
\text { Following Heavy Metals: Hexavalent Chromium, Mercury, Lead }\end{array}$ \\
\hline RL-SS12 & $\begin{array}{l}\text { Cost-effective, In-situ Remediation in the Vadose Zone of One or More of the } \\
\text { Following Radionuclides: Uranium, Plutonium, Cesium, Cobalt, and } \\
\text { Strontium-90 }\end{array}$ \\
\hline RL-SS15 & $\begin{array}{l}\text { Improved, In-situ Characterization to Determine the Extent of Soil } \\
\text { Contamination of One or More of the Following Heavy Metals: Hexavalent } \\
\text { Chromium, Mercury, Lead }\end{array}$ \\
\hline RL-SS16 & $\begin{array}{l}\text { Improved, In-situ Characterization to Determine the Extent of Soil } \\
\text { Contamination of One or More of the Following Radionuclides: Uranium, } \\
\text { Plutonium, Cesium, Cobalt, and Strontium-90 }\end{array}$ \\
\hline RL-SS21 & \begin{tabular}{l} 
Contaminant Mobility Beneath Tank Farms \\
\hline
\end{tabular}
\end{tabular}

\section{Contacts:}

For more information, contact:

Fred Serier, DOE

Shirley Rawson, PNNL
(509) $376-8517$

(509) $376-0223$ sa_rawson@pnl.gov 


\section{Hanford Site Science Need -- FY 1998 \\ Subsurface Contaminant Subgroup}

Identification No.: RL-SS34-S

Science Need Title: Remediation--Selectivity for Contaminants in the Hanford Subsurface

Site Priority Ranking: Remedial Action--High

\section{Functional Need:}

For Hanford site conditions, determine those chemical reactions that can select among contaminants and be used to separate contaminants from contaminated groundwaters and soils.

\section{Problem Description:}

Many sites at Hanford are contaminated with several different classes of chemicals, such as radionuclides, metals, and organic compounds. Mixtures of these contaminants are common. It is possible that remediation of a chemically complex site may require the implementation of multiple technologies. It will be important to assess whether the technology proposed for remediation one class of compound affects the behavior of another class of compounds. For example, if treatment of one compound to immobilize it results in the accelerated mobility of another class of compound, then these effects must be recognized prior to technology implementation. Sufficient information is needed to assess the synergistic effects of technology and to design selective treatments if warranted. The technical issue associated with this science need is the ability to implement chemistry that selects among contaminants in soil and groundwater.

\section{Science Need Description:}

Selectivity for different contaminants in soil and groundwater depends on the speciation and complexation of each contaminant, the types of reactions that change the chemical form on the contaminant (e.g., dissolution/precipitation, adsorption, oxidation/reduction), and the nature of the other contaminants in the mixture. Science needs include the identification of natural or engineered chemical reactions within aquifer systems that can serve to separate different contaminant classes in the aqueous and in the solid phases, determining speciation and complexation for the contaminants, and measuring rates of the reactions of interest. These data can then be used to propose and evaluate technologies that could be used to selectively remediate contaminants.

\section{Benefit:}

If the science needs are filled, then alternative technologies may be developed and deployed to enhance the remediation of contaminant mixtures. Use of in-situ remedial technology rather than ex-situ treatment will reduce risk and provide cost savings 
Benefit code: check all that apply:

$\checkmark$ Cost Savings $\checkmark$ Risk Reduction

$\checkmark$ Enabling Knowledge (i.e., solves a problem that cannot be remediated by current science/technology)

This Science Need also supports the following Hanford Subsurface Contaminant Technology Needs:

\begin{tabular}{||l|l||}
\hline RL-SS01 & $\begin{array}{l}\text { Cost-effective, In-situ Remediation of Carbon Tetrachloride in the Vadose Zone } \\
\text { and Groundwater }\end{array}$ \\
\hline RL-SS03 & Improved, Real-time, In-situ Detection of Carbon Tetrachloride in Groundwater \\
\hline RL-SS04 & Cost-effective, In-situ Remediation of Hexavalent Chromium in Groundwater \\
\hline RL-SS07 & $\begin{array}{l}\text { Improved, Real-time, In-situ Detection of Hexavalent Chromium in } \\
\text { Groundwater }\end{array}$ \\
\hline RL-SS09 & \begin{tabular}{l} 
Improved, Real-time, In-situ Detection of Strontium-90 in Groundwater \\
\hline RL-SS11
\end{tabular} $\begin{array}{l}\text { Cost-effective, In-situ Remediation in the Vadose Zone of One or More of the } \\
\text { Following Heavy Metals: Hexavalent Chromium, Mercury, Lead }\end{array}$ \\
\hline RL-SS12 & $\begin{array}{l}\text { Cost-effective, In-situ Remediation in the Vadose Zone of One or More of the } \\
\text { Following Radionuclides: Uranium, Plutonium, Cesium, Cobalt, and } \\
\text { Strontium-90 }\end{array}$ \\
\hline RL-SS15 & $\begin{array}{l}\text { Improved, In-situ Characterization to Determine the Extent of Soil } \\
\text { Contamination of One or More of the Following Heavy Metals: Hexavalent } \\
\text { Chromium, Mercury, Lead }\end{array}$ \\
\hline RL-SS16 & $\begin{array}{l}\text { Improved, In-situ Characterization to Determine the Extent of Soil } \\
\text { Contamination of One or More of the Following Radionuclides: Uranium, } \\
\text { Plutonium, Cesium, Cobalt, and Strontium-90 }\end{array}$ \\
\hline Contaminant Mobility Beneath Tank Farms \\
\hline
\end{tabular}

\section{Contacts:}

For more information, contact:

Fred Serier, DOE

Shirley Rawson, PNNL
(509) 376-8517

(509) $376-0223$ sa_rawson@pnl.gov 


\section{Hanford Site Science Need -- FY 1998 \\ Subsurface Contaminant Subgroup}

Identification No.: RL-SS35-S

Science Need Title: Monitoring of Contaminants--Use of Chemical Surrogates for Contaminants

Site Priority Ranking: Remedial Action--High

\section{Functional Need:}

To assess potential migration of difficult-to-measure contaminants in the Hanford subsurface, select relevant chemical analogues (similar group, charge, ionic size) to contaminant of interest that can be measured by existing measurement technologies.

\section{Problem Description:}

The chemical analysis of certain radiological or metallic constituents in Hanford subsurface plumes are difficult and time-intensive to perform, making monitoring of the performance of different remedial technologies very expensive. For some classes of compounds, chemical analogues have been identified based on chemical form, charge, and ionic size. The properties of these analogues are often similar to the contaminant of interest and the analogues have the advantage of being either easier or safer to measure. Existing technologies for chemical analysis make it possible to implement field monitoring for the analogs more readily than for the contaminants. The question arises as to the extent of similarity of the behavior of the analogue and the contaminant; the technical issue related to the science need is to demonstrate the adequacy of measuring the analogue to understand the behavior of the contaminant.

\section{Science Need Description:}

Science needs include the identification of adequate surrogates for the contaminants of interest. Given an adequate surrogate, it is then important to determine the types, mechanisms, and rates of reactions involving those surrogates, and the incorporation of such reactions into performance assessment tools. Given information on the speciation, complexation, and reactions affecting surrogates, the concentrations of the surrogates can be measured and used as estimators of the concentrations of hard-to-measure contaminants.

\section{Benefit:}

If the science needs are filled, then alternative measurements of technology performance can be made to trace the effectiveness of the remediation. Use of in-situ monitoring technology rather than ex-situ analysis may be possible, and will reduce risk and provide cost savings over full laboratory analyses needed for some radiological contaminants. 
Benefit code: check all that apply:

$\checkmark$ Cost Savings $\checkmark$ Risk Reduction $\checkmark$ Enabling Knowledge (i.e., solves a problem that cannot be remediated by current science/technology)

This Science Need also supports the following Hanford Subsurface Contaminant Technology Needs:

\begin{tabular}{|l|l|}
\hline RL-SS01 & $\begin{array}{l}\text { Cost-effective, In-situ Remediation of Carbon Tetrachloride in the Vadose Zone } \\
\text { and Groundwater }\end{array}$ \\
\hline RL-SS03 & Improved, Real-time, In-situ Detection of Carbon Tetrachloride in Groundwater \\
\hline RL-SS04 & Cost-effective, In-situ Remediation of Hexavalent Chromium in Groundwater \\
\hline RL-SS06 & $\begin{array}{l}\text { Improved, Real-time, In-situ Detection of Hexavalent Chromium in } \\
\text { Groundwater }\end{array}$ \\
\hline RI,-SS07 & Cost-effective, In-situ Remediation of Strontium-90 in Groundwater \\
\hline RL-SS09 & \begin{tabular}{l} 
Improved, Real-time, In-situ Detection of Strontium-90 in Groundwater \\
\hline RL-SS11
\end{tabular} $\begin{array}{l}\text { Cost-effective, In-situ Remediation in the Vadose Zone of One or More of the } \\
\text { Following Heavy Metals: Hexavalent Chromium, Mercury, Lead }\end{array}$ \\
\hline RL-SS12 & $\begin{array}{l}\text { Cost-effective, In-situ Remediation in the Vadose Zone of One or More of the } \\
\text { Following Radionuclides: Uranium, Plutonium, Cesium, Cobalt, and } \\
\text { Strontium-90 }\end{array}$ \\
\hline RL-SS15 & $\begin{array}{l}\text { Improved, In-situ Characterization to Determine the Extent of Soil } \\
\text { Contarnination of One or More of the Following Heavy Metals: Hexavalent } \\
\text { Chromium, Mercury, Lead }\end{array}$ \\
\hline RL-SS16 & $\begin{array}{l}\text { Improved, In-situ Characterization to Determine the Extent of Soil } \\
\text { Contarnination of One or More of the Following Radionuclides: Uranium, } \\
\text { Plutonium, Cesium, Cobalt, and Strontium-90 }\end{array}$ \\
\hline RL-SS21 & \begin{tabular}{l} 
Contarninant Mobility Beneath Tank Farms \\
\hline
\end{tabular}
\end{tabular}

V. Contacts:

For more information, contact:

Fred Serier, DOE

Shirley Rawson, PNNL
(509) $376-8517$

(509) $376-0223$ sa_rawson@pnl.gov 


\section{Hanford Site Science Need -- FY 1998 \\ Subsurface Contaminant Subgroup}

Identification No.: RL-SS36-S

Science Need Title: Monitoring of Contaminants--Chemical Indicators of Remedial Technology Processes

Site Priority Ranking: Remedial Action--High

\section{Functional Need:}

For Hanford site-specific conditions, identify the species that form during a remedial technology process (chemical, physical, and/or biological) and are indicative of key reactions that make the technology work. Determine concentrations of key species that represent the endpoint(s) of the technology process.

\section{Problem Description:}

Some of the remedial technologies that are identified for implementation at Hanford call for the introduction of chemical or biological materials to the subsurface. These materials will cause reactions in the groundwater system that are aimed at reducing or transforming the contaminant plumes. To assess performance of the remedial technologies and determine whether an endpoint has been reached, measurements of different chemical species will be made. Feasibility studies for remedial alternatives will have identified key important reactions for the different technologies. It will be important to know which species are indicative of endpoints for the chemical reactions involved in the technology. For example, if reduction and immobilization of chromate to chromium (IV) is part of a remedial technology, it will be important to know when the concentration of chromate drops below the necessary target level as an indication that the end of the process has been reached.

\section{Science Need Description:}

Science needs include measuring the rates of reactions fundamental to the operation of remedial technologies, and identifying the species and concentration indicative of the endpoint of the reactions and therefore the remedial processes. Information is needed for current remedial approaches and for those approaches being demonstrated at pilot scale, such as in-situ redox manipulation to reduce contaminants such as chromate, uranium, and chlorinated hydrocarbons.

\section{Benefit:}

If the science needs are filled, then it will be possible to design and implement a post-closure monitoring plan that adequately assesses technology performance and can be used to 
determine when a remediation is complete. Use of in-situ monitoring technology for endpoint concentrations will reduce risk to human health and provide cost savings.

Benefit code: check all that apply:

Cost Savings $\checkmark$ Risk Reduction $\checkmark$ Enabling Knowledge (i.e., solves a problem that cannot be remediated by current science/technology)

This Science Need also supports the following Hanford Subsurface Contaminant Technology Needs:

\begin{tabular}{|c|c|}
\hline RL-SS01 & $\begin{array}{l}\text { Cost-effective, In-situ Remediation of Carbon Tetrachloride in the Vadose Zone } \\
\text { and Groundwater }\end{array}$ \\
\hline $\mathrm{RL}-\mathrm{SS} 03$ & Improved, Real-time, In-situ Detection of Carbon Tetrachloride in Groundwater \\
\hline RL-SS04 & Cost-effective, In-situ Remediation of Hexavalent Chromium in Groundwater \\
\hline RL-SS06 & $\begin{array}{l}\text { Improved, Real-time, In-situ Detection of Hexavalent Chromium in } \\
\text { Groundwater }\end{array}$ \\
\hline $\mathrm{RL}-\mathrm{SSO} 7$ & Cost-effective, In-situ Remediation of Strontium-90 in Groundwater \\
\hline $\mathrm{RL}-\mathrm{SS} 09$ & Improved, Real-time, In-situ Detection of Strontium-90 in Groundwater \\
\hline RL-SS11 & $\begin{array}{l}\text { Cost-effective, In-situ Remediation in the Vadose Zone of One or More of the } \\
\text { Following Heavy Metals: Hexavalent Chromium, Mercury, Lead }\end{array}$ \\
\hline RL-SS12 & $\begin{array}{l}\text { Cost-effective, In-situ Remediation in the Vadose Zone of One or More of the } \\
\text { Following Radionuclides: Uranium, Plutonium, Cesium, Cobalt, and } \\
\text { Strontium-90 }\end{array}$ \\
\hline RL-SS15 & $\begin{array}{l}\text { Improved, In-situ Characterization to Determine the Extent of Soil } \\
\text { Contarnination of One or More of the Following Heavy Metals: Hexavalent } \\
\text { Chromium, Mercury, Lead }\end{array}$ \\
\hline RL-SS16 & $\begin{array}{l}\text { Improved, In-situ Characterization to Determine the Extent of Soil } \\
\text { Contarnination of One or More of the Following Radionuclides: Uranium, } \\
\text { Plutonium, Cesium, Cobalt, and Strontium-90 }\end{array}$ \\
\hline RL-SS21 & Contaminant Mobility Beneath Tank Farms \\
\hline
\end{tabular}


V. Contacts:

For more information, contact:

Fred Serier, DOE

Shirley Rawson, PNNL
(509) $376-8517$

(509) $376-0223$ sa_rawson@pnl.gov 


\section{Hanford Site Science Need -- FY 1998 \\ Subsurface Contaminant Subgroup}

Identification No.: RL-SS37-S

Science Need Title: Monitoring of Contaminants--Chemical Sensor Principles

Site Priority Ranking: Remedial Action--High

\section{Functional Need:}

Establish the physics and chemistry principles that underlie more accurate, more sensitive, and higher resolution measurements of contaminant concentrations in the aqueous and solid (surface) phases

\section{Problem Description:}

Monitoring technology performance requires the ability to measure contaminant concentrations in liquids and solids in a timely, safe manner either in-situ or in-line. Currently there are very few highly accurate in-situ or in-line sensors for contaminants of interest. Innovative probes based on fundamental principles are needed to address the gap.

\section{Science Need Description:}

Science needs include obtaining a better understanding of the physics and chemistry that will lead more accurate, more sensitive, and higher resolution measurements. Theory from the fields of electronics, electrical engineering, microfluidics, and chemical physics can be examined for their ability to provide innovative measurement technology.

\section{Benefit:}

If the science needs are filled, then it will be possible to make high-speed, accurate, highresolution analyses of different contaminant species in-situ. These new sensors will reduce risk to human health and provide cost savings.

Benefit code: check all that apply:

$\checkmark$ Cost Savings $\checkmark$ Risk Reduction $\checkmark$ Enabling Knowledge (i.e., solves a problem that cannot be remediated by current science/technology)

This Science Need also supports the following Hanford Subsurface Contaminant Technology Needs: 


\begin{tabular}{|c|c|}
\hline $\mathrm{RL}-\mathrm{SS} 02$ & $\begin{array}{l}\text { Improved, Real-time, In-line Detection of Carbon Tetrachloride in Process } \\
\text { Water }\end{array}$ \\
\hline $\mathrm{RL}-\mathrm{SS} 03$ & Improved, Real-time, In-situ Detection of Carbon Tetrachloride in Groundwater \\
\hline RL-SS05 & $\begin{array}{l}\text { Improved, Real-time, In-line Detection of Hexavalent Chromium in Process } \\
\text { Water }\end{array}$ \\
\hline RL-SS06 & $\begin{array}{l}\text { Improved, Real-time, In-situ Detection of Hexavalent Chromium in } \\
\text { Groundwater }\end{array}$ \\
\hline RL-SS08 & Improved, Real-time, In-line Detection of Strontium-90 in Process Water \\
\hline RI-SS09 & Improved, Real-time, In-situ Detection of Strontium-90 in Groundwater \\
\hline RL-SS15 & $\begin{array}{l}\text { Improved, In-situ Characterization to Determine the Extent of Soil } \\
\text { Contamination of One or More of the Following Heavy Metals: Hexavalent } \\
\text { Chromium, Mercury, Lead }\end{array}$ \\
\hline RL-SS16 & $\begin{array}{l}\text { Improved, In-situ Characterization to Determine the Extent of Soil } \\
\text { Contamination of One or More of the Following Radionuclides: Uranium, } \\
\text { Plutonium, Cesium, Cobalt, and Strontium-90 }\end{array}$ \\
\hline RL-SS21 & Contaminant Mobility Beneath Tank Farms \\
\hline
\end{tabular}

\section{Contacts:}

For more information, contact:

Fred Serier, DOE

Shirley Rawson, PNNL
(509) $376-8517$

(509) 376-0223 sa_rawson@pnl.gov 


\section{Subsurface Contaminant Priority Technology Needs \\ Fiscal Year 1997 to 1998 Crosswalk}

FY97 ID

Needs Title

FY98 ID

No.

No.

RL-SS01 In Situ Remediation of Carbon Tetrachloride in Groundwater

RL-SSOI

RI-SS02 In Situ Remediation of Hexavalent Chromium in the Groundwater RL-SS04 and the Vadose Zone

RL-SS03 In Situ Remediation of Strontium-90 Groundwater

RL-SS07

RL-SS04 Real-time, In-line Detection of Strontium, Chromium, Carbon

$\mathrm{RL}-\mathrm{SS} 02$

Tetrachloride, and Uranium in Water to Assist with Pump and Treat

Operation and Monitoring

$\mathrm{RL}-\mathrm{SS} 05$

RL-SS08

RL-SS05 Real-time, In Situ Detection of Strontium-90, Chromium, Carbon

Tetrachloride, and Uranium

RL-SS03

RL-SS06

RL-SS09

RL-SS06 Detection/Delineation of Burial Ground Contents

RI-SS10

RL-SS07 Detection and Location of Cultural Resources; Continuous Observation of Excavation

Deleted

RL-SS08 In Situ Detection and Characterization of Contaminants in Soils Under Waste Management Units and Tanks, Including Technetium99, Cesium-137, and Cobalt-60

RL-SS09 Cost Effective, Environmentally Safe and Compliant Method to

RL-SS12 Release Strontium-90 Currently Absorbed in the Soil Within the Aquifer

RL-SS010 In Situ Remediation of Radioactive and Inorganic Contaminants

RL-SS 11 from the Near-Surface "Concentrated Layer" at 1301-N and 1325-N 
The science needs for the Subsurface Contaminant Subgroup were developed through a new process in FY 1998. Staff from DOE-RL and Bechtel Hanford Incorporated, including project managers, engineers and representatives from the technology application office, held workshops with scientists from the William R. Wiley Environmental Molecular Sciences Laboratory. The workshop began an on-going dialogue intended to foster discussion between the three organizations and identify opportunities to link science into the technical baseline at Hanford. The workshop produced a package of science needs explicitly identified and endorsed by end-user organizations and expressed in the language of the scientific community.

However, since the workshop attendees did not use the FY 1997 science needs package as a specific starting point, it is more difficult to crosswalk last year's needs to this year's needs. The table below shows the needs, both for FY97 and FY98, in four general categories as a rough crosswalk.

FY 1997-1998 SUBCON SCIENCE NEEDS CROSSWALK

\begin{tabular}{|l|l|l|}
\hline \multicolumn{1}{|c|}{ Need Category } & \multicolumn{1}{|c|}{$\begin{array}{c}\text { FY97 Science Needs } \\
\text { in This Category }\end{array}$} & \multicolumn{1}{c|}{ FY98 Science Needs in This Category } \\
\hline $\begin{array}{l}\text { Detectiony } \\
\text { Distribution of } \\
\text { Contaminants }\end{array}$ & $\begin{array}{l}\text { RL-SS015-S, Remote Sensing of } \\
\text { Burial Ground Contents }\end{array}$ & $\begin{array}{l}\text { RL-SS23-S, Chemical Speciation and Complexation in } \\
\text { Site-Specific Groundwaters; RL-SS24-S, Chemical Binding } \\
\text { on Sit-Specific Mineral Surfaces; RL-SS25-S, Chemical } \\
\text { Form and Mobility of Dense, Non-Aqueous Phase Liquids in } \\
\text { Hanford Subsurface }\end{array}$ \\
\hline $\begin{array}{l}\text { Transport of } \\
\text { Contaminants }\end{array}$ & $\begin{array}{l}\text { RL-SS014-S, Dense, } \\
\text { Non-Aqueous Phase Liquid } \\
\text { (DNAPL) Chemistry and Physics } \\
\text { in the Subsurface }\end{array}$ & $\begin{array}{l}\text { RL-SS26-S, Reaction Rates for Key Contaminant Species and } \\
\text { Complexes in Site-Specific Groundwaters; RL-SS27-S, Rates } \\
\text { of Coupled Abiotic and Biogeochemical Reactions Involving } \\
\text { Contaminants in Hanford Subsurface; RL-SS28-S, Rates of } \\
\text { Colloid Formation and Colloidal Transport of Contaminants } \\
\text { in Site-Specific Groundwaters; RL-SS29-S, Effect of } \\
\text { Subsurface Heterogeneities on Chemical Reaction and } \\
\text { Transport; RL-SS30-S, Cs Migration Beneath Waste Tanks }\end{array}$ \\
\hline Remediation & $\begin{array}{l}\text { RL-SS012-S, Chlorinated } \\
\text { Solvent Dechlorination } \\
\text { Chemistry; RL-SS017-S, Surface } \\
\text { Barrier Longevity }\end{array}$ & $\begin{array}{l}\text { RL-SS31-S, Mathematical Formulations of Chemical } \\
\text { Reaction/Material Transport; RL-SS32-S, Reactivity of } \\
\text { Organics in the Hanford Subsurface; RL-SS33-S, Interaction } \\
\text { of Remedial Processes with Hanford Subsurface; RL-SS34-S, } \\
\text { Selectivity for Contaminants in the Hanford Subsurface }\end{array}$ \\
\hline Monitoring of & $\begin{array}{l}\text { RL-SS013-S, Analytical } \\
\text { Methods/Techniques for In-Situ } \\
\text { Measurements and Detection } \\
\text { During Treatment }\end{array}$ & $\begin{array}{l}\text { RL-SS35-S, Use of Chemical Surrogates for Contaminants; } \\
\text { RL-SS36-S, Chemical Indicators of Remedial Technology } \\
\text { Processes; RL-SS37-S, Chemical Sensor Principles }\end{array}$ \\
\hline
\end{tabular}




\section{TANKS TECHNOLOGY NEEDS}

\begin{tabular}{|l|l|}
\hline \multicolumn{1}{|c|}{ ID\# } & \multicolumn{1}{|c|}{ NEEDS TITLE } \\
\hline RL-WT01 & Technetium-99 Analysis in Low Level Waste Feed \\
\hline RL-WT02 & In-Tank Core Sampling...Off-Riser Capability \\
\hline RL-WT03 & Large Volume (3-5 liter) Sludge and Supernate Sampler \\
\hline RL-WT04 & DST Corrosion Monitoring \\
\hline RL-WT05 & Remote Inspection of High-Level Waste Single Shell Tanks \\
\hline RL-WT06 & $\begin{array}{l}\text { Identification and Management of Problem Constituents for HLW } \\
\text { Vitrification }\end{array}$ \\
\hline RL-WT07 & $\begin{array}{l}\text { Hanford Capsule Initiative (HCI): A Processing Demonstration of } \\
\text { Cs/Sr Capsules for Final Disposition }\end{array}$ \\
\hline RL-WT08 & $\begin{array}{l}\text { Advanced Methods for Achieving Low-Level Waste Volume } \\
\text { Minimization }\end{array}$ \\
\hline RL-WT09 & $\begin{array}{l}\text { Representative Sampling and Associated Analysis to Support } \\
\text { Operations and Disposal }\end{array}$ \\
\hline RL-WT010 & ILAW Product Acceptance Inspection and Test Methods \\
\hline RL-WT011 & IHLW Product Acceptance Inspection and Test Methods \\
\hline RL-WT012 & Secondary Products Acceptance Inspection and Test Methods \\
\hline RL-WT013 & Establish Retrieval Performance Evaluation Criteria \\
\hline RL-WT014 & Alternative to Baseline Tank Waste Mixing System \\
\hline RL-WT015 & Standard Method for Determining Waste Form Release Rate \\
\hline RL-WT016 & Glass Monolith Surface Area \\
\hline RL-WT017 & Long-Term Testing of Surface Barrier \\
\hline RL-WT018 & Testing of Sand-Gravel Capillary Barrier \\
\hline RL-WT019 & Getter Materials \\
\hline RL-WT020 & Service Integrity Testing of HLW Tanks and Piping \\
\hline RL-WT021 & Cleaning and Decontamination of Hanford Pits \\
\hline & \\
\hline &
\end{tabular}




\begin{tabular}{|c|l|}
\hline \multicolumn{1}{|c|}{ ID\# } & \multicolumn{1}{|c|}{ NEEDS TITLE } \\
\hline RL-WT022 & Tank Knuckle NDE \\
\hline RL-WT023 & $\begin{array}{l}\text { Prediction of Solid Phase Formation in Hanford Tank Waste } \\
\text { Solutions }\end{array}$ \\
\hline RL-WT024 & Enhanced Sludge Washing Process Data \\
\hline RL-WT025 & Remote Sensing Of Gas Retention In HLW Slurries \\
\hline RL-WT026 & $\begin{array}{l}\text { Tank Leak Detection Systems for Underground Single-Shel1 } \\
\text { Waste Storage Tanks (SSTs) }\end{array}$ \\
\hline RL-WT027 & Tank Leak Mitigation Systems \\
\hline RL-WT028 & Waste Mobilization Enhancement \\
\hline RL-WT029 & Data and Tools for Performance Assessments \\
\hline RL-WT030 & Contaminant Mobility Beneath Tank Farms \\
\hline
\end{tabular}




\section{TECHNOLOGY NEEDS/OPPORTUNITIES \\ STATEMENT OUTLINE}

Identification No.: $\underline{\mathrm{RL}}$-WT01

Date: September 1997

Program: Tanks - Characterization

OPS Office/Site: Richland

Operating Unit: Not Applicable

Waste Stream: Low Level Waste

Waste Management Unit: Not Applicable

Facility: 222-S Laboratory

Site Priority Ranking: High

Need Title: Technetium-99 Analysis in Low Level Waste Feed

Need Description: An accurate, robust production laboratory method for the measurement of technetium-99 concentration in Hanford waste tank material is needed. The measurement methodology needs to be tested for consistency of performance between DOE Sites characterizing waste materials (round robin exchange, etc.). This methodology must also be suitable for characterizing soils from the vadose zone which receives any leakage of tank wastes.

Functional Performance Requirements: A methodology is needed which is appropriate for production laboratory use to routinely measure the concentration of technetium-99 in waste tank matrices representing any of the waste classifications considered potential feed sources to the vitrification vendors.

1. Candidate methodologies should be tested by round robin exchanges of actual samples selected for variability due to matrix and interferences.

2. Absolute accuracy represented by agreement in the concentration value of better than $+/-$ 10 percent is required.

3. Precision, as measured by the reproducibility of replicate measurements of a sample should be no greater than $+/-15$ percent.

4. The methodology demonstrated should be rapid, representing no more than 4 hours to complete.

Schedule Requirements: Waste identification is in progress in 1997, and waste staging for the private vitrification contractor will be initiated by 1999 . Therefore the methodology needs to be available in 1998.

Problem Description: An accurate production laboratory method for establishing the technetium-99 concentration in low level waste and vadose zone soils is needed. Technetium-99 
concentration is a critical component of feed to the waste vitrification vendors. The absolute accuracy of these analytical results produced at Hanford has been questioned and found to be in disagreement with results produced at another DOE site. Variability of redox potential and interferences present in Hanford tank wastes produces inconsistent performance of sample preparation methods in use. In addition, the method must be applicable to soils which may receive waste material that leak from the tank. Technetium in the +7 oxidation state is known to be mobile in the soil column and therefore the concentration in tank wastes must be known well to estimate long term effects of waste tank leakage during storage or retrieval operations.

\section{ADSNo. RDSNo. WBSNo.}

1130

\section{Justification For Need:}

Technical: Private vendors will receive low level waste, after being characterized and concentrations of analytes documented. If sensitive analyte concentrations are inaccurately represented, the DOE will be responsible for environmental and process rework caused. Without this interiaboratory testing and acceptance, the liability is likely to remain unresolved.

Regulatory: The technetium-99 concentration in feed streams classified as low level waste is critical since the resulting vitrified product may contain inventory beyond the permitted quantities for on-site disposal.

Environmental Safety and Health: Pertechnetates can be volatilized during processing of waste for vitrification. High concentrations not removed during pretreatment may be disbursed through the gaseous emissions during the vitrification process. Feed to the private vitrification vendor must be properly classified and manifested. Leakage during storage or retrieval operations may deposit waste containing technetium-99 into the soils surrounding the tanks. The mobility and long half-life of the isotope makes the concentration value significant for environmental consequences.

Science: Measurement methodology must be demonstrated acceptable by peer review. This is performed by sample exchange between national laboratories and process control laboratories. The reduction-oxidation potential will be different from tank-to-tank as a result of organic and inorganic components present. Extractions performed to reduce the effects of radiochemical interferences are only effective when the isotope is in the +7 oxidation state. Therefore the measurement methodology must be robust to overcome the matrix reductants and oxidize all oxidations states of technetium to the pertechnetate form.

Cost Savings Potential (Mortgage Reduction): Potential cost savings are represented by a measurement method that assures the vendor and DOE that a true concentration of the technetium- 99 has been measured. Manifests of the waste are accurate and the vendor should not have concern about the DOE supplied concentration data. 
Cultural/Stakeholder Concerns: Measurement data will have better credibility with the oversight panels when the measurement methodology has been peer reviewed and accepted. Issues concerning emissions from the pretreatment and vitrification processes should be answerable with documented data.

Technical Point of Contact: J. J. Huni, Numatec Hanford Company, (509) 372-8183

End User Point of Contact: J.R. Prilucik, Waste Management Federal Services of Hanford, (509) $373-3830$

DOE Representative Point(s) of Contact: James A. Poppiti, (509) 376-4550; fax (509) 376-2002; e-mail: james_a_poppiti@rl.gov and Peter T. Furlong, (509) 372-1738; fax (509) 373-0628; e-mail: peter_t_furlong@rl.gov 


\section{TECHNOLOGY NEEDS/OPPORTUNITIES \\ STATEMENT OUTLINE}

Identification No.: RL-WT02

Date: September 1997

Program: Tanks - Characterization

oPS Office/Site: Richland

Operable Unit (if applicable): N/A

Waste Stream: Single Shell Tanks and Double Shell Tanks

Waste Management Unit (if applicable): N/A

Facility: Tank Farms

\section{Site Priority Ranking: Low}

Need Title: In-Tank Core Sampling...Off-Riser Capability

Need Description: There is a need to gather data on single shell and double shell tanks, in areas where conventional core sampling is not effective. Data gathered will support both stabilization and retrieval functions.

Functional Performance Requirements: The system developed must be compatible with the current rotary mode, and push mode core sampling systems. It must be used in conjunction with this system, when it is determined that retrieving a core segment has been unsuccessful (probably by using the $\mathrm{x}$-ray imaging system). This system should be able to deploy a sampler horizontally out from the drill string, at the elevation of the failed core segment, and attain a sample that will be representative of that layer, thus filling in the information void which would have been created if $N O$ sample were attained at this location.

Schedule Requirements: Needed by the Characterization Project in FY1999/2000 time frame, to support completion of the sampling needs, required per DNFSB 93-5.

Problem Description: Currently, the truck core sampling systems (i.e., rotary and push mode core trucks) have difficulty in attaining samples, sometimes. If there are sections (layers) of the tank that waste sample material is not available for analysis, critical information may be missing that is necessary to understand the tank contents, and ultimately dispose of the tank contents.

ADSNo. RDSNo. WBSNo.

1130

\section{Justification For Need:}

Technical: Proposed work scope would be used to gather critical waste sample data on single shell and double shell tanks. This information is needed to understand their contents 
sufficiently to retrieve them, and ultimately dispose of them. In areas where the core sampling is ineffective this data will be missing unless an alternative is developed

Regulatory: This technology will contribute to increasing the amount of tank characterization data, capable of being attained, and thus increase the confidence in the total tank waste inventory.

Environmental Safety \& Health: Will establish methods to calculate environmental insult due to tank waste. Cost Savings Potential (Mortgage Reduction): By increasing the confidence in each core sampling activity, the need to re-do these costly cores decreases. The cost of re-sampling one core is $\sim \$ 1$ million.

Cultural/Stakeholder Concerns: Resolution of major stakeholder issue related to tank waste characterization of both the DSTs and the SSTs.

Other: N/A

Consequences Of Not Filling Need: Costly core sampling activities will have to be re-run, when voids in characterization information are determined.

Outsourcing Potential: N/A

Current Baseline Technology: Push mode and Rotary Mode Core Sampling

End-User: TWRS (Characterization Project)

Site Technical Point(s)-of-Contact: M. Cremonini (NHC), (509) 373-1248

DOE End-User/Representative Point(s)-of-Contact: James Poppiti, (509) 376-4550 


\section{TECHNOLOGY NEEDS/OPPORTUNITIES STATEMENT OUTLINE}

Identification No.: Rl-WT03

Date: September 1997

Program: Tanks - Characterization

OPS Office/Site: Richland

Operable Unit (if applicable): N/A

Waste Stream: Single Shell Tanks and Double Shell Tanks

Waste Management Unit (if applicable): N/A

Facility: Tank Farms

Site Priority Ranking: High

Need Title: Large Volume (3-5 liter) Sludge and Supernate Sampler

Need Description: There is a need to obtain large quantities of material from the tanks for analysis, and testing, to support pre-treatment, safety, and retrieval.

Functional Performance Requirements: The system developed must be capable of removing large volumes ( 3-5I) of sludge, and/or supernate, from the DST's and the SST's. This system must be compatible with the current sample casks, and supporting transportation, and sample handling systems at Hanford's 222-S Lab.

Schedule Requirements: Needed by the Characterization Project in FY1999/2000 time frame, to support completion of the sampling needs, required per DNFSB 93-5.

Problem Description: There is no system available to aid in attaining large volume sludge, and Supernate The largest volume sampler for this active, currently, is the $125 \mathrm{ml}$ "Bottle-on - astring .

ADSNo. RDSNo. WBSNo. 1130

\section{Justification For Need:}

Technical: Proposed work scope would be used to gather critical waste sludge and supernate samples, for single shell and double shell tanks. This information is needed to understand their contents sufficiently to retrieve them, and ultimately dispose of them.

Regulatory: This technology will contribute to increasing the amount of tank characterization data, capable of being attained, and thus increase the confidence in the total tank waste inventory. 
Environmental Safety \& Health: Will establish methods to calculate environmental insult due to tank waste.

Cost Savings Potential (Mortgage Reduction): By increasing the amount of liquid/solid sampling material, the ability to adequately "characterize" the tanks is improved, greatly.

Cultural/Stakeholder Concerns: Resolution of major stakeholder issue related to tank waste characterization of both the DST's and the SSTs.

Other: N/A

Consequences Of Not Filling Need: Attaining the large volumes of siudge, and supernate required for the Privatization effort would have to be done using existing "technology", the needs in this area will not be completed., or it will take a longer time, and greater exposure.

Current Baseline Technology: 125-ml sampler.

End-User: TWRS (Characterization Project)

Site Technical Point(s)-of-Contact: M. Cremonini (NHC), (509) 373-1248

DOE End-User/Representative Point(s)-of-Contact: James Poppiti, (509) 376-4550 


\section{TECHNOLOGY NEEDS/OPPORTUNITIES \\ STATEMENT OUTLINE}

Identification No.: $\underline{\mathrm{Rl}-W T 04}$

Date: September 1997

Program: Tanks - Operations

OPS Office/Site: Richland

Operable Unit (if applicable): N/A

Waste Stream: Double Shell Tanks

Waste Management Unit (if applicable):

Facility: Tank Farms

Site Priority Ranking: High

Need Title: DST Corrosion Monitoring

Need Description: Corrosion monitoring of DSTs is currently provided by process knowledge and tank sampling. Tanks found to be within chemistry specification limits are considered to be not at risk for excessive corrosion damage. There have been no direct corrosion monitoring systems for DSTs in use at the Hanford Site. As many as 6 Double Shell Tanks (DSTs) have recently been identified as low hydroxide (out of corrosion specification). This condition indicates that this system is inadequate to support corrosion control. Tank samples are infrequent and their analysis difficult and expensive. Process knowledge is complicated by waste streams that are exempt from the corrosion control specifications. In-tank, real-time measurement of the corrosive characteristics of the tank wastes is needed to provide an acceptable level of corrosion control information. This need supports TWRS Program Logic "Conduct Tank Farm Safe Operations" and "Conduct Reduced Mortgage Tank Farm Safe Operations."

\section{Functional Performance Requirements:}

- Identify the onset of stress corrosion cracking.

- Identify the onset of pitting.

- Order of magnitude quantification of mass loss during pitting and cracking.

- Quantification of uniform corrosion rates.

Schedule Requirements: Work is to be performed in fiscal years 1998 through 2000

Problem Description: Corrosion control of high level waste DSTs is currently provided by concentration limits on hydroxide, nitrite, and nitrate. Monitoring of the chemistry is provided by tank samples and process knowledge. As many as 6 DSTs at Hanford have operated outside of corrosion chemistry limits in the past 2 years. Detection and remediation of these low hydroxide tanks has been slow and costly.

Available technology for corrosion monitoring has progressed to a point where it is now feasible to monitor and control corrosion by on-line monitoring of the corrosion process and direct addition of corrosion inhibitors. The potential benefits of a corrosion monitoring system include: 
1. Safer operation and reduced risk of tank liner faifure. Corrosion will be monitored directly, versus monitoring chemical species. Assumptions about tank waste homogeneity and accuracy of the corrosion chemistry specification will be reduced or removed.

2. Significant potential for cost reduction: More than $\$ 100 \mathrm{~K}$ in unplanned work scope at Hanford in fiscal year 1996 and 1997 on sampling and analysis to determine the extent of out of specification conditions.

3. Increased tank life due to more rapid identification and resolution of off-normal conditions.

4. Avoidance of unnecessary chemical additions due to unknown corrosion conditions: More than 10,000 gallons of waste volume added to the tanks at Hanford through fiscal year 1996 and 1997 through unscheduled sodium hydroxide additions. Direct monitoring of the actual tank corrosion conditions may have shown these additions to be unnecessary.

5. Possible cost savings over time as a result of the relaxation of corrosion inhibitor addition requirements as corrosion behavior becomes better understood. Each metric ton of sodium addition avoided (as sodium hydroxide corrosion inhibitor) will save approximately $\$ 1,000,000$ in low level waste vitrification costs.
ADS No.
RDS No.
WBS No.
11200
1.1.1.2.01
1.1.1.3.XX

\section{Justification For Need:}

Technical: Real time corrosion monitoring has been selected for preliminary evaluation at the Hanford Site. The use of such a system in Hanford waste tanks would allow for real-time monitoring of both corrosion processes and corrosion inhibitor addition. Realtime data collection would facilitate identification of the precise time when a corrosion process begins to occur in a tank. This, coupled with corrosion rate information also generated, would help in determining the extent of design life lost due to degradation by abnormal corrosion conditions. Similarly, real-time corrosion monitoring during inhibitor addition would allow one to observe corrosion conditions return to an acceptable level. Therefore, unnecessary inhibitor addition could be eliminated. The current system cannot offer this capability.

Available techniques offer the ability to distinguish between uniform corrosion, stress corrosion cracking, pitting, and other forms of localized corrosion as they occur. They also generate uniform corrosion rate data identical to what is currently derived from chemical sampling. Some available corrosion monitoring techniques using electrical resistance probes or linear polarization resistance probes are not capable of distinguishing between uniform and localized forms of corrosion. These would not be considered 
acceptable. The most likely cause of failure in DSTs is degradation due to some form of localized corrosion.

\section{Regulatory:}

-Washington Administrative Code 173-303-640(2)(c)(iii) requires consideration of existing corrosion protection when performing tank system integrity assessments. Online corrosion monitoring will provide an acceptable performance measurement of current corrosion protection measures and early warning of potentially corrosive conditions.

-DOE Order 5820.2A, Radioactive Waste Management, requires monitoring of cathodic protection systems, methods for periodically assessing waste storage system integrity, and adjustment of waste chemistry to control corrosion.

-DOE-STD-1073-93, Configuration Management, requires implementation of a Material Condition and Aging Management Program to control aging processes in major equipment and components. The primary aging processes in waste tank systems are corrosion related.

-DOE/RL-92-60, Tank Waste Remediation System Functions and Requirements contains corrosion control requirements for the Store Waste (F4.2.1.1) and Transfer Waste (F4.2.4.4) functions.

\section{Environmental Safety \& Health:}

-WHC-SD-WM-OSR-005, Single-Shell Tank Interim Operational Safety Requirements, WHC-SD-WM-OSR-004, Aging Waste Facility Interim Operational Safety Requirements, and WHC-SD-WM-OSR-016, Double-Shell Tank Interim Operational Safety Requirements. These support documents contain interim operational safety requirement - administrative controls for corrosion control, cathodic protection, and integrity assessments. Implementation of these administrative controls necessitates corrosion control activities.

-WHC-SD-WM-PLN-068, TWRS Life Management Program Plan, identifies stress corrosion cracking, pitting corrosion, and uniform corrosion as the primary aging mechanisms for DSTs. On-line monitoring of DSTs for these mechanisms will provide necessary data for damage prediction models being developed for the DST Life Management Program.

-BNL/DOE-HQ Tank Structural Integrity Panel, Guidelines for Development of Structural Integrity Programs for DOE High-Level Waste Storage Tanks - DRAFT, discusses the important role of corrosion monitoring in the context of a comprehensive structural integrity program.

\section{Cost Savings Potential (Mortgage Reduction):}

- Mortgage Reduction - Estimated Total Life Cycle Cost (TLCC) for wastes added to the 
DST system is $\$ 100$ per gallon. Avoidance of the 30,000 gallons of chemicals added in fiscal years $1994-1996$ would produce $\$ 3,000,000$ TLCC savings.

- Cost Avoidance - Avoid premature replacement of DSTs. Replacement cost estimated by the Multi-Function Waste Tank Facility Project was $\$ 67,000,000$ per tank.

- Cost Avoidance - Remove $\$ 50,000$ sampling cost for each corrosion sample avoided. This would also free the sampling crew and equipment to take more urgent samples (safety screening, outsourcing, etc.)

Cultural/Stakeholder Concerns: N/A

Other: N/A

\section{Consequences Of Not Filling Need:}

\section{Regulatory Impacts:}

The Hanford Operations contractor has previously entered into negotiations with the Washington State Department of Ecology (WDOE) for determination of acceptable compliance with WAC 173-303-640. Completion of this activity was a part of the negotiations. Failure to complete this activity might be construed by WDOE as failure to comply with WAC legal requirements and failure to negotiate compliance in good faith.

\section{Programmatic Impacts:}

Corrosion control of double shell tanks is currently provided by process knowledge and tank sampling. The continued operation of 4 low hydroxide (out of corrosion specification) tanks indicates that this system is inadequate to support corrosion control. Tank samples are infrequent and their analysis difficult and expensive. Process knowledge is complicated by waste streams that are exempt from the corrosion control specifications. In-line, real-time measurement of the corrosive characteristics of the tank wastes will augment the current system to provide an acceptable level of corrosion control information to satisfy the programmatic drivers above.

Outsourcing Potential: Modified commercial technology could be marketed back to the private sector. Several commercial vendors are available who could provide "turn-key" equipment for deployment at Hanford.

Current Baseline Technology: There is no baseline technology for direct monitoring of corrosion in high level waste tanks.

Programmatic Risks: A prototype corrosion probe was installed in 241-AZ-101 in fiscal year 1996. A second generation probe was installed in 241-AN-107 in fiscal year 1997. The successful deployment of these probes demonstrate that the successful use of this technology is not in question.

Connection to TWRS Logic: This need supports TWRS Program Logic "Conduct Tank Farm Safe Operations" and "Conduct Reduced Mortgage Tank Farm Safe Operations." 
End-User: Retrieval/Tank Farm Operations

Site Technical Point(s)-of-Contact: James L. Nelson, (509) 373-6296; Glenn L. Edgemon, (509) 373-7214, Lockheed Martin Hanford Corporation

DOE End-User/Representative Point(s)-of-Contact: Mark L. Ramsay, (509) 376-7924 


\section{TECHNOLOGY NEEDS/OPPORTUNITIES \\ STATEMENT OUTLINE}

Identification No.: RL-WT05

Date: September 1997

Program: Tanks - Operations

OPS Office/Site: Richland

Operable Unit (if applicable): N/A

Waste Stream: Single Shell Tanks

Waste Management Unit (if applicable):

Facility: Tank Farms

Site Priority Ranking: Medium

Need Title: Remote Inspection of High-Level Waste Single Shell Tanks

Need Description: The Tri Party Agreement (TPA) schedule requires retrieval of wastes in the Single Shell Tanks (SSTs) to begin by 2004 for future vitrification and permanent storage in a waste repository. In order to meet this schedule, a retrieval method needs to be selected to retrieve the waste for processing. A Non-Destructive Examination (NDE) of the tank needs to be performed prior to the selection of a retrieval method to assure successful retrieval of the waste from the tank.

Functional Performance Requirements: There are two categories of flaws to consider, non through-wall and through-wall. Non through-wall (partial penetration) needs to be evaluated to estimate the time to wall penetration. Through-wall flaws need to be evaluated to determine the potential for tank rupture and estimate rates of leaks that may occur in the future and assess appropriate actions.

Acceptance criteria for NDE has the following allowable flaw sizes:

Through- wall crack length-

$12^{\prime \prime}$

Maximum allowable crack depth- $\quad 3 / 16^{\prime \prime}$

Thinnest allowable wall section- $\quad 0.8 \mathrm{t}$

(where $t$ is the original thickness) and

Maximum allowable pit depth- $\quad 0.5 t$

The selected remote inspection method needs to be demonstrated in a SST with very little waste. Leakage rates from detected through-wall cracks have to be estimated to assess sluicing feasibility of the SST's.

Schedule Requirements: Functional systems must be deployed prior to December 31, 2000 in order to successfully meet the TPA schedule for retrieval of wastes from the SSTs to begin by 2004. 
Problem Description: Initially, SSTs that have little or no waste need to be selected for NDE of the tank wall and floor. If necessary, destructive metallurgical examination of small isolated sections of the SSTs may need to be performed to obtain a thorough understanding of the operating corrosion mechanisms. The number and size of the cracks that led to the leakage of wastes for the leaking SSTs need to be determined. Waste leakage rates should be estimated based on the defect information, and the acceptability of sluicing for retrieval operations needs to be evaluated for each selected SST.

In order to be able to meet the TPA SST waste retrieval schedule, initially only one tank from a group of tanks containing similar wastes should be studied. The retrieval decision made for this one tank should be extended to remaining tanks in the group.

Every effort should be made to perform the examination with a remote device such as the Light duty Utility Arm (LDUA) or similar robotic equipment to more efficiently minimize costs. The potential benefits of NDE evaluation (and possible destructive evaluation of some of the SSTs) include:

-Determination of feasibility of sluicing as a waste retrieval method for the SSTs.

-Prioritization of tanks for waste retrieval and processing.

$\begin{array}{lll}\text { ADS No. } & \text { RDSNo. } & \text { WBS No. } \\ 11200 & 1.1 .1 .2 .01 & 1.1 .1 .3 . \mathrm{XX}\end{array}$

\section{Justification For Need:}

Technical: Sluicing is the baseline approach for SST retrieval. As such, it is necessary to know early on whether or not it is feasible to use this method.

\section{Regulatory:}

-Washington Administrative Code 173-303-640 requires consideration of existing corrosion protection when performing tank system integrity assessments.

-DOE-STD-1073-93, Configuration Management, requires implementation of a Material Condition and Aging Management Program to control aging processes in major equipment and components. The primary aging processes in waste tank systems are corrosion related.

-DOE/RL-92-60, Tank Waste Remediation System Functions and Requirements contains corrosion control requirements for the Store Waste (F4.2.1.1) and Transfer Waste (F4.2.4.4) functions.

\section{Environmental Safety \& Health:}

-WHC-SD-WM-OSR-005, Single-Shell Tank Interim Operational Safety Requirements, 
WHC-SD-WM-OSR-004, Aging Waste Facility Interim Operational Safety

Requirements. These support documents contain interim operational safety requirement administrative controls for corrosion control, cathodic protection, and integrity assessments. Implementation of these administrative controls necessitates corrosion control activities.

-WHC-SD-WM-PLN-068, TWRS Life Management Program Plan, identifies stress corrosion cracking, pitting corrosion, and uniform corrosion as the primary aging mechanisms for DSTs.

-BNL/DOE-HQ Tank Structural Integrity Panel, Guidelines for Development of Structural Integrity Programs for DOE High-Level Waste Storage Tanks - DRAFT, discusses the important role of corrosion monitoring in the context of a comprehensive structural integrity program.

Cost Savings Potential (Mortgage Reduction): Determination of the integrity of SSTs prior to retrieval will avoid the use of more costly retrieval techniques.

\section{Cultural/Stakeholder Concerns: N/A}

Other: N/A

\section{Consequences Of Not Filling Need:}

Regulatory Impacts: The U. S. DOE has previously entered into a TPA commitment with the Washington State Department of Ecology (WDOE) and the U. S. Environmental Protection Agency to begin retrieval of SST wastes by the year 2004. Completion of this activity was a part of the negotiations. . Failure to complete this activity might be construed by WDOE as failure to comply with TPA commitments, WAC legal requirements, and failure to negotiate in good faith.

Programmatic Impacts: Sluicing is considered to be one of the primary methods to retrieve waste from the SSTs. It is possible that sluicing may not be a viable method for retrieval of some SSTs due to the extensive corrosion experienced by some of the tanks. Therefore, it is important to initiate tank inspection to rule out sluicing at an early stage in order to have adequate time to pursue other retrieval methods prior to the 2004 deadline to initiate retrieval of SST wastes.

Outsourcing Potential: Remote inspection capabilities developed at Hanford could be retumed to the private sector.

Current Baseline Technology: There is no baseline technology for in-situ inspection of SSTs to assess corrosion damage.

Programmatic Risks: There is an unknown, but undoubtedly high probability that some SSTs will leak when sluiced. If leakage volumes are unacceptably large, there will be high costs and lengthy delays to switch to another waste retrieval technology. 
Connection to TWRS Logic: This need supports TWRS Program Logic "Develop SST Retrieval Methods and Requirements."

End-User: Retrieval/Tank Farm Operations

Site Technical Point(s)-of-Contact: James L. Nelson, (509) 373-6296; Ramamohan P. Anantatmula, (509) 373-0785, Lockheed Martin Hanford Corporation

DOE End-User/Representative Point(s)-of-Contact: Mark L. Ramsay, (509) 376-7924 


\section{TECHNOLOGY NEEDS/OPPORTUNITIES \\ STATEMENT OUTLINE}

Identification No.: RL-WT006

Date: September 1997

Program: Tanks - Process Waste

OPS Office/Site: Richland

Operable Unit (if applicable): N/A

Waste Stream: High-level waste

Waste Management Unit (if applicable): N/A

Facility: Tank Farms

Site Priority Ranking: High

Need Title: Identification and Management of Problem Constituents for HLW Vitrification

Need Description: Currently, HLW glasses are formulated to assure that little or no insoluble phases exist in the HLW melter. Insoluble phases are caused by such problem constituents as chrome minerals, spinels, and noble metals. An alternative method for handling problem constituents in HLW glasses is needed. The volume of HLW glass that will be produced from the sludges at Hanford is dependent on the ability to solubilize or dilute problem constituents that make up a very small fraction of the overall waste. Minimizing the impact of the problem constituents is important for formulating a strategy and staging the wastes to be treated during the Phase II outsourcing effort. Diluting the problem constituents usually involves blending of waste types and/or increasing the volume of glass waste forms. Alternatively, separations of problem constituents is an option. All of these alternatives are expensive.

Information is needed on the technical viability of producing HLW glasses with insoluble phases. Information such as settling rates and theological properties is needed for insoluble phases to determine if the phases will settle in a HLW melter and, if so, whether the settled sludge can be discharged through a bottom drain or by other means. Information is also needed to determine the impact of the insoluble phases on the durability of the waste form. Ultimately, new HLW glass formulations can be produced that reduce the overall glass volume for various waste types and reduce the blending requirements at Hanford. Based on the results of this study, the cost and risk of producing waste forms with insoluble phases will have to be compared with other options such as blending or diluting to determine the best path forward. This information is needed to formulate a strategy for the Phase II outsourcing effort at Hanford. This includes waste blending requirements for the $\mathrm{DOE}$, waste volume minimization requirements for the Contractors, and overall contracting strategy.

\section{Functional Performance Requirements:}

- $\quad$ Based on current HLW feed processability reports, identify physical (particle size, particle morphology, and settling rate) and chemical (composition and crystalline 
structure) characteristics for insoluble phases in HLW glass formulations with high waste loadings

- If applicable, determine the physical characteristics of settled layers of insoluble particles (sludges)

- Evaluate the methods for removing the settled sludge layers either continuously or periodically.

- Evaluate the processability of the new glass formulations

ADSNo. RDSNo. WBSNo.

Schedule Requirements: This effort needs to be completed in FY 2001 to support trade studies which will be completed in FY 2002 in the Phase 2 RFP Planning.

\section{Justification For Need:}

Technical: Data from testing will be used to support the RFP generation for Phase 2 of the TWRS Outsourcing Effort.

Regulatory: Regulators agree that DOE should move ahead according to Tri-Party

Agreement. RCRA generally requires waste minimization.

Cost Savings Potential (Mortgage Reduction): This is an area of potential high return-oninvestment.

Cultural/Stakeholder Concerns: A representative of Hanford's Site Technology

Coordination Group has registered a suggestion to minimize High Activity or High Level

Waste be balanced with minimization of on-site disposal of LAW.

other: None

Consequences Of Not Filling Need: Implementation of baselines demonstrated in Phase 1 and accepting the strategy of relying on the Private sector to make long term technology investments for Phase 2 with private monies.

\section{Outsourcing Potential: High}

Current Baseline Technology: Current baseline will be defined when Private Contractors submit Phase Ia deliverables. DOE evaluation and downselection for Phase $\mathrm{Ib}$ is scheduled for May 1998. Standard pre-privitization flowsheets generated by the M\&O Contractor are assumed as baseline until Phase Ia deliverables are evaluated and selected by the DOE.

End-User: TWRS Process Waste Support Function

Technical Points of Contact: Rudy Carreon, (509) 373-7771

DOE End-User/Representative Point(s)-of-Contact: Peter T. Furlong, (509) 372-1738; fax (509) 373-0628; e-mail: peter_t_furlong@rl.gov or Catherine S. Louie (509)376-6834. 


\section{TECHNOLOGY NEEDS/OPPORTUNITIES \\ HANFORD CAPSULE INITIATIVE}

Identification No.: RL-WT007

Date: September 1997

Program: Tanks - Process Waste

OPS Office/Site: Richland

Operable Unit (if applicable): NA

Waste Stream: Cesium and Strontium Capsules

Waste Management Unit (if applicable): Tank Waste Remediation System

Facility: High-Level Waste Vitrification Facility

Site Priority Ranking: Medium

Need Title: Hanford Capsule Initiative ( $\mathrm{HCl}$ ): A Processing Demonstration of $\mathrm{Cs} / \mathrm{Sr}$ Capsules for Final Disposition

Need Description: To develop and demonstrate a concept for disassembling and processing the cesium and strontium capsules that will condition the halide salts for blending with other HLW feeds prior to vitrification. The effort is required to ensure the vitrification of capsule contents can be performed safely and efficiently.

Functional Performance Requirements: Using previous experience with the disassembly and processing of capsule contents, develop and demonstrate a concept that provides for the remote disassembly of a capsule. The processes needed include:

removal of the capsule contents:

-separation of the capsule contents them from the encapsulating materials;

-pulverize the $\mathrm{SrF}_{2}$ and transport it as slurry to a holding tank;

-dissolution of $\mathrm{CsCl}$ and removal of the chlorides.

All operations must be performed reliably and without excessively contaminating the surrounding hot cell.

The HCI will be performed in two phases. The first phase will be focussed on process development and cold testing and will be performed at Hanford. The second phase will be a hot small-scale demonstration of the process at the Savannah River Site, using capsules currently stored in Hanford's 300 Area and SRS's vitrification capabilities.

Schedule Requirements: A proven concept is required by 2008 to enable it to be incorporated into the design of a private HLW vitrification facility at Hanford.

Problem Description: The disassembly of these capsules is a messy operation that results in 
gross contamination of a hot cell. There is a need to develop and demonstrate methods for performing the disassembly without creating a significant contamination problem. The demonstration of a remote disassembly concept will make vitrification more acceptable as the final disposition of these capsules, and will provide sufficient confidence in the process so that requirements for capsule processing can be included in the outsourcing work scope.

$\begin{array}{lll}\text { ADS No.: } & \text { RDSNo.: } & \text { WBS No.: } \\ 1230 & \text { 1D4C } & 1.1 .1 .3 .4 .3 .2\end{array}$

Justification For Need:

Technical: Past experience with the disassembly of capsules is that the process results in the significant contamination of equipment and facilities. Contamination is a significant issue with the vitrification of the capsule contents. However, the vitrification option is attractive because it: 1) eliminates the repository disposal fee, i.e. blending the capsule contents with other HLW feeds does not increase the overall volume of vitrified product; and 2) the vitrified waste form is much more acceptable to the public than the soluble salt.

Regulatory: Decontamination of a hot cell and disassembly equipment, as well as the encapsulating materials and offgasses, will create effluents. The disposition of those effluents has to be identified and described in a permit. The concept can be tested outside of a hot cell using non-hazardous materials. If the cold demonstration is successful, the hot demonstration will create only minor contamination issues.

Environmental Safety \& Health: The hot demonstration will require the transport of capsules from Hanford to the Savannah River Site. The current Safety Analysis Reports for the Beneficial Uses Shipping System (BUSS) cask is in place.

Cost Savings Potential (Mortgage Reduction): The A-Cell in Hanford's 324 Building is currently unusable for other missions, since it is being used to store waste and products from the Federal Republic of Germany (FRD) program. The cell cannot be decontaminated until the capsules are removed from the hot cells. In their current configuration the capsules cannot be returned to the WESF their contents are repackaged. This initiative would allow the cell to be decontaminated without the need to repackage the capsules.

CulturaLStakeholder Concerns: This effort would be viewed positively by all stakeholders in that it enables further cleanup at Hanford to proceed.

\section{Other:}

Consequences Of Not Filling Need: If this need is not filled, then the closure of Hanford's 324 Building will wait until the capsules can be repackaged and returned to the WESF for indefinite storage, or an alternative solution is found. Insufficient data will be available for inclusion in the Phase II outsourcing RFP; vendors may be unable or unwilling to respond to this part of the RFP.

Outsourcing Potential: The results of this effort will be privatized if Hanford follows through 
on its concept of HLW outsourcing.

Current Baseline Technology:

Cost: $\$ 5$ million for development, cold testing and hot demonstration

Waste: Shredded metal alloy - one drum of remote-handled solid waste.

Inorganic resin - one drum of slightly radioactive resin. Liquid waste from the decontamination of hot-cell equipment

How Long It Will Take: The expected duration of this development is 2 years

End-User: Tank Waste Remediation System Program (Hanford Site)

Site Technical Point(s)-of-Contact: P. S. (Steve) Schaus, (509) 372-1149; R. D. Claghorn, (509) $373-1610$

DOE End-User/Representative Point(s)-of-Contact: Philip E. LaMont, (509) 376-6117;

fax (509) 372-1350; e-mail: philip_e_lamont@rl.gov 


\section{TECHNOLOGY NEEDS/OPPORTUNITIES \\ STATEMENT OUTLINE}

Identification No.: RL-WT008

Date: September 1997

Program: Tanks - Process Waste

OPS Office/Site: Richland

Operable Unit (if applicable): N/A

Waste Stream: Double and Single Shell Tanks

Waste Management Unit (if applicable).

Facility: LLW Pretreatment

Site Priority Ranking: High

Need Title: Advanced Methods for Achieving LLW Volume Minimization

Need Description: There is a need to minimize the volume of the low-level waste.

This is both prudent from an overall cost standpoint as well as a requirement when dealing with any RCRA waste. More specifically, there is a need to develop and demonstrate a concept for significant reduction in the volume of low level waste.

Functional Performance Requirements: The approach should be definitized enough to provide a suitable basis for scale up to Phase II production scale and allow a detailed engineering, business, and environmental evaluations of the approach for Phase II. The low-level waste minimization should be cost effective on a life-cycle cost basis.

Schedule Requirements: This effort needs to be completed in FY 2001 to support trade studies which will be completed in FY 2002 in the Phase 2 RFP Planning (Multi-Year Work Plan Schedule Identification Number $\mathrm{H} 2343$ ) and subsequent RFP completion and bid evaluation.

Problem Description: Currently, the amount of tank waste is so large that enormous quantities of immobilized low activity waste will be generated and require appropriate low level waste disposal. By removal of essentially non radioactive constituents from the waste by innovative chemical processes, the volume of low level waste requiring disposal can be significantly reduced.

ADSNo. RDSNo. WBSNo.

\section{Justification For Need:}

Technical: This effort is required to ensure that reasonable incentives for LLW minimization are developed so that they can be included in the Phase II RFP. This effort will also provide a technical basis for a fair cost estimate as well as for writing a meaningful RFP 
for Phase II.

Regulatory: Waste minimization is recommended for RCRA wastes.

Environmental Safety \& Health: Improvements in each of these areas will result from many fewer disposal vaults needing to be built, and filled. The volume of waste will be reduced, and some of the hazardous constituents such as nitrate will be destroyed to a considerable extent, thus reducing the source term for long term environmental impact. Disposal of secondary waste streams must be addressed as part of potential life-cycle cost savings.

Cost Savings Potential (Mortgage Reduction): A significant cost avoidance (Hundreds of Millions of Dollars) is expected if DOE is armed with information that allows a more precise RFP to be written and a realistic knowledge of Phase II costs with which to evaluate Vendors proposals.

Cultural/Stakeholder Concerns: LLW minimization has the potential to minimize land use for on site disposal of LLW.

Other: The byproducts of the waste minimization activity could be useful either in pursuing the cleanup at Hanford, other DOE sites, or for non DOE application. Examples could include materials for road construction, facility decommissioning, and site closure.

Consequences Of Not Filling Need: DOE will lack the data needed to tighten specifications over the current baseline for Tank Waste Treatment in the Phase 2 RFP. Breakthrough technologies that save the government money may not be demonstrated and available in Phase 2 unless industry chooses to make investments in long-term technology testing.

Outsourcing Potential: This area is targeted for outsourcing if proven beneficial.

Current Baseline Technology: The current technical baseline has yet-to-be-defined incentives for low level waste minimization.

End-User: TWRS Process Waste Support Function

Site Technical Point(s)-of-Contact: Rudy Carreon, (509) 373-7771

DOE End-User/Representative Point(s)-of-Contact: Peter Furlong, (509) 372-1738; fax (509) 373-0628; e-mail: peter_t_furlong@rl.gov or Catherine S. Louie (509)376-6834; email catherine_s_louie@rl.gov 


\section{TECHNOLOGY NEEDS/OPPORTUNTTIES \\ STATEMENT OUTLINE}

Identification No:: RL-WT009

Date: September 1997

Program: Tanks - Process Waste

OPS Office/Site: Richland

Operable Unit (if applicable): N/A

Waste Stream: Double Shell Tanks

Waste Management Unit (if applicable):

Facility: Tank Farms

Site Priority Ranking: High

Need Title: Representative Sampling and Associated Analysis to Support Operations and Disposal

Need Description: To develop and demonstrate a concept for taking representative samples and associated rapid analysis of feeds which are to be staged for cross site transfer or are to be staged as feed for the Outsourcing Contractors. Feed for Outsourcing Phase I immobilization demonstrations must be shown to be within the RFP feed envelope $A, B$, and $C$ specifications.

To accomplish this, the intermediate waste feed staging tank contents must be sampled while being mixed for transfer to the Private Contractors feed staging tank. A variable depth sampling system is needed that can be operated in conjunction with the active mixing system to certify that the tank contents meet the specified waste envelopes. (Reference: "Alternatives Generation and Analysis for the Phase I Intermediate Waste Feed Staging System Design Requirements, WHCSD-TWR-AGA-001, Rev.0)

Functional Performance Requirements: The sampling and analytical capabilities should be able to provide representative samples and measure the parameters needed to support successful cross site transfers and needed as specified in the Outsourcing Contract for envelopes A, B, and $C$ and envelope $D$. The Outsourcing Phase 1 supernate solutions to be sampled are targeted to be dilute slurry/supernate solutions with a maximum of $5 \%$ solids by volume. The samples will be drawn form the tank with a lift distance of up to $50 \mathrm{ft}$. The system to be provided will need to be deployed using existing spare tank penetrations or be installed into an existing process pit located in the tank farm. The sampling system shall provide required support subsystems as necessary to meet safety and operational requirements. The feed needs to be sampled and analyzed for these activities consistent with ALARA principles.

Schedule Requirements: The cross site transfer line from Tank 102-SY will be operational in FY 
1998; this sampling and analysis capability would be beneficially employed anytime thereafter. To support the outsourcing this method needs to be developed by 3/99 so that the LLW plan update can incorporate this method in FY 1999, and these methods can be installed in FY 2000, feed staging can begin in FY 2001, and delivery of feed to the Outsourcing Contractors' feed tanks can occur prior to hot start-up in FY 2002.

Problem Description: A representative, and preferably also rapid, sampling and analysis system has to be developed and demonstrated so that feeds to the cross site transfer line and to both the LLW and HLW Outsourcing Contractors can be staged successfully with a minimum impact on tank space. Current grab samplers consisting of "bottle-on-ia-string" are used for slurry/supernate sampling. This system of sampling has been found to be cross contaminated with material from higher elevations above the desired sample depth as it is withdrawn from the tank. Although this cross contamination is proportional, it could skew the sample results. Also, this method cannot be performed during active mixing system operation, therefore allowing time for in-tank stratification to be re-established before the sampling can be performed. The sampling is a manual operation performed thorough an existing riser using a portable "glove bag" for containment control that has potential for personal contamiration and exposure. With Hanford's existing capabilities it takes weeks or even months to sample and analyze a tank.

As the disposal program activities involving 200 Area waste retrieval and outsourcing proceed, Hanford will need the capability to sample and analyze much more rapidly in order to ensure that DOE provides feeds in accordance with its outsourcing contracts and with a minimum use of tank space. Representative sampling involving potentially non homogeneous waste feed is definitely needed. Long sample and analysis times will cause operations to tie up tanks until analytical results are available to determine how the waste should be staged. Quicker sample/analytical responses will provide more flexibility to the tank system.

Possible concept: On-line sampling and analysis could satisfy this need. AEA has developed the capability of obtaining representative samples of slurries of waste with a fluidics sampling pump, and this concept is being adapted for Savannah River Site waste tank use. If this device were combined with on-line analytical methods, this need could be satisfied.

$\begin{array}{lrll}\text { ADS No. } & \text { RDS No. } & \text { WBS No. } & \\ 1230 & \text { R96N0033 } & 1.1 .1 .3 .02 & \text { for outsourcing } \\ 1100 & \text { R96N0163 } & 1.1 .1 .3 .7 .2 .1 & \text { 200-W DST Operations } \\ 1210-0 & \text { R95W0006 } & 1.1 .1 .3 .1 .2 & \text { for Retrieval }\end{array}$

\section{Justification For Need:}

Technical: This effort is required to ensure that feed is delivered to the cross site transfer line and to Outsourcing Contractors in a timely manner with the use of minimum double shell tank space. This activity will seek improved sampling systems that support ALARA goals and can be operated at variable depths while the DST mixing system is operating.

Regulatory: Will enable waste transfer/transport between separately permitted RCRA TSD facilities. 
Environmental Safety \& Health: Using on-line instrumentation will reduce the exposure of personnel during taking of the samples in the field and analysis the samples in the laboratory. This will also help in avoiding plugged cross site transfer lines, and the increased exposure of personnel in taking the necessary actions to clear the plugging. The transportation of samples to the 222-S Analytical Lab would be avoided.

Cost Savings Potential (Mortgage Reduction): Set up time for sampling would be reduced and less personnel exposure will result in a cost reduction from current levels. A significant cost savings associated with the manpower to both take and analyze the samples would be achieved if an on-line instrument was developed. The cost of taking and analyzing samples currently is on the order of $\$ 400 \mathrm{~K}-\$ 500 \mathrm{~K}$ per sample. In the future as more tanks are being retrieved, more cross-site transfers will need to be made with less elapsed staging time to avoid the need for additional cross site transfer lines and additional staging tanks. The attank farm sampling will also reduce the need for additional sample transportation casks, vehicles, and staff, and reduce the need for additional analytical laboratory facilities and staff.

\section{CulturaLStakeholder Concerns: N/A}

Other: The Office of Science and Technology, EM-50, has funded the transfer of some non radioactive demonstrations of the sampling technology using power fluidics, and has developed the laser ablation mass spectrometer and installed a prototype unit in the 222-S Analytical laboratory in late FY 1996 . These technologies could be integrated in a demonstration relevant to the feed staging applications identified.

Consequences Of Not Filling Need: Greater risk of plugging the cross site transfer lines; increased delay in making transfers; possible slippage of retrieval schedules. Outsourcing Contractors' feed may not be delivered by DOE on schedule agreed to in the contract and DOE will be forced to pay the Outsourcing Contractors for idle facilities. PHMC staff will experience greater radiation exposure both in the field taking samples by current methods, and in the analytical laboratory handling the additional samples. Less accurate grab samples will be used which may result in feed that doesn't initially meet specifications (i.e., requires rework prior to transfer to the Private Contractors feed staging tank).

Outsourcing Potential: The representative sampler could be supplied and possibly also installed by AEA Technology, or possibly BNFL, or possibly Numatec or SGN Systems, or the Russians since this technology or variations thereof have been used by these foreign organizations in their waste management and waste processing activities. A laser ablation mass spectrometer has been developed by Pacific Northwest National Laboratory under EM-50 funding; this work could be made available with suitable contractual arrangements for outsourcing. The sampie distribution manifold system is available through British Columbia Research Inc., a Canadian technology development firm. The measurement of rheological properties associated with the representative samples would need to be made with analyzer equipment commercially available and adapted to the sample distribution manifold system. The analysis requirements would be different for the 
feed staging for the cross site transfer where the emphasis would be on ensuring pumpability. through the cross site transfer pipe and waste compatibility of what is being transferred versus what is in the receiver tank. On the other hand, for the requirements for the intermediate feed staging tanks for outsourcing, the emphasis is to ensure the tank contents complies with the desired feed envelope: A, B, or C for supernatants, and envelope D for sludges.

Current Baseline Technology: Current plans for feed staging tank sampling and analysis involve trying to mix the waste and take "bottle on the string" or other grab samples followed by analysis in the 222-S Laboratory. It takes weeks or even months to analyze a tank of waste.

End-User: Tank Farm Operations/Retrieval

Related Technology Needs/Opportunities Statement: "Real Time Waste Property Measurement System for Waste Transfer"

Site Technical Point(s)-of-Contact: J. D. Galbraith, (509) 376-7929; P. W. Gibbons (NHC), (509) 372-0095

DOE End-User/Representative Point(s)-of-Contact: Outsourcing: Peter T. Furlong, (509) 372-1738; fax (509) 373-0628; e-mail: peter_t_furlong@rl.gov; Retrieval: Bruce L. Nicoll, (509) 376-6006; fax (509) 372-1350; e-mail: bruce_1_nicoll@rl.gov 


\section{TECHNOLOGY NEEDS/OPPORTUNITIES \\ STATEMENT OUTLINE}

Identification No.: RL-WTO10

Date: September 1997

Program: Tanks - Process Waste

OPS Office/Site: Richland

Operable Unit (if applicable): N/A

Waste Stream: Immobilized High-Level Waste Immobilized Low-Activity Waste

Waste Management Unit (if applicable): N/A

Facility: TWRS

Site Priority Ranking: High

Need Title: ILAW Product Acceptance Inspection and Test Methods

Need Description: The United States Department of Energy (DOE), Richland Operations Office $(R L)$ is proceeding with a two-phased approach to privatize the treatment and immobilization of Hanford's low-activity and high-level wastes currently in storage in underground tanks. DOE will provide the tank wastes to the private contractors who will treat and immobilize the wastes and then return the final products to DOE for storage and final disposal. Acceptance of the immobilized wastes may be based on a combination of private contractor activities to qualify, verify, document, and certify the product and DOE activities to audit, review, inspect, and test the processes and products.

The immobilization contractors will provide to DOE the immobilized low-activity waste (ILAW) products in sealed containers, process and product grab samples, and the appropriate product certification which may include pertinent process data. The DOE may conduct non-destructive testing of the sealed irnmobilized waste containers and destructive and non-destructive testing of the process and product samples. Specific parameters of interest may include chemical composition of the waste forms, fillers, and containers phase composition radiochemical composition thermal history and surface temperature waste form volume and void space waste form and container weight container dimensions including wall thickness effectiveness of container closure or seal (leak tightness) presence of prohibited materials including free liquids and explosive, pyrophoric or combustible materials dose rate surface contamination waste form homogeneity waste form release rates. The ILAW is expected to be a glass, ceramic, or metal waste form in a $1.2 \mathrm{mx} 1.2 \mathrm{~m} \times 1.8 \mathrm{~m}$ rectangular metal box.

Generally, the inspection and test methods should not require opening or otherwise breaching the seal of the waste form containers. The appropriate sampling and analysis strategies should provide the basis for making statistically based statements with respect to the confidence with which the products meet specifications. The inspection and test methods must be shown to be relevant to the expected performance parameters of the ILAW. 
Functional Performance Requirements: Demonstrate non-destructive examination techniques on full-scale prototypic ILAW waste packages. Techniques must have the required sensitivity, precision, and accuracy to make decisions regarding the acceptability of the products. Techniques must have reliability for application in production type environment.

Schedule Requirements: Early indications of the adequacy of the inspection and test methods is needed early as input to product acceptance strategy revisions, Phase 1B contract negotiations, and inspection facility design. Inspection and test methods must be selected by September 2000 such that operating procedures can be prepared and implemented. Inspection operations will begin in June 2002.

Problem Description: Non-destructive examination techniques are currently being used at commercial and DOE operated disposal facilities to verify that packaged wastes meet acceptance criteria. Radiography, including real-time radiography, digital radiography, and X-ray computed tomography, is used to identify gross inhomogeneities and free liquids within waste containers. Gamma spectroscopy is a common technique for determining the concentration of gammaemitting radionuclides $\left({ }^{60} \mathrm{Co},{ }^{137} \mathrm{Cs},{ }^{152} \mathrm{Eu}\right.$, and $\left.{ }^{154} \mathrm{Eu}\right)$ within a waste drum. Passive/active neutron assay is used to determine the quantity of neutron-emitting and fissile material in waste packages. It is used to differentiate between LLW and TRU wastes. Application of these techniques to the larger ILAW boxes and more dense glass waste forms proposed for the current low-activity waste will need to be demonstrated. Other nondestructive techniques such as eddy current methods, and ultrasonic techniques may have application to the inspection of waste containers and their contents. Acoustics and optics based measuring devices are commercially available and would need to be adapted for measuring package dimensions.

\section{ADS No. RDS No. WBSNo. \\ $1250(1230)$}

\section{Justification For Need:}

Technical: Product acceptance inspection and test results will provide part of basis for justifying payment to private contractors. Methods mus: be technically defensible in case of litigation.

Regulatory: DOE Order 5820.2A requires that waste generators and waste receivers are jointly responsible for assuring compliance with waste acceptance criteria. Adequate product inspections and tests will probably be required to receive a Part-B permit from the Department of Ecology.

Environmental Safety \& Health: The ILAW product specifications were developed in part. to protect the safety of operators and to protect the environment. Failure to detect nonconforming products could lead to adverse environmental, safety and health impacts. 
Cost Savings Potential (Mortgage Reduction): Reduces risk of incurring cost in the future for remediating results of failure of waste packages previously accepted as meeting specifications.

CulturalStakeholder Concerns: Stakeholders continue to have concerns for the storage and disposal of radioactive wastes at Hanford.

\section{Other:}

Consequences of Not Filling Need: Potential increases for inadequate waste package slipping through acceptance process and later failing, causing safety and environmental impacts. Technically undefensible inspection and test techniques could lead to losses should payments to private contractors be contested in courts.

Outsourcing Potential: High. Private companies have systems that can be adapted to Hanford applications.

Current Baseline Technology: . None established. Non-destructive examination techniques including radiography, gamma spectroscopy, and passive/active neutron assay are currently used for LLW and TRU solid wastes.

Cost:

Waste:

How Long It Will Take:

End-User: TWRS

Site Technical Point(s)-of-Contact: J. H. Westsik, Jr., Pacific Northwest National Laboratory, (509) 376-5986; fax (509) 376-0166; e-mail: jh_westsik@pnl.gov

DOE End-User/Representative Point(s)-of-Contact: Philip E. LaMont,.(509) 376-6117; fax (509) 3.72-1350; e-mail: philip_e_lamont@rl.gov 


\section{TECHNOLOGY NEEDS/OPPORTUNITIES \\ STATEMENT OUTLINE}

Identification No.: RL-WT011

Date: September 1997

Program: Tanks - Process Waste

OPS Office/Site: Richland

Operable Unit (if applicable): NA

Waste Stream: Immobilized High-Level Waste

Waste Management Unit (if applicable): NA

Facility: TWRS

Site Priority Ranking: Medium

Need Title: IHLW Product Acceptance Inspection and Test Methods

Need Description: The United States Department of Energy (DOE), Richland Operations Office $(\mathrm{RL})$ is proceeding with a two-phased approach to privatize the treatment and immobilization of Hanford's low-activity and high-level wastes currently in storage in underground tanks. DOE will provide the tank wastes to the private contractors who will treat and immobilize the wastes and then return the final products to DOE for storage and final disposal. Acceptance of the immobilized wastes may be based on a combination of private contractor activities to qualify, verify, document, and certify the product and DOE activities to audit, review, inspect, and test the processes and proclucts.

The immobilization contractors will provide to DOE the immobilized high-level waste (IHLW) products in sealed canisters, process and product grab samples, and the appropriate product certification which may include pertinent process data. The DOE may conduct non-destructive testing of the sealed immobilized high-level waste canisters and destructive and non-destructive testing of the process and product samples. Specific parameters of interest may include chemical composition of the waste forms, fillers, and containers, phase composition, radiochemical composition, thermal history and surface temperature, waste form volume and void space, waste form and container weight, container dimensions including wall thickness, effectiveness of container closure or seal (leak tightness), presence of prohibited materials including free liquids and explosive, pyrophoric or combustible materials, dose rate, surface contamination, waste form homogeneity, and waste form release rates. The IHLW product is expected to be a glass waste form in a $61-\mathrm{cm}$ diameter by $3-$ to $5-\mathrm{m}$ long cylindrical stainless steel canister.

Generally, the inspection and test methods should not require opening or otherwise breaching the seal of the waste form containers. The appropriate sampling and analysis strategies should provide the basis for making statistically based statements with respect to the confidence with which the products meet specifications. The inspection and test methods must be shown to be relevant to the expected performance parameters of the IHLW. 
Functional Performance Requirements: Demonstrate non-destructive examination techniques on full-scale prototypic IHLW waste packages. Techniques must have the required sensitivity, precision, and accuracy to make decisions regarding the acceptability of the products.

Techniques must have reliability for application in production type environment.

Schedule Requirements: Early indications of the adequacy of the inspection and test methods is needed early as input to product acceptance strategy revisions, Phase 1B contract negotiations, and inspection facility design. Inspection and test methods must be selected by September 2000 such that operating procedures can be prepared and implemented. Inspection operations will begin in June 2002.

Problem Description: Non-destructive examination techniques are currently being used at commercial and DOE operated LLW and TRU disposal facilities to verify that packaged wastes meet acceptance criteria. Radiography, including real-time radiography, digital radiography, and $\mathrm{X}$-ray computed tomography, is used to identify gross inhomogeneities and free liquids within waste containers. Gamma spectroscopy is a common technique for determining the concentration of gamma-emitting radionuclides $\left({ }^{60} \mathrm{Co},{ }^{137} \mathrm{Cs}\right.$, ${ }^{152} \mathrm{Eu}$, and $\left.{ }^{154} \mathrm{Eu}\right)$ within a waste drum. Passive/active neutron assay is used to determine the quantity of neutron-emitting and fissile material in waste packages. It is used to differentiate between LLW and TRU wastes. Application of these techniques to the more radioactive and more dense IHLW glass waste forms will need to be demonstrated. Other nondestructive techniques such as eddy current methods, and ultrasonic techniques may have application to the inspection of waste containers and their contents. Acoustics and optics based measuring devices are commercially available and would need to be adapted for measuring IHLW canister dimensions
ADS No.
RDS No.
WBS No.
$1250(1230)$

\section{Justification For Need:}

Technical: Product acceptance inspection and test results will provide part of basis for justifying payment to private contractors. Methods must be technically defensible in case of litigation.

Regulatory: The immobilized high-level waste product must be acceptable for disposal at a federal HLW geologic repository. As such, the IHLW must meet the repository product specifications and quality assurance requirements.

Environmental Safety \& Health: The IHLW product specifications were developed in part to protect the safety of operators and to protect the environment. Failure to detect nonconforming products could lead to adverse environmental, safety and health impacts.

Cost Savings Potential (Mortgage Reduction): Reduces risk of incurring cost in the future for remediating results of failure of waste packages previously accepted as meeting 
specifications.

Cultural/Stakeholder Concerns: Stakeholders continue to have concerns for the storage and disposal of radioactive wastes at Hanford.

other: N/A

Consequences Of Not Filling Need: Potential increases for inadequate IHLW canisters slipping through acceptance process and later failing, causing safety and environmental impacts.

Technically indefensible inspection and test techniques could lead to losses should payments to private contractors be contested in courts.

Outsourcing Potential: High. Private companies have systems that can be adapted to Hanford applications.

Current Baseline Technology: None established. Non-destructive examination techniques including radiography, gamma spectroscopy, and passive/active neutron assay are currently used for LLW and TRU solid wastes.

Cost:

Waste:

How Long It Will Take:

End-User: WRS

Site Technical Point(s) of-Contact: J. H. Westsik, Jr., Pacific Northwest National Laboratory, (509) 376-5986; fax (509) 376-0166; e-mail: jh_westsik@pnl.gov

DOE End-User/Representative Point(s)-of-Contact: Philip E. LaMont, (509) 376-6117;

fax (509) 372-1350; e-mail: philip_e_lamont@rl.gov 


\section{TECHNOLOGY NEEDS/OPPORTUNITIES \\ STATEMENT OUTLINE}

Identification No.: RL-WT012

Date: September 1997

Program: Tanks - Process Waste

OPS Office/Site: Richland

Operable Unit (if applicable): NA

Waste Stream: Entrained Solids, ${ }^{137} \mathrm{Cs},{ }^{99} \mathrm{Tc},{ }^{90} \mathrm{Sr}$, and TRU

Waste Management Unit (if applicable): NA

Facility: TWRS

Site Priority Ranking: High

Need Title: Secondary Products Acceptance Inspection and Test Methods

Need Description: The United States Department of Energy (DOE), Richland Operations Office (RL) is proceeding with a two-phased approach to privatize the treatment and immobilization of Hanford's low-activity and high-level wastes currently in storage in underground tanks. DOE will provide the tank wastes to the private contractors who will treat and immobilize the wastes and then return the final products to DOE for storage and final disposal. The private contractors are to separate entrained solids, ${ }^{137} \mathrm{Cs},{ }^{99} \mathrm{Tc},{ }^{90} \mathrm{Sr}$, and TRU from the low-activity waste stream for later immobilization as HLW. Acceptance of the secondary waste products may be based on a combination of private contractor activities to qualify, verify, document, and certify the products and DOE activities to audit, review, inspect, and test the processes and products.

The private contractors will provide to DOE the secondary waste products as liquids or solids depending on the specifications and the appropriate product certification which may include pertinent process data. The DOE may conduct destructive and non-destructive testing of the process and product samples. Specific parameters of interest may include:

-chemical composition of the secondary waste products

-radiochemical composition

-thermal history and surface temperature of secondary waste containers

-weight and/or volume of secondary product

- container dimensions including wall thickness

-effectiveness of container closure or seal (leak tightness)

-presence of prohibited materials including free liquids and explosive, pyrophoric or

combustible materials

-dose rate

-surface contamination

-flow properties of liquid secondary waste products 
The separated ${ }^{137}$ cesium product will be a dry, free flowing product in a container with a 50-year storage capability. The entrained solids, ${ }^{90}$ strontium, transuranics, and ${ }^{99}$ technetium will be in a liquid or slurry form with the technetium a distinctly separate product stream.

Generally, the inspection and test methods should not require opening or otherwise breaching the seal of the separated ${ }^{137}$ cesium product containers. In-tank or in-pipeline inspection and test methods may be needed for the liquid wastes. The appropriate sampling and analysis strategies should provide the basis for making statistically based statements with respect to the confidence with which the products meet specifications.

Functional Performance Requirements: Demonstrate destructive and non-destructive examination techniques and chemical and radiochemical analysis techniques for inspecting and testing expected secondary waste products. Techniques must have the required sensitivity, precision, and accuracy to make decisions regarding the acceptability of the products.

Techniques must have reliability for application in production type environment.

Schedule Requirements: Early indications of the adequacy of the inspection and test methods is needed early as input to product acceptance strategy revisions, Phase 1B contract negotiations, and inspection facility design. Inspection and test methods must be selected by September 2000 such that operating procedures can be prepared and implemented. Inspection operations will begin in June 2002.

Problem Description: Chemical and radiochemical analytical techniques must be demonstrated to have the required sensitivity, precision, and accuracy to characterize the composition and radionuclide content of the entrained solids, ${ }^{137} \mathrm{Cs},{ }^{99} \mathrm{Tc},{ }^{90} \mathrm{Sr}$, and TRU waste products. Techniques to verify that the solutions and slurries can be safely transported via cask or pipeline. Non-destructive techniques are needed to confirm that separated ${ }^{137} \mathrm{Cs}$ waste product and its container meet the specifications for those materials.
ADS No.
RDS No.
WBS No. $1250(1230)$

\section{Justification For Need:}

Technical: Product acceptance inspection and test results will provide part of basis for justifying payment to private contractors. Methods must be technically defensible in case of litigation.

Regulatory: DOE: Order 5820.2A requires that waste generators and waste receivers are jointly responsible for assuring compliance with waste acceptance criteria. Adequate product inspections and tests will probably be required to receive a Part-B permit from the Department of Ecology.

Environmental Safety \& Health: The secondary waste product specifications were developed in part to protect the safety of operators and to protect the environment. Failure to 
detect non-conforming products could lead to adverse environmental, safety and health impacts.

Cost Savings Potential (Mortgage Reduction): Reduces risk of incurring cost in the future for remediating results of failure of secondary waste products previously accepted as meeting specifications.

Cultural/Stakeholder Concerns: Stakeholders continue to have concerns for the storage and disposal of radioactive wastes at Hanford.

Other: N/A

Consequences Of Not Filling Need: Potential increases for inadequate secondary waste products slipping through acceptance process and upsetting later HLW immobilization, causing cost, safety, and environmental impacts. Technically indefensible inspection and test techniques could lead to losses should payments to private contractors be contested in courts.

Outsourcing Potential: High - Private companies have systems that can be adapted to Hanford applications.

Current Baseline Technology: None established - Some techniques are currently used by Hanford tank farm operations to assure that wastes received in the tanks meet tank specifications.

Cost:

Waste:

How Long It Will Take:

End-User: TWRS

Site Technical Point(s)-of-Contact: J. H. Westsik, Jr., Pacific Northwest National Laboratory (509) 376-5986; fax (509) 376-0166; e-mail: jh_westsik@pnl.gov

DOE End-User/Representative Point(s)-of-Contact: Peter T. Furlong, (509) 372-1738;

fax (509) 373-0628; e-mail: peter_t furlong@r)rl.gov and Philip E. LaMont, (509) 376-6117;

fax (509) 372-1350; e-mail: philip_e_lamont@rl.gov 


\section{TECHNOLOGY NEEDS/OPPORTUNITIES \\ STATEMENT OUTLINE}

Identification No.: RL-WT013

Date: September 1997

Program: Tanks - Retrieval

OPS Office/Site: Richland

Operable Unit (if applicable): N/A

Waste Stream: Single Shell Tanks

Waste Management Unit (if applicable): N/A

Facility: Tank Farms

Site Priority Ranking: High

Need Title: Establish Retrieval Performance Evaluation Criteria

Need Description: The Tri-Party Agreement (TPA) establishes an interim retrieval performance goal to leave no more than 360 cubic feet of waste in 75 foot diameter SSTs, and no more than 30 cubic feet in 20 foot diameter SSTs. This interim goal is intended to be finalized or modified over time based on demonstrations of retrieval technology, and on evaluation of cost, technical practicability, exposure of workers and public to radiation, and compliance with Nuclear Regulatory Commission requirements that will establish authority to regulate disposal of the radioactive component of residual waste.

A principal function of waste retrieval is to remove sufficient waste from tanks to permit tank closure. The TWRS EIS evaluated environmental impacts associated with retrieval of waste from SSTs using technologies that are expected to leave residual volumes of waste approximating the interim TPA retrieval performance goal. If residual waste must be retrieved from SSTs as part of closure operations, environmental impacts of such waste retrieval, including impacts on tank waste processing, have not been evaluated.

An additional aspect of establishing retrieval performance objectives concerns the amount of leakage of tank waste that would be allowable during retrieval operations. The amount of leakage that would be allowable depends on what will be done to remediate soil as a consequence of such leakage. Thus determination of allowable tank leakage during retrieval is related to and dependent on criteria for closing tank farms.

Evaluation of alternatives for tank farm closure, which would include evaluation of environmental impacts associated with retrieval of waste to the degree required for "clean closure" was not included within the scope of the TWRS EIS. The TWRS EIS stated that "sufficient information is not available to make final decisions on closure." The TWRS EIS states that the Hanford Tanks Initiative would. "gather information and reduce uncertainties associated with tank closure" and that "information that would be gathered through the Hanford 
Tanks Initiative would be used to establish processes and criteria.for future closure options."

In a report summarizing its review of the TWRS EIS, the Committee on Remediation of Buried and Tank Wastes, National Research Council, criticized DOE's and Ecology's decision to defer analysis of closure alternatives, because of the interrelationship of retrieval and closure. The Committee endorsed DOE's decision to address issues on retrieval and closure through the Hanford Tanks Initiative.

Several discrete technology needs must be satisfied to support decisions for tank closure alternatives. These needs include improvements to equipment and methods for tank heel removal, conditioning of wastes to slurries acceptable for transport, techniques to measure the residual waste volume following retrieval efforts, methods to capture samples of waste that are not directly below the riser, and methods to map contaminants in the vadose zone. These needs are expanded in the following paragraphs.

Need Title: Vadose Zone Contaminants Distribution

Needs Description: Alternative technologies to conventional core drilling for characterization of the vadose zone that are fast, economical and minimize intrusion to the vadose zone are needed. These technologies should: 1) quantify (i.e., 3-D map) the extent of contaminants leaked to the tank backfill material and vadose zone in tank farms; ; and 2) obtain soil samples at selected depths for confirmatory laboratory analysis. The technology must be capable to detect metal pipes and obstructions. The sampled soil column must be sealed (i.e., grouted) to eliminate any potential pathway for contaminant leakage to the aquifer. Technology to verify the quantity and extent of contaminants leaked to the vadose zone in tank farms will reduce the uncertainty associated with estimates of radionuclide and chemical inventory, which are vital input data to the performance assessment model(s) proposed for tank farms closure.

Need Title: SST Retrieval Equipment/System Development

Need Description: Performance and cost data comparing alternate and enhanced retrieval methods to the performance baseline of past-practice sluicing is needed. Data will be applied to the selection of retrieval systems for 1)Tank C-106 Heel Removal, 2) M\&I retrieval of SSTs during Outsourcing Phase I, 3) ISSTRS concept design technical input to the Outsourcing Phase II specification (TPA Milestone M-45-04A) and 5) performance assessment for SST closure. Supports maintaining core competency by providing expertise in the application of retrieval tools, regardless of the implementor.

Need Title: Waste Conditioning for Tank Heel Transfer

Need Description: The affects of the physical and chemical properties of waste on pipeline transfer, interim storage and subsequent transfer to pretreatment processed needs to be better understood so that waste conditioning requirements can be cletermined before any Single Shell Tank hard heels (including the tank 106-C heel) can be safely and efficiently transferred to a storage tank for later processing. 
Need Title: Methods For Waste Heel Volume Determination Including Thickness and Profile

Need Description: Methods are needed to accurately determine the volume of residual waste in a tank for use in a tank closure assessment. Surface profile and heel thickness are needed to determine waste volume in tanks with unknown tank bottom flatness.

Functional Performance Requirements: Estimated requirement is (t/-) $40 \mathrm{cu}$. ft. ( $10 \%$ op 360 cu. ft. -- target residual) (Will be negotiated based on available cost-effective technology/methodology).

Need Title: Sampling Methods For Residual Heels - Off Riser Axis

Need Description: Methods are needed to sample the residual waste in a tank for use in establishing retrieval performance evaluation criteria. Conventional sampling methods can prove ineffective due to little or no waste being located directly below the access riser. In addition, enough locations in the tank need to be sampled to show adequate characterization of residual waste for use in tank specific performance assessment work.

Functional Performance Requirements: These will be established through interaction with stakeholders and regulators as part of the task to establish retrieval performance objectives..

Schedule Requirements: Completion of definition of retrieval performance objectives is needed by FY 2000 so that the results can be incorporated into the Outsourcing Phase II specification due to be completed in FY2003 and the first Single Shell Tank Closure Plan, due to be completed by November, 2004 (TPA M-45-06-T01).

Problem Description: Other than the retrieval performance goal provided in the Tri-Party Agreement, which is recognized by the Washington Department of Ecology and DOE in a memorandum of understanding as only an "interim" goal, no basis currently exists for defining retrieval performance objectives that address how much waste must be removed from SSTs and how much leakage during retrieval of SSTS will be allowable.
ADS No.
RDS No.
WBS No.
$1210-0$
R9@N0130
1.1.1.3.1.1

\section{Justification For Need:}

Technical: This effort is required to establish retrieval system performance requirements relating to how much waste must be removed from SSTs, and how much waste may leak from SSTs during retrieval operations.

Regulatory: Analyses completed as part of the effort to address this technology need will serve as the basis for reaching agreement with regulatory agencies on establishing retrieval performance objectives and criteria for closure of Hanford SSTs. 
Environmental Safety \& Health: Health and safety risks to workers and members of the public associated with alternatives for closing tank farms will be evaluated as part of the effort to address this technology need.

Cost Savings Potential (Mortgage Reduction): A significant cost avoidance is expected if DOE can reduce uncertainty in the degree of waste removal required for waste retrieval operations and in limiting leakage during retrieval. Reduction of uncertainty in waste retrieval performance requirements will lead to lower contingency factors included in Outsourcing Phase II proposals. In addition, early establishment of retrieval performance objectives will reduce the risk that retrieval systems will need to be deployed a second time in a given SST, after a final retrieval performance goal is established, for SSTs that are retrieved by the PHMC contractor during Phase I Outsourcing.

Cultural/Stakeholder Concerns: The Washington Department of Ecology and DOE have signed a memorandum of understanding that commits to establishing retrieval performance objectives, as part of the effort to address this technology need, through soliciting input from Indian Nations and stakeholders, through interaction with the Hanford Advisory Board, Community Leaders Network, and the Site Technology Coordinating Group.

Other: N/A

Consequences Of Not Filling Need: Establishing retrieval system performance objectives based solely on what is technologically achievable, without regard to practicality, cost, and health and safety risk, could lead to inappropriate allocation of site cleanup funds. Deferring establishment of retrieval performance objectives will increase contingency in Phase 2 Outsourcing proposals for retrieval of SST wastes, and will increase the likelihood of requiring multiple deployments of SST retrieval systems by the PHMC contractors during Phase 1 Outsourcing.

Outsourcing Potential: Retrieval system performance specifications will be provided to the Phase 2 Outsourcing Contractor.

Current Baseline Technology: No baseline technology or approach has been established for closing tank farms, or for establishing the degree of waste removal from tanks that will be sufficient to close tank farms..

End-User: Retrieval/Tank Farm Operations

Site Technical Point(s)-of-Contact: R. W. Root (HTI Project Manager), (509) 373-1328

DOE End-User/Representative Point(s)-of-Contact: Bruce L. Nicoll, (509) 376-6006; fax (509) 372-1350; e-mail: bruce_1_nicoll@rl.gov 


\section{TECHNOLOGY NEEDS/OPPORTUNITIES STATEMENT OUTLINE}

Identification No.: RL-WT014

Date: September 1997 .

Program: Tanks - Retrieval

OPS Office/Site: Richland

Operable Unit (if applicable): N/A

Waste Stream: Double Shell Täns

Waste Management Unit (if applicable): N/A

Facility: Tank Farms

Site Priority Ranking: Low

Need Title: Alternative to Baseline Tank Waste Mixing Systems

Need Description: Mixing system to homogenize and dilute slurry/supernate waste to support the following objectives: mobilization of settled solids heels; enhance and/or accelerate the dissolution of precipitated soluble salts; homogenize stratified waste layers; mobilization of problematic solids for removal from intermediate feed staging tanks; and to provide the capability to recover from receiving out of specification waste. Feed for Outsourcing Phase I Immobilization Demonstrations must be certified to comply with RFP waste envelope requirements. To accomplish this, the intermediate feed staging tanks contents must be well mixed before being sampled and transferred to the Privatization Phase contractors.

Functional Performance Requirements: The waste solution to be mixed will be a dilute slurry/supernate with a maximum of $5 \%$ solids by volume. The system shall be capable of homogenizing dilute slurry/supernate and removing approximately $95 \%$ of settled solids heel from the tank. Proposed system will be installed into existing tank penetrations. System may be deployed into tanks currently storing wastes.

Schedule Requirements: Needed for Phase I feed beginning in FY 2000.

Problem Description: Baseline mixing systems are designed for sludge mobilization.

Historically, such mixing systems used at other DOE sites have had a short expected operational life. This situation has led to high Life Cycle Costs related to removal and disposal costs. The system to be proposed should provide equipment that has a high reliability for the environment that it will operate in and also have an improved operational life expectancy.

$\begin{array}{ccc}\text { ADS No. } & \text { RDS No. } & \text { WBSNo. } \\ 1210-0 & \text { R95W0006 } & 1.1 .1 .3 .1 .2\end{array}$




\section{Justification For Need:}

Technical: This activity will identify systems that more closely fit the demands of the mixing operation while providing the needed mobilization capabilities. The proposed system shall provide enhanced reliability.

Regulatory: Will support certification of the waste that is to be transferred to the Phase I. Privatization Contractor for immobilization.

Environmental Safety \& Health: Less required replacement of failed equipment is ALARA.

Cost Savings Potential (Mortgage Reduction): Less expensive mixer systems. Fewer equipment failure requiring replacement and disposal of failed equipment and reduce personnel exposure related to removing and reinstallation of equipment.

\section{Cultural/Stakeholder Concerns: N/A}

Other: N/A

Consequences Of Not Filling Need: Baseline mixing systems with lower reliability will be used with higher life cycle costs.

Outsourcing Potential: This task will show where industry has the capabilities to perform now and the potential for mobilization and retrieval success under Privatization Phase II:

Current Baseline Technology: Mixer pumps

End-User: TWRS (Retrieval/Tank Farm Operations)

Site Technical Point(s)-of-Contact: J. D. Galbraith, (509) 376-7929; P. W. Gibbons, (509) 372.0095

DOE End-User/Representative Point(s)-of-Contact: Bruce L. Nicoll, (509) 376-6006; fax (509) 372-1350; e-mail: bruce_1_nicoll@rl.gov

Proposed Concepts: Pulse-air, AEA pulse tubes. 


\section{TECHNOLOGY NEEDS/OPPORTUNITIES \\ STATEMENT OUTLINE}

Identification No.: $\underline{\text { RL-WT015 }}$

Date: September 1997

Program: Tanks - Storage \& Disposal

OPS Office/Site: Richland

Operable Unit: Not Applicable

Waste Stream: Immobilized Low-Activity Tank Waste

Waste Management Unit: Not Applicable

Facility: Tank Farms

Site Priority Ranking: Medium

Need Title: Standard Method for Determining Waste Form Release Rate

Need Description: The release of radionuclides from a waste form and package to the environment results from the interactions between the waste form and water in the disposal system. For the disposal of immobilized low- activity tank waste (ILAW), the waste form and package are expected to be in an extremely dry environment. In such an environment, the release rate is a sensitive function of physical (temperature, water content) and chemical environment (pH, amount and type of mineral and non-mineral species).

Waste forms are typically developed to minimize the rate of release as measured by a variety of test methods. Current ILAW product specifications require PCT testing and ANS 16.1 testing of the waste forms which involve testing the waste form in an environment where water is abundant and where chemical effects are minimized. These test methods will not be representative of the expected disposal system environment at Hanford. A release rate test method yielding results that can be related to the waste form release rate under expected service conditions is needed as a basis for Phase 2 ILAW product specifications.

Tests are also used to determine release data for use in the analysis for the assurance that longterm public health and safety will be protected using the proposed disposal method. Such tests must examine a wider set of environmental conditions that product acceptance tests and will form the basis of the Performance Assessment for the disposal action. As shown in the "Hanford Low-Level Tank Waste Interim Performance Assessment" (WHC-EP-0884), the contaminant release rate from the waste form is one of the few major factors in the assurance of public health and safety.

As part of the performance activity, the Pressurized Unsaturated Flow (PUF) test was developed (Proceedings of the American Ceramic Society and of Materials Research Society) by the Pacific Northwest National Laboratory to obtain contaminant release rates from waste form under dry conditions. 


\section{Functional Performance Requirements:}

1) Develop and standardize a waste form release rate method applicable to dry environments. The effort should compare results from this method to others.

2) Conduct sufficient tests (under a variety of geochemical and hydraulic conditions and using a variety of waste forms) to provide data to form a basis for Phase 2 waste form release rate specification.

3) Coordinate efforts with Hanford Low-Level Tank Waste Performance Assessment to ensure that environmental conditions are typical of Hanford.

\section{Schedule Requirements:}

1) For use in the Hanford Low-Level Tank Waste Performance Assessments such data and testing are needed by February 2001. Preliminary versions of the performance assessments will need data by January 1999.

2) A standard method for determining waste form release rate and supporting data is needed to prepare the ILAW product specifications for Phase 2 of the TWRS outsourcing beginning in approximately 2003 .

Problem Description: Develop a standard waste form release rate test method that is relevant to expected performance in the disposal environment and that can be used as a ILAW product specification. The test should be accepted by a standards test organization such as the ASTM.

The test method must provide usable results within a 90-day time period such that the compliance of the waste form to the product specifications can be confirmed and payment to the private contractor authorized. The test method will be implemented in a production environment.

The test method must be suitable over a range of temperatures $\left(\mathrm{T}=14\right.$ to $\left.90^{\circ} \mathrm{C}\right)$, moisture conditions $(=0.1$ to 1.0$)$, and $\mathrm{pH}(\mathrm{ph}=6.0$ to 12.0$)$ conditions for use in performance assessment activities.

$\begin{array}{lll}\text { ADS: } & \text { RDS: } & \text { WBS: } \\ 1250 & ? ? ? & 1.1 .1 .3 .04 .01 .03\end{array}$

\section{Justification for Need:}

Technical: Numerous test methods including the MCC test, PCT, and ANS 16.1 have been used to determine waste form release rates. Current methods for measuring release-rates from a waste form do not mimic the conditions that the waste form will experience in the disposal environment. A standardized test is needed. 
Regulatory: DOE Order 5820.2a requires that waste acceptance criteria address chemical and structural stability of waste packages. The same order requires an assessment of longterm public health and safety. Contaminant release rates are an important input to this assessment.

Environmental Health and Safety: The long-term contaminant release rate is the driving factor in determining human health and environmental impact from the disposal of the lowactivity fraction of the Hanford tank waste.

Cost Savings Potential: A better understanding of long-term release might allow DOE to relax requirements for the short-term testing now required under the outsourcing contract. A more relevant test method could lead to product specifications that are easier to achieve and perhaps to simpler disposal system designs.

Cultural Stakeholder Concerns: Stakeholders are interested in the parameters which drive environmental impact rather than the parameters that are specified in a contract and only have a weak relationship to real-life performance.

Consequences of Not Filling Need: Without data for long-term tests under expected conditions, the performance assessment will use conservative parameters which would require DOE to set tighter requirements on immobilization product vendors or on disposal facility design. Inadequate specification of release rates could lead to future environmental impacts.

Outsourcing Potential: Uses of glass as a waste form are in unsaturated media. Having a more suitable, standardized test would be of significant value in the DOE complex as well as in private industry.

Current Baseline Technology: Standardized tests are in fully emersed or saturated media (PCT, $\mathrm{MCC}$ ) or in vapor (at high temperatures). Performance of tests at proper temperature, moisture, and $\mathrm{pH}$ is not currently possible but relies on extrapolation.

\section{Cost:}

Waste:

How Long It Will Take:

End-User: TWRS Storage and Disposal Project

Site Technical Point(s)-of-Contact: Fred Mann, Fluor Daniel Northwest; (509)376-5728; fax: (509)376-1293; email: frederick_m_mann@rl.gov or v92515@fep0.rl.gov J. H. Westsik, Jr., Pacific Northwest National Laboratory; (509) 376-5985; fax: (509) 376-0166

DOE Representative Point of Contact: Phil LaMont, RL/TWRS; (509)376-6117; fax:(509)3721350; philip_e_lamont@rl.gov 


\section{TECHNOLOGY NEEDS/OPPORTUNITIES \\ STATEMENT OUTLINE}

Identification No:: RL-WT016

Date: September 1997

Program: Tanks - Storage \& Disposal

OPS Office/Site: Richland

Operable Unit: Not Applicable

Waste Stream: Immobilized Low-Activity Tank Waste

Waste Management Unit: Not Applicable

Facility: Tank Farms

Site Priority Ranking: High

Need Title: Glass Monolith Surface Area

Need Description: A method is needed to estimate the surface area of vitrified low activity waste. The contaminant release rate from glasses is proportional to the surface area reachable by moving moisture. As glass cools it experiences internal stresses and strains which may cause the glass to crack and hence increase the surface area on the glass. External stresses (for example, those caused by earthquakes) could also increase surface area.

In addition, cracks may expose imperfections in waste form (internal gas pockets, nucleation sites, devitrification regions) which may cause increased contaminant release rates. Relatively little is known about the long-term behavior of such cracks. Yet the total contaminant release must be known (or at least estimated) for thousands of years.

\section{Functional Performance Requirements:}

For typical low-level waste glass monoliths using a variety of sizes and cooling methods:

1) Determine surface area and crack patterns.

2) Determine area reachable by moisture.

3) Accelerate aging and repeat measurements.

4) Determine unsaturated hydraulic properties of fractured and aged specimens.

Schedule Requirements: For use in the Hanford Low-Level Tank Waste Performance Assessments such data and testing are needed by September 2000. Preliminary versions of the performance assessments will need data by September 1998.

Problem Description: Status of technology for measurement and aging not known.

$\begin{array}{lll}\text { ADS: } & \text { RDS: } & \text { WBS: } \\ 1250 & ? ? ? & 1.1 .1 .3 .04 .01 .03\end{array}$




\section{Justification for Need:}

Technical: Contaminant release from the waste form is proportional to the surface area reachable by moving moisture. This release rate determines the impact from waste disposal using very slow-release waste forms.

Regulatory: Contaminant release rates are an important input the performance assessment which is required under DOE Order 5820.2A (soon to be codified under 10 CFR 834).

Environmental Health and Safety: The long-term contaminant release rate is the driving factor in determining human health and environmental impact from the disposal of the lowactivity fraction of the Hanford tank waste.

Cost Savings Potential: A better understanding of long-term release might allow DOE to relax requirements for the short-term testing now required under the outsourcing contract. Possible cost savings could be in the hundred's of millions of dollars.

Cultural Stakeholder Concerns: Stakeholders are interested in the parameters which drive environmental impact rather than the parameters that are specified in a contract and only have a weak relationship to real-life performance.

Consequences of Not Filling Need: Without data, the performance assessment will use conservative parameters which would require $\mathrm{DOE}$ to set tighter requirements on immobilization product vendors or on disposal facility design, thus increasing costs. Better definition of contaminant release will lead to a performance assessment which can more easily be defended.

Outsourcing Potential: Methods could support the vitrification technology industry by providing a means to quantify long-term performance of vitrified products.

Current Baseline Technology: Rule of thumb (based on very limited and probably inapplicable experience)

Cost:

Waste:

How Long It Will Take

End-User: TWRS Storage and Disposal Project

Site Technical Point-of-Contact: Fred Mann, Fluor Daniel Northwest; (509)376-5728; fax: (509)376-1293; email: frederick_m_mann@rl.gov or v92515@fep0.rl.gov

DOE Representative Point of Contact: Phil LaMont, RL/TWRS; (509)376-6117; fax:(509)3721350; philip_e_lamont@ri.gov 


\section{TECHNOLOGY NEEDS/OPPORTUNITLES \\ STATEMENT OUTLINE}

Identification No.: RL-WT017

Date: September 1997

Program: Tanks - Storage \& Disposal

OPS Office/Site: Richland

Operable Unit: Not Applicable

Waste Stream: Immobilized Low-Activity Tank Waste

Waste Management Unit: Not Applicable

Facility: Tank Farms

Site Priority Ranking: Medium

Need Title: Long-Term Testing of Surface Barrier

Need Description: Surface barriers are being used over many Hanford environmental restoration and waste management sites and more barriers are expected in the future. Such barriers are used to reduce moisture infiltration and plant and animal intrusion.

Short-term testing of barriers has occurred under project-sponsored activities, but long-term studies remain a funding orphan. Project-specific funding at Hanford ends in September 1997. Since the design life of the barrier is 1,000 years, need data on degradation to better understand the validity of the design life estimate.

A similar Technology Needs statement has also been included in the Subcon needs list.

Functional Performance Requirements: Monitor performance of an existing barrier under both natural conditions and artificially applied increases in precipitation to reflect variability of natural conditions and possible human intrusion). Develop degradation experiments and perform them.

Schedule Requirements: For use in the Hanford Low-Level Tank Waste Performance Assessments such data and testing are needed by September 2000. Preliminary versions of the performance assessments will need data by September 1998. Closure will start occurring in 2005.

Problem Description: Short-term testing has been performed. Need continuing testing.

$\begin{array}{lll}\text { ADS: } & \text { RDS: } & \text { WBS } \\ 1250 & ? ? ? & 1.1 .1 .3 .04 .01 .03\end{array}$

Justification for Need:

Technical: The estimated natural recharge at the proposed tank waste disposal facility location is $3 \mathrm{~mm} / \mathrm{year}$. The specifications of the Hanford surface barrier are $0.5 \mathrm{~mm} / \mathrm{year}$ for 1,000 years. 
Regulatory: DOE Order 5820.2A (soon to be codified as 10 CFR 834) requires a performance assessment. The length of time required to move contaminants from the disposal facility to groundwater is proportional to the amount of infiltration allowed through by the surface barrier. Given headquarters definition of the time of compliance as not more than 1,000 years, the design life of the surface barrier becomes an element in a defense in depth philosophy for waste disposal system design.

Environmental Health and Safety: See regulatory just above.

Cost Savings Potential: Surface barriers are being used among the DOE complex and particularly at Hanford. Improvements in design would establish confidence in long-term performance and would greatly affect both waste management and environmental restoration budgets.

Cultural Stakeholder Concerns: A major environmental impact identified in the Hanford Remedial Action Environmental Impact Statement is the mining of materials for surface barrier construction from the McGee Ranch of the Hanford Site. The McGee-Ranch area is a wildlife corridor which many see as vital in maintaining the unique shrub-steppe biological community in this area.

Consequences of Not Filling Need: The performance assessment may need to use conservative values or the facility design may be more expensive than necessary. In particular, more material than necessary may be used from an area of significant cultural value or the DOE may be forced to import suitable materials from a considerable distance.

Outsourcing Potential: Surface barriers are used at many DOE and commercial sites to reduce water infiltration. Research will aid many waste management areas, particularly those in arid and semi-arid Western states.

Current Baseline Technology: A cover is undergoing testing at the 200-BP-1 site at Hanford using environmental restoration funds. However, the funds are being greatly reduced and are scheduled to be eliminated after FY 1997.

Cost:

Waste:

How Long It Will Take:

End-User: TWRS Storage and Disposal Project

Site Technical Point-of-Contact: Fred Mann, Fluor Daniel Northwest; (509) 376-5728; fax: (509)376-1293; email: frederick_m_mann@rl.gov or v92515@fep0.rl.gov

DOE Representative Point of Contact: Phil LaMont, RL/TWRS; (509)376-6117; fax:(509)3721350; philip_e_lamont@rl.gov 


\section{TECHNOLOGY NEEDS/OPPORTUNITIES \\ STATEMENT OUTLINE}

Identification No.: Rl-WT018

Date: September 1997

Program: Tanks - Storage \& Disposal

OPS Office/Site: Richland

Operable Unit: Not Applicable

Waste Stream: Immobilized Low-Activity Tank Waste

Waste Management Unit: Not Applicable

Facility: Tank Farms

Site Priority Ranking: Low

Need Title: Testing of Sand-Gravel Capillary Barrier

Need Description: Water is the driving force behind releasing contaminants from waste forms and then carrying those contaminants to groundwater. Surface moisture barriers (such as the Hanford barrier) have a design life of a 1,000 years. Yet because of the dry conditions at Hanford, moisture infiltration should be minimized for thousands of years.

Unlike a surface barrier (which uses many of the same hydrologic principles), the capillary barrier diverts water away from the object underneath rather than storing the water until evaporation or plant transpiration removes the water. Thus the capillary barrier is expected to have a significantly longer life and be more effective than a surface barrier for moisture diversion.

Although the principles of sand-gravel capillary barriers are well established, such barriers (especially the ones the size needed for DOE applications) have not been extensively tested.

Functional Performance Requirements: Design, construct, and operate a sand-gravel capillary barrier of significant extent. A variety of water input rates (ranging from those expected from the use of a surface barrier to those expected from crop irrigation) should be applied with moisture seepage through and around the barrier being collected. Effort should be expended to identify failure mechanisms.

Schedule Requirements: Such experiments should be started as soon as possible as such a barrier is seen as a key component in the design of the low-level Hanford tank waste disposal facility.

Problem Description: A sand-gravel capillary barrier consists of a layer of fine material having high conductivity (such as sand) over a layer of coarse material having low conductivity (such as gravel). These layers are slopped in order to encourage water runoff. Experiments are needed to 
determine the range of application as well as technical parameters such as the slope of the layers and the optimal types of materials in the layers.

$\begin{array}{lll}\text { ADS: } & \text { RDS: } & \text { WBS: } \\ 1250 & ? ? ? & 1.1 .1 .3 .04 .01 .03\end{array}$

\section{Justification for Need:}

Technical: The "Hanford Low-Level Tank Waste Interim Performance Assessment" (WHCEP-0884) as well as earlier studies have identified the sind-gravel capillary barrier as a key component in the design of the disposal facility.

Regulatory: DOE Order 5820.2A (soon to be codified as 10 CFR 834) requires a performance assessment for DOE radioactive waste disposal facilities. The infiltration of moisture into the facility is a key parameter in determining the performance.

Environmental Health and Safety: See regulatory just above

Cost Savings Potential: The sand-gravel capillary barrier (if it can be shown to work in the field) is much less expensive than other facility design options (which probably will not work for the time periods needed) or requiring a significantly better performing waste form. If restrictions on waste form, then procurement costs for the waste form could be reduced by hundreds of millions of dollars.

Cultural Stakeholder Concerns: Disposal of.low-activity tank waste has the largest environmental impact of any intentional Hanford action.

\section{Other:}

Consequences of Not Filling Need: Other facility design option must be identified or (more likely) the specifications for Phase 2 of Hanford TWRS Privatization must be significantly tightened. The latter could add hundreds of millions of dollars to the procurement costs.

Outsourcing Potential: May have application to the design and construction of barriers over solid waste and especially hazardous waste landfills in the arid and semi-arid Western United States.

Current Baseline Technology: Theory is well understood. Limited field experience on related surface barriers.

Cost:

Waste:

How Long It Will Take:

End-User: TWRS Storage and Disposal Project 
Site Technical Point-of-Contact: Fred Mann, Fluor Daniel Northwest; (509)376-5728; fax: (509)376-1293; email: frederick_m_mann@rl.gov or v92515@fep0.rl.gov

DOE Representative Point of Contact: Phil LaMont, RL/TWRS; (509)376-6117; fax:(509)3721350; philip_e_lamont@rl.gov 


\title{
TECHNOLOGY NEEDS/OPPORTUNITIES \\ STATEMENT OUTLINE
}

Identification No.: RL-WT019

Date: September 1997

\author{
Program: Tanks - Storage \& Disposal \\ OPS Office/Site: Richland \\ Operable Unit: Not Applicable \\ Waste Stream: Immobilized Low-Activity Tank Waste \\ Waste Management Unit: Not Applicable \\ Facility: Tank Farms
}

Site Priority Ranking: Medium

Need Title: Getter Materials

Need Description: In order to meet the contaminant release specifications for the disposal of Hanford low-activity tank waste, radiocontaminants are physically trapped in glass. However, only a few of these radioelements drive the performance assessment. If these key radioelements could be chemically trapped after their release from glass, then the performance of the waste . disposal system could be significantly improved. Hydraulic properties of getter materials (original, loaded, and discharged) need to be measured to fully understand waste disposal performance in the presence of getters. The use of getter materials in the Savannah River Site's disposal of the Saltstone waste was an important consideration in the approval of that site's disposal of tank waste.

Functional Performance Requirements: For the conditions expected to occur in the Hanford low-level tank waste disposal facility (pH around 10, various chemical species), identify and measure the geochemical and hydraulic properties of a material that can chemically trap technetium (and preferably selenium). The material must be low in cost because large quantities could be used and the disposal site should not represent an attractive natural resource following site closure. The getter material should not introduce any additional environmental hazard.

Schedule Requirements: For use in the Hanford Low-Level Tank Waste Performance Assessments such data and testing are needed by September 2000. Preliminary versions of the performance assessments will need data by September 1998 .

Problem Description: Although limited effort to identify such getter materials (Pacific Northwest and Sandia National Laboratories) has been performed, no material has had sufficient testing to be selected. Instrumentation to determine properties is available. It is the identification of the material that has proved difficult. 
ADS: $\quad$ RDS: $\quad$ WBS:

1250

1.1.1.3..04.01.03

Justification for Need:

Technical: If technetium (and selenium to a lesser extent) can be chemically trapped, then the requirements of the disposal facility and of the waste form can be lessened.

Regulatory: DOE Order 5820.2A (soon to be codified as 10 CFR 834) requires a performance assessment for DOE radioactive waste disposal facilities.

Environmental Health and Safety: See regulatory just above

Cost Savings Potential: A better understanding of chemical interaction between radiocontaminants and the soil may allow simpler disposal facility designs, less stringent waste form performance requirements, or higher inventories. Such cost savings could exceed hundreds of millions of dollars.

Cultural Stakeholder Concerns: Disposal of low-activity tank waste has the largest environmental impact of any intentional Hanford action.

\section{Other:}

Consequences of Not Filling Need: This potentially very useful design option for the disposal facility will not be available. Containment of the wastes will have to be performed by physical entrapment.

Outsourcing Potential: Technetium is normally the most important radiocontaminant in the contamination of groundwater. Inexpensive getter materials may be an important aid in any future waste management facility.

\section{Current Baseline Technology:}

\section{Cost:}

Waste:

How Long It Will Take:

End-User: TWRS Storage and Disposal Project

Site Technical Point-of-Contact:: Fred Mann, Fluor Daniel Northwest; (509)376-5728; fax: (509)376-1293; email: frederick_m_mann@rl.gov or v92515@fep0.rl.gov

DOE Representative Point of Contact: Phil LaMont, RL/TWRS; phone (509)376-6117; fax:(509)372-1350; philip_e_lamont@ri.gov 


\section{TECHNOLOGY NEEDS/OPPORTUNITIES STATEMENT OUTLINE}

Identification No.: RL-WT020

Date: September, 1997

Program: Tanks - Operations

OPS Office/Site: Richland

Operable Unit (if applicable): N/A

Waste Stream: Single Shell Tanks and Transfer Systems

Waste Management Unit (if applicable):

Facility: Tank Farms

Site Priority Ranking: Medium

Need Title: Service Integrity Testing of High-Level Waste Tanks and Piping

Need Description: Hanford uses an aging infrastructure of single shell tanks and transfer piping for storage of high-level radioactive waste. Many systems are near or beyond their design services lives. There is presently no reliable system for determining whether a transfer system is fit for service in three critical areas: leak tightness, remaining service life, and extent of impaired service (partial plugging). The baseline methods for leak detection of transfer piping (hydrostatic testing and conductivity sensors) are prone to low sensitivity and false alarms. An improved method of leak testing is required to make operational decisions of whether or not a piping system can continue to be used, to avoid releases of radioactive waste to the Hanford soil. A piping system near failure may pass a leak tightness test yet fail while in service. An improved mean of assessing remaining service life is required. Significant partial plugging of a transfer system may complete stop a waste transfer will remaining undetectable to standard integrity tests.

There is presently no volumetric leak detection method for single shell tanks. The current practice in the Hanford single shell system employs level indication in tanks with liquid surfaces and gamma probes in liquid observation wells in tanks without liquid surfaces. Neither of these methods have been evaluated for performance following regulatory and industry standard practices. Moreover, there is no current capability to evaluate remaining service life for sound tanks during retrieval operations. Such a capability is required to evaluate the suitability of using past practice sluicing to retrieve wastes from single shell tanks.

Functional Performance Requirements: Design and install equipment for testing transfer lines at the Hanford site. Conduct a service integrity test program on at least two transfer systems in each of fiscal years 1999 and 2000. Quantify the leak tightness of the transfer systems per Environmental Protection Agency (EPA) guidelines for probability of detection and probability of false alarm. Design and install leak detection equipment for service integrity testing of single shell tanks. Conduct a leak test program for at least two single sheil tanks by fiscal years 2001 and 2002. Quantify leak tightness of the single shell tanks per EPA guidelines. 
Schedule Requirements: Work is to be performed in fiscal years 1999, 2000, and 2001.

Problem Description: Hanford does not have a protocol for determining "fitness for use" of transfer systems and single shell tanks. In service failure results in releases of wastes to Hanford soils and programmatic delays. Transfer systems fail unpredictably from leaks and plugging. Standard hydrostatic leak tests are unreliable and cannot evaluate remaining service life. Single shell tanks have no reliable leak detection system and no means to evaluate remaining service life for retrieval operations.
ADS No.
RDS No.
WBS No.
11200
1.1.1.2.01
1.1.1.3.XX

\section{Justification For Need:}

Technical: The current unquantified leak testing and leak detection practices are inadequate for making operational decisions such as whether or not to continue with a waste transfer or whether a particular tank is sound.

Regulatory: Washington Administrative Code 173-303-640(2)(c)(v) requires the results of a leak test or other integrity examination when performing tank system integrity assessments. Leak tests must be capable of taking into account the effect of temperature variations, tank end deflection, vapor pockets and high water table effects.

Environmental Safety \& Health: WHC-SD-WM-OSR-005, Single-Shell Tank Interim Operational Safety Requirements, WHC-SD-WM-OSR-004, Aging Waste Facility Interim Operational Safety Requirements, and WHC-SD-WM-OSR-016, Double-Shell Tank Interim Operational Safety Requirements. These support documents contain interim operational safety requirements - administrative controls for leak detection and monitoring requirements.

Cost Savings Potential (Mortgage Reduction): Undetected failures create unnecessary cleanup costs and programmatic delays.

Cultural/Stakeholder Concerns: Missed alarms can allow a leaking system to continue to leak many gallons of waste directly to the soil before being detected by external methods like drywell monitors. False alarms consume scarce resources with no productive outcome.

Other: N/A

\section{Consequences Of Not Filling Need:}

Regulatoru Impacts: The baseline leak detection and monitoring systems are not 
compliant with EPA guidelines for volumetric leak testing, and are not compliant with WAC 173-303-640.

Programmatic Impacts: The baseline system of leak detection and monitoring is unreliable in its capability to detect leaks and avoid false alarms. Delays and extra costs to programs are always involved in resolving these issues.

Outsourcing Potential: A private vendor will be sought to procure service integrity and monitoring services.

Current Baseline Technology: The current practice in the Hanford single shell system employs level indication in tanks with liquid surfaces and gamma probes in liquid observation wells in tanks without liquid surfaces. None of these methods have been evaluated for performance following regulatory and industry standard practices.

The present practice for leak testing waste transfer lines involves a short duration hydrostatic pressure test. This method does not provide information in quantities of regulatory interest. $(<1 \mathrm{gal} / \mathrm{hr})$.

End-User: Retrieval/Tank Farm Operations

Site Technical Point(s)-of-Contact: James L. Nelson, Lockheed Martin Hanford Corporation, (509) 373-6296

DOE End-User/Representative Point(s)-of-Contact: Mark L. Ramsay, (509) 376-7924 


\section{TECHNOLOGY NEEDS/OPPORTUNITIES \\ STATEMENT OUTLINE}

Identification No.: $\underline{\text { RL-WT021 }}$

Date: September, 1997

OPS Office/Site: Richland

Operable Unit (if applicable):

Waste Stream:

Waste Management Unit (if applicable):

Facility: Tank Farms

Site Priority Ranking: High

Need Title: Cleaning and Decontamination of Hanford Pits

Need Description: Waste retrieved from Hanford tanks must pass through a number of pits associated with single shell tanks before it is received by the privatization contractor for disposal. Many of these pits will have to be modified before the waste can be transferred. Current methods for modifying, operating, cleaning and decontaminating these pits are labor intensive and costly and result in a high dose to workers. Currently, work associated with pits is the single largest contribution to TWRS operations dose levels. For example, the dose in the 241-C-106 pits was $40 \mathrm{R} / \mathrm{hr}$. After investing $\$ 2$ million and 5 months, the dose had been reduced to only $20 \mathrm{R} / \mathrm{hr}$.

Functional Perfoimance Requirements: Improved methods of pit decon must reduce setup time and in pit debris/equipment removal time and thereby lower overall cost while at the same time reducing the dose received by the workers. Cleaning and decon methods should be able to reduce the background radiation in the pits better than present methods which are only capable of a factor of 2 reduction. Specifically:

1) Reduce the dose levels at the edge of the pit to $1-2 \mathrm{R} / \mathrm{hr}$, by a combination of trash removal and decon, in one week.

2) Remotely change out the seals in a Hanford connector in less than one shift.

3) Provide jumper and connector measurements, accurate to $t /-1 / 64$ inch, so replacements/alternate jumpers can be fabricated without operator entry into the pit to obtain measurements.

4) Provide devices to change out and/or install alternate jumpers in less than one shift. Schedule Requirements: The HTI project will begin decontamination of pits on tank 241-C-106 in June, 1999. New methods of pit decon will be needed on this project.

Problem Description: Technologies for remote mapping or remote handling must be adapted to the configuration and specific tasks that are required. Existing commercial equipment cannot be deployed without modification. Chemical methods to decontaminate surfaces must be demonstrated to be effective and methods must be 
developed to assure cleaning solutions can be contained during decontamination, and suitably disposed after the solution is loaded with contaminants.

ADSNo. RDSNo. WBSNo.

Justification For Need:

Technical: Existing approaches rely on highly labor intensive methods and unique job-specific tools. Improved methods can exploit technologies developed for remote handling, surface decontamination with chemicals, and mapping techniques. Small to significant adaptation may be needed.

Environmental Safety \& Health: Present methods require significant worker dose, particularly when manned entry is required for complicated tasks.

Cost Savings Potential (Mortgage Reduction): Over 600 pits exist at Hanford, representing a range of contamination and complexity. Recent experience on the W-320 Project required more than $\$ 2$ million for decontamination of a single pit, and was not completed sufficiently to allow manned entry.

Cultural/Stakeholder Concerns: None identified for mapping or remote systems. Ecology and tribal nations have concerns about use of chemical cleaning solutions that could escape the pit and accelerate contamirant transport in the vadose zone.

Consequences of Not Filling Need: For HTI, about 2 million dollars has been budgeted for pit decon on pits that have already been decontaminated (at a cost of about 2 million dollars) by a predecessor project (W-320). If 67 Hanford tanks must be retrieved with a pit decontamination cost of 4 million dollars each, total costs could exceed a quarter billion dollars.

Outsourcing Potential: All phases of this need have potential for commercial applications

Current Baseline Technology: Manual, long-reach tools

End-User: Tank Farm Operations, TWRS Projects

Site Technical Point(s)-of-Contact: Tom May, NHC (509) 372-2493

DOE End-User/Representative Point(s)-of-Contact: Mike Royack, (509) 376-4420 


\section{TECHNOLOGY NEEDS/OPPORTUNITIES \\ STATEMENT OUTLINE}

Identification No.: RL-WT022

Date: September 1997

Program: Tanks - Operations

OPS Office/Site: Richland

Operable Unit (if applicable): N/A

Waste Stream: Double Shell Tanks

Waste Management Unit (if applicable):

Facility: Tank Farms

Site Priority Ranking: High

Need Title: Tank Knuckle NDE

Need Description: The Tri Party Agreement (TPA) schedule requires the completion of the Double Shell Tank (DST) system Integrity Assessment Program by the end of fiscal year 1999. It is required that no fewer than 6 DSTs will undergo a non-destructive evaluation (NDE) of a portion of the tank wall, bottom knuckle, and bottom. NDE equipment must be deployed to fulfill this requirement. Fracture mechanics analysis indicates that the knuckle region of the DST that rests on the concrete foundation is the highest-stressed region of the tanks. This high-stressed region is not accessible using current ultrasonic technology. This region is accessible for examination only by propagating ultrasonic energy around a plate with a one-foot radius bend. Current inspection studies demonstrate that defects in this region can be detected. However, . characterizing the length and through-wall extent of defects is not possible using current technology.

Functional Performance Requirements: Functional requirements for ultrasonic inspection capable of characterizing defects in the knuckle region include:

-Propagating ultrasound a distance of four feet around a plate with a one-foot radius.

-Detect cracks that exceed 0.18 inches and determine the through wall extent to an accuracy of 0.1 inch.

-Detect corrosion that exceeds $25 \%$ wall thickness and determine the through wall extent to an accuracy of 0.05 inches.

Schedule Requirements: The system must be deployed in fiscal year 1999 to meet TPA milestone commitments.

Problem Description: Comprehensive NDE of DST primary and secondary tank walls is required by TPA commitment and for evaluations of remaining useful DST life. Ensuring 
the structural integrity of the current waste tanks while developing innovative solutions to waste management and consolidation is the main mission of contractors at the Hanford reservation. The ability to examine the inner shell of double-shell waste tanks and perform examination of the main cylinder section of a tank was demonstrated on 241AW-103 in fiscal year 1996 .

The next challenge in ensuring the integrity of the double shell tanks requires the examination of the knuckle region of the tank. This examination poses a significant technical challenge because a portion of the area that requires examination is accessible only by propagating ultrasonic energy around a plate with a one-foot radius bend. Initial studies conclude that detection of defects in the knuckle region is not a problem. However, characterizing the defect length and through wall extent presents a very difficult problem.

TSAFT imaging technology is a proven technology that provides a potential solution for characterizing defects in the knuckle region of the waste tanks. The technology needs to be adapted to the geometry of the knuckle region and sound propagation distances of up to four feet.

$\begin{array}{lll}\text { ADS No. } & \text { RDS No. } & \text { WBSNo. } \\ 11200 & & 1.1 .1 .2 .01 \\ & & 1.1 .1 .3 . \mathrm{XX}\end{array}$

\section{Justification For Need:}

Technical: Present nondestructive evaluation (NDE) techniques can only detect and characterize stress corrosion cracks (SCC), corrosion or other anomalies in the narrow slot regions at the bottom of the double-shell tanks. These slot areas only provide access to $1-2 \%$ of the high-stress region of the tanks, which is not adequate for integrity assessment. TSAFT technology, developed at PNNL for inspecting components and piping in nuclear reactor systems, has the potential for providing detailed characterization of cracking or corrosion in the entire knuckle region of the tanks.

Regulatory: Completion of the physical examinations of the DSTs is required by TPA commitment and as a prerequisite for obtaining Resource Conservation and Recovery Act (RCRA) Part B permit status for continued operation of the DST system.

-Washington Administrative Code 173-303-640(2)(c)(iii) requires a physical examination (NDE) or leak test as a part of an integrity assessment program.

Environmental Safety \& Health: Assessing the integrity of double shell tanks helps ensure that no catastrophic leaks will occur in the double shell tanks. Early detection of any degradation of double shell tanks provides an opportunity to plan 
and develop corrective actions.

Cost Savings Potential (Mortgage Reduction): Developing tank knuckle NDE technology will reduce the time required for examining double shell tanks by reducing the area that must be scanned for defect detection and characterization. This technology is needed to provide the quantitative information on the length and depth of the flaws of any flaws detected during the inspection of the knuckle region of the tanks. Without this technology, very conservative assumptions will have to be made about the flaw size.

CulturalStakeholder Concerns: The oversight committee on tank integrity has identified inspection of the knuckle region of double shell tanks as critical.

Other: N/A

\section{Consequences Of Not Filling Need:}

Regulatory Impacts: The U.S. DOE has previously entered into negotiations with the Washington State Department of Ecology (WDOE) and the U. S. Environmental Protection Agency for determination of acceptable compliance with WAC-173-303-640. Completion of DST NDE was a part of these negotiations. Programmatic Impacts: If knuckle NDE technology is not developed, a majority of the high-stress region of the knuckle that rests on the concrete foundation can not be examined. The inability to examine critical sections of the tank creates a major knowledge gap when attempting to assess the near- and long-term integrity of the tanks. That uncertainty contributes to programmatic risk of serious delays in the TWRS program should a leak occur.

Outsourcing Potential: N/A

Current Baseline Technology: Baseline NDE technology is capable of evaluating only wall thinning on uniform plate in the DST annuli. There is no capability for examining the bottom knuckle or tank bottom. Moreover, the ability to identify pitting and cracking is limited.

Programmatic Risks: The TWRS program needs knuckle NDE technology to avoid two serious risks:

-Delay of the program as a consequence of a DST leak unexpectedly taking one or more tanks out of service.

-Physical regulatory non-compliance and the resulting negative attention.

Connection to TWRS Logic: This need supports TWRS Program Logic "Maintain Authorization Basis" and "Conduct Tank Farm Safe Operation."

End-User: Retrieval/Tank Farm Operations 
Site Technical Point(s)-of-Contact: Dan C. Pfluger, (509) 376-6164, Lockheed Martin Hanford Corporation, Tom T. Taylor, (509) 375-4331, Pacific Northwest National Laboratory, Jim L. Nelson, (509) 373-6296, Lockheed Martin Hanford Corporation.'

DOE End-User/Representative Point(s)-of-Contact: Mark L. Ramsay, (509) 376-7924 


\section{TECHNOLOGY NEEDS/OPPORTUNITIES \\ STATEMENT OUTLINE}

Identification No.: $\underline{\mathrm{RL}-\mathrm{WT} 023}$

Date: September 1997

Program: Tanks - Process Waste

oPS Office/Site: Richland

Operable Unit: (if applicable): N/A

Waste Stream: Single Shell Tanks and Double Shell Tanks

Waste Management Unit: if applicable): N/A

Facility: Tank Farms

Site Priority Ranking: High

Need Title: Prediction of Solid Phase Formation in Hanford Tank Waste Solutions

Need Description: Information is needed on the solubility of various components in the complex solid and liquid matrices of the Hanford tank wastes. This information is needed to predict when solids will precipitate or when gels will form in retrieval, wash, and leach solutions, and to supplement empirical water wash and caustic leach data from enhanced sludge wash testing of Hanford tank sludge and saltcake samples. Much information is available from past solubility chemistry work at Hanford and from other DOE sites. Available information needs to be compiled for easier use, missing data need to be identified, and work performed to supply the missing data. The information will be used to support the planning for and performance of the Hanford tank waste remediation. This remediation involves pretreating almost $150,000 \mathrm{~m}^{3}$ of sludge and saltcake solids and $60,000 \mathrm{~m}^{3}$ of supernatants from 177 waste tanks (Hanlon 1996).

Functional Performance Requirements: A compilation of available solubility data in the form of charts, figures, correlations, and calculational methods that can be easily to predict solids precipitation or gel formation in processing solutions, or can be used to predict wash and leach efficiencies based on key sludge or saltcake composition data. The compilation should accurately and efficiently predict solubilities for the major problem species expected in the complex solid and liquid matrices expected in the Hanford tank wastes. Examples of problem species are aluminates, phosphates, fluorophosphates, silicates, and chromates. The information should be suitable for inclusion in the Aspen software program and the Environmental Simulation Program (ESP), both of which are in use at Hanford. The work should identify what solubility data are missing and identify what experimental work is needed to provide the missing data. The identified experiments should be performed and the resulting data included in the compilation.

Schedule Requirements: This effort needs to be initiated in FY1999 to feed the 
preparation of the Phase II privatization RFP (H2343). It provides needed information for specifying the interface between the Retrieval Contractor and the High-Level Waste Contractor.

The LLW outsourcing vendors feed must be less than 5 volume percent solids. These tests need to be completed by $3 / 99$ so that the LLW plan. update can incorporate these findings in FY99, any necessary field modifications such as caustic addition capabilities can be completed in FY00, feed staging can begin in FY01, and delivery of feed to the Outsourcing Contractors' feed tanks can occur prior to hot start-up in FY02.

Problem Description: Solids and gels are known to form in the Hanford tank wastes when the solution ionic strength is decreased. Transfer lines have been plugged when solids or geis inadvertently formed. Knowledge of the solubility envelope for the waste is necessary to avoid unwanted precipitation or gel formation in supernatants. Sludge washing and leaching performance and saltcake dissolution evaluations are based on empirical data extrapolated from individual tanks to groups of tanks based on waste types. Improvements in processing efficiency are expected if the wash, leach, and dissolution processes are based on an understanding of the dissolution thermodynamics and kinetics rather than just empirical data. Water usage and makeup chemical addition can also be reduced which together with the improvement in efficiency can reduce the amount of HLW glass produced.
$A D S:$
RDS:
WBS:
1240
R96N0034
1.1.1.3.3

Justification for Need:

Technical: This effort will provide a basis for writing a meaningful RFP for Phase II.

Regulatory: N/A

Environmental Safety \& Health: N/A

Cost Savings Potential (Mortgage Reduction) : A significant cost avoidance is expected if DOE has information that allows a more precise RFP to be written.

Cultural Stakeholder Concerns: N/A

Other: N/A

Consequences of Not Filling Need: The lack of technical understanding of Phase II wastes will cause the Phase II vendors' estimated costs to be to be higher due to an inexact RFP being written.

Outsourcing Potential: N/A 
Current Baseline Technology: A thermodynamic model known as the Environmental Simulation Program (ESP) has been only partially validated with actual waste solubility data.

End-User: TWRS (Program/Waste Disposal Division)

Site Technical Points-of-Contact: Steve Schaus, (509) 372-1149; Randy Kirkbride, (509) $372-2115$

DOE Representative Point of Contact: Peter T. Furlong, (509) 372-1738; fax (509) 3730628; e-mail: peter_t_furlong@rl.gov 


\section{TECHNOLOGY NEEDS/OPPORTUNITIES \\ STATEMENT OUTLINE}

Identification No.: RL-WT024

Date: September 1997

Program: Tanks - Process Waste

OPS Office/Site: Richland

Operable Unit: (if applicable): N/A

Waste Stream: Single Shell Tanks

Waste Management Unit: if applicable): N/A

Facility: Tank Waste Pretreatment

Site Priority Ranking: High

Need Tïtle: Enhanced Sludge Washing Process Data

Need Description: Enhanced sludge wash (ESW) process data are needed to prepare enough feed to satisfy the maximum order quantity for Phase I preparation of the Phase II privatization request for proposal, and for bid evaluation of vendors proposals. A high emphasis needs to be placed on obtaining information on the $\mathrm{Cr}$ chemistry in the sludges and saltcakes. Chromium removal is needed to reduce the impact of $\mathrm{Cr}$ on the HLW glass volume. This is a continuation of the ESW testing program currently in progress. Additional data on the affect of varying temperature and caustic concentration on leach performance would be beneficial.

Functional Performance Requirements: Enhanced sludge wash process data representing $90+\%$ of the SST sludge volume and $70+\%$ of the DST sludge volume. An understanding of the $\mathrm{Cr}$ removal chemistry that allows reduction of the impact of $\mathrm{Cr}$ on $\mathrm{HLW}$ glass by $50 \%$.

Schedule Requirements: The identification of Phase I candidate feed tanks is needed in the middle of FY 1999 to provide information to the HLW feed staging plan update in FY 1999 (H1233) and allow enough time to install the needed retrieval equipment and pretreatment equipment to extend the HLW Privatization Contractor's Phase I operation to FY 2001. This work is required to support the transfers scheduled to begin for Tank 241-AZ-101 in June, 2002 for Tank 241-AZ-102 in September, 2003, and for Tank 241AY-102 in November, 2004. For Phase II, this effort needs to be initiated in FY 1999 to feed the preparation of the Phase II Privatization RFP (H2343) and subsequent bid evaluation.

Problem Description: Currently only about 70 to 80 percent of the maximum order quantity for phase I sludge washing has been identified. Additional feeds must be identified that can satisfy envelope $\mathrm{D}$ after pretreatment to ensure that the Private 
Contractors will be able to operate through 2011.

By March 1998 a decision will have been made whether ESW produces a reasonable number of HLW glass canisters. Assuming that ESW is successful in producing a reasonable number of glass canisters, additional data on ESW performance are required to provide a sound basis for the second phase of privatization. A strategy was developed for ESW testing based on obtaining 47 SST and 10 DST sludge samples (Kupfer 1996). Not all of that sampling and testing will have been completed before the March 1998 decision. Completion of that strategy is necessary to craft the Phase II RFP and to provide enough definitive information for a fair cost estimate for bid evaluation purposes. Currently siudge wash laboratory data to support delivery of feed for HLW immobilization in. Phase 1B Privatization are limited to that work done by PNNL (Lumetta and Rapko) and LANL (Tiemers) for the HLW Project. This small scale laboratory work is at the $5 \mathrm{gram} /$ test level. Data are needed to support scaling the process up to full scale $\left(5 \times 10^{9} \mathrm{~g}\right)$; an intermediate scale test (large bench scale, small pilot scale) involving about a 15 gallon size vessel and a few hundred gallons of actual waste will provide the appropriate scale up information. Information is needed about the effects of temperature on such process steps as dilution and perhaps re-precipitation of solids, washing efficiency, leaching efficiency, and quantity of caustic needed. The various Privatization Phase 1 sludges need to be tested to support the full scale processing planned for tanks 241-AZ-101, 241-AZ-102, and 241-AY-102 (including material retrieved from tank 241-C-106). Oxidation states of some of the chemical species (e.g. chromium) may need to be altered to ensure dissolution to support overall project objectives.

$\begin{array}{lll}\text { ADS: } & \text { RDS: } & \text { WBS: } \\ 1230 & \text { R96N0159 } & 1.1 .1 .3 .3 \\ & \text { R96N0034 } & \end{array}$

\section{Justification for Need:}

Technical: This effort will allow additional feeds to be identified as candidate feeds to the Phase I Privatization Contractor for HLW. For Phase II it provides a basis for a fair cost estimate and the writing of a meaningful RFP.

Regulatory: The tests performed at the large bench scale (small pilot scale) will be extremely useful, and may be critical, for creating the safety documentation leading to full scale deployment of the in-tank sludge washing and caustic leach processes.

\section{Environmental Safety \& Health: N/A}

Cost Savings Potential (Mortgage Reduction): A significant cost avoidance is expected if DOE is armed with information that allows a more precise RFP to be written and a realistic knowledge of the phase 2 costs with which to evaluate Vendors proposals. 


\section{Cultural Stakeholder Concerns: N/A}

Consequences of Not Filling Need: 1) The use of the Phase I HLW facility will be less than planned due to inadequate feed. 2) The lack of technical understanding of Phase II will cause the Phase II Vendors facilities to be more expensive due to an inexact RFP and a lack of understanding upon which to do a bid evaluation.

Outsourcing Potential:: N/A

Current Baseline Technology: Satisfying this technical need is required to meet the current baseline.

End-User: TWRS (High Level Waste Project)

Site Technical Point-of-Contact: Steve Schaus, (509) 372-1149; Randy Kirkbride, (509) $372-2115$

DOE Representative Point of Contact: Peter T. Furlong, (509) 372-1738; fax (509) 373-0628; e-mail: peter_t_furlong@rl.gov 


\section{TECHNOLOGY NEEDS/OPPORTUNITIES \\ STATEMENT OUTLINE}

Identification No.: RL-WT025

Date: September 1997

Program: Tanks - Retrieval

OPS Office/Site: Richland

Operable Unit: (if applicable): N/A

Waste Stream: Single Shell Tanks/Double Shell Tanks

Waste Management Unit: if applicable): N/A

Facility: Tank Farms

Site Priority Ranking: Medium

Need Title: Remote Sensing Of Gas Retention In HLW Slurries

Need Description: A method is needed to determine the extent of gases entrained in waste slurries in a waste storage tank. During waste retrieval and transfer of solids, a potential exists for the creation of "slurry growth" conditions (i.e., entrapped gases) in the receiver tank with a subsequent gas release event (GRE) similar to the behavior exhibited by Tank 101-SY.

Functional Performance Requirements: The systems and components necessary for determining entrained gas inventory must be installed in either the tank dome area or the ventilation off gas system; must comply with Hanford tank farms design requirements for flammable gas conditions and must be capable of measuring the gas volume within (+/-) $5 \%$ of the waste volume.

Schedule Requirements: The technologies required to accurately determine gas retention are needed to support the retrieval of 106-C in the FY1998/99 time frame. Beyond this period, the most significant retrieval and transfer of solids will involve SST retrieval and DST waste consolidation activities. The initial SST retrieval systems will begin the design/construction phase in FY1999, complete in FY2003 and become operational in FY2004. The DST waste consolidation will involve the transfer of 102-SY solids beginning in FY1999. Therefore, the systems and components necessary for determining tank evaporative losses must be developed, tested and demonstrated prior to FY1999.

Problem Description: When entrapped gases are released during a GRE, the potential for a defiagration exists due to the presence of ignition sources in the tank. If the presence of entrapped gases can be detected and measured, then the retrieval activity can be managed in a way to minimize the consequences and risk of such an event. 
ADS: $\quad$ RDS: $\quad$ WBS:

1210-0 R96N0130 1.1.1.3.1.1

R95W0006 1.1.1.3.1.2

Justification for Need:

Technical: No technology is currently available to directly or indirectly measure the volume of gas in a slurry of inhomogeneous solids density, particle size, and liquid specific gravity.

Regulatory: N/A

Environmental Safety \& Health: Accident and consequence analyses show that the deflagration of entrapped gases corresponding to more than two inches of slurry growth in a DST exceeds risk evaluation guidelines.

Cost Savings Potential (Mortgage Reduction): Accurate accounting of tank waste and gas inventory will allow for larger retrieval increments to be transferred, thereby reducing the total activity duration and operating cost.

Cultural Stakeholder Concerns: N/A

Other: N/A

Consequences of Not Filling Need: Potential creation of GRE tanks that require active mitigation.

\section{Outsourcing Potential: N/A}

Current Baseline Technology: Manual psychrometrics/flow measurements are used to calculate a material balance. Slurry growth caused by entrapped gasses can be masked if the tank evaporative losses are not taken into account during material balance calculations.

End-User: Retrieval/Tank Farm Operations

Site Technical Points-of-Contact: W. B. Barton (509) 376-5118, S. D. Estey, (509) $372-$ 2461, D. G. Baide (LMHC), (509) 376-3274

DOE Representative Point of Contact: Bruce L. Nicoll, (509) 376-6006; fax (509) 3721350; e-mail: bruce_I_nicoll@ril.gov 


\section{TECHNOLOGY NEEDS/OPPORTUNITIES \\ STATEMENT OUTLINE}

Identification No:: RL-WT026

Date: September, 1997

Program: Tanks - Retrieval

OPS Office/Site: Richland

Operable Unit (if applicable): N/A

Waste Stream: Single Shell Tanks

Waste Management Unit (if applicable): N/A

Facility: Tank Farms

Site Priority Ranking: High

Need Title: Tank Leak Detection Systems for Underground Single-Shell Waste Storage Tanks (SSTs)

Need Description: The use of past-practice sluicing for SST waste removal involves the addition of liquid to tanks and therefore increases the potential for waste leakage to the environment. Leak detection applies to all SST retrieval, including retrieval during Phase I and preparation of the Phase II specification. Leak detection methods are needed that can signal and quantify a leak from a tank when only a small amount of waste has escaped.

Functional Performance Requirements: The final leak detection approach and requirements will be negotiated with DOE-RL and Ecology. Candidate detection systems will be evaluated by such criteria as overall cost-benefit and risk-reduction potential, ease of use and deployment, overall effectiveness, and capability to verify effectiveness.

Detection systems should address the following types of issues:

- Sensitivity to detect a minimum leak volume of not more than 2000 gallons of liquid

- Determine the quantity of leaked material to $+/-50 \%$

- Limit the false detection of a leak to no more than $20 \%$

- Use of hardware systems that are deployable in or around the target tank to required locations that will facilitate use as designed

- Availability and/or deployability in order to operate during the time frame of need (e.g., at the time frame of a sluicing campaign)

- Cost-benefit and risk-reduction when compared to the baseline approach and noaction scenario

- The detection tool/system must include a capability for installation verification and periodic performance verification while installed and/or in service

- The detection tool/system must utilize materials that are compatible with the 
waste (i.e., won't degrade), appropriate to the planned period of use, capable of "surviving" deployment

Schedule Requirements: This need supports TPA milestones for submitting annual progress reports on the development of waste tank leak detection, monitoring, and mitigation (LDMM) activities. TPA milestones $\mathrm{M} 45-08 \mathrm{~A}$ and $\mathrm{B}$ require presentation of the leakage mitigation approach that will be used during sluicing of SSTs, and demonstration and evaluation of those tools that prove to be viable.

Problem Description: Detection systems that improve on the capabilities of the current baseline approach are needed. The objective is to detect a minimum quantity of liquid escaping the containment of a waste tank in real time so that appropriate mitigation measures can be implemented. The tank farm areas are quite congested with underground utilities and pipelines, so instrumentation deployed deep in the ground must take into consideration the difficulty of placing the sensing probes. There are relatively few access ports (tank risers) available for deployment of sensors inside a tank.

$\begin{array}{lrr}\text { ADS No. } & \text { RDS No. } & \text { WBS No. } \\ 1210-0 & \text { R96N0130 } & 1.1 .1 .3 .1 .1\end{array}$

\section{Justification For Need:}

Technical: Provisions for leakage detection are prerequisite to initiating actions to remove waste from leaking tanks. TPA Milestone $\mathrm{M}-45-08 \mathrm{~A}$ requires measures for leak detection to be inciuded in the design of the initial SST retrieval task. This effort is required to ensure that the specification for initial SST waste retrieval, and the Phase II Privatization Contract, are adequate for bidders to make informed decisions and to show a minimum cost.

Regulatory: This task will contribute to the information base that is used during negotiation with Ecology and Hanford Stakeholders regarding a regulatory position for final retrieval and closure of Hanford SSTs. Leakage mitigation is a major Hanford Stakeholder value and is expressed as a concern by Ecology through the TPA milestones of the M45-08 series. In particular, milestone M45-08-T02 requests a statement of "...acceptable leak monitoring/detection and mitigation measures necessary to permit sluicing operations."

Environmental Safety \& Health: Leakage must not be allowed to occur to an extent that will preclude the use of available tools and methods for remediating the contaminated soil. The establishment and technology to control leakage within allowable leakage volumes ( $A L V s$ ) is an important mitigation action since that approach sets operational limits within which soil remediation and closure can still proceed even in the event that leakage may occur. A viable approach to leakage mitigation during sluicing will contribute to the capability to ensure that leakage is 
managed below ALVs, and to maintain overall safe operations during waste retrieval.

Cost Savings Potential (Mortgage Reduction): Mitigation of leakage is directly related to the potential extent of action required for tank and tank farm closure, and the implementation of potential closure options. Mitigation and reduction of leakage can, therefore, be directly related to the cost of soil remediation, should that become necessary. A significant cost avoidance is expected if DOE can avoid this type of higher contingency factor in the Phase II Privatization bids.

Cultural/Stakeholder Concerns: Leakage detection and mitigation during waste retrieval are major issues of concern with Ecology and Hanford Stakeholders. This concern is reflected in TPA milestones, review of the TWRS EIS, and in other public documentation.

Other: N/A

Consequences Of Not Filling Need: A position based upon current baseline detection and mitigation tools and capabilities will be negotiated with Ecology. Since current capabilities for detection are based on material balances, the inherent sensing sensitivity is a function of the sensitivity and accuracy of tank level measuring systems. However, continued effort to seek new, or enhanced old methods and tools is a major Hanford Stakeholder value that will be associated with approval to proceed. Phase II Privatization Contractors would have to put a larger contingency in their bids for retrieval of SSTs to negotiate this matter with Ecology, Hanford Stakeholders, and the public by themselves.

Outsourcing Potential: Demonstration of candidate mitigation tools and methods will show where industry has the capabilities to perform now and where additional technology would be helpful.

Current Baseline Technology: The current baseline detection approach is based on measuring the tank inventory and flowrates of material introduced to a tank for sluicing and discharged from the tank as retrieved waste to conduct a material balance. A discrepancy among these figures may indicate a leak. The leak sensitivity is estimated to be about 8000 gallons.

End-User: Retrieval/Tank Farm Operations

Site Technical Point(s)-of-Contact: D. F. Iwatate (DESH), (509) 376-8856; P. W. Gibbons (NHC), (509) 372-0095

DOE End-User/Representative Point(s)-of-Contact: Bruce L. Nicoll, (509) 376-6006; fax (509) 372-1350; e-mail: bruce_1_nicoll@ri.gov 


\section{TECHNOLOGY NEEDS/OPPORTUNITIES \\ STATEMENT OUTLINE}

Identification No: : RL-WT027

Date: September 1997

Program: Tanks - Retrieval

OPS Office/Site: Richland

Operable Unit: (if applicable): N/A

Waste Stream: Single Shell Tanks

Waste Management Unit (if applicable): N/A

Facility: Tank Farms

Site Priority Ranking: High

Need Title: Tank Leak Mitigation Systems

Need Description: The use of past-practice sluicing for SST waste removal involves the addition of liquid to tanks and therefore increases the potential for waste leakage to the environment. Leakage mitigation applies to all SST retrieval, including retrieval during Phase I and preparation of the Phase II specification. Leakage mitigation efforts and tools, that can be shown to provide cost-benefit and significant risk reduction over baseline methods, should be incorporated into retrieval system design and operating procedures. Existing mitigation techniques (i.e., the current baseline approach) must continue to be evaluated against potential/candidate mitigating technologies to ensure that the most costeffective, risk reducing approach is applied. Periodic identification and evaluation of potential leakage mitigation tools for possible application during SST retrieval operations is required on a continuing basis.

Functional Performance Requirements: The final leakage mitigation approach and requirements will be negotiated with DOE-RL and Ecology. Candidate mitigation systems will be evaluated by such criteria as overall cost-benefit and risk-reduction potential, ease of use and deployment, overall effectiveness, and capability to verify effectiveness. Mitigation systems should address the following types of issues:

- Maximizing in-tank and/or ex-tank opportunities to reduce or stop leakage prior to, during, or following sluicing

- Use of hardware systems that are deployable in or around the target tank to required locations that will facilitate use as designed

- Availability and/or deployability in order to operate during the time frame of need (e.g., at the time and location of a detected leak, or within the time frame of a sluicing campaign)

- Cost-benefit and risk-reduction when compared to the baseline approach and noaction scenario 
- The mitigation tool/system must include a capability for installation verification and periodic performance verification while installed and/or in service

- The mitigation tool/system must utilize materials that are compatible with the waste (i.e., won't degrade), appropriate to the planned period of use, capable of "surviving" deployment

- Should not produce tank or tank waste conditions that preclude further attempts at waste retrieval or tank/tank farm closure, or that create additional, more complex retrieval problems or conditions.

Schedule Requirements: This need supports TPA milestones for submitting annual progress reports on the development of waste tank leak detection, monitoring, and mitigation (LDMM) activities. TPA milestones M45-08A and B require presentation of the leakage mitigation approach that will be used during sluicing of SSTs, and demonstration and evaluation of those tools that prove to be viable.

Problem Description: Mitigating systems that improve on the capabilities of the current baseline approach are needed. The objective is to prevent, curb, or eliminate the possibility or extent of liquid waste leakage from underground storage tanks into the surrounding soils. If cost-benefit, risk-reduction, and alternatives evaluations of new mitigating technologies determine that deployment, implementation, and operation is feasible, then further evaluation should be pursued. Such evaluations may include demonstrations and testing. Example concepts that could be evaluated include retrieval methods which minimize the potential for leakage, leak point and potential leak point location, "seek-and-seal" devices and methods, administrative approaches that maximize the use and coordination of currently available tools and methods, sheet barriers, close-coupled grout injection barriers, and dry-air containment barriers.
ADS:
RDS:
WBS:
$1200-0$
R96N0130
1.1.1.3.1.1

\section{Justification for Need:}

Technical: Provisions for leakage mitigation are prerequisite to initiating actions to remove waste from leaking tanks. TPA Milestone M[-45-08A requires measures for leak mitigation to be included in the design of the initial SST retrieval task. This effort is required to ensure that the specification for initial SST waste retrieval, and the Phase II Privatization Contract, are adequate for bidders to make informed decisions and to show a minimum cost.

Regulatory: This task will contribute to the information base that is used during negotiation with Ecology and Hanford Stakeholders regarding a regulatory position for final retrieval and closure of Hanford SSTs. Leakage mitigation is a major Hanford Stakeholder value and is expressed as a concern by Ecology through the TPA milestones of the M45-08 series. In particular, milestone M45-08-T02 requests a statement of “...acceptable leak monitoring/detection and mitigation measures necessary to permit 
sluicing operations."

Environmental Safety \& Health: Leakage must not be allowed to occur to an extent that will preclude the use of available tools and methods for remediating the contaminated soil. The establishment and use of allowable leakage volumes (ALVs) is an important mitigation action since that approach sets operational limits within which soil remediation and closure can still proceed even in the event that leakage may occur. A viable approach to leakage mitigation during sluicing will contribute to the capability to ensure that leakage is managed below ALVs, and to maintain overall safe operations during waste retrieval.

Cost Savings Potential (Mortgage Reduction): Mitigation of leakage is directly related to the potential extent of action required for tank and tank farm closure, and the implementation of potential closure options. Mitigation and reduction of leakage can, therefore, be directly related to the cost of soil remediation, should that become necessary. A significant cost avoidance is expected if DOE can avoid this type of higher contingency factor in the Phase II privatization bids.

Cultural Stakeholder Concerns: Leakage detection and mitigation during waste retrieval are major issues of concern with Ecology and Hanford Stakeholders. This concern is reflected in TPA milestones, review of the TWRS EIS, and in other public documentation.

\section{Other: N/A}

Consequences of Not Filling Need: A position based upon current baseline mitigation tools and capabilities will be negotiated with Ecology. However, continued effort to seek new, or enhanced old methods and tools is a major Hanford Stakeholder value that will be associated with approval to proceed. Phase II privatization Contractors would have to put a larger contingency in their bids for retrieval of SSTs to negotiate this matter with Ecology, Hanford Stakeholders, and the public by themselves.

Outsourcing Potential: Demonstration of candidate mitigation tools and methods will show where industry has the capabilities to perform now and where additional technology would be helpful.

Current Baseline Technology: Current baseline mitigation approach includes the following measures:

- Use of "smart sluicing" by Retrieval Operations to minimize aggravation of tank weak points

- Sluicing with appropriate diligence to determine, at the earliest possible time, if leakage is occurring

- Removal of water from tanks via interim stabilization when leakage rate and volume warrant 
- Minimization of operational/system down-time during which leaks can proceed by providing availability of [backup] equipment and staff

- Designing retrieval systems and equipment for dependability and minimum maintenance.

End-User: Retrieval/Tank Farm Operations

Site Technical Points-of-Contact: D. F. Iwatate (DESH), (509) 376-8856; P. W. Gibbons (NHC), (509) 372-0095

DOE Representative Point of Contact: Bruce L. Nicoll, (509) 376-6006; fax (509) 3721350; e-mail: bruce_1_nicoll@rl.gov 


\section{TECHNOLOGY NEEDS/OPPORTUNITIES \\ STATEMENT OUTLINE}

Identification No.: $\underline{\mathrm{RL}}$-WT028

Date: September 1997

Program: Tanks - Retrieval

OPS Office/Site: Richland

Operable Unit: (if applicable):

Waste Stream:

Waste Management Unit: if applicable):

Facility: Tank Farms

Site Priority Ranking: Medium

Need Title: Waste Mobilization Enhancement

Need Description: Retrieval of certain double-shell tanks (DSTs) are needed to provide adequate HLW feed to Phase 1 privatization, extended order quantity. Retrieval of DSTs using the baseline of two mixer pumps could leave a considerable amount of hard' sludge heel. While this is adequate for initial HLW feed, the program needs assurance that if the effective cleaning radius of the mixers proves insufficient, that a backup method can be deployed to mobilize enough residual waste to complete the mission. Further effort in predicting the effective cleaning radius by characterizing the shear strength, or resistance to mobilization, of the sludge is needed to plan for us of a backup method. Alternate or supplementary methods are needed to better mobilize sludge from DSTs containing HLW feed for Phase I privatization.

Waste stream: Double Shell Tanks, Tank Farms

Functional Performance Requirements: Any device or equipment used to characterize tank wastes in situ or to modify sludge strength must be easily deployable through a 12" riser, must be constructed to be inherently safe, and must not exert forces on the tanks that could cause damage. Methods or devices to characterize the waste properties should result in a correlation between the measured property and mixer pump effectiveness. Methods or devices to weaken siudges should develop an improvement of the effective cleaning radius of at least $25 \%$.

Schedule Requirements: Phase I privatization is expected to begin receiving waste in 2002.

Problem Description: Methods to mobilize sludges that are more effective than baseline mixer pumps are needed. Methods are needed that enhance mixer pump performance. Mixer pump have certain limitations - i.e., we have to turn the pumps off at a certain depth, and hence cannot re- mobilize solids (without adding dilution liquid) if waste is transferred in 
batches. Minimize planned or inadvertent water addition during mobilization. Need to determine if mixer pumps do an adequate job homogenizing the suspension for all scenarios. I. E. Will there be a problem with uniformity when the tank level is getting low? A method is needed for getting a meaningful understanding of physical properties of in situ waste so that the cleaning radius and the need for a backup systern can be predicted..

Proposed concepts: A sonic probe that uses low frequency sonic vibration can effectively lower the shear strength of the sludge. By reducing the strength of the sludge, the mixer pumps will provide adequate mobilization to meet the waste removal needs. The sonic probe was originally developed as an alternate to the mixer pump technology for mitigation of tank 101-SY. Alternatively, a clean water sluicer or a few pulse-jet air-operated mixers may provide the best solution.
ADS:
RDS:
WBS:
$1210-0$
R95W0006
1.1.1.3.1.2

\section{Justification for Need:}

Technical: This effort is required to ensure that sufficient $\mathrm{HLW}$ sludges are available for the Phase I Extended Order Quantity. Approximately 90 to $95 \%$ of the sludge in tanks selected to provide HLW feed for Phase I privatization must be retrieved to supply enough sludge for the Extended Order Quantity. Water addition to the tank for the purpose of retrieval or as a result of the process is limited by the cost and schedule of subsequent evaporation.

Regulatory: Disposal and handling of $\mathrm{HLW}$

Environmental Safety \&Health:

Cost Savings Potential:

Cultural Stakeholder Concerns:

Other:

Consequences of Not Filling Need: Sufficient HLW meeting the Phase I specification may not be available for the Extended Order Quantity.

Outsourcing Potential:: This effort to characterize wastes would not be easily prioritized but equipment to weaken sludges should easily be provided by industry.

Current Baseline Technology: Two mixer pumps

End-User: TWRS (Retrieval/Tank Farm Operations) 
Site Technical Point-of-Contact: D.L. Lamberd, (509) 372-0845; John Van Beek, (509) $372-2813$

DOE Representative Point of Contact: Bruce L. Nicoll, Work Phone: (509) 376-6006; Fax Number: (509) 372-1650; Email: bruce_1_nicoll@rr.gov 


\section{TECHNOLOGY NEEDS/OPPORTUNITIES \\ STATEMENT OUTLINE}

Identification No: : RL-WT029

Date: September, 1997

Program: Tanks - Storage \& Disposal

OPS Office/Site: Richland

Operable Unit: (if applicable): N/A

Waste Stream: Immobilized Low-Activity Tank Waste

Waste Management Unit: if applicable): N/A

Facility: Tank Farms

Site Priority Ranking: Medium

Need Title: Data and Tools for Performance Assessments

Need Description: Performance assessments must be developed for all disposal actions, and the models that are used for these assessments require a defensible basis for the movement of water. Most databases describe recharge and distribution of water for non-arid conditions. The arid conditions at Hanford are not accurately represented by the existing data. This need is comprised of two elements:

1) Recharge water is the primary means for dissolution and release of contaminants from the buried waste and transport of those contaminants to the groundwater. Estimation of these rates is difficult under arid conditions because the rates are very low. In addition, there are significant questions about the adequacy of the estimated recharge rates given the heterogeneity of the environmental processes, the effect of facility features, the uncertainty of climate, and the influence of humans. Furthermore, no attempt has been made to quantify the distribution of recharge rates to enable sounder estimates of the mean and range of rates to be expected during the time of compliance of the facility.

2) Assessments of waste disposal require the knowledge of hydraulic properties in the unsaturated sediments (the vadose zone). Typically, these properties are inferred or estimated from small cores or particle size distributions obtained from a drilled borehole. Field measurements of hydraulic properties will eliminate the uncertainty when extrapolating small-scale laboratory measurements.

This Technology Needs statement has been included in the Subcon needs list.

\section{Functional Performance Requirements:}

For recharge issues:

1) Identify range of factors that affect recharge

2) Develop new and innovative methods to determine recharge rates in and around subsurface disposal facilities

3) Estimate recharge rates for a subset of the range of factors and correlate estimates 
from multiple methods.

4) Use estimates to quantify spatial and temporal distribution of recharge rates for the spatial and temporal extent of the disposal facility.

Factors of interest that can contribute to variable recharge rates include soil type, vegetation, facility and surface cover design, human activity, climate, and time.

For hydraulic properties:

Design, construct, and operate a device to measure hydraulic properties in the vadose zone. Measurement of variables such as water content and matric potential, which are used to calculate conductivity, must be accurate and quick. The device must be portable and reusable.

Schedule Requirements: For use in the Hanford Low-Level Tank Waste Performance Assessments, such data and testing are needed by September 2000. Preliminary versions of the performance assessments will need data by September 1998 .

Problem Description: Computer codes, hydraulic measurements, and tracer movement can be used to estimate recharge rates. These techniques are not often used in conjunction, and hardly ever to characterize the spatial distribution of recharge rates.

$\begin{array}{lll}\text { ADS: } & \text { RDS: } & \text { WBS: } \\ 1250 & & 1.1 .1 .3 .04 .01 .03\end{array}$

\section{Justification for Need:}

Technical: Provide technical basis for characterizing the distribution of hydraulic properties and recharge rates in and around the Hanford Low-Level Tank Waste Disposal System. Such information will also be required for other waste management actions involving subsurface disposal.

Regulatory: Performance assessments are required by DOE Order $5820.2 \mathrm{~A}$, soon to be revised and issued as DOE Order 435.1. Composite analyses, which also require knowledge of recharge, are required under separate guidance and are related to the soon to be issued 10 CFR 834, Radiation Protection of the Public and the Environment.

Environmental Health and Safety: Recharge water is the main means for dissolution/release of contaminants from waste and the transport of those contaminants to groundwater.

Cost Savings Potential: Less conservative values for hydraulic properties and recharge rates in and around disposal facilities will allow less stringent release contaminant specifications for the Phase II immobilization Request for proposals (and hence lower product costs to $\mathrm{DOE})$ as well as less stringent requirements for waste disposal facility design.

Cultural Stakeholder Concerns: Disposal of low-activity tank waste has the largest 
environmental impact of any intentional Hanford action.

Consequences of Not Filling Need: Conservative methods and data will be used in the performance assessment, likely requiring more stringent contaminant release specifications in the waste product request for proposal and requiring more expensive disposal facilities.

Outsourcing Potential:: N/A

Current Baseline Technology: Point estimates of recharge and laboratory measurements of hydraulic properties on small cores.

End-User: TWRS Storage and Disposal Project

Site Technical Point-of-Contact: Fred Mann, Fluor Daniel Northwest, phone: (509)376-5728; fax: (509)376-1293; ernail: frederick_m_mann@rl.gov or v92515@fep0.rl.gov

DOE Representative Point of Contact: Phil LaMont, RL/TWRS, phone (509)376-6117; fax:(509)372-1350; email: philip_e_lamont@rl.gov 


\section{TECHNOLOGY NEEDS/OPPORTUNITIES \\ STATEMENT OUTLINE}

Identification No.: $\underline{\mathrm{RL}} \mathrm{WT030}$

Date: September, 1997

OPS Office/Site: Richland

Operable Unit (if applicable): Tank Farms and ZP-1

Waste Stream: Past-practice PFP and tank farm discharges to ground

Waste Management Unit (if applicable): N/A

Facility: Tank Farms and PFP cribs

Site Priority Ranking: High

Need Title: Contaminant Mobility Beneath Tank Farms

Need Description: Tank farm leak sites and TRU soil column disposal sites are the two most significant vadose sources of potential groundwater contamination at the Hanford Site. Assessment of contaminant mobility of these sources requires site-specific information.

This Technology Needs statement also is included in the Subcon needs list.

Tank Farms. Recent borehole spectral gamma data at the Hanford Site indicate that cesium-137 has migrated deeper than previously expected at both the SX and BX tank farms. Groundwater data for several tank farm waste management areas also suggest that pathways through the vadose żone exist and could impact groundwater quality. These observation suggest that fundamental assumptions about contaminant mobility that support single shell tank cleanup options and schedules may be incorrect, a finding echoed by a recent peer review and the National Academy of Sciences. The transport mechanisms and pathways involved are of concern since other waste components not detectable by spectral gamma logging (e.g., plutonium, technetium-99, strontium-90, chromate, nitrate) may also have migrated farther than anticipated and could still be moving. Revised conceptual models coupled with supplemental geophysical and sorption (mobility) data, are needed to:

1) quantify and understand the evolution of the present distribution of contaminants and

2) to evaluate the potential mobility of the individual contaminants under all "leave or retrieve" options.

Soil Column disposal Sites (PFP Cribs.) Similar needs exist for PFP soil column disposal sites that received large quantities $(-20,000 \mathrm{Ci})$ of transuranics in both a highly acidic aqueous phase and as an organic complex dissolved in an organic phase (carbon tetrachloride). The total contaminated soil volume beneath the PFP cribs is about 1,000,000 cubic meters and may extend to a depth of $40 \mathrm{~m}$ or more below ground surface. Some TRU may have migrated deep in the 
vadose zone in association with the DNAPL. The cost to package, handle and dispose of this volume of TRU (or near TRU) waste ( $>100 \mathrm{nCi} / \mathrm{g}$ ) could easily exceed 1 billion dollars.

Excavation and persomel safety related costs would be in addition. Thus stabilization in place, to the extent possible, would be a significant cost savings. Be that as it may, evaluation of either leave or retrieve options will require detailed knowledge of the sorptive status (degree of natural soil "fixation") of the deeply distributed plutonium and americium beneath PFP cribs and trenches.

Functional Performance Requirements: The most cost efficient approach to acquisition of the needed data is to conduct the work as one integrated study of vadose zone contaminant mobility. However, there are specific requirements for the two primary study areas, noted as follows.

Tank Farms. Each tank farm is a highly complex facility consisting of many underground structures, piping, and conduits. All technology solutions must be able to work within this environment and be compatible with tank farm safety operations. Any solution seeking to quantify contaminants and temporal changes must be able to measure the entire range of chemical concentrations (i.e., as high as the $10 \mathrm{M}$ in the original tank liquor) and radionuclide levels (e.g., 0.1 to $10^{7} \mathrm{pCi} / \mathrm{g}$ cesium-137). Spectral gamma logging or geophysical methods must also be able to distinguish between interior/exterior borehole contamination versus contamination in the surrounding formation. Sample media dependent methods (e.g., laboratory sorption and pore fluid extraction and analysis on core samples) must be capable of recovering contaminated, semi-continuous core with minimal disturbance (e.g., no drilling fluids and minimal compaction) down to a depth of $200+\mathrm{ft}$.

TRU Soil Column Disposal Sites (PFP Cribs). Selected new core samples from beneath the PFP disposal sites are needed to address the TRU mobility issue. A building over one of the main sites (Z-9 trench) precludes direct drilling and coring through the disposal site. Thus angle drilling and coring methods must be used. The core samples must be semi-continuous all the way to groundwater and must be from directly beneath the structure to ensure passing through the main soil column contaminant plume down to groundwater. Drilling and coring operations must be compatible with on-going activities in the area (soil vapor extraction). Core samples must be minimally disturbed (no drilling fluids) and radiological containment and handling of TRU waste (cuttings and core samples) is required. Evaluation of the sorptive status of transuranics must include "desorption" or leachability testing for which radiologically contained test equipment is required (e.g., ultracentrifuge, core sectioning glove box, etc.). Trained personnel and equipment to conduct this specialized work are unique to the Hanford Site. Thus expensive shipping and handling of TRU contaminated sample media can be avoided by conducting the work on site.

Schedule Requirements: The ER program is scheduled to begin vadose zone characterization and remediation in the 200 Areas (where the tank farms and PFP cribs are located) in 2003. The mobility data is needed at an early date to support technically sound cleanup decisions. A recent U.S. senate inquiry (Senator Wyden, Oregon) on the same subject underscores these concerns. Requirements for long-term stabilization and/or cleanup of residual waste left in the tanks, or in the soil column beneath tanks and soil column disposal sites, are included in a recent 
stakeholder-prepared document (Requirements for the Columbia River Comprehensive Impact Assessment, Part II, TPA milestone M-15-80A and B). In addition, because of uncertainty about the mobility of the contaminants, stakeholders such as the states of Oregon and Washington and Native American tribes are concerned about what is moving now.

Problem Description: Inadequate in situ contaminant mobility data exists for single shell tank leaks and major soil column transuranic disposal sites to support cleanup, closure or performance assessment related decisions.

ADS No. $1250 \quad$ RDSNo. WBS No.

\section{Justification For Need:}

Technical : In situ contaminant mobility data for tank leak and TRU disposal sites is not currently available, and currently available tools for in situ characterization are inadequate.

Environmental Safety \& Health: Contaminant mobility data is fundamental to prediction of environmental and human health effects (dose) due to groundwater and Columbia River exposure pathways, as called for in the CRCIA requirements document and cleanup related risk assessments.

Cost Savings Potential (Mortgage Reduction) : Stabilization in place option for TRU beneath PFP cribs alone could result in a savings of over 1 billion dollars. Potential return on investment is $\sim 1000: 1$.

Cultural/Stakeholder Concerns: Lack of contaminant mobility data is a major concern among stakeholders as expressed in $\mathrm{HAB}$ communications and the CERCLA requirements document.

Regulatory: Needed for on-going tank farm RCRA assessments of nature and extent of the cause of groundwater contamination at nearly half the tank farm sites.

Consequences Of Not Filling Need: Without knowledge about the distribution of contaminants beneath the tank farms, and without the ability in hand to predict contaminant movement, it will be impossible to assure the public that the DOE can predict:

a) the impact of leaks during sluicing of the tanks during cleanup, and

b) the impact of leaving the tanks (and their associated subsurface contamination) in place.

Furthermore, the vadose zone cleanup schedule for the 200 Areas could be delayed if the mobility status of deeply distributed transuranics is unknown, or inadequately 
characterized, well enough in advance. For example, if it is eventiually determined that retrieval of TRU-contaminated soil down to $40 \mathrm{~m}$ or more beneath PFP cribs is required, the cleanup schedule could be greatly impacted due to inadequate financial planning for excavation and handling costs that could approach 1 billion dollars or more. The sooner this issue is resolved the sooner more accurate financial and schedule forecasts can be made.

Outsourcing Potential: aspects that do not require recovery and handling of highly contaminated sample media may have outsourcing potential (e.g., advanced geophysical logging ). A CRADA with Schlumberger was previously in place for some of the advanced geophysical logging needs.

Current Baseline Technology: Existing tools and approaches and improvements needed are described as follows.

Geophysical methods. Logging methods currently employed in the tank farms (e.g., HPGe) cannot quantify radionuclide concentrations at high levels. Tools are needed that are capable of both high resolution and quantification over a range of $\sim 1 \mathrm{pCi} / \mathrm{g}$ to $10^{8}$ $\mathrm{pCi} / \mathrm{g}$. Additional needs not currently available include methods that can measure soil salinity through steel cased boreholes along with reliable soil moisture contents. The latter are needed to:

1) compare the depth distribution of the salt matrix (due to sodium nitrate, etc.) from a tank leak with cesium -137 and

2) to determine the extent of dilution of the original tank liquor.

This would allow use of existing boreholes to assess the relative mobility of cesium-137 and the salt matrix (assumed to be completely mobile) around those tanks that have leaked. In addition, current methods do not distinguish strontium-90 (due to bremsstrahlung radiation from the beta decays) from other gamma emitters. This capability would greatly expand in situ detection/quantification for the two dominant components of tank waste (Sr-90 and Cs-137).

Soil fixation/binding mechanisms. Current predictive models of contaminant transport beneath single shell tanks rely on general Kd information derived from laboratory sorption studies in synthetic media. The extreme chemical conditions associated with tank liquor (pH up to 14) and PFP crib discharges ( $\mathrm{pH}$ to -1 ), and the associated changes in sorptive properties of the porous media, are difficult if not impossible to simulate. Prior characterization studies (mid 70 's) provided valuable information to build on. However, due to moderately slow changes in conditions over time (e.g., silicate hydrolysis) the $\mathrm{pH}$ and other chemical conditions in the soil column beneath receiving sites may be different today than $20-25$ years ago. Thus contemporary contaminated media is needed to assess the existing field mobility status of major contaminants in the soil column. The sorptive mechanisms need to be studied to determine how tightly bound $\mathrm{Sr}-90, \mathrm{Cs}-137, \mathrm{Pu}$ and $\mathrm{Am}$ are today. This involves: 
1) extraction of pore fluid (free fraction) and the "reverse" of laboratory sorption studies (i.e., leaching or desorption studies) using actual contaminated media and

2) assessment of the role of potential chemical reactions induced by the soil mineral fraction.

For example, what is the role of iron (II) rich silicate minerals (pyroxenes) present in Hanford soils on reduction-sorption of transuranics? Acid hydrolysis due to the acidity of the effluent may have enhanced the reducing capability of iron (II) rich minerals and resulted in irreversible sorption of transuranics (Johnson and Hodges, 1997 -Second Symposium on Hydrogeology of Washington, abstracts). Hot, high $\mathrm{pH}$ media (original tank waste) also modified the soil matrix in unpredictable ways. Silicate minerals dissolve and reprecipitate, colloids may form, etc. Actual modified media is needed to evaluate existing conditions. Some work of the latter type is planned for FY98 (TWRS Vadose Characterization Program). Additional or supplemental work is needed for a comprehensive assessment of 200 Area soil column disposal and tank farm sites.

End-User: DOE: 1) TWRS Vadose Characterization Program (David Shafer) 2) ER vadose/groundwater program, Mike Thompson

Site Technical Point(s)-of-Contact: V. G. Johnson (PNNL), (509) 376-0916; R. J. Serne (PNNL), (509) 376-8429; M. Fayer (PNNL), (509) 372-6045

DOE End-User/Representative Point(s)-of-Contact: David Shafer (DOE-RL), (509) 3769255/David Myers (IT), (509) 373-5870; Mike Thompson (DOE-RL), (509) 373-0750 


\section{FY 1998 TANKS SCIENCE NEEDS}

\begin{tabular}{|c|c|c|}
\hline $\begin{array}{l}\text { RL-WT } \\
\text { Number } \\
\end{array}$ & Need Title & $\begin{array}{c}\text { FY98 } \\
\text { Priority } \\
\end{array}$ \\
\hline RL-WT031-S & Rapid Waste Characterization & $\mathrm{L}$ \\
\hline RL-WT032-S & Monitoring of Key Waste Physical Properties During Retrieval and Transport & M \\
\hline RL-WT033-S & Chemistry of Problem Constituents for HLW Vitrification & M \\
\hline RL-WT034-S & Long-Term Performance of LAW Forms & $\mathrm{H}$ \\
\hline RL-WT035-S & Moisture Flow and Contaminant Transport in Arid Conditions & $\mathrm{H}$ \\
\hline RL-WT036-S & Alternate Waste Form Development & L \\
\hline RL-WT037-S & Sludge Treatment & M \\
\hline RL-WT038-S & Process Models for Sludge Treatment & M \\
\hline RL-WT039-S & Advanced Methods for Achieving LLW Volume Minimization & $\mathrm{H}$ \\
\hline RL-WT040-S & Mechanisms of Line Plugging & $\mathrm{L}$ \\
\hline RL-WT041-S & Radionuclide Partitioning & $\mathrm{L}$ \\
\hline RL-WT042-S & Flammable Gas Generation, Retention, and Release in HLW Tanks & $\mathrm{M}$ \\
\hline RL-WT043-S & Effect of Human and Natural Influences on Long-Term Water Distribution & $\mathrm{H}$ \\
\hline RL-WT044-S & Distribution of Recharge Rates & $\mathrm{H}$ \\
\hline RL-WT045-S & Vadose Zone Flow Simulation Tool Under Arid Conditions & $\mathrm{H}$ \\
\hline RL-WT046-S & Getter Materials & $\mathrm{L}$ \\
\hline RL-WT047-S & Tritium Separations & $\mathrm{H}$ \\
\hline RL-WT048-S & Innovative Methods for Radionuclide Separation & M \\
\hline RL-WT049-S & Effect of Processing on Waste Rheological and Sedimentation Properties & $\mathrm{M}$ \\
\hline RL-WT050-S & Effect of Organic Constituents on Waste Processing & $\mathrm{L}$ \\
\hline RL-WT051-S & Foam Generation and Stability & $\mathrm{L}$ \\
\hline RL-WT052-S & $\begin{array}{l}\text { Characterization of Organic Species in Waste Feed to LAW and HLW Treatment } \\
\text { Facilities }\end{array}$ & $\mathrm{L}$ \\
\hline RL-WT053-S & Contaninant Mobility Beneath Tank Farms & $\mathrm{H}$ \\
\hline RL-WT054-S & Solids Yield and Deagglomeration & $\mathrm{L}$ \\
\hline RL-WT055-S & Tank Integrity Verification & $\mathrm{M}$ \\
\hline RL-WT056-S & Half-Lives of Se-79 and Sn-126 & $M$ \\
\hline RL-WT057-S & Materials for Long-Term Waste Isolation & $\mathrm{M}$ \\
\hline
\end{tabular}




\section{Hanford Site Science Need \\ Tanks Subgroup}

Identification No: RL-WT031-S

Need Title: Rapid Waste Characterization

FY98 Site Priority Ranking: Low

\section{Functional Need:}

Characterization of the waste is needed to: 1) support methods used to determine what, if any, actions are required to assure safe interim storage of each waste type; 2) determine suitable waste mixing to assist in development of transport methods and requirements; 3 ) develop efficient and cost effective separations processes; and 4) determine the basis for payment of waste treatment services by private contractors.

Qualification of major organic constituents in Hanford tank wastes is needed to estimate flammability and fuel content. Rapid yes/no evaluation of volatile hazardous components (e.g. radionuclides and carcinogens) are needed to assure adequate storage and retrieval protocols. Presently, little is known about the organic forms and their distribution in the tanks. Identification and distribution of organic materials are needed to determine if the wastes can be classification as "safe", "conditionally safe", or "unsafe". Similarly, data is not presently available concerning the content, distribution and form of fissile material.

Information concerning the chemical forms and concentrations of the matrix components and their radioactive constituents is necessary before adequate waste consolidation (mixing) protocols and/or separations processes can be engineered. Knowledge of the wastes chemical and physical properties are required to construct appropriately designed retrieval, pretreatment and waste stabilization facilities.

Under TWRS Privatization, private contractors operating waste treatment facilities will be paid for services based on the amount of sodium processed and the waste oxide loading in the immobilized low-activity waste (minus sodium and silicon oxides). In particular, a determination of soluble sodium (vs. insoluble sodium in entrained solids) delivered with the feed will be required. Accurate, rapid (one-week turnaround) characterization of the feed stream will be needed to support the feed certification plan and provide a timely method for resolving disputes.

\section{Problem Description:}

There is currently a lack of cost-effective and timely methods to sample and characterize the chemical and physical properties of tank wastes. Lack of data has resulted in employment of conservative, timeconsuming; and potentially over-engineered methods in order to satisfy worst case scenarios. Qualitative on-site and preferably in-situ analysis is needed to address concerns related to safety, waste forms (physical and chemical properties), and their distributions in the tank. One of the major problems with characterizing wastes is assuring that the methods used to retrieve wastes provide representative samples with respect to volume and distribution. These deficiencies drive the need for rapid, at least qualitative, in situ analysis. 
Present analysis methods are time-consuming or insufficient to provide the data needed to address the needs listed above. In addition, the data that is obtained often carries unreasonable precision and accuracy requirements. Highly precise and accurate measurements may be necessary for final waste processing requirements; however, the information needed to assist in designing viable retrieval and pretreatment methods do not require highly accurate determinations of elements but rather qualification of their form and distribution in the waste tank.

III. Science Need Description:

Presently, samples are removed from the tanks, extruded in a hot cell facility, with subsamples subsequently analyzed. Analytical techniques now require time-consuming preparation. Derivatization, caustic dissolution, leaching, and phase separations are required to fully characterize the organic and inorganic constituents. Methods which employ more direct analysis approaches should be used and ideally developed for on-line or in-situ determinations.

Need Timing: $1-3$ years

IV. Benefit:

Benefit code: check all that apply:

$\checkmark$ Cost Savings $\quad \checkmark$ Risk Reduction $\quad \checkmark$ Enabling Knowledge

V. Contacts:

For more information, contact:

Catherine Louie, DOE-RL TWRS

Loni Peurrung, PNNL
(509) $376-6834$

(509) 373-0201 catherine_s_louie@rl.gov

lm_peurrung@pnl.gov 


\section{Hanford Site Science Need \\ Tanks Subgroup}

Identification No.: RL-WT032-S

Need Title: Monitoring of Key Waste Physical Properties During Retrieval and Transport

FY98 Site Priority Ranking: Medium

I. Functional Need:

Ensure safe operations during retrieval and transport of waste, including the prevention of pipe plugging.

\section{Problem Description:}

During Phase I of privatization, TWRS will retrieve waste by water addition (sluicing). While precipitated salts are expected to go back into solution, this has not been verified with actual wastes. If solids remain undissolved, they can cause operational difficulties during transfer. Moreover, they can result in the transferred stream being greater than $5 \%$ solids, which is the contractual maximum specified in the Privatization contracts. The chemistry of these concentrated supernates is quite complex, and the dilution itself may cause additional precipitation. For example, dilution may aid dissolution of sodium nitrate but may also cause gibbsite (aluminum hydroxide) to precipitate. Formation of foams during retrieval or transport could also result in processing complications. Monitoring of key waste physical properties such as particle size, shape, and density distribution; particle charge; bubble size, shape, and spatial distribution; interstitial liquid and mixture densities; rheological properties such as viscosity, yield stress, compressibility, and shear modulus will provide broad safety margin for waste retrieval and transport.

\section{Science Need Description:}

There are a number of scientific challenges in this area. The key issue common to most of the physical properties is the colloidal nature of the solids in the waste slurries. Off-line monitoring and characterization risks the possibility of changing many of the physical properties from their in-situ conditions. The properties especially susceptible to these changes are particle and bubble characteristics and theological behavior of the waste. However, in-situ and on-line (or in-line) monitoring of these parameters face a number of difficulties such as fouling, attenuation, radiation damage, drift, and safety risks. In addition, it is often difficult to implement the principles required for measurement of these parameters. As an example, implementation of a vibrating rod viscometer, while simple in application, does not provide information about steady shear viscosity.

Direct measurements of the above parameters are more preferred over indirect and heuristic methods in which a substantial amount of validation and calibration is required for each waste slurry to be retrieved. As an example, response of bubbles to an acoustic wave is commonly viewed as being an attractive method for size characterization of bubbles suspended in a simple liquid. However, in a complex solidliquid-gas network, many rheological issues complicate this method of measurement and render it less direct. Further work on these issues and alternative approaches to measuring these waste properties is required. 
Need Timing: 4-10 years

IV. Benefit:

Monitoring of many of the parameters described above provide additional tools for more precise analysis of the waste conditions, which would enable the operators and decision makers to perform retrieval and transport operations while minimizing the cost and risks of failure and damage.

Benefit code: check all that apply:

$\sqrt{ }$ Cost Savings $\quad \sqrt{ }$ Risk Reduction $\quad \sqrt{ }$ Enabling Knowledge

V. Contacts:

For more information, contact:

Catherine Louie, DOE-RL TWRS

(509) $376-6834$

Loni Peurrung, PNNL

(509) 373-0201

catherine_s_louie@rl.gov

lm_peurrung@pnl.gov 


\section{Hanford Site Science Need \\ Tanks Subgroup}

Identification No.: RL-WT033-S

Need Title: Chemistry of Problem Constituents for HLW Vitrification

FY98 Site Priority Ranking: Medium

\section{Functional Need:}

Minimize the volume of immobilized waste produced through maximum loading of waste into the waste form.

\section{Problem Description:}

Currently, HLW glasses are formulated to assure that little or no insoluble phases exist in the HLW melter. Insoluble phases are caused by such problem constituents as chrome minerals, spinels, and noble metals. An alternative method for handling problem constituents in HLW glasses is needed. The volume of HLW glass that will be produced from the sludges at Hanford is dependent on the ability to solubilize or dilute problem constituents that make up a very small fraction of the overall waste. Minimizing the impact of the problem constituents is important for formulating a strategy and staging the wastes to be treated during the Phase II privatization effort. Diluting the problem constituents usually involves blending of waste types and/or increasing the volume of glass waste forms. Both of these alternatives are expensive.

\section{Science Need Description:}

There is a need for a better understanding of the solution thermodynamics in multicomponent borosilicate liquids. In many cases, the solubility of one oxide is limited by the presence of another in the melt. For example, large amounts of either $\mathrm{Zr}$ or $\mathrm{Al}$ (important waste components) are soluble in sodium silicate liquids, but when $\mathrm{Al}$ is added to a sodium zirconium silicate liquid, $\mathrm{ZrO}_{2}$ precipitates. The chemistry behind this phenomenon needs to be understood if optimum waste compositions are to be achieved. Other problematic components are those which have an acidic nature, such as $\mathrm{Cr}$ or $\mathrm{P}$. Their solubility is considerably reduced by the presence of other acidic oxides such as $\mathrm{B}_{2} \mathrm{O}_{3}$. The structural roles and chemistry which leads to these effects is poorly understood and data are lacking. Data is needed to support the development of predictive models for liquidus temperature and durability as a function of waste composition and process characteristics. New theoretical and experimental methods for describing and studying this type of behavior need to be developed if waste formulation is to be done by means other than trial and error.

Need Timing: 4-10 years

IV. Benefit:

Better predictive capability would reduce the need for mixing, reduce waste volumes and reduce costly errors in the event that ill understood mixing actually increased waste volumes. It also provides enabling knowledge, because existing theories of silicate solution thermodynamics do not work well for 
multicomponent system, and current experimental methods are costly and time consuming.

Benefit code: check all that apply:

$\checkmark$ Cost Savings $\quad \checkmark$ Risk Reduction $\quad \checkmark$ Enabling Knowledge

This science need supports the following Hanford tanks technology need(s):

RL-WT006 Identification and Management of Problem Constituents for HWW Vitrification

V. Contacts:

For more information, contact:

Catherine Louie, DOE-RL TWRS

(509) 376-6834

Loni Peurrung, PNNL

(509) 373-0201

catherine_s_louie@rl.gov

Im_peurrung@pnl.gov 


\section{Hanford Site Science Need \\ Tanks Subgroup}

Identification No:: RL-WT034-S

Need Title: Long-Term Performance of LAW Forms

FY98 Site Priority Ranking: High

\section{Functional Need:}

To validate LAW waste form performance in environmental media.

\section{Problem Description:}

The release rate of radionuclides from a waste form to the environment is a complex function of the interactions between the waste form, water, and other waste package components in the disposal system. For the disposal of immobilized low-activity tank waste (ILAW), the waste form and package are expected to be in a dry environment. In such an environment, the release rate is sensitive to variations in the physical (temperature, water content) and chemical ( $\mathrm{pH}$, solution composition) environment, which are affected by corrosion of the waste form itself and the formation of secondary phases. The contaminant release rate is also proportional to the surface area accessible to moving moisture. Thermal stress fractures in glasses increase the total surface area, but it is not known whether such cracks are accessible to water in a dry environment. Models are needed that describe the radionuclide release rate as a function of these physical and chemical variables to provide a source-term for risk assessment. A credible long-term performance model must, therefore, include:

- An explicit functional relationship between the dissolution kinetics of the waste form and the chemistry of the water in contact with the form, including any secondary mechanisms, such as ionexchange, that may either directly release radionuclides or indirectly impact the dissolution kinetics

- Secondary phase paragenesis, especially for solids that impact the waste form corrosion rate or limit solubility of radionuclides

- Constitutive relationships that describe the surface area accessible to moisture, which may be more than the external, geometric surface area of the waste form but less than a total area that includes all internal fracture surfaces

- Constitutive relationships that correlate variations in unsaturated flow properties of the waste form/package as secondary phases form from waste form corrosion.

Better test methods are also needed to guide model development and to develop product specifications. Current ILAW product specifications require short duration PCT and ANS 16.1 testing of the waste forms, which do not provide data relevant to long-term performance for the expected disposal system environment 
at Hanford. A test method yielding results that can be related to the waste form release rate under expected service conditions is needed as a basis for Phase 2 ILAW product specifications.

\section{Science Need Description:}

Develop and validate a long-term waste-form performance model for ILAW that describes the radionuclide release rate from the waste form as a function of the physical and chemical environment of the disposal system. Collect fundamental data on waste form dissolution kinetics, secondary phase thermodynamic properties and precipitation kinetics, unsaturated flow properties of the waste form/package and the effects of secondary phase formation on these properties. Develop test methods that are more representative of expected disposal system conditions at Hanford for use in evaluating long-term behavior of waste forms, validating performance models, and in setting product specifications.

Need Timing: $4-10$ years

IV. Benefit:

Current risk assessments utilize arbitrary, constant radionuclide release rates for ILAW that are not technically defensible. Development of a scientifically-credible release model and testing methods for ILAW will allow for development of more accurate waste form specifications, potentially saving hundreds of millions of dollars.

Benefit code: check all that apply:

$\checkmark$ Cost Savings $\quad \checkmark$ Risk Reduction $\quad \checkmark$ Enabling Knowledge

This science need supports the following Hanford tanks technology need(s):

RL-WT016 Glass Monolith Surface Area

V. Contacts:

For more information, contact:

Catherine Louie, DOE-RL TWRS

Loni Peurrung, PNNL
(509) 376-6834

(509) 373-0201 catherine_s_louie@rl.gov

lm_peurrung@pnl.gov 


\section{Hanford Site Science Need \\ Tanks Subgroup}

Identification No.: RL-WT035-S

Need Title: Moisture Flow and Contaminant Transport in Arid Conditions

FY98 Site Priority Ranking: High

I. Functional Need:

To understand the movement of contaminants through zones of low moisture (region-wide saturation less than $10 \%$ ) for use in risk assessments.

\section{Problem Description:}

Many waste disposal sites in the western U.S. are located in dry climates in which volumetric soil water contents are less than $10 \%$. Both the movement of water and the sorption potential of contaminants under these very dry conditions are poorly understood, yet knowledge of both processes is vitally important for predicted contaminant transport for risk assessments.

Moisture flow is the driving force for contamination release from waste and the transport of the contaminants. This flow (as both liquid and vapor) is poorly understood under the arid conditions frequently found in Western sites used for waste disposal and especially for fractured media. In particular, for those arid sites where moisture barriers or diverters are used, the theory and parameters describing . liquid and vapor flow under very dry conditions need to be better understood.

Many contaminants are retarded in the soil by geochemical interactions. Such interactions are usually measured under saturated conditions. However, experiments at the Pacific Northwest National Laboratory have indicated that the retardation of uranium for various Hanford soils varies with the moisture content and with the type of soil. Moreover, retardation is known to depend on the chemical and physical form (e.g. charge and oxidation state, attachment to a colloid). However, it is not known how these effects vary with moisture content.

\section{Science Need Description:}

Theories of moisture flow and contaminant transport are extrapolated from theories in which the soil pores (the conduits for moisture flow) are nearly filled with water. For the dry conditions expected at arid Western sites, the pores will be nearly empty (having only a thin water film on soil particle surfaces). The movement of water in liquid and vapor phases and retention of water on particle surfaces must be understood in order to predict how the water moves through such systems. Volumetric moisture contents are expected to be less than $10 \%$. At such low moisture contents, the conductivity is expected to be extremely low, necessitating specialized measurement techniques. Measurements of hydraulic parameters (conductivity and moisture retention) of both sediments (e.g. Hanford formation sands and Hanford formation gravels, clastic dike materials and Ringold Formation strata) as well as disposal facility materials (e.g. fractured glass and structural materials) are necessary to create a data base from which an understanding can be developed. The movement of water in both liquid and vapor phases is of interest 
because of the high salt content of many DOE wastes and waste forms. Upon degradation, wastes containing high salt contents may raise the salt content of soil moisture in the liquid phase, causing soil vapor to be drawn to the waste. However, the formation of secondary minerals could consume soil water, and thus a limited supply of soil water could decrease the release process. The physics of multiphase water flow and the tradeoffs between vapor phase flow and waters of reaction must be better understood to quantify the potential releases from wastes forms.

The retardation of contaminants in actual soils under natural conditions must be understood for dose calculations. Measurement of retardation factors for important contaminants ( $\mathrm{Tc}, \mathrm{Se}, \mathrm{U}, \mathrm{Cs}$, and $\mathrm{Sr}$ ) must be measured as a function of moisture content as well as of cheraical and physical form. An understanding of the soil physics must be obtained that will allow the calculation of such dependencies for other soils so that the need for further measurements is minimized.

Need Timing: 1-3 yeäs

\section{Benefit:}

The setting of waste form specifications for the immobilization of low-activity Hanford Tank waste and of disposal facility specifications will be determined by analyses using this type of information. Setting such specifications will result in trading cost (hundred of millions of dollars) and risk ( $\mathrm{mrem} / \mathrm{yr}$ in drinking water exposure - $4 \mathrm{mrem} / \mathrm{yr}$ is current EPA limit). Other projects at Hanford (e.g., tank closure, soil remediation) will also benefit.

Benefit code: check all that apply:

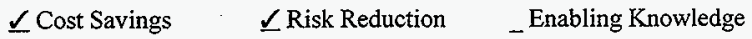

This science need supports the following Hanford tanks technology need(s):

RL-WT030 Data and Tools for Performance Assessments

V. Contacts:

For more information, contact:

Catherine Louie, DOE-RL TWRS

Loni Peurrung, PNNL

Fred Mann, FDNW
(509) 376-6834

(509) 373-0201

(509)376-5728 catherine_s_louie@rl.gov

Im_peurrung@pnl.gov

frederick_m_mann@rl.gov 


\section{Hanford Site Science Need \\ Tanks Subgroup}

Identification No.: RL-WT-036-S

Need Title: Alternate Waste Form Development

FY98 Site Priority Ranking: Low

\section{Functional Need:}

Development of alternative waste forms for high- and low-level waste immobilization.

\section{Problem Description:}

Development and knowledge of alternative waste forms to borosilicate glass could reduce costs and increase the long-term performance of immobilized high- and low-level waste. These alternative waste forms could potentially be used by private vendors during Phase II privatization.

\section{Science Need Description:}

Many waste feeds present at the Hanford site are not soluble in or are incompatible with the baseline borosilicate glass host. Alternative glass or crystalline (mineral or synthetic) waste forms that can incorporate all components of a specific waste feed are desirable. A viable alternative waste form must be capable of forming a stable glass or crystalline material with a minimum of waste dilution. The waste must be easy to process under remote handling conditions and should not be corrosive to melters or related processing equipment. In addition, relatively low processing temperatures are desirable, as are simple heat treatment cycles. The waste form must be chemically durable under environmental storage conditions (aqueous environments are of primary concern) and thermally stable under repository conditions over a geologic time scale.

Development of alternate waste forms will require an understanding of glass and ceramic structures and phase stabilities. Identification and characterization of the range of glass or ceramic phases that can be produced for a given waste feed as a function of feed composition is critical so that thermodynamics and geological evidence can be used to assess long term stability 2 and compatibility with repository conditions. Qualification of a new, alternate waste from will also rely on the determination of 1 ) solubility limits of waste in a host and the factors that control them, 2) long- and short-range atomic structures of potential waste form hosts, and 3) the effect of composition and structure on key waste form properties such as chemical durability and processing temperatures.

Need Timing: 4-10 years

IV. Benefit:

A limited number of alternate waste forms can significantly reduce costs by minimizing final waste volumes and simplifying pretreatment processes. Alternate waste forms with superior durability to borosilicate glass can reduce the risk of contamination to the environment. 
Benefit code: check all that apply:

$\checkmark$ Cost Savings $\quad \_$Risk Reduction $\quad$ Enabling Knowledge

V. Contacts:

For more information, contact:

Catherine Louie, DOE-RL TWRS $\quad$ (509) 376-6834

(509) 373-0201

catherine_s_louie@rl.gov

Loni Peurrung, PNNL

lm_peurrung@pnl.gov 


\section{Hanford Site Science Need \\ Tanks Subgroup}

Identification No.: RL-WT037-S

Need Title: Sludge Treatment

FY98 Site Priority Ranking: Medium

I. Functional Need:

Safe, effective, and efficient waste processing to reduce the volume of the immobilized HLW stream.

\section{Problem Description:}

An understanding of the enhanced sludge wash (ESW) process is needed to prepare for Phase I and Phase II privatization and for bid evaluation of vendors' proposals. Currently, only about 70 to 80 percent of the maximum order quantity for Phase I sludge washing has been identified. Additional feeds must be identified that can satisfy Envelope D after pretreatment to ensure that the Private Contractors will be able to operate through 2011. Moreover, this knowledge is needed to support development of the Phase II specification for TWRS waste pretreatment.

DOE has determined that ESW produces a reasonable number of $\mathrm{HCW}$ glass canisters. Additional data on ESW performance are required to provide a sound basis for the second phase of privatization. A high emphasis needs to be placed on obtaining information on chromium chemistry in the sludges and saltcakes. Chromium removal is needed to reduce its impact on the HLW glass volume. Additional data on the effect of varying temperature and caustic concentration on leach performance would also be beneficial.

\section{Science Need Description:}

Fundamental understanding of aluminum and chromium chemistry is a prerequisite to the development of predictive capabilities regarding the behavior of these components in Hanford tank systems.

Quantification of the solubilities and dissolution rates of $\mathrm{Al}$ and $\mathrm{Cr}$ compounds in high ionic strength, strongly basic solutions as a function of temperature, alkalinity, oxidation state of the tank environment, etc., is necessary for predicting the relative efficiency of various strategies proposed for their removal from the waste stream.

Sludge leaching with concentrated $\mathrm{NaOH}$ solutions at elevated temperatures is the proposed strategy for the removal of $\mathrm{Al}$ and $\mathrm{Cr}$ from the waste stream. Systematic evaluations of the effects of temperature, alkalinity, ionic strength and other parameters on the rates of dissolution and solid state phase transformations (such as interconversion of gibbsite to boehmite, or reactions rates involving sodium aluminate) are presently unavailable. Our present level of understanding of the behavior of $\mathrm{Cr}$ in the Hanford waste tanks is inadequate. There are few available data on the equilibrium behavior of $\mathrm{Cr}$ compounds in tank-like environments, and kinetic information under these conditions is virtually nonexistent. Like aluminum, chromium dissolution in basic solutions is not an instantaneous process; preliminary unpublished data on the dissolution of $\mathrm{Cr}$ solids in high base suggests a significant decrease in solubility with time. The $\mathrm{Cr}$ system is complicated by a multiplicity of valence states, thus, systematic 
evaluation of the solubility and kinetics of chromium compounds must also cover the oxidation of $\mathrm{Cr}$ (III) to $\mathrm{Cr}(\mathrm{VI})$. Since available data from tank sludige samples indicates that chromium in the solid phases is present mostly as $\mathrm{Cr}$ (III) whereas, in the aqueous phase, $\mathrm{Cr}$ appears to be present mostly as $\mathrm{Cr}(\mathrm{VI})$, fundamental investigations of the equilibria and kinetics of reacrions involving the $\mathrm{Cr}(\mathrm{III})_{\mathrm{s}}-\mathrm{Cr}(\mathrm{VI})_{\mathrm{aq}}$ transitions are also necessary. Furthermore, such transitions are likely to be strongly dependent on temperature, alkalinity and various other parameters. Thus, a systematic investigation of the general equilibria and dissolution/precipitation kinetics of $\mathrm{Cr}$ compounds in concentrated alkaline solutions is key to predicting the behavior and speciation of $\mathrm{Cr}$ in the Hanford tank systems.

Need Timing: $1-3$ years

\section{Benefit:}

Tank sludge pretreatment is projected to save billions of dollars in processing and disposal of Hanford $\mathrm{HLW}$. A sound scientific understanding of the pretreatment processes will reduce the overall risk associated with implementing these processes.

Benefit code: check all that apply:

$\measuredangle$ Cost Savings _ Risk Reduction . _ Enabling Knowledge

This science need supports the following Hanford tanks technology need(s): RL-WT025 Enhanced Sludge Washing Process Data

\section{Contacts:}

For more information, contact:

Catherine Louie, DOE-RL TWRS

(509) 376-6834

catherine_s_louie@rl.gov

Loni Peurrung, PNNL

(509) 373-0201

Im_peurrung@pnl.gov 


\section{Hanford Site Science Need \\ Tanks Subgroup}

Identification No: $\underline{\text { RL-WT038-S }}$

Need Title: Process Models for Sludge Treatment

FY98 Site Priority Ranking: Medium

\section{Functional Need:}

Safe, effective, and efficient waste processing to minimize the volume of HLW stream.

\section{Problem Description:}

Information is needed on the solubility of various components in the complex solid and liquid matrices of the Hanford tank wastes. This information is needed to predict when solids will precipitate or when gels will form in retrieval, wash, and leach solutions, and to supplement empirical water wash and caustic leach data from enhanced sludge wash testing of Hanford tank sludge and saltcake samples.

\section{Science Need Description:}

Predicting the precipitation of solids in a complex, concentrated brine requires a suitable model and a welldesigned set of data from which model parameters can be obtained. Although the identity and approximate abundances of major and minor chemical components in the Hanford tanks are fairly well defined, there are inadequate fundamental experimental data to support an adequate predictive model, and there has been inadequate use of existing data. The solubilities of solid phases in high-ionic strength brines that approximate subsets of the actual Hanford chemical systems need to be measured to: a) determine equilibrium constants, and b) extract electrolyte model parameters describing the behavior of sparingly soluble compounds.

Because of its importance to both precipitation and gel formation, Al speciation and reaction kinetics need to be examined in both simple and complex electrolyte solutions. Three key issues need to be addressed: the speciation/polymerization reactions of $\mathrm{Al}$ in complex electrolytes under high base conditions, the interactions of specific ions, especially $\mathrm{Na}^{+}, \mathrm{NO}_{2}{ }^{+}$and possible selected organic chelators with $\mathrm{Al}$ species that could form under base or acid conditions, and mechanistic studies of solutions known to be oversaturated with respect to specific solid phase precipitation reactions.

Need Timing: 4-10 years

\section{Benefit:}

Carefully designed experiments supporting development of a well-focused thermodynamic model allows bringing all available knowledge on the thermophysical properties of DOE waste to bear with minimum resort to expensive experimentation using actual tank waste. This includes: predicting and avoiding precipitation or gelation due to changes in temperature, dilution, or bulk chemistry during waste mixing 
and transport; predicting speciation important to designing and understanding the importance of chemical separations; and predicting speciation and precipitation during thermochemical, electrochemical, and other conversion processes.

Benefit code: check all that apply:

$\checkmark$ Cost Savings $\quad \checkmark$ Risk Reduction $\quad \checkmark$ Enabling Knowledge

This science need supports the following Hanford tanks technology need(s):

RL-WT025 Enhanced Sludge Washing Process Data

\section{Contacts:}

For more information, contact:

Catherine Louie, DOE-RL TWRS

(509) 376-6834

Loni Peurrung, PNNL

catherine_s_louie@rl.gov

lm_peurrung@pnl.gov 


\section{Hanford Site Science Need \\ Tanks Subgroup}

Identifiction No: : RL-WT039-S

Need Title: Advanced Methods for Achieving LLW Volume Minimization

FY98 Site Priority Ranking: High

I. Functional Need:

Minimization of LAW volume.

\section{Problem Description:}

Development and demonstration of alternative processing concepts could result in significant reduction in the volume of immobilized low-level waste. Waste volume minimization is both prudent from an overall cost standpoint as well as a requirement when dealing with any RCRA waste. Two technologies currently being developed and evaluated for reduction of the LLW volumes are the Clean Salt Process and electrochemical salt splitting.

\section{Science Need Description:}

The clean salt process involves acidification of the supernate and dissolved salt cake to a $\mathrm{pH}$ of 2 . The salts are then crystallized from solution by concentrating and cooling the solution below the saturation point. An understanding of the thermodynamics and kinetics associated with the removal of $\mathrm{NaNO}_{3}$, $\mathrm{NaNO}_{2}$, and other major sodium-containing salts (i.e. crystallization process) from complex radioactive waste solutions is desired. Specific issues include a definition of the conditions under which crystals of various salts form, understanding the nucleation mechanism and how it impacts the process performance, an understanding of the crystallization processes that limit the purity of the crystals obtained in the process (i.e. contaminates are occluded in the crystals), and definition of the effect of process variables on the size and type of crystal formation.

The salt splitting process involves using a divided electrochemical cell to separate the waste salts into the associated acids and bases. With this process the generation of solids is not generally desirable due to the potential for fouling of the processing equipment. An understanding of the thermodynamic behavior of the waste subjected to expected processing conditions would allow the process to be designed and operated at conditions that would avoid the precipitation of solids.

Need Timing: 4-10 years

IV. Benefit:

The development of a scientific basis for the clean salt process and salt splitting process will reduce the cost of deployment of these technologies by reducing the number and scale of experiments required with simulant and actuai wastes, and improve the efficiency of the design process. Risk will be reduced by defining the process regimes in which these processes will be successful. 
Benefit code: check all that apply:

$\checkmark$ Cost Savings $\quad \checkmark$ Risk Reduction . _ Enabling Knowledge

This science need supports the following Hanford tanks technology need(s):

RLWT-12 Advanced Methods for Achieving LLW Volume Minimization

V. Contacts:

For more information, contact:

Catherine Louie, DOE-RL TWRS

Loni Peurrung, PNNL
(509) $376-6834$

(509) 373-0201 catherine_s_louie@rl.gov

lm_peurrung@pnl.gov 


\section{Hanford Site Science Need \\ Tanks Subgroup}

Identification No.: $\underline{\text { RL-WT040-S }}$

Need Title: Mechanisms of Line Plugging

FY98 Site Priority Ranking: Low

\section{Functional Need:}

Safe, effective and efficient waste storage, retrieval and transport, including the prevention of pipe plugging and transport line pressurization.

\section{Problem Description:}

Inter-area transport lines for particulate slurries have become plugged in the past due to particle settling, phase changes, or reactions accompanied by precipitation or gel formation that occurred during transport. Information to predict pressure drop and critical transport velocity of wastes with known properties is required to ensure that wastes can be safely transported without risk of plugging. To minimize the dilution required to modify waste properties, methods to predict the effect of dilution, washing, or leaching on the slurry properties is also required. Dilution both increases the volume of the waste and has negative implications for tank waste management both from a space perspective and for settling and separation of solids. Waste compatibility is also an issue in the case of blending of wastes from several simultaneous or sequential retrievals.

\section{Science Need Description:}

The science need is the ability to predict transport requires understanding of both the hydrodynamics of slurries with known properties and the chemical mechanisms that affect the properties of wastes. Hydrodynamic features that must be understood are: 1) the critical suspension velocity of a slurries containing particle sizes similar to those in radioactive wastes, 2) pressure drop as a function of flow in particulate and non-Newtonian fluids, and 3 ) the rate of particle attrition during transport. When gas generating wastes are transported, the effect of gas on the speed of sound in the mixture must be understood sufficiently to avoid choking.

An empirical model (but with a strong foundation in theory) is needed that could predict chemical adjustments required both to support transport operations as well as reagglomeration of materials in order to promote settling. The model should incorporate theory associated with agglomeration, sedimentation, and fluid dynamics. Dilution effects, including temperature reduction and solids dissolution/precipitation, should also be included. This model would have as its inputs the waste composition and particle size distribution. It would provide a technical basis for pipeline transport specifications that is currently lacking and may be over-restrictive. This tool should also be able to predict the effect of blending waste types of different chemistries.

The chemical mechanisms that affect flow encompass reactions which generate particles (precipitation), cause aggregation, and generate gas. To predict the chemistry effectively, the chemical principles and 
colloidal behavior in high salt environments must be understood. Specifically, solution containing multiple components must be investigated to identify the conditions where precipitation and gelation occurs.

Need Timing: $4-10$ years

IV. Benefit:

The ability to predict the pressure drop and critical suspension velocity in slurries would allow engineers to design and operate transport lines in a manner that avoids plugging due to particle settling. The hydrodynamic information is useful only when the physical properties of the mixture are known. Some method to predict changes in physical properties during transport is also required. Understanding the chemical mechanisms and hydrodynamic mechanisms affecting particle size, viscosity and concentration would further improve engineers ability to operate the transport line.

Benefit code: check all that apply:

$\checkmark$ Cost Savings $\quad \checkmark$ Risk Reduction $\quad \checkmark$ Enabling Knowledge

V. Contacts:

For more information, contact:

Catherine Louie, DOE-RI TWRS

(509) 376-6834

Loni Peurrung, PNNL

(509) 373-0201

catherine_s_louie@rl.gov

Im_peurrung@pnl.gov 


\section{Hanford Site Science Need \\ Tanks Subgroup}

Identification No: $\underline{\text { RL-WT041-S }}$

Need Title: Radionuclide Partitioning

FY98 Site Priority Ranking: Low

\section{Functional Need:}

Safe, effective, and efficient waste processing to minimize the volume of the HLW stream.

\section{Problem Description:}

Current strategies for reducing the total volume of radioactive tank waste requiring disposal at Hanford and other DOE sites call for the development of methods to selectively remove non-radioactive elements such as $\mathrm{Al}, \mathrm{P}$, and $\mathrm{Cr}$ while retaining or precipitating the radioactive elements, including fission products and the actinide elements in the HLW stream. Unfortunately, the presence of a large number of possible solid phases, aqueous complexants, and the high ionic strength (often several molal) of these solutions makes it extremely difficult determine and predict the distribution of radionuclides between the sludges, suspended solids and aqueous supernatants. Such a lack of fundamental knowledge about the distribution of radionuclides in the HLW stream significantly impacts the numbers of glass logs requiring disposal and as a result the ultimate $\mathrm{HLW}$ disposal cost.

\section{Science Need Description:}

The sludges and suspended solids are composed of insoluble precipitates of actinides, radioactive fission products, and nonradioactive components. The supernatants are neutral to strongly alkaline solutions that can contain soluble actinides and fission products as well as high concentrations of major electrolytes including sodium hydroxide, nitrate, nitrite, phosphate, carbonate, aluminate, sulfate, and organic complexants. What is needed is a fundamentally sound means of determining or predicting the partitioning of important radionuclides (especially technetium-99) among the waste processing solutions, suspended solids, and precipitates in these complex high ionic strength solutions. Development of this predictive capability will require characterization of solid and solution phase speciation as well as experimental thermodynamic and kinetic data on important radionuclide aqueous speciation reactions, precipitation/dissolution reactions, and solid phase adsorption reactions.

Need Timing: 4-10 years

\section{Benefit:}

Significantly reduced processing and disposal costs through optimization of waste processing conditions for individual tank sludges or supernatants. 
Benefit code: check all that apply:

$\measuredangle$ Cost Savings _ _ Risk Reduction _ Enabling Knowledge

This science need supports the following Hanford tanks technology need(s):

RL-WT025 Enhanced Sludge Washing Process Data

V. Contacts:

For more information, contact:

Catherine Louie, DOE-RL TWRS.

(509) $376-6834$

Loni Peurrung, PNNL

(509) 373-0201

catherine_s_louie@rl.gov

lm_peurrung@pnl.gov 


\section{Hanford Site Science Need \\ Tanks Subgroup}

Identification No: RL-WT042-S

Need Title: Flammable Gas Generation, Retention, and Release in HLW Tanks

FY98 Site Priority Ranking: Medium

\section{Functional Need:}

Safe, effective and efficient waste storage, retrieval and transport, including the prevention of pipe plugging, foam generation, and transport line pressurization.

\section{Problem Description:}

The generation, retention, and uncontrolled release of flammable gases in Hanford high-level waste tanks is a continuing safety and processing issue. A better understanding of gas transport mechanisms and waste properties is needed to ensure that the tanks are maintained in a safe condition until the waste can be processed into a safer storage system. This work would support resolution of both the Organic Safety Issue and continued tank farm operations (e.g., salt-well pumping, retrieval).

\section{Science Need Description:}

Analysis of the physics of the flammable gas safety issue must embody the cause-and-effect relationship of generation, retention, and release. Gas generation is the ultimate source of the hazard (though head space data indicate it is not a hazard in itself), gas retention is a measure of the potential hazard, and gas release represents the actual hazard. The scientific needs for understanding each of the three facets is described below.

Gas generation processes must be understood well enough to estimate the generation rate and relative gas composition. The generation rates of the major fuel and diluent species determine the minimum tank ventilation rate required to prevent a flammable mixture buildup in the head space. Scientific knowledge of radiolytic and thermolytic rate parameters provide the means to predict gas generation rates and composition of generated gas. These rate parameters are needed as a function of major waste type groupings and chemical components.

The retained gas volume (and composition) in the waste is a direct measure of the potential flammable gas hazard. Each plausible mechanism of gas retention exhibits its own specific process of gas release. A scientific understanding of gas retention, both mechanisms and volume, is necessary to understand gas release, including its likelihood, rate, and amount. This understanding of retention mechanisms is needed for different waste types and waste configurations.

The flammable gas hazard of a tank depends on the possible consequences of a gas release. Flammable gas cannot create consequences until it is actually released in a closed volume at a concentration that can be ignited and burn, elevating the pressure. A scientific understanding of gas release mechanisms, such as bubble movement or gas diffusion, is needed to estimate release rate, volume, and frequency and then to 
relate each of these to the tank waste configuration and properties to evaluate the probable consequences. This understanding of release mechanisms is needed for different waste types and waste configurations.

Need Timing: $4-10$ years

IV. Benefit:

Understanding how to identify and quantify situations where flammable gases pose hazards results in risk reduction. In addition, the hazards associated with the presence of flammable gases are minimized through the appropriate application of controls, process modifications, and new process equipment. Understanding and quantifying the flammable gas hazard associated with each tank and each processing step allows for a graded application of controls and safety equipment. This graded approach results in cost savings because expensive controls and equipment are only used when needed, and not in all situations when they are clearly not needed.

Benefit code: check all that apply:

$\leq$ Cost Savings $\quad \leq$ Risk Reduction $\quad$ Enabling Knowiedge

This science need supports the following Hanford tanks technology need(s):

RL-WT026 Remote Sensing of Gas Retention in HLW Slurries

\section{Contacts:}

For more information, contact:

Catherine Louie, DOE-RL TWRS

(509) 376-6834

Loni Peurrung, PNNL

(509) 373-0201

catherine_s_louie@rl.gov

lm_peurrung@pnl.gov 


\section{Hanford Site Science Need \\ Tanks Subgroup}

Identification No:: RL-WT043-S

Need Title: Effect of Human and Natural Influences on Long-Term Water Distribution

FY98 Site Priority Ranking: High

I. Functional Need:

Fundamental data to improve confidence in the performance assessment under realistic conditions.

\section{Problem Description:}

Water passing through the soil surface to the waste disposal facility provides both the agent to release the contaminants from the waste form as well as the medium to transport the contaminants to the groundwater. The amount of water applied to the surface over the next thousands of years will vary because of climate changes and because of human-initiated events .

\section{Science Need Description:}

Efforts are needed to 1) consider long-term land and water use at DOE sites by future generations; 2) consider natural phenomena such as near-term climate change (which is forecast to impact society in the next 100 years) or long-term climate change as we transition into the next ice age; and 3) incorporate those uses and impacts into modeling efforts to predict the transport of contaminants.

Need Timing: $4-10$ years

\section{Benefit:}

The time at which contaminants enter the accessible environment is proportional to the rate at which water passes through the soil. For most waste forms, the amount of released contaminants is also proportional to the this rate as well. Understanding the causes for the rate at which water enters a disposal facility will allow a better design of the disposal facility and better setting of the specifications for the waste form. The manner in which human-caused events are factored into the analysis could affect the acceptability of the disposal action, particularly to a major subset of Hanford stakeholders.

Benefit code: check all that apply:

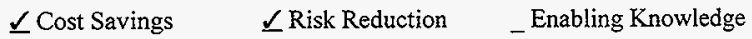

This science need supports the following Hanford tanks technology need(s):

RL-WT030 Data and Tools for Performance Assessments 
V. Contacts:

For more information, contact:

Catherine Louie, DOE-RL TWRS Loni Peurrung, PNNL Fred Mann, FDNW
(509) 376-6834

(509) 373-0201

(509) $376-5728$ catherine_s_louie@rl.gov lm_peurrung@pnl.gov frederick_m_mann@rl.gov 


\section{Hanford Site Science Need \\ Tanks Subgroup}

Identification No:: RL-WT044-S

Need Title: Distribution of Recharge Rates

FY98 Site Priority Ranking: High

\section{Functional Need:}

Fundamental data to improve confidence in the performance assessment under realistic conditions.

\section{Problem Description:}

Recharge water is the primary means for dissolution and release of contaminants from the buried waste and transport of those contaminants to the groundwater. Estimation of these rates is difficult under arid conditions because the rates are very low. In addition, there are significant questions about the adequacy of the estimated recharge rates given the heterogeneity of the environmental processes, the effect of facility features, the uncertainty of climate, and the influence of humans. Furthermore, no attempt has been made to quantify the distribution of recharge rates to enable sounder estimates of the mean and range of rates to be expected during the lifetime of the facility.

\section{Science Need Description:}

Measurements at the Hanford Site have shown that the amount of water naturally passing through the upper soil surface depends on the amount of precipitation, soil type and texture, and vegetation cover. A detailed understanding how these variables interact across a sparsely vegetated landscape over long times (thousands of years) and a comparison of such an understanding with estimates of long-term rates (through tracer measurements) is necessary.

Also needed is the quantification of 1) the distribution of recharge throughout the Hanford Site as well as through the waste site, 2) the variability (uncertainty) possible in the distribution of recharge, and 3) the time delay between recharge through the land surface and that into the water table. Knowledge of the distribution of recharge throughout the Hanford Site is important because it determines the direction and magnitude of groundwater flow beneath waste sites. Because recharge rate is known to be a significant factor in the release and migration of contaminants, knowledge of the uncertainty in spatial estimates of recharge will contribute to estimates of risk. Finally, because society is becoming more interested in estimates of near-term impacts to the environment, if simulations of contaminant release, migration and fate are to be compared quantitatively to field observations, then the time delay between surface infiltration and groundwater recharge must be taken into account. This will be of greater importance if the prediction of contaminant fate in the next 100 to 1000 years becomes the focal point of assessments of impacts to human health.

Need Timing: 4-10 years 


\section{Benefit:}

The time at which contaminants enter the accessible environment is proportional to the rate at which water passes through the soil. For most waste forms, the amount of contaminants is also proportional to this rate as well. Understanding the causes for the rate at which water enters a disposal facility will allow a better design of the disposal facility and better setting of the specifications for the waste form. By varying the specifications for the waste form, procurement costs and disposal facility costs could vary by hundreds of millions of dollars.

Production of recharge distributions for the Hanford Site, and perhaps other large DOE sites in the arid and semi-arid Western United States, will enable the inclusion of the spatial variability and uncertainty in a key release and fate parameter (recharge) in an analysis of uncertain health impacts. The importance of recharge rate in the assessment of waste disposal in the arid West has been demonstrated. Our uncertainty in estimates of recharge feeds directly our uncertainty in risk and cost envelopes associated with waste management decisions.

Benefit code: check all that apply:

$\leq$ Cost Savings $\quad \_$Risk Reduction _ _ Enabling Knowledge

This science need supports the following Hanford tanks technology need(s):

RL-WT030 Data and Tools for Performance Assessments

\section{Contacts:}

For more information, contact:

Catherine Louie, DOE-RL TWRS

Loni Peurrung, PNNL

Fred Mann, FDNW
(509) 376-6834

(509) 373-0201

(509) $376-5728$ catherine_s_louie@rl.gov

lm_peurrung@pnl.gov

frederick_m_mann@rl.gov 


\section{Hanford Site Science Need \\ Tanks Subgroup}

Identification No: RL-WT045-S

Need Title: Vadose Zone Flow Simulation Tool Under Arid Conditions

FY98 Site Priority Ranking: High

\section{Functional Need:}

To understand the movement of contaminants in very complex geometries through zones of low moisture for use in risk assessments.

\section{Problem Description:}

To predict the movement of contaminants from the disposal of waste, a wide variety of chemical and physical phenomena must be modeled over large spatial scales and over time periods lașting thousands of years. For the release of contaminants from immobilized low-level tank waste, the physical condition and surrounding water chemistry for thousands of canisters must be modeled, where the physical and chemical environment vary with time and position in the disposal vault. For the modeling of flow into disposal facilities or around tanks in large tank farms, detailed three-dimensional geometric models must be used transient moisture fronts and steep concentration gradients must be analyzed. Finally, because of the low moisture content of Hanford soils and the significant thickness of the vadose zone, simulations over many thousands of years are required, even for the most mobile contaminants.

\section{Science Need Description:}

Develop a computer code using modern computer science techniques that combines time and spatiallydependent geochemical modeling with transient moisture flow and contaminant transport and which allows the determination on the results of modeling and data uncertainties. The simulator must handle geometrically complex objects and a large number of chemical species. Current extrapolated running times must be reduced by one to two orders of magnitude. The code should be structured to economically address the quantification of sensitivity of responses to uncertain physical and geochemical model parameters.

Determine the real transport properties and phenomena at a western site having complex flow and transport conditions (such as the Hanford Site). Such properties should include chemical retardation (e.g. dependency on moisture and geologic layers) and unsaturated hydraulic data. Transport phenomena should include not only transport through homogenous media but also transport through fractured and preferred vertical flow paths (such as clastic dikes).

Need Timing: 4-10 years 
IV. Benefit:

Current techniques require that oversimplified models be used, making analyses too conservative. Better modeling techniques will allow more accurate waste form specifications for immobilized Hanford tank waste, potentially saving hundreds of millions of dollars, and will allow a better determination for the closure of Hanford tank farms, potentially allowing a large fraction of tanks to be remediated in a more cost-effective manner.

With a simulation tool which calculates uncertainty progation, resources can be concentrated on those data and methods having the largest impact on the calculations of environmental responses. By reducing the most important uncertainties and by providing greater assurance that the modeling is accurate and reliable, the total life-cycle cleanup will be reduced.

Benefit code: check all that apply:

$\checkmark$ Cost Savings $\quad \_$Risk Reduction $\quad$ Enabling Knowledge

This science need supports the following Hanford tanks technology need(s):

RL-WT030 Data and Tools for Performance Assessments

V. Contacts:

For more information, contact:

Catherine Louie, DOE-RL TWRS

Loni Peurrung, PNNL

Fred Mann, FDNW
(509) 376-6834

(509) 373-0201

(509)376-5728 catherine_s_louie@rl.gov

Im_peurrung@pnl.gov

frederick_m_mann@rl.gov 


\section{Hanford Site Science Need \\ Tanks Subgroup}

Identification No.: RL-WT046-S

Need Title: Getter Materials

FY98 Site Priority Ranking: Low

\section{Functional Need:}

Fundamentai data to improve confidence in the performance assessment under realistic conditions.

\section{Problem Description:}

In order to meet the contaminant release specifications for the disposal of Hanford low-activity tank waste, radiocontaminants are physically trapped in glass. However, only a few of these radioelements drive the performance assessment. If these key radioelements could be chemically trapped after their release from glass, then the performance of the waste disposal system could be significantly improved. Hydraulic properties of getter materials (original, loaded, and discharged) need to be measured to fully understand waste disposal performance in the presence of getters. The use of getter materials in the Savannah River Site's disposal of the Saltstone waste was an important consideration in the approval of that site's disposal of tank waste.

\section{Science Need Description:}

Negatively charged elements and compounds (e.g. $\mathrm{TcO}_{4}^{-}, \mathrm{Se}^{-}$) are poorly sorbed on most materials under basic $(\mathrm{pH}>7)$ conditions. However, some negatively charged materials (e.g. I ) do sorb on Hanford soils under basic conditions. An understanding of how important contaminants interact with the soil will aid the development of appropriate materials to retard the transport of those contaminants.

Need Timing: 4-10 years

IV. Benefit:

If low-cost getter materials can be developed for use in waste disposal, then requirements on waste forms can be reduced, potentially saving hundreds of millions of dollars in the Hanford TWRS Disposal

Program. The Savannah River Site uses FeS to trap technetium, and many disposal sites use concrete to trap uranium.

Benefit code: check all that apply:

$\leq$ Cost Savings $\quad \_$Risk Reduction $\quad$ Enabling Knowledge

This science need supports the following Hanford tanks technology need(s):

RL-WT019 Getter Materials 
V. Contacts:

For more information, contact:

Catherine Louie, DOE-RL TWRS Loni Peurrung, PNNL

Fred Mann, FDNW
(509) 376-6834 (509) 373-0201

(509)376-5728 catherine_s_louie@rl.gov lm_peurrung@pnl.gov frederick_m_mann@rl.gov 


\section{Hanford Site Science Need \\ Tanks Subgroup}

Identification No.: RL-WT047-S

Need Titie: Tritium Separations

FY98 Site Priority Ranking: High

\section{Functional Need:}

Limit the release of tritium to the environment.

\section{Problem Description:}

This problem involves the Hanford 100 Area and decontamination and decommissioning (D\&D) of the Nand K-Basins. These basins contain (or have contained) spent nuclear fuel within rod assemblies for up to 10 years. The highly radioactive fuel has subjected the water in the storage basins to a neutron flux sufficient to increase the tritium content of the water. The $N$-Basin water currently contains $39 \mu \mathrm{Ci} / \mathrm{L}$ of HTO, while $\mathrm{KE}$-Basin contains $3 \mu \mathrm{Ci} / \mathrm{L}$. The $\mathrm{KW}$-Basin contains the lowest concentration, at $0.3 \mu \mathrm{Ci} / \mathrm{L}$. However, each of these concrete basins contain 1 to 1.5 million gallons of contaminated water.

A demonstratable technology would also be applicable for the Effluent Treatment Facility (ETF). The ETF treats Hanford process waters (primarily condensate from the 242-A Evaporator) but does not remove tritium. A tritium removal technology could be placed at the effluent point of the ETF to bring the effluent into compliance with the EPA Drinking Water Act limit of $20,000 \mathrm{pCi} / \mathrm{L}$. (Currently, treated effluent from the facility is disposed at a state-approved land disposal site in the 200-West area.)

Concentrations greater than $2,000,000 \mathrm{pCi} / \mathrm{L}$ have been detected in Hanford ground water in the 12 wells in the 200-East area. The highest levels in the Hanford Site $(5,360,000 \mathrm{pCi} / \mathrm{L})$ were near the cribs that received effluent from the PUREX plant. More importantly, the movement of the tritium plume extends from 200-East to the Columbia River. Similar problems with tritium, as HTO, are present at SRS, INEL, and Lawrence Livermore National Laboratory. It must be emphasized that, currently, there is no costeffective method of separating tritium from these dilute streams.

This problem involves Tri-Party Agreement (TPA) milestone M-26-05, which indicates an annual review will be made of the developing technologies for tritium separation in an effort to settle on a technology to mitigate tritiated water. There is a further milestone (M-34-01) which requires $\mathrm{K}$-East basin to have a reduction of tritium from $3 \times 10^{6}$ to $3 \times 10^{5} \mathrm{pCi} / \mathrm{L}$ at a date under consideration by TPA participants.

\section{Science Need Description:}

Many processes have been developed to separate hydrogen isotopes in feed streams where the tritium is at a relatively high level and the feed volume is low. For instance, combined electrolysis-catalytic exchange and water distillation operate quite well with higher concentrations of tritiated water. Generally, high capital and power costs reduce their usefulness for separating low levels of tritium in high feed volumes. However, recent work has been directed toward increasing favorable tritium exchange with catalyzed 
systems using dual-temperature countercurrent cascades. Pervaporation and membrane distillation have been examined for the separation of deuterium oxide from light water $\left(\mathrm{H}_{2} \mathrm{O}\right)$ with moderate success. PNNL recently reported the separation of HTO from light water using supported polyphosphazene membranes under nanofiltration (cross-flow) filtration conditions. Tritiated water reductions of approximately $40 \%$ were obtained in the permeate with supported carboxylated-polyphosphazene membranes. The tritium concentration in the feed water ranged from $10,000 \mathrm{pCi} / \mathrm{L}$ to $3 \mathrm{mCi} / \mathrm{L}$.

The regulatory drivers and stakeholder concerns support the continued search for a cost-effective tritium separation process. It is apparent that processes currently used to treat very high concentrations of tritium are too capital and energy demanding.

Need Timing: 4-10 years

\section{Benefit:}

Waters containing unacceptable tritium concentrations (that is, above environmental release limits or drinking water standards) are released at DOE sites, including Hanford, Savannah River, Idaho National Engineering Laboratory, and Lawrence Livermore National Laboratory. Currently, water from some test wells at Hanford contain tritium concentrations approaching $6 \times 10^{3} \mathrm{mCi} / \mathrm{L}$ while the $\mathrm{K}$ and $\mathrm{N}$-Storage Basins are as high as $39 \mathrm{mCi} / \mathrm{L}$. There are no economically acceptable removal options for remediation for tritium, especially ground water, other than unigration with time through geological formations. The functional need is the next step to develop a process that will reduce the risk to the environment and public, reduce the costs for ultimate disposal for the tritium-containing water, and provide a way to recover the tritium in a concentrated form for disposal or use.

Benefit code: check all that apply:

_Cost Savings $\_$Risk Reduction $\_$Enabling Knowledge

V. Contacts:

For more information, contact:

Catherine Louie, DOE-RL TWRS

Loni Peurrung, PNNL
(509) $376-6834$

(509) 373-0201 catherine_s_louie@rl.gov

lm_peurrung@pnl.gov 


\section{Hanford Site Science Need Tanks Subgroup}

Identification No: RL-WT048-S

Need Title: Innovative Methods for Radionuclide Separation

FY98 Site Priority Ranking: Medium

\section{Functional Need:}

Reliable means for separating fission products and other troublesome components from the feed to LLW vitrification.

\section{Problem Description:}

Development and demonstration of innovative approaches are needed to avert the technical risk that existing technologies are not adequate to proceed with the 10 year plan for remediating Hanford tank wastes. Failure to meet required decontamination factors (DFs), reasonable volumes of HLW and LLW, or to maintain reasonable total plant operating efficiency because of operational problems with any of several separation steps could substantially delay or slow retrieval, pretreatment, and immobilization of tank waste.

\section{Science Need Description:}

The presence of $\mathrm{Cs}, \mathrm{Sr}$, and $\mathrm{Tc}$ cause radiation and performance assessment problems and must be removed from the feed to LLW vitrification. The current baseline calls for removal of these species by ion exchange. The "placeholder" baseline process for Cs has been the ion exchange resin CS-100, but its performance is not adequate. Only one other technology exists for Cs (crystalline silicotitanate). It cannot be eluted, and so new material must be purchased and vitrified each time it is loaded. A means for removing $\mathrm{Sr}$ and $\mathrm{Tc}$ have not been confirmed. Only ion exchange technologies are being considered, all of which are subject to the same potential problems: replacement of degenerated or loaded ion exchangers; unintentional filtration of particulates; channeling caused by swelling cycles; down time associated with cyclic operation; decontamination factors limited by problems with ion exchange kinetics or packing.

Therefore, fundamentally different types (not just versions) of technologies need to be available to preclude "common mode" failures among options, which could delay clean up of tank waste.

The ability to separate a radionuclide depends crucially on its speciation; without this knowledge, installed processes could be ineffective, particularly if chemical conditions change. The identity of dissolved $\mathrm{Sr}$ and $T_{c}$ is not known and could be complicated. It has been assumed that dissolved Sr may be in complexed form which can be removed if the complexant is oxidized, but the actual DF that would result is difficult to predict. It has been assumed that $\mathrm{Tc}$ exists as pertechnetate and can be removed by anion exchange, but recent results show perhaps $20 \%$ of $\mathrm{Tc}$ is in some other, non-exchangeable form. Basic research on the speciation of $\mathrm{Sr}$ and $\mathrm{Tc}$ and oxidation state of free and complexed Tc needs to be performed.

Need Timing: $4-10$ years 


\section{Benefit:}

New technologies would reduce waste stream volumes and reduce technical risk that existing technologies are not adequate to meet current performance requirements.

Benefit code: check all that apply:

$\checkmark$ Cost Savings $\quad \checkmark$ Risk Reduction $\checkmark$ Enabling Knowledge

This science need supports the following Hanford tanks technology need(s):

RL-WT008 Advanced Methods for Achieving LLW Volume Minimization

\section{Contacts:}

For more information, contact:

Catherine Louie, DOE-RL TWRS Loni Peurrung, PNNL
(509) 376-6834

(509) 373-0201 catherine_s_louie@rl.gov

Im_peurrung@pnl.gov 


\section{Hanford Site Science Need \\ Tanks Subgroup}

Identification No.: RL-WT049-S

Need Title: Effect of Processing on Waste Rheological and Sedimentation Properties

FY98 Site Priority Ranking: Medium

I. Functional Need:

Safe, effective, and efficient waste processing to minimize the volume of HLW stream:

\section{Problem Description:}

Information is needed on the effect of processing on the rheological and sedimentation properties of the complex solid and liquid matrices of the Hanford tank wastes. This information is needed to predict when gels will form in retrieval, wash, and leach solutions, and to supplement empirical water wash and caustic leach data from enhanced sludge wash testing of Fianford tank sludge and saltcake samples.

\section{Science Need Description:}

A large portion of the insoluble solids in tank sludge may be in the form of colloidal particles. Depending on the $\mathrm{pH}$ and ion concentrations of the surrounding solution, these particles may attract each other to form a porous network of particle chains, also known as a gel. The formation of a colloidal gel can impact several aspects of tank waste processing. For example, the formation of a colloidal gel can change a low-viscosity Newtonian suspension into a highly-viscous shear-thinning fluid. In another example, the efficiency of solidliquid separation through sedimentation depends on the final sediment density, which may be dramatically reduced if a colloidal gel is formed.

The rheological and sedimentation properties of the waste depend both on the strength of connection between individual particles and the structure of the particle networks that form. Areas of interest include: effect of processing (e.g., retrieval, transport, solid/liquid separations) on theological properties of waste; colloid behavior and flocculation; particle size distributions; surface charge and interfacial properties; and mechanical mixing effects (e.g., erosion, deagglomeration). Models must be developed to predict when gels will form in retrieval, wash, and leach solutions.

Need Timing: $4-10$ years

\section{Benefit:}

The research described here has large potential impact on retrieval, transport and treatment of tank waste. There are large economic risks associated with the plugging of a transport line, the failure of a solid-liquid separation process or the formation of a gel during a processing step. The results of this research would be used to identify situations of potential risk during tank waste processing. 
Benefit code: check all that apply:

$\checkmark$ Cost Savings $\quad \checkmark$ Risk Reduction $\checkmark$ Enabling Knowledge

This science need supports the following Hanford tanks technology need(s):

RL-WT024 Prediction of Solid Phase Formation in Hanford Tank Waste Solutions

\section{Contacts:}

For more information, contact:

Catherine Louie, DOE-RL TWRS

(509) 376-6834

Loni Peurrung, PNNL

(509) 373-0201

catherine_s_louie@rl.gov

Im_peurrung@pnl.gov 


\section{Hanford Site Science Need \\ Tanks Subgroup}

Identification No: RL-WT050-S

Need Title: Effect of Organic Constituents on Waste Processing

FY98 Site Priority Ranking: Low

I. Functional Need:

Safe, effective, and efficient waste processing to minimize the volume of the HLW stream.

\section{Problem Description:}

An understanding of the chemistry of organic constituents (including complexants) in tank wastes is needed to support the Phase II privatization request for proposals. In particular, partitioning of radionuclides between the liquid and solid phases in the waste is hindered by organic complexants present in the wastes. The complexation of radionuclides must be controlled to separate the waste into high- and low-level fractions effectively. This may entail destroying the complexants or removing the dissolved radionuclides using advanced separation processes. Also, there are safety concerns associated with organic-containing wastes. Radiolytic and thermal reactions of organics with nitrate and nitrite salts in HLW produce flammable and toxic gases: hydrogen, nitrous oxide, and ammonia. Wastes that contain organics may combust if allowed to dry out. Changing waste storage conditions may alter organic aging to increase gas production. However, changes that accelerate aging of organic complexants would facilitate separation of radionuclides.

\section{Science Need Description:}

Factors that influence separation and safety issues and steps for treatment and mitigation may be result from learning the products, mechanisms, and kinetics of organic reactions that occur under conditions of waste storage, retrieval, and processing. Reactions induced by heat and radiation need to be studied to assess hazards and develop methods for organic destruction. Understanding is needed of how ammonia is produced in the wastes. Also, an understanding is needed of the role of oxygen and metal ion redox catalysts in promoting gas production and organic aging. The studies should include organics chemicals that were added to tank wastes and their aging products, as well as organic chemicals and materials that may be used in processing the wastes. As an alternative to destroying chelators, the design and development of relevant advanced separation materials is needed.

Need Timing: $1-3$ years

\section{Benefit:}

This science will provide benefits by providing enabling knowledge about organic tank waste chemistry that will result in 1) improved risk assessment 2) reduced risks associated with storage and processing, and 3) improved processing performance. 
Benefit code: check all that apply:
$\checkmark$ Cost Savings
$\checkmark$ Risk Reduction
$\checkmark$ Enabling Knowledge

V. Contacts:

For more information, contact:

Catherine Louie, DOE-RL TWRS

(509) $376-6834$

Loni Peurrung, PNNL

(509) 373-0201

catherine_s_louie@rl.gov

Im_peurrung@pnl.gov 


\section{Hanford Site Science Need \\ Tanks Subgroup}

Identification No: RL-WT051-S

Need Title: Foam Generation and Stability

FY98 Site Priority Ranking: Low

\section{Functional Need:}

Safe, effective and efficient waste storage, retrieval and transport, including the prevention of pipe plugging, foam generation, and transport line pressurization.

\section{Problem Description:}

Flammable gases, including hydrogen, ammonia, and nitrous oxide, are generated and retained in the highlevel waste stored in Hanford tanks. The presence of these flammable gases pose a number of safety concerns. A better understanding of gas transport mechanisms and waste properties is needed to ensure that the tanks are maintained in a safe condition and that retrieval and waste processing are conducted in a safe manner. During retrieval operations, retained gases may breakup into very fine bubbles, or foams, that are easily entrained into downstream processing equipment. Depending on the type and configuration of the equipment, these entrained gases may accumulate within the equipment, presenting safety concerns.

In addition, waste retrieval and transport operations may generate foams composed primarily of entrained air. These foams may lead to plugging or over-pressurization of transport lines.

\section{Science Need Description:}

The formation of foam and its stability must be understood well enough to estimate the amount of flammable gases that would be entrained into downstream processing equipment. Scientific knowledge is needed to quantify the stability of generated foams as a function of major waste type groupings and chemical components. In addition, an understanding of the mechanisms of foam generation during waste operations is needed.

Transport of waste slurries containing bubbles may lead to complications in transport operations such as pump cavitation, additional foam generation, and possibly over-pressurization of the transport lines. Existing bubbles of any size distribution, when subjected to the high shear fields inside of the pump impeller and within the cross-site transfer lines, are likely to break up into much smaller sizes, thus increasing their number density. The stability of these bubbles in the waste slurries is again a critical issue. In addition, an understanding is needed of the transport properties of bubbly waste slurries in the transport lines.

During waste retrieval operations, foams can also be created by entraining air into the waste. An understanding of how foams can be created by entrainment of air is needed.

Need Timing: 4-10 years 


\section{Benefit:}

Understanding how to identify and avoid situations where foam formation may occur will minimize the risk of equipment damage and system failure due to the presence of foams. Understanding how to identify and avoid situations where flammable gases may be carried to other processing equipment will reduce the flammable gas safety hazard and risk. By understanding how to avoid transporting flammable gases, fewer controls and less redundant safety equipment will be needed to arcomplish the waste retrieval and transport operations.

Benefit code: check all that apply:
$\checkmark$ Cost Savings
$\checkmark$ Risk Reduction
_. Enabling Knowledge

V. Contacts:

For more information, contact:

Catherine Louie, DOE-RL TWRS

Loni Peurrung, PNNL
(509) 376-6834

(509) 373-0201 catherine_s_louie@rl.gov

1m_peurrung@pnl.gov 


\section{Hanford Site Science Need \\ Tanks Subgroup}

Identification No.: RL-WT052-S

Need Title: Characterization of Organic Species in Waste Feed to LAW and HLW Treatment Facilities

FY98 Site Priority Ranking: Low

I. Functional Need:

Measurement of the amount of certain RCRA and TSCA organic compounds in waste feed to the private contractors that may impact process and plant design.

\section{Problem Description:}

For acceptance at the repository, the immobilized high-level waste (IHLW) form cannot contain significant amounts of more than 200 RCRA or TSCA organic species. ILAW must meet LDRs, which also forbid a large number of hazardous constituents. In addition, a number of compounds known as toxic air pollutants will have to be addressed in permitting of the facilities. (Savannah River's tank waste is not listed waste, so this is not an issue at DWPF.)

While the waste feed to the private contractors will contain many RCRA organics, the private contractors' process will have to destroy or remove these compounds in order to meet the restrictions above. The quantity of each of these compounds present in the waste feed stream to the private contractors will need to be established so that they can design their facility and demonstrate that they can meet the permitting requirements. DOE, the regulators, and the private contractors will have to resolve which organization will perform which analyses for compliance. DOE is making an effort as part of its planning phase to provide additional information for environmental planning. This will involve characterization of organic components in tank waste. Most of these compounds can be analyzed by current methods with some modification or development of sample preparation techniques. There may be a limited set of compounds important to environmental planning that will require a more significant effort in method development. This set is currently being reviewed by DOE and Ecology.

\section{Science Need Description:}

Development of analytical methods to address DOE and regulatory requirements. The analyses could use existing analytical tools but would require the development of sample preparation steps, calibration, and method validation for their application to organic species in tank waste.

Need Timing: The completion of this effort must be targeted for input to DOE early in FY2000.

IV. Benefit:

Development of these methods. will support environmental planning for permitting of the private contractors' facilities. If methods developed can demonstrate that certain RCRA and TSCA compounds are not present in the waste, the contractors may be able to design more simple processes, saving money. 
If no method is developed and if RCRA compounds are later shown to be present in the output streams of the plant, the plants may have to shut down and retool, and significant cost will be incurred.

Benefit code: check all that apply:

$\checkmark$ Cost Savings $\quad \checkmark$ Risk Reduction $\quad \checkmark$ Enabling Knowledge

V. Contacts:

For more information, contact:

Catherine Louie, DOE-RL TWRS

(509) 376-6834

Loni Peurrung, PNNL

(509) 373-0201

catherine_s_louie@rl.gov

Im_peurrung@pnl.gov 


\section{Hanford Site Science Need \\ Tanks Subgroup}

Identification No.: $\underline{\text { RL-WT053-S }}$

Need Title: Contaminant Mobility Beneath Tank Farms

FY98 Site Priority Ranking: High

\section{Functional Need:}

To quantify and understand the evolution of the present distribution of contaminants, both radioactive and nonradioactive (particularly cesium- 137 but also $\mathrm{Pu}, \mathrm{TC}-99, \mathrm{Sr}-90, \mathrm{Cr}$, and nitrate), beneath the tank farms and to evaluate their potential mobility under all "leave or retrieve" options.

\section{Problem Description:}

The current understanding of the mobility of contaminants from single shell tank leaks and major soil column transuranic disposal sites is inadequate to fully support cleanup, closure, or performance assessment related decisions. Notably, bore-hole logging in SX Tank Farm revealed cesium-137 at depths of 130 feet, significantly deeper than predicted by current models. Further investigations, including the drilling of two additional wells, confirmed the presence of migrated cesium in the formation. The report issued by the TWRS Vadose Zone Expert Panel concluded that cesium migration was poorly understood and that insufficient data were available to validate migration models.

Without knowledge about the distribution of contaminants beneath the tank farms, and without the ability in hand to predict contaminant movement, it will be impossible to assure the public that the DOE can predict:

a) the impact of leaks during sluicing of the tanks during cleanup, and

b) the impact of leaving the tanks (and their associated subsurface contamination) in place.

Furthermore, the vadose zone cleanup schedule for the 200 Areas could be delayed if the mobility status of deeply distributed contaminants is unknown or inadequately characterized well in advance. For example, if it is eventually determined that retrieval of TRU-contaminated soil down to $40 \mathrm{~m}$ or more beneath PFP cribs is required, the cleanup schedule could be greatly impacted due to financial requirements for excavation and handling costs that could approach 1 billion dollars or more. Similar excavation requirements for leaking SSTs could drive the costs of cleanup higher by several orders of magnitude. The sooner this issue is resolved, the sooner more accurate technical, financial and schedule forecasts can be made.

\section{Science Need Description:}

Colloidal transport mechanisms. Studies are needed to evaluate the importance of colloids in enhancing the migration of radionuclides. 
Soil fixation/binding mechanisms. Current predictive models of contaminant transport beneath single shell tanks rely on general $\mathrm{K}_{d}$ information derived from laboratory sorption studies in synthetic media. The extreme chemical conditions associated with tank liquor ( $\mathrm{pH}$ up to 14) and PFP crib discharges ( $\mathrm{pH}$ to -1 ), and the associated changes in sorptive properties of the porous media, are difficult if not impossible to simulate. Prior characterization studies (mid $70^{\prime}$ s) provided valuable information on which to build. However, due to moderately slow changes in subsurface conditions over time (e.g., silicate hydrolysis), the $\mathrm{pH}$ and other chemical conditions in the soil column beneath receiving sites may be different today than 20-25 years ago. Thus, contemporary contaminated media is needed to assess the existing field mobility status of major contaminants in the soil column. The sorptive mechanisms need to be assessed to determine how tightly bound $\mathrm{Sr}-90, \mathrm{Cs}-137, \mathrm{Pu}$, and Am are today. This involves:

1) extraction of pore fluid (free fraction) and the "reverse" of laboratory sorption studies (i.e., leaching or desorption studies) using actual contaminated media, and

2) assessment of the role of potential chemical reactions induced by the soil mineral fraction.

For example, what is the role of iron (II) rich silicate minerals (pyroxenes) present in Hanford soils on reduction-sorption of transuranics? Acid hydrolysis due to the acidity of the effluent may have enhanced the reducing capability of iron (II) rich minerals and resulted in irreversible sorption of transuranics (Johnson and Hodges, 1997, Second Symposium on Hydrogeology of Washington, abstracts). Hot, high$\mathrm{pH}$ media (original tank waste) also modify the soil matrix in unpredictable ways. Silicate minerals dissolve and reprecipitate, colloids may form, etc. Actual modified media is needed to evaluate existing conditions. Some work of the latter type is planned for FY98 (as part of the TWRS Vadose Characterization Program). Additional or supplemental work is needed for a comprehensive assessment of 200 Area soil column disposal and tank farm sites.

Development of a modeling tool. A computer code should be developed to model the migration of radionuclides due to tank leakage incorporating the unique considerations described above (e.g., high $\mathrm{pH}$, colloidal transport, moderately unsaturated to saturated conditions, etc.). The model should combine time and spatially-dependent geochemical modeling with transient moisture flow and contaminant transport and allow the determination of modelling and data uncertainities. The simulator must handle geometrically complex objects and a large number of chemical species. The code should be structured to economically address the quantification of sensitivity of responses to uncertain physical and geochemical model parameters. Transport phenomena should include not only transport through homogenous media but also transport through fractured and preferred vertical flow paths (such as clastic dikes). This effort should build on the work that Jacobs Engineering has already done as pait of the Hanford Tanks Initiative.

Need Timing: $4-10$ years

IV. Benefit:

Benefit code: check all that apply:

$\checkmark$ Cost Savings $\quad \checkmark$ Risk Reduction $\quad \checkmark$ Enabling Knowledge

This science need supports the following Hanford tanks technology need(s):

RL-WT031 Contaminant Mobility Beneath Tank Farms 


\section{Contacts:}

For more information, contact:

Catherine Louie, DOE-RL TWRS

Loni Peurrung, PNNL
(509) 376-6834

(509) 373-0201 catheriness_louie@rl.gov

lm_peurrung@pnl.gov 


\section{Hanford Site Science Need \\ Tanks Subgroup}

Identification No.: RL-WT054-S

Need Title: Solids Yield and Deagglomeration

FY98 Site Priority Ranking: Low

\section{Functional Need:}

To predict how much sludge the mixer pumps will stir up inside double-shell tanks (DSTs).

\section{Problem Description:}

Correlations have been developed through scaled mixer pump testing to predict how much sludge will be mixed to a pumpable slurry by the DST mixer pumps. These correlations have some uncertainties associated with them that must be resolved.

One of the largest uncertainties in mixer pump performance is waste shear strength. Shear strength measurements have been made on samples in the hot cell but may not truly represent the in-tank values. To make accurate and defensible mixer pump performance predictions, the in situ shear strength of the sludge must be known at the waste temperature expected during mixer pump operation. Disruption of waste samples during core sampling and extrusion may significantly decrease the sludge shear strength. Conversely, hot cell measurements are usually made at temperatures lower than those expected during retrieval, and this may bias the hot cell shear strength measurements too high. Both these effects must be quantified before hot cell shear strength measurements can be used to make mixer pump performance predictions.

Another uncertainty in the mixer pump performance correlations is the effect of interstitial fluid dilution (varying ionic strength) on the strength of the sludge near the sludge/slurry interface. Decreases in the ionic strength may decrease the cohesion between sludge particles, thereby facilitating sludge mobilization and mixing. This effect is not addressed in the existing correlations, and it should be evaluated.

\section{Science Need Description:}

Addressing these two major uncertainties in the mixer pump prediction correlations will likely require two, fully independent studies. One study is needed to improve the reliability of waste shear strength measurements. The second study is needed to address the effects of ionic strength changes and deagglomeration on the performance of mixer pumps.

The first study will require either that in situ shear strength measurements be made or that tests be performed on sludge simulants in an effort to bound the magnitude of the core sampling and extrusion. disruption effects. Measurement of sludge strength in situ is the technically preferred option, but costs may be prohibitive. Regardless of whether in situ strength measurements are made, waste samples will need to be tested in the hot cell at elevated temperatures to simulate the conditions during mixer pump operation. These high-temperature shear strength measurements are needed to quantify the decrease in 
strength expected to occur when interstitial salt crystals dissolve as temperature is increased. This temperature effect may be significant enough that concerns related to inadequate mixer pump performance can be eliminated for some tanks. Once this study is completed, the existing mixer pump performance correlations can be applied to the improved shear strength estirnates to more accurately predict sludge mobilization in the DSTs.

The second study will require the development of a more fundamental understanding of the microscale mechanisms that result in the resistance of sludge to impinging mixer pump jets. Sludge erosion resistance is due to a combination of cohesive forces acting between particles. Only some of these forces are sensitive to changes in ionic strength due to dilution. A determination must be made of which forces are most important so that the effects of ionic strength changes on sludge mobilization resistance can be predicted. Some testing using waste simulants and possible waste samples may be required. Once complete, this study will allow the prediction of how much improvement in mixer pump performance can be expected when the supernate ionic strength is reduced.

Need Timing: 4-10 years

\section{Benefit:}

This activity supports Phase II of TWRS Privatization by allowing specification of retrieval performance. Moreover, during Phase $I$ it is DOE's responsibility to provide feed to the privatization vendors. If the mixer pumps don't perform as well as is currently expected, DOE: and its contractors might not be able to meet their feed delivery obligations and could lead to breach of contract.

Benefit code: check all that apply:

$\checkmark$ Cost Savings $\checkmark$ Risk Reduction $\checkmark$ Enabling Knowledge

This science need supports the following Hanford tanks technology need(s):

RL-WT013 Establish Retrieval Performance Evaluation Criteria

\section{Contacts:}

For more information, contact:

Catherine Louie, DOE-RL TWRS

Loni Peurrung, PNNL
(509) $376-6834$

(509) 373-0201 catherine_s_louie@rl.gov im_peurrung@pnl.gov 


\section{Hanford Site Science Need \\ Tanks Subgroup}

Identification No.: RL-WT055-S

Need Title: Tank Integrity Verification

FY98 Site Priority Ranking: Medium

I. Functional Need:

Conceptual approaches for verifying the integrity of waste tanks before retrieval or before turnover to or from a private vendor.

\section{Problem Description:}

Prior to single-shell tank waste retrieval, a verification or characterization of tank integrity is needed in order to choose appropriate retrieval technologies. This knowledge is also needed to support liability issues associated with transfer of ownership of the tanks under the privatization scenario envisioned for Phase II. Currently, the applicability of existing technologies that could perform this assessment for singleshell tanks is not understood or the modifications necessary have not been identified. Potentially, visual, ultrasonic or electrical techniques could be applicable. An understanding or characterization of the integrity of both the steel liner and its concrete shell is needed.

\section{Science Need Description:}

The degradation mechanisms of the tanks needs to be better understood in order to predict tank lifetimes. In addition, non-destructive assay methods should be evaluated for applicability to single-shell tanks. These could include existing or new conceptual approaches for integrity verification.

Need Timing: $4-10$ years

\section{Benefit:}

This work reduces risk during retrieval of waste, supports decisions on retrieval methods, and addresses liability issues associated with turnover of tanks and their return to DOE during Phase II of privatization.

Benefit code: check all that apply:

$\checkmark$ Cost Savings $\quad \checkmark$ Risk Reduction $\quad \checkmark$ Enabling Knowledge

This science need supports the following Hanford tanks technology need(s):

RL-WT027 Tank Leak Detection Systems for Underground SSTs

RL-WT028 Tank Leak Mitigation Systems 
V. Contacts:

For more information, contact:

Catherine Louie, DOE-RL TWRS

(509) 376-6834

Loni Peurrung, PNNL

(509) 373-0201

catherine_s_louie@rl.gov

lm_peurrung@pnl.gov 


\section{Hanford Site Science Need \\ Tanks Subgroup}

Identification No: $\underline{\text { RL-WT056-S }}$

Need Title: Half-Lives of Se-79 and Sn-126

FY98 Site Priority Ranking: Medium

I. Functional Need:

Measure the half-lives of Se-79 and Sn-126 to within $10 \%$.

II. Problem Description:

The half-lives of Se-79 and Sn-126 are uncertain, causing uncertainties in predicted doses. For the disposal of immobilized low-activity Hanford tank waste, Sn-126 is the most important isotope in inadvertent intruder scenarios and Se-79 is the next most important isotope for the groundwater scenario. There exists one measurement of Se-79 (1949). However, the value reported (less than 65,000 years in ORNL-499 report on page 45) is in contradiction with fission yield systematics. A reanalysis of the conversion of the raw data into a half-life value has found that the reported half-live is low by a factor of 10. (For more information see Nuclear Data Sheets, Vol. 70 (1993) 437.

Recently (J.Radioanal. Nucl. Chem. Letters Vol 212 (1996) 93) a new value was measured for Sn-126 $\left(2.5 \times 10^{5} \mathrm{y}\right)$ using the UK fission yield for normalization. This replaces a value $(\sim 100,000$ years $)$ published in an abstract (Bull. Amer. Phys. Soc. Vol. $\underline{3}$ (1958) 165).

\section{Science Need Description:}

Measurements of the half-lives of Se-79 and Sn-126 are needed to within $+/-10 \%$. Immobilized waste will be disposed of starting in 2002 . This information is needed to determine if additional separations are needed and if special operational handling is necessary.

Need Timing: $4-10$ years

IV. Benefit:

Technical:: Se-79 is the second most important radionuclide for long-term protection of the environment. There are significant incentives in the contracts with private vendors for greatly reducing the amount of the most-important radionuclide, Tc-99. Since the estimated dose is linearly proportionally to the inverse of the half-life, an uncertain half-life in Se-79 will greatly affect the estimated dose. It should be noted that the only measurement is for a bound of the halflife.

Sn-126 is the most important radionuclide in the protection of inadvertent intruders. Present calculations ("Hanford Low-Level Tank Waste Interim Performance Assessment") indicate that 
using the previously accepted half-life value, that if any of the 177 Hanford tanks have concentrations 4 times the average tank concentration, then performance objectives would not be meet. The newly measured value increases the margin by only 2.5 . If tank concentrations are too high, additional separations or special disposal facility operations would be required.

Environmental Safety \& Health: The estimated dose is inversely proportional to the half-life. For the inadvertent dose, $\mathrm{Sn}-126$ is by far the most important nuclide. For the groundwater scenario, Se-79 will drive the estimated doses if significant amounts of Tc-99 are removed.

Cost Savings Potential (Mortgage Reduction): Lower values of half-live could mean an decrease in the height of waste acceptable in the disposal facility, particularly for Sn-126, causing significant greater area and hence construction cost. The amount of the change will depend on the difference in half-life found and the amount of conservatism required in the disposal decision. Doubling the area of disposal facility could require construction costs of hundred's of millions of dollars.

Benefit code: check all that apply:

$\checkmark$ Cost Savings $\quad \checkmark$ Risk Reduction $\quad \checkmark$ Enabling Knowledge

V. Contacts:

For more information, contact:

Catherine Louie, DOE-RI TWRS

(509) 376-6834

Loni Peurrung, PNNL

(509) 373-0201

Fred Mann, FDNW

(509) $376-5728$

catherine_s_louie@rl.gov

lm_peurrung@pnl.gov

frederick_m_mann@rl.gov 


\section{Hanford Site Science Need \\ Tanks Subgroup}

Identification No.: RL-WT057-S

Need Title: Materials for Long-Term Waste Isolation

FY98 Site Priority Ranking: Medium

\section{Functional Need:}

New subsurface waste disposal facilities should incorporate new and innovative materials ideally suited for each waste type and disposal environment. These materials would serve as alternatives to the typical materiais (e.g., concrete, steel) that are known to have degradation problems.

\section{Problem Description:}

New waste disposal facilities should be designed to be as durable as possible to meet the appropriate disposal requirements. The materials used in the facilities should be chosen in part because they are ideally suited for the waste type and disposal environment. For example, standard concrete vaults use steel reinforcement that is known to cause spalling and cracking as the steel corrodes and expands. New materials may be able to provide an equivalent level of strength without the associated corrosion-induced cracking (a significant degradation mechanism in concrete).

\section{Science Need Description:}

The greatest needs are to identify those new materials that show the greatest promise of benefits with respect to waste disposal in the subsurface and to develop the data and models necessary to demonstrate their durability and performance for the lifetime of the disposal facility. In order for barriers involving getters to be considered, these barriers must withstand long-term performance assessment integrity assumptions that normal engineered structures do not withstand. Natural materials (e.g., minerals) that have the ability to self-heal fractures are highly desirable. Natural materials have the additional advantage that performance data over the long term are potentially available.

The goal of DOE is to protect the environment for at least 1,000 years, while NRC only recognizes manmade materials (particularly concrete) as lasting at most 500 years. Thus, the design life of new systems should be at least 1,000 years.

Need Timing: 4-10 years

\section{Benefit:}

More durable materials for disposal facilities could decrease long-term public exposure and increase the lifetime of the disposal facility. 
Benefit code: check all that apply:
$\simeq$ Cost Savings
$\underline{\checkmark \text { Risk Reduction }}$
_ Enabling Knowledge

V. Contacts:

For more information, contact:

Catherine Louie, DOE-RL TWRS

(509) 376-6834

Loni Peurrung, PNNL

(509) 373-0201

catherine_s_louie@rl.gov

lm_peurrung@pnl.gov 


\section{FY 1998 TANKS SCIENCE AND TECHNOLOGY NEEDS CROSSWALK}

\begin{tabular}{|c|c|c|c|c|c|}
\hline $\begin{array}{l}\text { New } \\
\text { (FY98) } \\
\text { RL-WT } \\
\text { Number }\end{array}$ & $\begin{array}{c}\text { Old } \\
\text { (FY97) } \\
\text { RL-WT } \\
\text { Number }\end{array}$ & Need Title & $\begin{array}{l}\text { STCG } \\
\text { FY97 } \\
\text { Priority }\end{array}$ & $\begin{array}{c}\text { STCG } \\
\text { FY98 } \\
\text { Priority }\end{array}$ & $\begin{array}{l}\text { Notes } \\
\text { (RL-WT identifiers refer to FY } \\
97 \text { numbers) }\end{array}$ \\
\hline \multicolumn{6}{|c|}{ Technology Needs } \\
\hline 1 & 2 & $\begin{array}{l}\text { Technetium-99 } \\
\text { Analysis in Low } \\
\text { Level Waste Feed }\end{array}$ & $\mathrm{H}$ & $\mathrm{H}$ & $\begin{array}{l}\text { Need to develop production analysis } \\
\text { method and conduct round robin on } \\
\text { procedure to validate }\end{array}$ \\
\hline 2 & 4 & $\begin{array}{l}\text { In-Tank Core } \\
\text { Sampling... Off-Riser } \\
\text { Capability }\end{array}$ & $\mathrm{H}$ & $\mathrm{L}$ & $\begin{array}{l}\text { Early programmatic drivers for } 2 \text { core } \\
\text { samples/tank have disappeared, and } \\
\text { characterization now appears to be } \\
\text { focusing on waste after retrieval. Work } \\
\text { in HTI project may satisfy this need }\end{array}$ \\
\hline 3 & 5 & $\begin{array}{l}\text { Large Volume }(3-51) \\
\text { Sludge and Supernate } \\
\text { Sampler }\end{array}$ & $\mathrm{L}$ & $\mathrm{H}$ & $\begin{array}{l}\text { This need appears to now to be driven } \\
\text { also by Private contractor requests for } \\
\text { larger samples. Infrastructure to handle } \\
\text { samples is not in place }\end{array}$ \\
\hline 4 & 6 & $\begin{array}{l}\text { DST Corrosion } \\
\text { Monitoring }\end{array}$ & $\mathrm{H}$ & $\mathrm{H}$ & $\begin{array}{l}\text { Need is considered high in long term, } \\
\text { but is not an immediate/urgent need }\end{array}$ \\
\hline 5 & 7 & $\begin{array}{l}\text { Remote Inspection } \\
\text { of High-Level Waste } \\
\text { Tanks }\end{array}$ & M & M & . \\
\hline 6 & 10 & $\begin{array}{l}\text { Identification and } \\
\text { Management of } \\
\text { Chromium and Other } \\
\text { Problem Constituents } \\
\text { for HLW } \\
\text { Vitrification }\end{array}$ & $\mathrm{H}$ & $\mathrm{H}$ & Remains an important need \\
\hline 7 & 11 & $\begin{array}{l}\text { Hanford Capsule } \\
\text { Initiative (HCI): A } \\
\text { Processing } \\
\text { Demonstration of } \\
\text { Cs/Sr Capsules for } \\
\text { Final Disposition }\end{array}$ & M & M & $\begin{array}{l}\text { No change to assessment - important } \\
\text { but not urgent }\end{array}$ \\
\hline 8 & 12 & $\begin{array}{l}\text { Advanced Methods } \\
\text { for Achieving Low- } \\
\text { level waste volume } \\
\text { minimization }\end{array}$ & $\mathrm{H}$ & $\mathrm{H}$ & Remains an important need \\
\hline
\end{tabular}




\begin{tabular}{|c|c|c|c|c|c|}
\hline $\begin{array}{l}\text { New } \\
\text { (FY98) } \\
\text { RL-WT } \\
\text { Number }\end{array}$ & $\begin{array}{l}\text { Old } \\
\text { (FY97) } \\
\text { RL-WT } \\
\text { Number }\end{array}$ & Need Title & $\begin{array}{c}\text { STCG } \\
\text { FY97 } \\
\text { Priority }\end{array}$ & $\begin{array}{l}\text { STCG } \\
\text { FY98 } \\
\text { Priority }\end{array}$ & $\begin{array}{l}\text { Notes } \\
\text { (RL-WT identifiers refer to FY } \\
97 \text { numbers) }\end{array}$ \\
\hline 9 & 18 & $\begin{array}{l}\text { Representative } \\
\text { Sampling and } \\
\text { Associated Analysis } \\
\text { to Support } \\
\text { Operations and } \\
\text { Disposal }\end{array}$ & $\mathrm{H}$ & $\mathrm{H}$ & $\begin{array}{l}\text { This is both a feed delivery and a } \\
\text { private vendor concern. }\end{array}$ \\
\hline 10 & 19 & $\begin{array}{l}\text { ILAW Product } \\
\text { Acceptance } \\
\text { Inspection and Test } \\
\text { Methods }\end{array}$ & $\mathrm{H}$ & $\mathrm{H}$ & Also a Waste Integration Team need \\
\hline 11 & 20 & $\begin{array}{l}\text { IHLW Product } \\
\text { Acceptance } \\
\text { Inspection and Test } \\
\text { Methods }\end{array}$ & M & M & Also a Waste Integration Team need \\
\hline 12 & 21 & $\begin{array}{l}\text { Secondary Waste } \\
\text { Product Acceptance } \\
\text { Inspection and Test } \\
\text { Methods }\end{array}$ & $\mathrm{H}$ & $\mathrm{H}$ & Also a Waste Integration Team need \\
\hline 13 & 23 & $\begin{array}{l}\text { Establish Retrieval } \\
\text { Performance } \\
\text { Evaluation Criteria } \\
\end{array}$ & $\mathrm{H}$ & $\mathrm{H}$ & $\begin{array}{l}\text { Need was evaluated for each } \\
\text { component of HTI. All were } \\
\text { considered high except one for dilution } \\
\text { tests, which have been deleted from } \\
\text { HTI scope }\end{array}$ \\
\hline 14 & 26 & $\begin{array}{l}\text { Alternative to } \\
\text { Baseline Tank Waste } \\
\text { mixing Systems }\end{array}$ & M & L & $\begin{array}{l}\text { "Need is speculative, not yet established } \\
\text { as actual" }\end{array}$ \\
\hline 15 & 29 & $\begin{array}{l}\text { Standard Method for } \\
\text { Determining Waste } \\
\text { Form Release Rate }\end{array}$ & M & M & Still remains an unfulfilled need \\
\hline 16 & 30 & $\begin{array}{l}\text { Glass Monolith } \\
\text { Surface Area }\end{array}$ & $\mathrm{H}$ & $\mathrm{H}$ & $\begin{array}{l}\text { Essential for determining release rates. } \\
\text { Still a need }\end{array}$ \\
\hline 17 & 31 & $\begin{array}{l}\text { Long-Term Testing } \\
\text { of Surface Barrier }\end{array}$ & M & M & $\begin{array}{l}\text { Need more data than just } 3 \text { years on } \\
\text { prototype }\end{array}$ \\
\hline 18 & 32 & $\begin{array}{l}\text { Testing of Sand- } \\
\text { Gravel Capillary } \\
\text { Barrier }\end{array}$ & L & $\mathrm{L}$ & $\begin{array}{l}\text { Not part of Hanford barrier, need is } \\
\text { speculative }\end{array}$ \\
\hline 19 & 34 & Getter Materials & $\mathbf{L}$ & $\mathrm{M}$ & \\
\hline
\end{tabular}




\begin{tabular}{|c|c|c|c|c|c|}
\hline $\begin{array}{c}\text { New } \\
\text { (FY98) } \\
\text { RL-WT } \\
\text { Number }\end{array}$ & $\begin{array}{l}\text { Old } \\
\text { (FY97) } \\
\text { RL-WT } \\
\text { Number }\end{array}$ & Need Title & $\begin{array}{l}\text { STCG } \\
\text { FY97 } \\
\text { Priority }\end{array}$ & $\begin{array}{l}\text { STCG } \\
\text { FY98 } \\
\text { Priority }\end{array}$ & $\begin{array}{l}\text { Notes } \\
\text { (RL-WT identifiers refer to FY } \\
97 \text { numbers) }\end{array}$ \\
\hline 20 & New & $\begin{array}{l}\text { Service Integrity } \\
\text { Testing of HLW } \\
\text { Tanks and Piping }\end{array}$ & & M & This is a recent new submission. \\
\hline 21 & New & $\begin{array}{l}\text { Cleaning and } \\
\text { Decontamination of } \\
\text { Hanford Pits }\end{array}$ & & $\mathrm{H}$ & $\begin{array}{l}\text { This was derived from the TDI proposal } \\
\text { for valve pit cleaning and mapping } \\
\text { technologies }\end{array}$ \\
\hline 22 & New & Tank Knuckle NDE & & $\mathrm{H}$ & $\begin{array}{l}\text { Addresses most vulnerable part of } \\
\text { DSTs }\end{array}$ \\
\hline 23 & New & $\begin{array}{l}\text { Prediction of Solid } \\
\text { Phase Formation in } \\
\text { Hanford Waste } \\
\text { Solutions }\end{array}$ & & $\mathrm{H}$ & $\begin{array}{l}\text { Combined Needs RL-WT015 \& RL- } \\
\text { WT016 }\end{array}$ \\
\hline 24 & New & $\begin{array}{l}\text { Enhanced Sludge } \\
\text { Washing Process } \\
\text { Data }\end{array}$ & & $\mathrm{H}$ & Combined RL-WT017 and RL-WT022 \\
\hline 25 & New & $\begin{array}{l}\text { Remote Sensing of } \\
\text { Gas Retention In } \\
\text { HLW Slurries }\end{array}$ & & M & $\begin{array}{l}\text { Recast version of RL-WT027 to } \\
\text { broaden need beyond psychrometric } \\
\text { method improvement. }\end{array}$ \\
\hline 26 & New & $\begin{array}{l}\text { Tank Leak Detection } \\
\text { Systems for } \\
\text { Underground Single- } \\
\text { Shell Waste Storage } \\
\text { Tanks (SSTs) }\end{array}$ & & $\mathrm{H}$ & $\begin{array}{l}\text { Split apart from RL-WT025 to delete } \\
\text { mitigation }\end{array}$ \\
\hline 27 & New & $\begin{array}{l}\text { Tank Leak Mitigation } \\
\text { Systems }\end{array}$ & & $\mathrm{H}$ & $\begin{array}{l}\text { "Split apart from RL-WT025, which } \\
\text { combined detection with mitigation" }\end{array}$ \\
\hline 28 & New & $\begin{array}{l}\text { Waste mobilization } \\
\text { enhancement }\end{array}$ & & M & $\begin{array}{l}\text { This was recast from RL-WT024 so } \\
\text { that the sonic probe was not considered } \\
\text { the only acceptable approach }\end{array}$ \\
\hline 29 & New & $\begin{array}{l}\text { Data and Tools for } \\
\text { Performance } \\
\text { Assessments }\end{array}$ & & M & Combined RL-WT036 and RL-WT037 \\
\hline \multirow[t]{2}{*}{30} & New & $\begin{array}{l}\text { Contaminant } \\
\text { Mobility Beneath } \\
\text { Tank Farms }\end{array}$ & & $\mathrm{H}$ & $\begin{array}{l}\text { This was derived from the TDI proposal } \\
\text { for } \mathrm{SX} \text { farm investigation. }\end{array}$ \\
\hline & 1 & $\begin{array}{l}\text { Larger Sample Hot } \\
\text { Cell DSC/TGA } \\
\text { Based Energetics } \\
\text { Measurement }\end{array}$ & M & Deleted & $\begin{array}{l}\text { USQ will be closed without this need } \\
\text { being met. Industry could not respond } \\
\text { with instrument, and other lab methods } \\
\text { have been used to satisfy data need. }\end{array}$ \\
\hline
\end{tabular}




\begin{tabular}{|c|c|c|c|c|c|}
\hline \multirow[t]{10}{*}{$\begin{array}{l}\text { New } \\
\text { (FY98) } \\
\text { RL-WT } \\
\text { Number }\end{array}$} & $\begin{array}{l}\text { Old } \\
\text { (FY97) } \\
\text { RL-WT } \\
\text { Number }\end{array}$ & Need Title & $\begin{array}{c}\text { STCG } \\
\text { FY97 } \\
\text { Priority }\end{array}$ & $\begin{array}{l}\text { STCG } \\
\text { FY98 } \\
\text { Priority }\end{array}$ & $\begin{array}{l}\text { Notes } \\
\text { (RL-WT identifiers refer to FY } \\
97 \text { numbers) }\end{array}$ \\
\hline & 3 & $\begin{array}{l}\text { Rapid Speciation of } \\
\text { Organic Acids and } \\
\text { complexants }\end{array}$ & $\mathrm{M}$ & Delered & $\begin{array}{l}\text { This need was met through procedure } \\
\text { development funded by EM-30 }\end{array}$ \\
\hline & 8 & $\begin{array}{l}\text { Criticality Basis - } \\
\text { Actinide Studies }\end{array}$ & $\mathrm{H}$ & Deleted & $\begin{array}{l}\text { USQ studies have shown that criticality } \\
\text { USQ can be closed without filling this } \\
\text { need }\end{array}$ \\
\hline & 9 & $\begin{array}{l}\text { Safety Related } \\
\text { Transport Properties } \\
\text { of Fuel Rich } \\
\text { Organics }\end{array}$ & $\mathrm{H}$ & Deleted & $\begin{array}{l}\text { USQ studies have shown that criticality } \\
\text { USQ can be closed without filling this } \\
\text { need }\end{array}$ \\
\hline & 13 & $\begin{array}{l}\text { Formulation of } \\
\text { Reference Glass for } \\
\text { Immobilized LAW }\end{array}$ & L & Deleted & $\begin{array}{l}\text { This need deleted - should now be met } \\
\text { by the glasses produced for acceptance } \\
\text { by the private contractors }\end{array}$ \\
\hline & 14 & $\begin{array}{l}\text { Standard Method for } \\
\text { Determining Waste } \\
\text { Form Release Rate }\end{array}$ & M & Deleted & Same as WT-029, this one deleted \\
\hline & 15 & $\begin{array}{l}\text { Avoidance of } \\
\text { Formation of Solids } \\
\text { in Phase } 1 \text { Liquid } \\
\text { Tank Wastes }\end{array}$ & $\mathrm{H}$ & Revised & $\begin{array}{l}\text { Replaced with a new writeup that } \\
\text { combines this and WT-016 }\end{array}$ \\
\hline & 16 & $\begin{array}{l}\text { Prediction of Gel and } \\
\text { Precipitate Formation } \\
\text { in Hanford Tank } \\
\text { Waste Solutions }\end{array}$ & $H$ & Revised & $\begin{array}{l}\text { Replaced with a new writeup that } \\
\text { combines this and WT-015 }\end{array}$ \\
\hline & 17 & $\begin{array}{l}\text { Provide Enhanced } \\
\text { Sludge Wash Process } \\
\text { Data for extended } \\
\text { operations of Phase I } \\
\text { and for Phase II RFP } \\
\text { and Contract Award }\end{array}$ & M & Revised & Rewritten to combine with WT- 022 \\
\hline & 22 & $\begin{array}{l}\text { Small-Scale } \\
\text { Radioactive } \\
\text { Demonstration of } \\
\text { Phase } 1 \text { Sludge } \\
\text { Washing }\end{array}$ & M & Revised & $\begin{array}{l}\text { Need wash/settle/decant data to reduce } \\
\text { uncertainty - rewritten to be combined } \\
\text { with WT-017 }\end{array}$ \\
\hline
\end{tabular}




\begin{tabular}{|c|c|c|c|c|c|}
\hline $\begin{array}{l}\text { New } \\
\text { (FY98) } \\
\text { RL-WT } \\
\text { Number }\end{array}$ & $\begin{array}{l}\text { Old } \\
\text { (FY97) } \\
\text { RL-WT } \\
\text { Number }\end{array}$ & Need Title & $\begin{array}{l}\text { STCG } \\
\text { FY97 } \\
\text { Priority }\end{array}$ & $\begin{array}{l}\text { STCG } \\
\text { FX98 } \\
\text { Priority }\end{array}$ & $\begin{array}{l}\text { Notes } \\
\text { (RL-WT identifiers refer to FY } \\
97 \text { numbers) }\end{array}$ \\
\hline & 24 & $\begin{array}{l}\text { Initial Waste } \\
\text { Mobilization } \\
\text { Methods Needed to } \\
\text { Enhance Advanced } \\
\text { Design mixer Pump } \\
\text { Retrieval for DST } \\
\text { Waste Not Affected } \\
\text { by Existing Mixing } \\
\text { Pump Performance }\end{array}$ & M & Revised & $\begin{array}{l}\text { Rewritten to be more generic so as not } \\
\text { to target the sonic probe as the only } \\
\text { acceptable response }\end{array}$ \\
\hline & 25 & $\begin{array}{l}\text { Tank Leak Mitigation } \\
\text { Systems for } \\
\text { Underground Single- } \\
\text { Shell Waste SSTs }\end{array}$ & $\mathrm{H}$ & Revised & $\begin{array}{l}\text { Rewritten to be two needs - one for } \\
\text { mitigation and one for detection }\end{array}$ \\
\hline & 27 & $\begin{array}{l}\text { High Accuracy } \\
\text { Psychrometric/Flow } \\
\text { Measurements }\end{array}$ & M & Revised & $\begin{array}{l}\text { "Rewritten to address generic problem } \\
\text { of gas retention in waste slurries, not } \\
\text { the specific weakness of using material } \\
\text { balances to support accurate volume } \\
\text { measurements" }\end{array}$ \\
\hline & 28 & $\begin{array}{l}\text { Multi-phase Moisture } \\
\text { Flow in Arid } \\
\text { Conditions }\end{array}$ & $\mathrm{L}$ & Deleted & Need was satisfied this year \\
\hline & 33 & $\begin{array}{l}\text { Moisture Dependence } \\
\text { of Kd }\end{array}$ & $\mathrm{L}$ & Deleted & $\begin{array}{l}\text { Work completed in FY } 97 \text { - need } \\
\text { satisfied }\end{array}$ \\
\hline & 35 & $\begin{array}{l}\text { In-Situ Testing of } \\
\text { Glass Release }\end{array}$ & $\mathcal{L}$ & Deleted & $\begin{array}{l}\text { Dropping this one because of low } \\
\text { feasibility }\end{array}$ \\
\hline & 36 & $\begin{array}{l}\text { Field Measurements } \\
\text { of Vadose Zone } \\
\text { Hydraulic Properties }\end{array}$ & M & Revised & Rewritten to be combined with WT-037 \\
\hline & 37 & $\begin{array}{l}\text { Distribution of } \\
\text { Recharge Rates }\end{array}$ & M & Revised & Rewritten to be combined with WT-036 \\
\hline \multicolumn{6}{|c|}{ Science Needs } \\
\hline 31-S & $38-S$ & $\begin{array}{l}\text { Rapid Waste } \\
\text { Characterization }\end{array}$ & $\mathrm{L}$ & $\mathrm{L}$ & $\begin{array}{l}\text { Renamed/rewritten to emphasize } \\
\text { science rather than technology; added } \\
\text { emphasis on basis for payment (Na, } \\
\text { waste oxides - } \mathrm{Na} \text { - } \mathrm{Si} \text { ) }\end{array}$ \\
\hline
\end{tabular}




\begin{tabular}{|c|c|c|c|c|c|}
\hline $\begin{array}{l}\text { New } \\
\text { (FY98) } \\
\text { RL-WT } \\
\text { Number }\end{array}$ & $\begin{array}{l}\text { Old } \\
\text { (FY97) } \\
\text { RL-WT } \\
\text { Number }\end{array}$ & Need Title & $\begin{array}{l}\text { STCG } \\
\text { FY97 } \\
\text { Priority }\end{array}$ & $\begin{array}{l}\text { STCG } \\
\text { FY98 } \\
\text { Priolity }\end{array}$ & $\begin{array}{l}\text { Notes } \\
\text { (RL-WT identifiers refer to FY } \\
\quad 97 \text { numbers) }\end{array}$ \\
\hline $32-S$ & $39-S$ & $\begin{array}{l}\text { Monitoring of Key } \\
\text { Waste Physical } \\
\text { Properties During } \\
\text { Retrieval and } \\
\text { Transport }\end{array}$ & M & M & Unaltered \\
\hline $33-S$ & $40-S$ & $\begin{array}{l}\text { Chemistry of } \\
\text { Problem Constituents } \\
\text { for HLW } \\
\text { Vitrification }\end{array}$ & M & M & $\begin{array}{l}\text { Added language on need for data } \\
\text { supporting predictive models for } \\
\text { liquidus temperature and durability }\end{array}$ \\
\hline $34-S$ & $41-S$ & $\begin{array}{l}\text { Long-Term } \\
\text { Performance of LAW } \\
\text { Forms }\end{array}$ & $\mathrm{H}$ & $\mathrm{H}$ & Unaltered \\
\hline $35-S$ & $42-S$. & $\begin{array}{l}\text { Moisture Flow and } \\
\text { Contaminant } \\
\text { Transport in Arid } \\
\text { Conditions }\end{array}$ & $\mathrm{H}$ & $\mathrm{H}$ & Unaitered \\
\hline $36-S$ & 44-S & $\begin{array}{l}\text { Alternate Waste } \\
\text { Form Development }\end{array}$ & $\mathrm{L}$ & $\mathrm{L}$ & Unaltered \\
\hline $37-S$ & $45-S$ & Sludge Treatment & M & M & $\begin{array}{l}\text { Text updated to note decisions made } \\
\text { during FY97 }\end{array}$ \\
\hline $38-S$ & $46-S$ & $\begin{array}{l}\text { Process Models for } \\
\text { Sludge Treatment }\end{array}$ & M & M & Unaltered \\
\hline $39-S$ & $47-S$ & $\begin{array}{l}\text { Advanced Methods } \\
\text { for Achieving LLW } \\
\text { Volume } \\
\text { Minimization }\end{array}$ & $\mathrm{H}$ & $\mathrm{H}$ & Unaltered \\
\hline $40-S$ & $48-S$ & $\begin{array}{l}\text { Mechanisms of Line } \\
\text { Plugging }\end{array}$ & L & $L$ & $\begin{array}{l}\text { Text revised to eliminate mention of } \\
\text { foam generation (covered in a separate } \\
\text { need) and de-emphasize settling but } \\
\text { include dilution }\end{array}$ \\
\hline $41-S$ & $49-S$ & $\begin{array}{l}\text { Radionuclide } \\
\text { Partitioning }\end{array}$ & L & $\mathrm{L}$ & $\begin{array}{l}\text { Name changed for clarity; Tc } \\
\text { emphasized }\end{array}$ \\
\hline $42-S$ & $50-S$ & $\begin{array}{l}\text { Flammable Gas } \\
\text { Generation, } \\
\text { Retention, and } \\
\text { Release in HLW } \\
\text { Tanks }\end{array}$ & M & M & Unaltered \\
\hline
\end{tabular}




\begin{tabular}{|c|c|c|c|c|c|}
\hline $\begin{array}{l}\text { New } \\
\text { (FY98) } \\
\text { RL-WT } \\
\text { Number }\end{array}$ & $\begin{array}{l}\text { Old } \\
\text { (FY97) } \\
\text { RL-WT } \\
\text { Number }\end{array}$ & Need Title & $\begin{array}{c}\text { STCG } \\
\text { FY97 } \\
\text { Priority }\end{array}$ & $\begin{array}{l}\text { STCG } \\
\text { FY98 } \\
\text { Priority }\end{array}$ & $\begin{array}{l}\text { Notes } \\
\text { (RL-WT identifiers refer to FY } \\
97 \text { numbers) }\end{array}$ \\
\hline 43-S & $51-S$ & $\begin{array}{l}\text { Effect of Human and } \\
\text { Natural Influences on } \\
\text { Long-Term Water } \\
\text { Distribution }\end{array}$ & $\mathrm{H}$ & $\mathrm{H}$ & Unaltered \\
\hline 44:S & $52-S$ & $\begin{array}{l}\text { Distribution of } \\
\text { Recharge Rates }\end{array}$ & $\mathrm{H}$ & $\mathrm{H}$ & Unaltered \\
\hline $45-S$ & $53-S$ & $\begin{array}{l}\text { Vadose Zone Flow } \\
\text { Simulation Tool } \\
\text { Under Arid } \\
\text { Conditions }\end{array}$ & $\mathrm{H}$ & $\mathrm{H}$ & $\begin{array}{l}\text { Removed references to tank closure and } \\
\text { incorporated those into new need }\end{array}$ \\
\hline $46-S$ & $54-S$ & Getter Materials & L & $\mathrm{L}$ & Unaltered \\
\hline $47-S$ & $55-\mathrm{S}$ & Tritium Separations & M & $\mathrm{H}$ & $\begin{array}{l}\text { (Currently being coordinated with D\&D } \\
\text { and SubCon subgroups for best fit) }\end{array}$ \\
\hline $48-S$ & $56-\dot{S}$ & $\begin{array}{l}\text { Innovative Methods } \\
\text { for Radionuclide } \\
\text { Separation }\end{array}$ & M & $\mathrm{M}$ & $\begin{array}{l}\text { Name changed (duplicate with other } \\
\text { need name); prescriptive language } \\
\text { removed }\end{array}$ \\
\hline $49-S$ & $57-S$ & $\begin{array}{l}\text { Effect of Processing } \\
\text { on Waste } \\
\text { Rheological and } \\
\text { Sedimentation } \\
\text { Properties }\end{array}$ & $M$ & $\mathrm{M}$ & Unaltered \\
\hline $50-\mathrm{S}$ & $58-\mathrm{S}$ & $\begin{array}{l}\text { Effect of Organic } \\
\text { Constituents on } \\
\text { Waste Processing }\end{array}$ & I & $\mathcal{L}$ & Unaltered \\
\hline $51-\mathrm{S}$ & $59-\mathrm{S}$ & $\begin{array}{l}\text { Foam Generation and } \\
\text { Stability }\end{array}$ & I & L & Unaltered \\
\hline $52-S$ & New & $\begin{array}{l}\text { Characterization of } \\
\text { Organic Species in } \\
\text { Waste Feed to LAW } \\
\text { and HLW Treatment } \\
\text { Facilities }\end{array}$ & & L & $\begin{array}{l}\text { IHLW cannot contain any of } 200+ \\
\text { RCRA organic species. Need to } \\
\text { develop methods to analyze for these in } \\
\text { waste feed to support permitting. } \\
\text { Identified by TWRS Privatization. }\end{array}$ \\
\hline $53-S$ & New & $\begin{array}{l}\text { Contaminant } \\
\text { Mobility Beneath } \\
\text { Tank Farms }\end{array}$ & . & $\mathrm{H}$ & $\begin{array}{l}\text { Corresponding science need for } \\
\text { technology need RL-WT030. Less } \\
\text { characterization focused, more } \\
\text { understanding focused. }\end{array}$ \\
\hline
\end{tabular}




\begin{tabular}{|c|c|c|c|c|c|}
\hline $\begin{array}{l}\text { New } \\
\text { (FY98) } \\
\text { RL-WT } \\
\text { Number }\end{array}$ & $\begin{array}{l}\text { Old } \\
\text { (FY97) } \\
\text { RL-WT } \\
\text { Number }\end{array}$ & Need Title & $\begin{array}{l}\text { STCG } \\
\text { FY97 } \\
\text { Priority }\end{array}$ & $\begin{array}{l}\text { STCIS } \\
\text { FY98 } \\
\text { Priority }\end{array}$ & $\begin{array}{l}\text { Notes } \\
\text { (RL-WT identifiers refer to FY } \\
\quad 97 \text { numbers) }\end{array}$ \\
\hline 54-S & New & $\begin{array}{l}\text { Solids Yield and } \\
\text { Deagglomeration }\end{array}$ & & $\mathrm{L}$ & $\begin{array}{l}\text { Supports predictions of retrieval } \\
\text { effectiveness. Determine waste yielding } \\
\text { and deagglomeration properties under } \\
\text { varying shear and chemical } \\
\text { environments (ionic strength). Identify } \\
\text { key waste properties. }\end{array}$ \\
\hline 55-S & New & $\begin{array}{l}\text { Tank Integrity } \\
\text { Verification }\end{array}$ & & M & $\begin{array}{l}\text { Conceptual approaches for verifying the } \\
\text { integrity of waste tanks before retrieval } \\
\text { or before turnover to or from a private } \\
\text { vendor. Includes science to predict tank } \\
\text { lifetimes and development of non- } \\
\text { destructive assay. }\end{array}$ \\
\hline $56-S$ & New & $\begin{array}{l}\text { Half-Lives of Se- } 79 \\
\text { and Sn-126 }\end{array}$ & & M & $\begin{array}{l}\text { Address uncertainty in key radionuclide } \\
\text { half-lives. }\end{array}$ \\
\hline \multirow[t]{3}{*}{$57-S$} & New & $\begin{array}{l}\text { Materials for } \\
\text { Long-Term Waste } \\
\text { Isolation }\end{array}$ & & M & Alternatives to concrete for vaults. \\
\hline & $43-S$ & $\begin{array}{l}\text { Waste Forms for } \\
\text { Secondary Waste } \\
\text { Immobilization }\end{array}$ & M & Deleted & $\begin{array}{l}\text { Made obsolete by contract changes } \\
\text { within TWRS Privatization }\end{array}$ \\
\hline & $60-S$ & $\begin{array}{l}\text { Chemical and } \\
\text { Physical Assessment } \\
\text { Needs for Waste } \\
\text { Characterization }\end{array}$ & L & Deleted & $\begin{array}{l}\text { Need eliminated since it is no longer } \\
\text { timely for addressing the nuclear } \\
\text { criticality safety issue. }\end{array}$ \\
\hline
\end{tabular}




\section{APPENDIX}

\section{ASSUMPTIONS USED BY STCG SUBGROUPS}

\section{Assumptions Used by D\&D Subgroup for Technology Needs Prioritization}

- Scoring criteria were used as a guide and projects determined all scores.

- Many of the technology needs identified could be met by industry innovations and enhancements.

\section{Assumptions Used By Mixed Waste Subgroup for Technology Needs Prioritization}

- The WIPP facility would be the ultimate disposal facility for all TRU waste.

- $\quad$ The WIPP WAC would be followed for TRU waste shipped to WIPP.

- Scoring criteria were used as a guide and projects determined all scores.

- Needed technologies that are known to be readily available were not included as technology needs

\section{Assumptions Used by Subcon Subgroup for Technology Needs Prioritization}

- Scoring criteria were used as a guide.

- Hanford 10-year plan was used as the basis.

- No budget for the 200 Area.

- Focus on the 100 and 300 Areas.

- Waste disposal costs at ERDF would continue to be lower than in situ treatment technologies for soil. 


\section{Assumptions Used by Tank Subgroup for Technology Needs Prioritization}

\section{Technical Assumptions}

- Assumptions in the TWRS Multi-Year Work Plan and the TWRS Systems Engineering Top-Level Logic were adopted.

- Technologies required to receive primary and secondary waste products from Privatization contractors were considered (e.g., disposal of technetium-99).

- Assumptions specific to the Hanford Tanks Initiative (HTI) were added as follows:

- HTI work will not preclude final closure decisions/options, but will provide key technical data.

- HTI will be integrated with the Hanford Remedial Action EIS, performance assessment work, and other Hanford risk assessments.

\section{Process Assumptions}

- EM-50 funding for high-priority needs is not guaranteed. Needs should be important enough to the EM-30 Program that EM-30 will consider investing in technology activities if not funded through EM-50.

- Technology needs associated with Privatization were specifically reviewed by DOE for applicability (i.e., pretreatment and immobilization technologies).

- Scoring criteria were used as a group discussion guide, not a formal decision tool. 


\section{TECHNOLOGY NEEDS PRIORITIZATION CRITERIA}

\begin{tabular}{|l|c|}
\hline \hline Impacts & Score \\
\hline \hline Technology Gaps & \\
\hline $\begin{array}{l}\text { This technology need addresses a critical gap in the existing program baseline. There } \\
\text { are no proven technologies to accomplish the functional need. }\end{array}$ & 2 \\
\hline $\begin{array}{l}\text { This technology need relates to an important enhancement or a promising alternative to } \\
\text { the existing baseline technology. }\end{array}$ & 1 \\
\hline This technology need is not critical. Existing technology is adequate. & 0 \\
\hline Urgency & 1 \\
\hline $\begin{array}{l}\text { This technology need is extremely urgent for meeting cleanup schedules or reducing } \\
\text { existing risks. }{ }^{1} \text { It is on the program's critical path. Any technology to meet this need } \\
\text { must be developed/irnplemented within the next } 1-3 \text { years. }\end{array}$ & 2 \\
\hline $\begin{array}{l}\text { This technology need is moderately urgent for meeting cleanup schedules or reducing } \\
\text { existing risks. }{ }^{1} \text { Any technology to meet this need must be developed/implemented } \\
\text { within the next 3-5 years. }\end{array}$ & 1 \\
\hline $\begin{array}{l}\text { This technology need is not urgent. Any technology to meet this need will not have to } \\
\text { be implemented for } 5 \text { years or more, so there is a long lead time for technology } \\
\text { development. }\end{array}$ & 0 \\
\hline Cost Reduction & 2 \\
\hline $\begin{array}{l}\text { This technology need has the potential for significant cost savings (more than } \$ 5 \\
\text { million or more than } 50 \% \text { ) over the current baseline technology. }\end{array}$ & 1 \\
\hline $\begin{array}{l}\text { This technology need has the potential for moderate cost savings ( } \$ 1-5 \text { million or } 10- \\
50 \% \text { ) over the current baseline technology. }\end{array}$ & \begin{tabular}{l} 
\\
\hline $\begin{array}{l}\text { This technology need has the potential for minimal cost savings (less than } \$ 1 \text { million or } \\
\text { less than } 10 \% \text { ) over the current baseline technology. }\end{array}$
\end{tabular} \\
\hline Effectiveness Improvement & 0 \\
\hline $\begin{array}{l}\text { This technology need has the potential for significant increase in effectiveness over the } \\
\text { current baseline technology. }\end{array}$ & 2 \\
\hline
\end{tabular}

1 The RL Risk Council Charter defines "risk" as follows: the probability that a hazard will cause exposure and that exposure will cause injury, combined with the potential severity of the injury. 


\begin{tabular}{|l|c|}
\hline \multicolumn{1}{|c|}{ TECHNOLOGY NEEDS PRIORITIZATION CRITERIA } & Score \\
\hline \hline Impacts & 1 \\
\hline $\begin{array}{l}\text { This technology need has the potential for moderate increase in effectiveness over the } \\
\text { current baseline technology. }\end{array}$ & 0 \\
\hline $\begin{array}{l}\text { This technology need has the potential for minimal increase in effectiveness over the } \\
\text { current baseline technology. }\end{array}$ & 2 \\
\hline Safety Improvement & 1 \\
\hline $\begin{array}{l}\text { This technology need has the potential for significant improvement in worker safety } \\
\text { over the current baseline technology. }\end{array}$ & 0 \\
\hline $\begin{array}{l}\text { This technology need has the potential for moderate improvement in worker safety over } \\
\text { the current baseline technology. }\end{array}$ & 1 \\
\hline $\begin{array}{l}\text { This technology need has the potential for minimal improvement in worker safety over } \\
\text { the current baseline technology. }\end{array}$ & 2 \\
\hline Schedule Improvement & 0 \\
\hline $\begin{array}{l}\text { This technology need has the potential for significant improvement in cleanup schedule } \\
\text { over the current baseline technology. }\end{array}$ & 2 \\
\hline $\begin{array}{l}\text { This technology need has the potential for moderate improvement in cleanup schedule } \\
\text { over the current baseline technology. }\end{array}$ & 1 \\
\hline $\begin{array}{l}\text { This technology need has the potential for minimal improvement in cleanup schedule } \\
\text { over the current baseline technology. }\end{array}$ & 1 \\
\hline \hline
\end{tabular}




\section{U.S. Department of Energy}

J. M. Augustenborg, WPD

L. K. Bauer, AME

M. S. Broido, EM-74

D. A. Brown, STP

J. E. Conner, ID

J. A. Frey, STP

D. W. Geiser, EM-53

K. D. Gerdes, EM-53

M. A. Gilbertson, EM-52

M. J. Glasper, STP

R. O. Gonzalez, TPD

C. A. Hansen, AMW

P. W. Hart, FETC

R. F. Hirsch, ER-73

M. A. Hunemuller, TWR

J. E. Kinzer, TWR

P. M. Knollmeyer, AMW

C. S. Louie, WDD

P. W. Lurk, EM-53

L. S. Mamiya, STP

B. M. Mauss, STP

J. L. Murphy, AME

D. J. Pepson, EM-38

K. G. Picha, EM-32

K. T. Price, ID

C. B. Purdy, EM-53

R. M. Rosselli, AMT

S. N. Saget, STP

F. R. Serier, RPS

D. E. Trader, STP

J. J. Waring, WPD

D. D. Wodrich, TWR

J. A. Wright, SR

L. W. Yarborough, AL

\section{OFF SITE}

Jimmy Bell, BCI

Barry Burks, ORNL John Carberry, DUPONT
Gregory Choppin, FSU

Paul Clayton, OGI

Jim Cochran, WSU

Roger Collis, ETP

Robert Cook, YIN

Allen Croff, MME

Rico Cruz, NPIN

Paul Danielson, NPIN

Gary Eller, LANL

Tom Engel, UW

Robert Erdmann

Dennis Faulk, EPA

Joe Gentilucci, JAG

Dib Goswami, ECOLOGY

Stuart Harris, CTUIR

Thomas Hirons, LANL

Earl Holtzscheiter, WSRC

Ken Hubbard, UM

Moses Jaraysi, ECOLOGY

Arvid Jensen, LMITCO-ID

Dawn Kaback; CCEM

Roy Koch, PSU

Bruce Kowalski, UW

Alvin Kwiram, UW

Jim Lee, SNL

Brenda Lewis, WSRC

Todd Martin, HAB

C. P. McGinnis, MMES

Jerry Morin, WSRC

Bill Prindle

James Rice, SNL

Richard Scanlan, OSU

Wally Schulz

Jean'ne Shreeve, UI

Robert Smith, WSU

Stan Sobczyk, NPIN

Peter Spencer, OHSU

Harold Sullivan, LANL

John Swanson

Robert Swenson, MSU

Larry Tavlarides, SU

Tom Tebb, ECOLOGY

Tom Thomas, LMITCO-ID 
Major Thompson, WSRC

Steadman Upham, UO

Nancy Uziemblo, ECOLOGY

George Vandegrift, ANL

Paul Wang, STL

Jack Watson, ORNL

Tom Weber

J. R. Wilkinson, CTUIR

Tom Woods, YIN

\section{ON SITE CONTRACTORS}

R. C. Adams, PNNL

R. W. Allen, PNNL

T. L. Anderson, FDH

J. F. Bagley, PNNL

S. A. Bailey, PNNL

E. G. Baker, PNNL

W. R. Barchet, PNNL

G. T. Berlin, FDH

W. F. Bonner, PNNL

D. M. Boyd, PNNL

T. M. Brouns, PNNL

M. L. Brown, PNNL

J. L. Buelt, PNNL

S. D. Colson, PNNL

T. J. Doherty, PNNL

D. D. Doneen, PNNL

R. M. Ecker, PNNL

D. W. Engelman, NHC

G. T. Frater, FDH

T. A. Fryberger, PNNL

J. L. Fuller, PNNL

B. A. Garrett, PNNL

R. E. Gephart, PNNL

N. W. Green, FDH

R. L. Gruel, PNNL

M. S. Hanson, PNNL

J. S. Hartman, PNNL

H. J. Hatch, FDH

S. W. Heaberlin, PNNL

J. O. Honeyman, LMHC

L. D. Kannberg, PNNL

K. J. Koegler, BHI

D. W. Koppenaal, PNNL
W. L. Kuhı, PNNL

J. D. LaFemina, PNNL

C. L. Lee, PNNL

P. E. Long: PNNL

J. A. Mahaffey, PNNL

G. W. McNair, PNNL

G. L. McVay, PNNL

B. J. Merrill, PNNL

J. L. Olson, PNNL

N. J. Olson, PNNL

T. Paluszkjewicz, PNNL

L. M. Peurrung, PNNL

L. R. Pond, PNNL

B. A. Pulsipher, PNNL

M. J. Quadrel, PNNL

R. K. Quinn; PNNL

S. A. Rawson, PNNL

B. F: Saffell, PNNL

J. D. Saffer, PNNL

S. N. Schlahta, PNNL

P. A. Scott, PNNL

L. J. Sealock, PNNL

B. D. Shipp, PNNL

S. C. Slate, PNNL

K. L. Soldat, PNNL

S. L. Stein. PNNL

T. L. Stewart, PNNL

J. J. Thomas, PNNL

T. L. Walton, PNNL

W. C. Weimer, PNNL

J. D. White, BHI

R. E. Wildung, PNNL

M. K. Yates, FDH 